Carine de Godoi Rezende Costa

\title{
Physical processes in The
}

\section{SAntos-São Vicente-Bertioga Estuarine System: FROM OBSERVATIONS TO FORECASTS}

\author{
Corrected Version
}

A thesis presented to the Oceanographic Institute of the University of São Paulo in partial fulfillment of the requirements for obtaining the degree of Doctor of Science, Oceanography Program, concentration area of Physical Oceanography

Advisor: Prof. Dr. Belmiro Mendes de Castro Co-Advisor: Prof. Dr. Alan F. Blumberg

São Paulo 



\title{
UNIVERSITY OF SÃO PAULO \\ OCEANOGRAPHIC INSTITUTE
}

Physical processes in the Santos-São Vicente-Bertioga Estuarine System: FROM OBSERVATIONS TO FORECASTS

\author{
Carine de Godoi Rezende Costa
}

\section{Corrected Version}

A thesis presented to the Oceanographic Institute of the University of São Paulo in partial fulfillment of the requirements for obtaining the degree of Doctor of Science, Oceanography Program, concentration area of Physical Oceanography

Judged on _ I _ I I

Prof. Dr. Belmiro Mendes de Castro

$\operatorname{Prof}(a) \cdot \operatorname{Dr}(a)$

Grade

$\operatorname{Prof}(\mathrm{a}) \cdot \operatorname{Dr}(\mathrm{a})$

Grade

$\operatorname{Prof}(a) \cdot \operatorname{Dr}(a)$.

Grade 



\section{Acknowledgments}

I would like to express my immense and sincere gratitude to my advisor, Professor Belmiro Castro, for the enlightening guidance in the development of this study. It has been an honor and a privilege working with you. I equally wish to extend my deepest appreciation to my co-advisor, Professor Alan Blumberg, for the contribution to this work and for giving me the opportunity to develop a deep learning on the research field. I also acknowledge Dr. José Roberto Leite, who started all the numerical modeling present in this work and immensely contributed to my thesis. I am deeply thankful for your friendship and for all your teaching. I extend my deepest gratitude to Professor Marcelo Dottori, whose contribution was essential for me to expand the knowledge about physical processes. Further, I wish to express my sincerest thanks and recognition to Professor Ilson da Silveira, who made much of this research possible. To Professor Luiz Miranda, whose knowledge and authentic passion for estuaries and oceans inspires me. Finally, I would like to express my sincere admiration to Dr. Nickitas Georgas, who much cooperated to teach me operational modeling skills and did not measure efforts to revise any of my endless paper versions. I am very pleased to write these acknowledgements to every one of you.

I am gratefully thankful to the Oceanographic Institute of the University of São Paulo, for the support and the opportunity. This thesis is part of my work as a technician at the Coastal Hydrodynamics Lab. I feel immensely happy to join working and learning in the same place. I extend my recognition to the NAP-OceanoS project, that gave me the opportunity to join LHiCo and develop my career.

I deeply thank Professor Joseph Harari, for the great lessons. They are essential for the fully understanding of the numerical modeling engine. I also gratefully acknowledge Professor Elisabete Saraiva for the support and cooperation during these years. They were crucial for me to realize my objectives. Many thanks to all the Professors at IO, specially, Paulo Polito, Olga Sato and Sueli de Godoi, for being great instructors throughout these years.

I greatly acknowledge the committee members, Professors Felipe Pimenta (UFSC), Luciano Pezzi (INPE) and Ricargo de Camargo (USP) for the valuable comments and suggestions to this thesis.

This study was also possible because of HidroMares, specially Gabriel, Alexandre and Adriene. Thank you very much for all your kind cooperation and understanding. I extend my acknowledge to Praticagem, that provided the data used in this work.

I thank the ECOSAN project and everyone who worked hard to collect the hydrographic and current data used in this work.

My sincere thanks to all the students at $\mathrm{LHiCo}$, that make the work atmosphere easier and happier. I am very proud to be part of this great team. Special thanks to Paulo Victor for the spiring talks about science and life. I am also thankful to all the colleagues at LIO, with whom I am always learning. Many thanks to the IT guys, Eder and Ricardo. Your work made all the modeling part of this thesis possible. 
Further, I wish to thank Silvana, Ana Paula, Daniel and Leticia, for the kind patience and support. I extend my gratitude to Didi, Bertão and Inês, that make me happy everyday!

My deeply thanks to my lovely friends Carolina, Daniela, Juliana, Renata, Vivian, André and Paulo. Thank you for all these years of friendship. You were always there to encourage me.

My warm thanks to my dear friends Carla, Daniela, Juliana, Mariana, Natália, Patricia and Tathiane. I could not make it without your support and friendship. I own much of my love for the oceans to you.

A very special thanks to my lovely friends in Hoboken, Louise, Andy, Mirjam, Bjorn, Gaby, Mariana, Thiago, Luis, Liz, Sundar, Beh Noush and Majid. You were the best family I could ever had in the USA. I miss you!

My warm thanks to my grandmother Olga. I want to be like you! And also to my grandmother Waldete and my uncle Lourdes, for all the love and care you have had for me during all these years. A very happy thanks to all my adorable cousins too!

My deepest gratitude to my family Eliane, Edison, Letícia, Daniel, Mariana, Renan and Jully. Thank you for your love and understanding, and specially for helping Lucas and I to build our lives together with this thesis.

I profoundly thank my dear parents Luzia and Cláudio, who knows better than anyone is this world what a graduate student needs. We were three in the same house. Thank you for all your love, support and inspiration. I could never had done this without you.

A very happy special thanks to Carol, João, Lego and Luke. You are my inspiration. Thank you for always guiding me. The world is small for you!

My deepest thanks to my husband, Lucas, whose status progressively grew from boyfriend to husband together with my academic degrees. I profoundly thank you for coming to this journey with me. This thesis was part of our lives. Thank you for all your help and strength to go further. I am really fortunate to have you in my life.

This study was financed in part by the Coordenação de Aperfeiçoamento de Pessoal de Nível Superior - Brasil (CAPES) - Finance Code 001. I extend my acknowledges to REMARSUL project (CAPES, process $88882.158621 / 2014-01)$.

I gratefully thank the Center for Weather Forecasts and Climate Studies (CPTEC) for providing the atmospheric forecasts used in this thesis.

This study has been conducted using E.U. Copernicus Marine Service Information. Thank you for making available the global ocean data used in this work. 
We are stardust brought to life, then empowered by the universe to figure itself out - and we have only just begun. Neil deGrasse Tyson 



\section{Abstract}

This thesis investigates the physical processes in the Santos-São Vicente-Bertioga Estuarine System (SSVBES) using observed and modeled data. The goals of this study are: the description and validation of the Santos Operational Forecasting System (SOFS) implemented to monitor and predict short-term ( $<3$ days) sea surface elevations and surface currents in the SSVBES (Chapter 2); the characterization of the physical processes of the estuarine dynamics in the SSVBES focused in the Porto Channel (Chapter 3); and the assessment of possible climate change-induced storm tide modifications in terms of number and intensity of events in the SSVBES (Chapter 4). The observed data used for this analysis include real-time sea surface elevations and surface currents collected by the Santos Pilots in stations placed along the Porto Channel; and the hydrographic and current measurements from the ECOSAN cruises collected at the entrance of the same channel. The numerical simulations were performed with the Princeton Ocean Model (POM) version POM-rain. The implementation of the model comprises two one-way nested grids, a coarse resolution for the South Brazil Bight (SBB) and a high resolution grid for the SSVBES. The SBB grid is forced by winds, density gradients and the Brazil Current flowing offshore. The SSVBES grid is forced by the SBB elevations and density fields, tides, winds and river runoff. The performance of the SOFS, tested in Chapter 2, showed that the accuracy of modeled sea level and surface currents reaches $\mathrm{O}(10) \mathrm{cm}$ and $\mathrm{O}(10) \mathrm{cm} / \mathrm{s}$, respectively. Seven recent (since 2016) storm tides were simulated with average skills of 0.95 and average root mean square errors of $17.0 \mathrm{~cm}$. The SOFS is the first operational system in the SSVBES able to simulate and predict the 3D currents within the estuary, also nested in an unprecedented forecasting system for the SBB region named PreAMar (http://preamar.io.usp.br/en). The results of Chapter 3 revealed that the Porto Channel behaves as a partially mixed estuary, being synchronous and tide-dominated, where tides propagate along the estuary mostly as a standing wave. In Chapter 4, the storm tides in the SSVBES were studied at both present and future conditions under two of the Intergovernmental Panel on Climate Change (IPCC) Representative Concentration Pathways (RCPs) scenarios for the end of the 21st century. The results showed that the storm tides in the SSVBES may increase in number but not in intensity, which may be comparable to the actual strengths. The sea level rise was the responsible for this conclusion whereas the expected changes in atmospheric circulation fields alone would produce less frequent and less intense storm tides.

keywords: Santos. Numerical modeling. Estuaries. Storm tides. Climate Change. Operational forecasting. South Brazil Bight. 



\section{Resumo}

Esta tese investiga os processos físicos no Sistema Estuarino de Santos-São Vicente-Bertioga (SESSVB) utilizando dados observados e resultados de modelo. Os objetivos deste estudo são: a descrição e a validação do Sistema de Previsão Operacional de Santos (SPOS), implementado para monitorar e prever variações de curto período ( $<3$ dias) das elevações da superfície do mar e das correntes superficiais no SESSVB (Capítulo 2); a caracterização dos processos físicos da dinâmica estuarina do SESSVB, com foco no Canal do Porto (Capítulo 3); a avaliação de possíveis alterações no número e na intensidade das ressacas no SESSVB provocadas por mudanças climáticas (Capítulo 4). Os dados observados utilizados nestas análises incluem dados de nível do mar e correntes superficiais, obtidos em tempo real pela Praticagem de Santos ao longo do Canal do Porto, bem como dados hidrográficos e correntográficos coletados pelos cruzeiros do ECOSAN na entrada do Canal do Porto. As simulações numéricas foram realizadas utilizando a versão do modelo Princeton Ocean Model (POM) nomeada POM-rain. A implementação do modelo compreende duas grades aninhadas em uma direção, uma de menor resolução para a Plataforma Continental Sudeste (PCSE) e outra de maior resolução para o SESSVB. A grade da PCSE é forçada por ventos, gradientes de densidade e pela Corrente do Brasil que flui como corrente de contorno oeste. A grade do SESSVB é forçada pelo nível do mar e pelos campos de densidade provenientes da PCSE, marés, ventos e descargas fluviais. O desempenho do SPOS, testado no Capítulo 2, mostrou que a acurácia do nível do mar modelado e das correntes superficiais alcançam $\mathrm{O}(10) \mathrm{cm}$ e $\mathrm{O}$ (10) $\mathrm{cm} / \mathrm{s}$, respectivamente. Sete ressacas recentes (desde 2016) foram simuladas com valores médios de skill iguais a 0.95 e erros quadráticos médios de $17.0 \mathrm{~cm}$. O SPOS é o primeiro sistema operacional no SESSVB capaz de simular e prever as correntes 3D no estuário, que também é aninhado no sistema inédito de previsão do mar para a região da PCSE nomeado PreAMar (http://preamar.io.usp.br). Os resultados do Capítulo 3 revelaram que o Canal do Porto se comporta como um estuário parcialmente misturado, síncrono e dominado por maré, cuja propagação ao longo do estuário tem características predominantes de uma onda estacionária. No Capítulo 4, as ressacas no SESSVB foram estudadas em condições atuais e futuras, para o final do século XXI, sob dois cenários denominados Representative Concentration Pathways (RCPs) do Painel Intergovernamental de Mudanças Climáticas (IPCC, do acrônimo em inglês). Os resultados mostraram que as ressacas no SESSVB devem aumentar em número, mas não em intensidade, com forças comparáveis às ressacas atuais. A elevação do nível do mar foi a principal responsável por esta conclusão, enquanto que as mudanças esperadas na circulação atmosférica, se consideradas isoladamente, produziriam ressacas menos frequentes e menos intensas.

Palavras-chave: Santos. Modelagem numérica. Estuários. Ressacas. Mudanças climáticas. Previsão Operacional. Plataforma Continental Sudeste. 



\section{List of Figures}

1.1 Geographic location of the Santos-São Vicente-Bertioga Estuarine System and the main estuarine channels. The names of the cities are written in brown. . . . . . . . . . . . . 26

1.2 Sketch of total water elevation in equation (1.1), with the positive vertical axis pointing upwards. . . . . . . . . . . . . . . . . . . .

2.1 SBB model grid with bathymetry $(\mathrm{m})$ shown in colors. The black rectangle encloses the SSVBES region shown in Figure 2.2 . . . . . . . . . . . . . . . . .

2.2 SSVBES model grid with bathymetry $(\mathrm{m})$ shown in colors. SBB grid cell centers are shown by black points. Magenta triangles symbolize positions where rivers are imposed. Orange circles mark sea level observation stations. The box encloses the area shown in Figure 2.3 .

2.3 Zoom of the SSVBES grid in the Porto Channel entrance, indicated in Figure 2.2 by the black rectangle. The observation stations are labeled in orange. Bathymetry $(\mathrm{m})$ is shown in colors

2.4 Examples of temperature (left) and salinity (right) sections at $26.5^{\circ}$ and $22.9^{\circ} \mathrm{S}$ from the spring climatology used as initial conditions for the SBB spin-up run. The location of the sections are indicated in the bottom left corner of each panel by the blue line. The gray lines show the limit of the model grid domain . . . . . . . . . . . . . . . . .

2.5 Flowchart of the SOFS framework. The number of each module is indicated. "BC" means boundary conditions. Programming languages used in each step are symbolically represented

2.6 Online results of the SSVBES forecasts released at http://preamar.io.usp.br/en. Example of sea surface elevation and surface currents forecasts for May 23, 2019 . . . . . . . . . . .

2.7 Stream plot of the SBB best-guess surface currents resulting from the 110-day spin-up run. Color and thickness of stream lines change according to current speed. The 100-m, 200-m, 500-m, 1000-m and 1800-m isobaths are shown by black contours . . . . . . . . . .

2.8 Cross-shore section of alongshore velocity near Cabo Frio. Contours are plotted every 0.05 $\mathrm{m} / \mathrm{s}$. Northward (southward) currents are shown in red (blue) colors. The location of the section is indicated in the bottom left corner . . . . . . . . . . . . . . . . .

2.9 Comparisons of observed (blue) and modeled (red) tide (top panels) and along-estuary component of surface tidal currents (bottom panels) at Capitania, Praticagem and Palmas

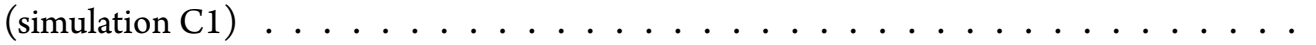


2.10 Comparisons of observed (blue) and modeled (red) sea surface elevations (top panels) and along-estuary component of surface currents (bottom panels) at Capitania, Praticagem and Palmas (simulation C2) . . . . . . . . . . . . . . . . . .

2.11 Tidal ellipses of the four major tidal components (M2, S2, O1 and K1) for the observed (blue) and modeled (red) surface currents at Capitania (top), Praticagem (middle) and Palmas (bottom). Note that velocity scales are different at each station. The location of each region is indicated in the map at the top right corner. . . . . . . . . . . .

2.12 Observed storm tide (orange) at Capitania (dotted), Praticagem (dashed) and Palmas (solid). Black and turquoise lines show the tidal and storm surge signals, respectively, with the same line pattern for each station . . . . . . . . . . . . . . . . . . . .

2.13 Storm tide event on August 21-22, 2016. Solid lines show the total water elevation time series of observed data (blue) and the modeled results (red) at the three stations. Dashed lines show the storm surge component. The peaks of water level heights are indicated in each

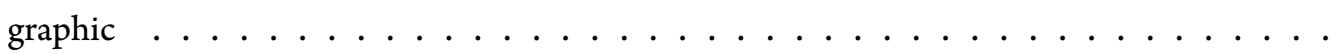

2.14 Skills and RMSEs of 3D (blue) and 2D (gray) models in simulating the storm tides ST1-ST7 (Table 2.1). The values represent the average between the three observed stations (Capitania, Praticagem and Palmas). The standard deviations are shown by the error bars. . . . . .

2.15 Storm tides (solid lines) and storm surges (dashed lines) at Capitania station for the seven analyzed events. The observed data is plotted in black and the 3D (2D) model is plotted in blue (gray). The vertical black lines limit the time period for which the statistics in Figure 2.14 were calculated. . . . . . . . . . . . . . . . . . .

2.16 Modeled vertical profiles of temperature $(\mathrm{T})$, salinity $(\mathrm{S})$ and along-channel velocity (ualong) at Capitania (a) and Praticagem (b) stations during the storm tide ST1 (top panels). The bottom panels in (a) and (b) show the total water elevations (black thick lines), the storm surges (black dashed lines) and the difference between bottom and surface water density $(\rho)$ (black thin line). The background color in the bottom panels marks the time of each correspondent profile in the top panels. Positive (negative) values of $u$-along indicate waters flowing down-estuary (up-estuary) . . . . . . . . . . . . . . . .

3.1 Diagram of the physical processes controling the circulation within coastal plain estuaries. "Tropic" is barotropic component, "clinic" is baroclinic component, "circ" is circulation, "long" is longitudinal, "grad" is gradient, "S" is salinity, "PGF" is pressure gradient force and "freq" is frequency. . . . . . . . . . . . . . . . . . . . . .

3.2 Locations of the 36 points analyzed along the navigation channel, numbered from south to north. The colors represent the SSVBES grid bathymetry. The positions of observation stations are shown in orange circles. The river discharge points are marked by the magenta triangles. . . . . . . . . . . . . . . . . . . . 
3.3 Absolute differences between surface (Ssurf) and bottom (Sbottom) salinities along the modeled C2 simulation (gray line). The 12-h average surface to bottom differences of observed salinity in 3 different months during the ECOSAN project (2005) are shown in green lines. . . . . . . . . . . . . . . . . . . . . . . .

3.4 Vertical profiles of temperature (top left) and salinity (top right) observed at the fixed station in Porto Channel in July. The $y$-axes is the non-dimensional depth (Z). Tidal elevation is shown at the bottom panel in black. Colored lines mark the time of each correspondent profile. 65

3.5 Similar to Figure 3.4 for August, $2005 \ldots \ldots \ldots \ldots$

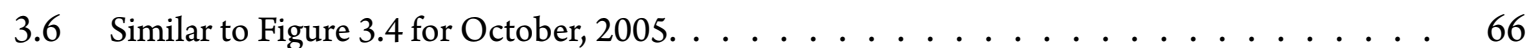

3.7 Similar to Figure 3.4 for November, $2005 \ldots \ldots \ldots$

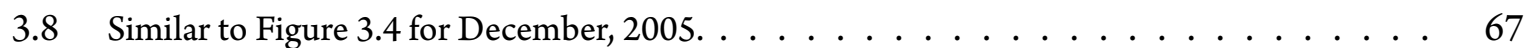

3.9 Observed currents at surface (black arrows) and bottom layers (gray arrows) measured with a vessel-mounted ADCP over the trajectory sketched by the gray line. Position of the fixed CTD station is marked with a " $x$ ". The last panel illustrates the location where the measurements were conducted. . . . . . . . . . . . . . . . . . . .

3.10 Velocity components measured by each ADCP profile in transect 8 of Figure 3.9. Black solid (dashed) lines represent the lateral mean of longitudinal (transversal) component. . . . . .

3.11 Lateral mean longitudinal velocity profiles for the July Cruise. Each transect in Figure 3.9 is represented by a different line. Same color code of Figure 3.4 applies. . . . . . . . . . . .

3.12 Similar to Figure 3.11 for August. . . . . . . . . . . . . . . . . . . . . . 69

3.13 Similar to Figure 3.11 for October. . . . . . . . . . . . . . . . . . . . . . . . 69

3.14 Similar to Figure 3.11 for November. . . . . . . . . . . . . . . . . . 69

3.15 Similar to Figure 3.11 for December. . . . . . . . . . . . . . . . . . . . . . . 69

3.16 Temporal variations of the depth-mean salinity (orange line) and the tidal elevation (blue line) observed in July (left) and August (right). Linear correlation between time series is show in titles.

3.17 Time series of the estuarine Richardson number $\left(R i_{e}\right)$ (red line) calculated from the modeled C2 simulation at Praticagem. The tidal signal in the depth-mean velocity is shown in blue and features the spring and neap tidal periods. . . . . . . . . . . . . . .

3.18 Amplitudes of tidal elevations (left) and surface tidal currents (right) for M2, S2, O1 and K1 constituents (from top to bottom) along the navigation channel. The solid lines show the modeled results for the 36 locations marked in Figure 3.2. Some locations are labeled for reference. The dashed lines are the observed results at the 4 stations shown in Figure 3.2. . .

3.19 Depth-mean velocity $(\mathrm{m} / \mathrm{s})$ as a function of channel width $(\mathrm{m})$ for 16 points along the navigation channel (loc 8 to loc 23 in Figure 3.2$) \ldots \ldots \ldots \ldots$ 
3.20 Lag correlation between the modeled sea surface elevations (dashed blue lines) and the depth-mean along-channel velocities (orange lines) at the 36 locations along the navigation channel (Figure 3.2).The maximum linear correlation coefficient between the lagged elevation (dashed blue lines) and the depth-mean velocity (orange lines) are written in the titles, as well as the corresponding temporal lag (in hours). The solid blue line is the original elevation, with no temporal lag. Correlations were calculated for the entire 2016 spring season and the panels show a zoomed view from October 12 to October $14 \ldots \ldots \ldots$

3.21 (a) Diagram of tidal elevation against tidal velocity for the modeled results at Praticagem, Capitania and Alemoa. The colors represent four different 25 - $\mathrm{h}$ tidal cycles indicated in (b). The black thin lines are for the shifted tidal elevations (dashed lines in Figure 3.20), representing the progressive wave solution. (b) Sea surface elevation time series. The periods plotted in $(\mathrm{a})$ are indicated in colors. . . . . . . . . . . . . . . .

3.22 Stratification-circulation diagram of Hansen and Rattray (1966) showing solutions for different values of the diffusive fraction of the total upstream salt flux $(\nu)$. The dashed line divides type $a\left(\delta S / \bar{S}<10^{-1}\right)$ from type $b\left(\delta S / \bar{S}>10^{-1}\right)$ estuaries. Colored circles were calculated from $\sim 12 \mathrm{~h}$ measurements of salinity and velocity profiles in Porto Channel in 2005. Neap and spring tidal cycles of each observation are denoted by "N" and "S", respectively. Colored " $X$ ” symbolizes modeled results for spring (green) and neap (light purple) tide cycles. The black " $\times$ " represents the results during the storm tide of October 29, 2016. Symbols "BN" and "BS" are the values found by Miranda and Castro (1998) in Bertioga Channel and "PN" and "PS" are Miranda et al. (2012) results for Piaçaguera Channel. 80

4.1 Map of the SSVBES region with the names of the main channel. The colors represent the bathymetry of the SSVBES model grid $(\mathrm{m})$. The orange circles mark the positions of the sea level observation stations. . . . . . . . . . . . . . .

4.2 Sea level rise projections under RCP8.5 (black line) and RCP4.5 (gray line) scenarios derived from the HadGEM2-ES output for rlilp1 in a coastal point in front of Santos - SP Brazil $\left(24.1^{\circ} \mathrm{S} 46^{\circ} \mathrm{W}\right)$. The angular coefficient of the linear trends are equal to $7.6 \mathrm{~mm} / \mathrm{yr}$ for RCP8.5 (red line) and $7.1 \mathrm{~mm}$ /year for RCP4.5 (blue line). The upper (lower) dashed line depicts the December 2099 (August 2016) sea level height above the geoid from RCP8.5, equal to $1.95 \mathrm{~m}(1.31 \mathrm{~m})$, relative to $1860-2005$. Similarly, the upper and lower dotted lines delineate the future $(1.91 \mathrm{~m})$ and actual $(1.32 \mathrm{~m})$ sea levels from RCP4.5, respectively. . . .

4.3 Global average steric sea level change under RCP8.5 (thick red line) and RCP4.5 (thick blue line) scenarios derived from the HadGEM2-ES output for rlilp1. The thin red (blue) line depicts the December 2099 global average steric sea level for RCP8.5 (RCP4.5), equal to

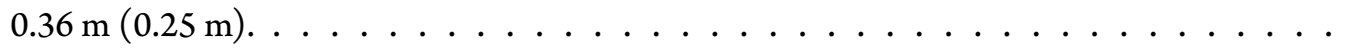


4.4 Determination of spring-neap cycles. The black line shows the fortnightly oscillation and the black circles mark the peak of each spring tide. The red line highlights the duration of each spring period. The blue and red lines depict the neap and spring terms, respectively, for the tidal elevation time series observed at Capitania. . . . . . . . . . . . . . . . .

4.5 Storm surges (blue dots) detected in the observed data at Capitania. The black line shows the subtidal (or storm surge) component of the elevation time series. The threshold over which a subtidal sea level increase is identified as a significant surge is shown by the red line $(1.34 \mathrm{~m})$. The magenta vertical lines numbered from 1 to 5 mark the strongest storm surges, from higher to lower intensity. . . . . . . . . . . . . . . .

4.6 Storm tides (blue dots) detected in the observed data at Capitania. The black line shows the total water elevation time series. The magenta vertical lines numbered from 1 to 5 mark the strongest storm tides, from higher to lower intensity. . . . . . . . . . . . . . .

4.7 Maximum and mean significant surge water levels per season (left panel) and number of significant surge per season (right panel) for the 91 events identified in the 4-year time series at Capitania. The vertical lines in the left panel show the standard deviations of the maximum surge levels for each season. . . . . . . . . . . . . . . . . . . . . 9

4.8 Number of observed storm tide events from summer 2015 to spring 2018 at Capitania. . . 94

4.9 Number of storm tides (left panel) and frequency of storm tide ocurrence (right panel) for the 35 storm tides observed in the 4 -year time series at Capitania. . . . . . . . . . . . . .

4.10 Storm tide water level peaks (top) and duration (bottom) of the 26 events identified from summer 2015 to spring 2018 at Capitania. Each colored symbol represents a different storm tide and panels have the same color correspondence. . . . . . . . . . . . . . . .

4.11 Subtidal component (black lines) of total water elevation at Capitania showing the detected storm surges (highlighted in red) during the winter of 2016. The top, middle and bottom panel show the observed data, the E1 control experiment and the E2 SLR experiment, respectively. The threshold over which a subtidal sea level increase is identified as a significant surge is shown by the blue line $(1.34 \mathrm{~m}) \ldots \ldots \ldots \ldots \ldots$

4.12 Total water elevation (black lines) at Capitania showing the detected storm tides (red dots) during the winter of 2016. The top, middle and bottom panels show the observed data, the E1 control experiment and the E2 SLR experiment, respectively. . . . . . . . . . . . .

4.13 Sea surface elevation at Capitania from E1 experiment plus SLR of $0.6 \mathrm{~m}$ (blue dotted line) and from $\mathrm{E} 2$ experiment (orange line). The differences between the two series in shown in

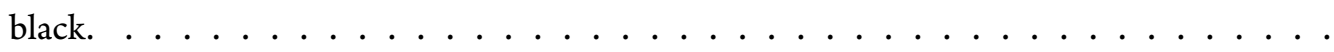

4.14 Subtidal component (black lines) of total water elevation at Capitania under RCP8.5 showing the detected storm surges (highlighted in red) during the winter of 2096, 2097, 2098 and 2099 (from top to bottom). The four time series are from the E3 experiments without SLR (E3-96, E3-97, E3-98 and E3-99). The threshold over which a subtidal sea level increase is identified as a significant surge is shown by the blue line $(1.34 \mathrm{~m}) \ldots \ldots \ldots$. . . . . . 
4.15 Total water elevation (black lines) at Capitania under RCP8.5 showing the detected storm tides (red dots) during the winter of 2096, 2097, 2098 and 2099 (from top to bottom). The four time series are from the E3 experiments without SLR (E3-96, E3-97, E3-98 and E3-99). 103

4.16 Subtidal component (black lines) of total water elevation at Capitania under RCP4.5 during the winter of 2096, 2097, 2098 and 2099 (from top to bottom). The four time series are from the E4 experiments without SLR (E4-96, E4-97, E4-98 and E4-99). The threshold over which a subtidal sea level increase is identified as a significant surge is shown by the blue line $(1.34 \mathrm{~m}) \ldots \ldots \ldots \ldots \ldots \ldots$

4.17 Total water elevation (black lines) at Capitania under RCP4.5 during the winter of 2096, 2097, 2098 and 2099 (from top to bottom). The four time series are from the E4 experiments without SLR (E4-96, E4-97, E4-98 and E4-99) . . . . . . . . . . . . . . . . 105

4.18 Wind rose for a SBB grid point in front of Santos city. Each graph represents the wind distribution for the entire winter period of experiments E1 (from CPTEC, BRAMS model), E3-96, E3-97, E3-98 and E3-99 (from HadGEM2-ES). . . . . . . . . . . . . . . . . 106

4.19 Wind rose for a SBB grid point in front of Santos city. Each graph represents the wind distribution for the entire winter period of experiments E1 (from CPTEC, BRAMS model), E4-96, E4-97, E4-98 and E4-99 (from HadGEM2-ES). . . . . . . . . . . . . . .

4.20 Maps of sea level atmospheric pressure (mbar) averaged over the duration of experiments E1 (from CPTEC, BRAMS model), E3-96, E3-97, E3-98 and E3-99 (from HadGEM2-ES). The solid contours show the atmospheric pressure isolines and the dashed contours represent the $100-\mathrm{m}$ and 200-m isobaths. The black marker shows the position of the wind time series used to plot the wind roses in Figure $4.18 \ldots \ldots \ldots \ldots \ldots$

4.21 Maps of sea level atmospheric pressure (mbar) averaged over the duration of experiments E1 (from CPTEC, BRAMS model), E4-96, E4-97, E4-98 and E4-99 (from HadGEM2-ES). The solid contours show the atmospheric pressure isolines and the dashed contours represent the $100-\mathrm{m}$ and 200-m isobaths. The black marker shows the position of the wind time series used to plot the wind roses in Figure $4.19 \ldots \ldots \ldots \ldots \ldots$

4.22 Subtidal component (black lines) of total water elevation at Capitania from the E3 experiments with SLR (E3-96-SLR, E3-97-SLR, E3-98-SLR and E3-99-SLR) during the winter of 2096, 2097, 2098 and 2099 (from top to bottom). The detected storm surges are highlighted in red. The threshold over which a subtidal sea level increase is identified as a significant surge is shown by the blue line $(1.34 \mathrm{~m}) \ldots \ldots \ldots \ldots$

4.23 Total water elevation (black lines) at Capitania from the E3 experiments with SLR (E3-96SLR, E3-97-SLR, E3-98-SLR and E3-99-SLR) during the winter of 2096, 2097, 2098 and 2099 (from top to bottom). The detected storm tides are marked in red dots. . . . . . . .

4.24 Subtidal component (black lines) of total water elevation at Capitania from the E4 experiments with SLR (E4-96-SLR, E4-97-SLR, E4-98-SLR and E4-99-SLR) during the winter of 2096, 2097, 2098 and 2099 (from top to bottom). The threshold over which a subtidal sea level increase is identified as a significant surge is shown by the blue line $(1.34 \mathrm{~m}) \ldots$. . . . 
4.25 Total water elevation (black lines) at Capitania from the E4 experiments with SLR (E4-96SLR, E4-97-SLR, E4-98-SLR and E4-99-SLR) during the winter of 2096, 2097, 2098 and 2099 (from top to bottom). The detected storm tides are marked in red dots. . . . . . . . 114

4.26 Comparisons between actual (purple) and future storm tides under RCP8.5 (green) and RCP4.5 (blue) in term of number of events, average duration and average peaks of storm surges and storm tides. The vertical bars represent the standard deviations. The statistics were computed during four winter periods of present (2014-2018) and future (2096-2099) conditions, from the observed data and the modeled E3 + SLR and E4 + SLR results. 



\section{List of Tables}

2.1 Numerical simulations performed in this study. 2D means that only the vertically integrated forms of motion and continuity equations were solved and that the equations for conservations of temperature and salinity as well as the river runoffs were not taken into account. No air-sea heat fluxes neither precipitation are considered in any of the simulations. . . . . . .

2.2 Skill assessment statistics for simulations $\mathrm{C} 1$ (tides only) and C2 for sea surface elevations at Capitania (1), Praticagem (2) and Palmas (3) . . . . . . . . . . . . .

2.3 Skill assessment statistics for simulations $\mathrm{C} 1$ (tides only) and C2 for the along-estuary surface current component at Capitania (1), Praticagem (2) and Palmas (3) . . . . . . .

2.4 Observed and modeled semimajor axis $(A, \mathrm{~cm} / \mathrm{s})$ and inclination $(\theta$, degrees $)$ of tidal ellipse components shown in Figure 2.11. Stations are numbered from north to south: Capitania (1), Praticagem (2) and Palmas (3) . . . . . . . . . . . .

2.5 Skill assessment statistics for the storm tide (st) and the storm surge (ss) components in the 3D (shown in Figure 2.13) and 2D (not shown) simulations of storm tide ST1. The peak errors are the difference between observed and modeled water peaks. Positive (negative) means that modeled peak is higher (lower) than the observed peak. The values in parentheses show the lag in the arrival time. Positive (negative) means that modeled peak occurred later (earlier) than the observed peak. Stations are numbered from north to south: Capitania (1), Praticagem (2) and Palmas (3) . . . . . . . . . . . . . . . .

3.1 Estuarine quantities addressed in the study and the type of data used in each calculation. $R i_{e}$ is the estuarine Richardson number. . . . . . . . . . . . . . . . . . . . . .

3.2 Maximum, minimum and average values of the estuarine Richardson number $\left(R i_{e}\right)$ for spring and neap tidal cycles. . . . . . . . . . . . . . . . . . . . . .

3.3 Values of the circulation and stratification parameters for Piaçaguera Channel(Miranda et al., 2012), Bertioga Channel(Miranda and Castro, 1998) and Porto Channel, for modeled (mod) and observed (obs). Spring and neap values are shown for Piaçaguera, Bertioga and Porto (mod). In Porto (obs), parameters are shown for July and November, when minimum and maximum values occur, respectively. . . . . . . . . . . . . . . 
4.1 Experiments conducted to evaluate possible climate change impacts over storm tides in the SSVBES. SLR means that a sea level rise constant value was added to the simulation. A check mark under RCP scenarios means that the experiments were forced with projected fields of atmospheric circulation changes. HadGEM2-ES is the Hadley Centre Global Environment Model 2 of the UK Met Office Hadley Centre . . . . . . . . . . . . . . . . . . .

4.2 Comparisons between observed (obs) and modeled E1 and E2 experiments for the two storm tides in the winter of 2016 in terms of duration of the event, maximum total water elevation $(\max$ elev) and maximum surge height (max surge) . . . . . . . . . . .

4.3 Summary of the 20 storm tides identified in the E2 experiment in terms of duration of the event, maximum total water elevation (max elev) and maximum surge elevation (max surge). For each parameter, the minimum, the maximum, the average and the standard deviation (std) values are shown. . . . . . . . . . . . . . . . . . .

4.4 Comparisons between observed and modeled experiments under RCP8.5 (E3 and E3 + SLR) and RCP4.5 (E4 + SLR) scenarios for the storm tides in the winter seasons in terms of number of events, maximum total water elevation (max total elev) and maximum surge height $(\max$ surge $) . \ldots \ldots \ldots$. . . . . . . . . . . . . . . 115 


\section{List of Acronyms}

ADCP

AR5

$\mathrm{BC}$

BC-IWBC

BRAMS

CMEMS

CMIP5

CPTEC

ES

ESGF

GMSL

HadGEM2

IPCC

LECZ

LHiCo

MLLW

NOAA

NYHOPS

POM

RCPs

$R i_{e}$

RMSE

S

SBB
Acoustic Doppler Current Profiler

IPCC Fifth Assessment Report

Brazil Current

Brazil Current-Intermediate Western Boundary Current

Brazilian developments on the Regional Atmospheric Modeling System

Copernicus Marine Environment Monitoring Service

Coupled Model Intercomparison Project Phase 5

Center for Weather Forecasts and Climate Studies

Earth System

Earth System Grid Federation

Global Mean Sea Level

Hadley Centre Global Environment Model 2

Intergovernmental Panel on Climate Change

Low-Elevation Coastal Zones

Coastal Hydrodynamics Laboratory

Mean Lower Low Water

National Oceanic and Atmospheric Administration, USA

New York Harbor Observing and Prediction System

Princeton Ocean Model

Representative Concentration Pathways

estuarine Richardson number

Root Mean Square Error

Salinity

South Brazil Bight 
SLR

SOFS

SSVBES

$\mathrm{T}$

TS

WCRP

WRF
Sea Level Rise

Santos Operational Forecasting System

Santos-São Vicente-Bertioga Estuarine System

Temperature

Temperature and Salinity

World Climate Research Program

Weather Research and Forecasting 


\section{Contents}

1 Introduction $\quad 25$

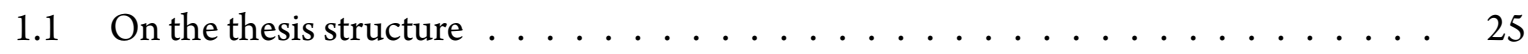

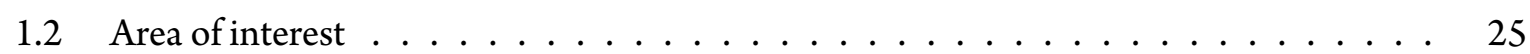

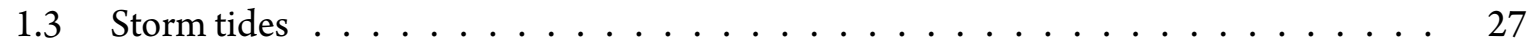

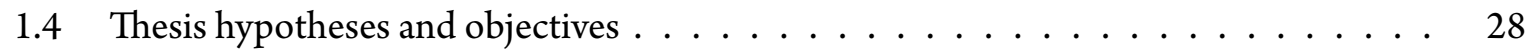

2 An operational forecasting system for physical processes in the Santos-São Vicente-Bertioga Estuarine System, Southeast Brazil 29

2.1 Introduction . . . . . . . . . . . . . . . . . . . . . . . 29

2.2 Materials and Methods . . . . . . . . . . . . . . . . . . . 30

$2.2 .1 \quad$ SBB and SSVBES model grids . . . . . . . . . . . . . . . . . 30

2.2.2 Numerical model . . . . . . . . . . . . . . . . . . . . . . . 31

2.2 .3 SBB spin-up run . . . . . . . . . . . . . . . . . 34

2.2 .4 Tidal forcing specification . . . . . . . . . . . . . . . 35

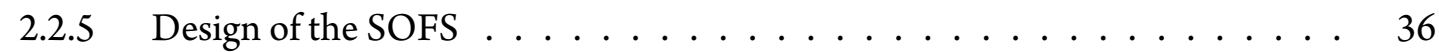

2.2 .6 SOFS skill assessment . . . . . . . . . . . . . . . . . . . . . 39

2.3 Results . . . . . . . . . . . . . . . . . . . . . 41

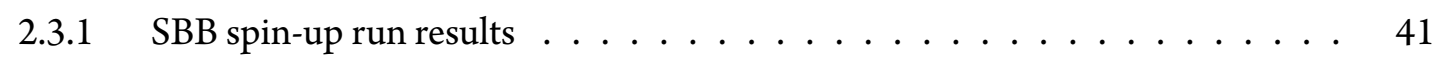

2.3 .2 SOFS calibration . . . . . . . . . . . . . . . . 42

2.3 .3 SOFS validation . . . . . . . . . . . . . . . . . 48

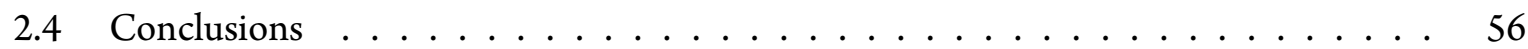

3 Estuarine Physics of the Santos-São Vicente-Bertioga Estuarine System 57

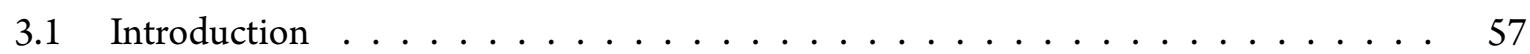

3.2 Data and methods . . . . . . . . . . . . . . . . . . . 59

3.2.1 Estuarine physics definitions _................ 61

3.2.2 The ECOSAN observed data . . . . . . . . . . . . . . . . . . . 64

3.3 Results ............................ 70

3.3.1 Observed temperature and salinity profiles . . . . . . . . . . 70

3.3.2 Estuarine quantities . . . . . . . . . . . . . . . . 71

3.3 .3 Tidal propagation . . . . . . . . . . . . . . 72 


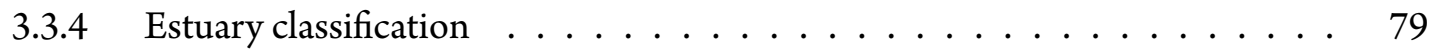

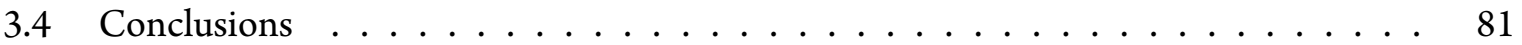

4 Storm tides in the Santos-São Vicente-Bertioga Estuarine System for present conditions and climate change projections $\quad 83$

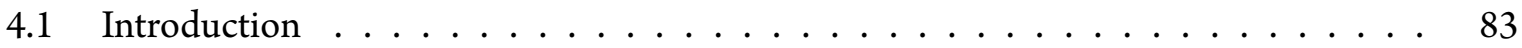

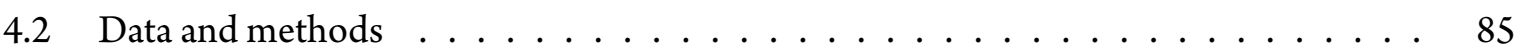

$4.2 .1 \quad$ Observed sea level . . . . . . . . . . . . . . . . . . . 85

4.2.2 Long-term simulations . . . . . . . . . . . . . . . . . . . 85

4.2 .3 Detection of storm tide events . . . . . . . . . . . . . . . . . . 90

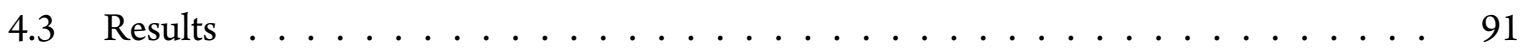

$4.3 .1 \quad$ Observed storm tides $\ldots \ldots \ldots \ldots \ldots$. . . . . . . . . . . . 91

4.3.2 The winter of $2016 \ldots \ldots \ldots \ldots$. . . . . . . . . . . . . 96

$4.3 .3 \quad 2096-2099$ winter projections . . . . . . . . . . . . . . 100

4.4 Conclusions . . . . . . . . . . . . . . . . . . . . . . 117

5 Final remarks $\quad 119$

5.1 Thesis summary . . . . . . . . . . . . . . . . . . . . . . . . . 119

5.2 Future work . . . . . . . . . . . . . . . . . . . . . . . 120

$\begin{array}{ll}\text { References } & 122\end{array}$ 


\section{Chapter 1}

\section{Introduction}

\subsection{On the thesis structure}

This thesis is organized in five main chapters in which the hydrodynamic aspects of the Santos-São Vicente-Bertioga Estuarine System (SSVBES) are investigated. Chapter 1 presents a general introduction for the following chapters. Chapters 2, 3 and 4 are written in the form of self-contained manuscripts. Chapter 2 describes the Santos Operational Forecasting System, established within the observational and prediction system for the São Paulo State coast named PreAMar (http://preamar.io.usp.br/en). Chapter 3 details the estuarine physics of the SSVBES and Chapter 4 compares the storm tides in the SSVBES for present conditions and future projections. Final remarks and future work suggestions are presented in Chapter 5.

\subsection{Area of interest}

The region of study of this thesis is the Santos-São Vicente-Bertioga Estuarine System. The SSVBES is located in the Metropolitan Region of Baixada Santista in the central part of São Paulo State coastal zone, near latitude $24.0^{\circ} \mathrm{S}$ and longitude $46.3^{\circ} \mathrm{W}$. Baixada Santista is composed by nine cities (Bertioga, Cubatão, Guarujá, Itanhaém, Mongaguá, Peruíbe, Praia Grande, Santos and São Vicente) occupying almost 2,500 $\mathrm{km}^{2}$. The population estimated for 2018 in Baixada Santista is of almost 1.8 millions residents (Seade, 2018).

Geographically, the SSVBES is a complex of estuarine channels, rivers and mangroves that borders six of the cities of Baixada Santista and separate São Vicente Island and Santo Amaro Island from the continent (Figure 1.1). There are four main estuarine channels: Piaçaguera Channel, São Vicente Channel, Porto Channel and Bertioga Channel. Piaçaguera extends from Cubatão City, on the northern limit, until São Vicente Channel on the northwest of São Vicente Island and Port Channel on the northeast. Bertioga Channel flows in an almost west-to-east direction discharging water in the Port Channel on the western end and directly into the inner shelf on the eastern limit. São Vicente Channel surrounds 


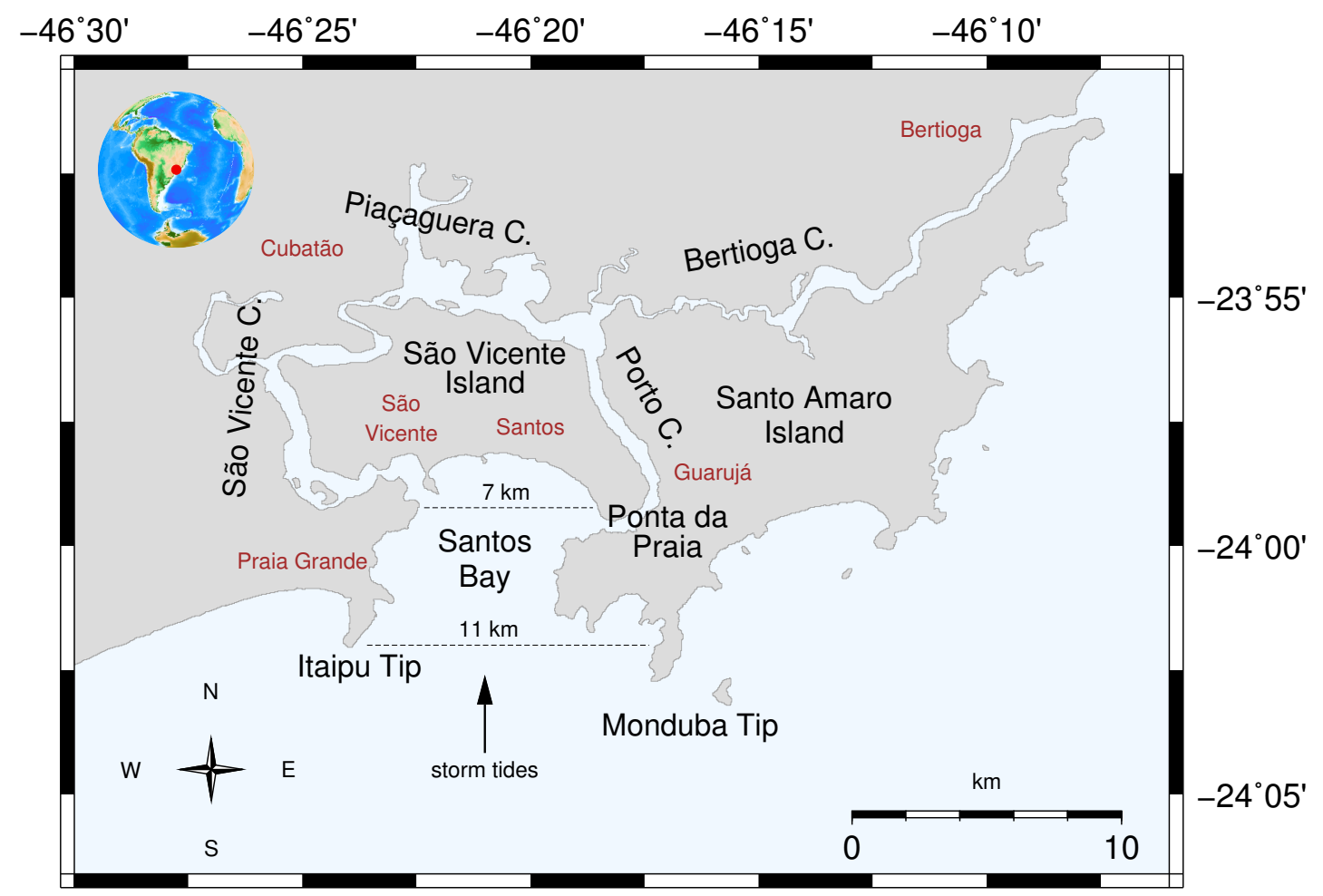

Figure 1.1: Geographic location of the Santos-São Vicente-Bertioga Estuarine System and the main estuarine channels. The names of the cities are written in brown.

São Vicente Island on its western limit and Porto Channel borders both São Vicente and Santo Amaro Islands on their east and west borders, respectively. Both São Vicente and Porto Channels discharge water into the Santos Bay, which communicates with the inner shelf in a semi-enclosed entrance of approximately $11 \mathrm{~km}$ limited by Itaipu Tip on the west and Monduba Tip on the east sides. Santos Bay is limited on the north by the São Vicente Island and receives São Vicente and Porto Channels discharges, these two distant nearly $7 \mathrm{~km}$ apart.

We are primarily interested in the Porto Channel, that harbors the Santos Port, the biggest sea port in Latin America. The Santos Port has recently been equipped with real-time observed stations that measures the environmental conditions of estuarine waters (sea surface elevations, surface currents and water temperature), important for safe navigation. These information are monitored by the Santos Pilot, a Brazilian company responsible for the ship traffic through Santos Port. The data collected by the Santos Pilot are used in this thesis.

The land area on the southeast of Santos City where Porto Channel connects with Santos Bay is a neighborhood called Ponta da Praia (Figure 1.1). The region is densely populated with high cost infrastructure built close to the shoreline. In the recent years, strong beach erosion and eventual episodes of flooding has been observed in Ponta da Praia. Flooding is caused by rough sea conditions in the Santos Bay, caused by the isolated effect of high frequency waves with relative great wave heights or combined with a weather induced sea level increase on top of an astronomical high tide. The last is known as storm tide and it will be introduced in the following section. The investigation of storm tides in the SSVBES is one of the motivations of this thesis. 


\subsection{Storm tides}

The total water elevation during storm events in coastal zones is often referred to as storm tide. Storm tide is the combination of the astronomical tide with a meteorological induced sea level rise producing anomalous high water. Tides are generated by the gravitational forces of the Moon and the Sun with dominant energy in the semidiurnal and diurnal frequencies. The meteorological component, known as storm surge, has frequencies lower than the tidal variability. Storm surges are short lived $(<10$ days) events of abnormal sea level rise in coastal regions. A storm surge happens when strong wind velocity and low sea level pressure conditions push the sea water towards the coast. Such conditions happen, for instance, when hurricanes pass through the eastern coast of the United States. In Brazil, specifically in the South Brazil Bight (from $22^{\circ} \mathrm{S}$ to $28.5^{\circ}$ S, approximately; see also Figure 2.1), storm surges are induced during cold front passages, when the southwesterly winds promotes Ekman transport convergence on the coast. Also, the low atmospheric pressure contributes to sea level rise through the inverse barometer effect. When storm surges overlaps the tides during spring cycle, coastal flooding is very likely to occur.

Besides storm surges and tides, many processes in the continental shelf region contribute to the sea surface oscillation, such as waves of different frequencies and wavelengths (Gravity Waves, Poincare Waves, Kelvin Waves and Continental Shelf Waves) . In estuaries, the proximity to river runoff makes the fresh water inputs also important to the sea level variation. Therefore, we can define the total water elevation in estuaries in relation to the sea floor $(h)$ as:

$$
h=h_{m}+\eta_{s}+\eta_{t}+\eta_{r}+\eta_{w}
$$

where $h_{m}$ is the mean sea level and $\eta_{s}, \eta_{t}, \eta_{r}$ and $\eta_{w}$ are the anomaly components caused, respectively, by storm surges, tides, rivers and the waves mentioned before (sketch in Figure 1.2). The terms in equation (1.1) are typically of order $10 \mathrm{~m}\left(h_{m}\right), 1 \mathrm{~m}\left(\eta_{s}, \eta_{t}\right), 1 \mathrm{~cm}\left(\eta_{r}\right)$ and $1-10 \mathrm{~m}\left(\eta_{w}\right)$ in the SSVBES.

Although equation (1.1) isolates the contributions of each process to sea level variations, there may be both linear and non-linear interactions between the terms. For example, changing the mean sea level changes not only the total water elevation directly, but also through changing tides and storm surges dynamics. (Flather and Williams, 2000). Also, the storm surges can modulate the phase of tidal propagation, as first observed by Rossiter (1961) in the Thames estuary. Georgas et al. (2014) observed that tide-surge interaction in the New York Harbor during the hurricane Sandy produces lower total water elevations in relation to what is expected from a liner superposition of wave heights.

Changing the components at the right-hand side of equation (1.1) through both mean sea level rise and more severe storm surges may contribute to enhance the low-lying coastal regions vulnerability to flooding. Thus, future environmental changes may have direct impact over coastal cities and population. Coastal societies were established around the world during periods of stable sea level. But since the mid-19th century, the rate of global mean sea level rise has increased (Church et al., 2013). The 


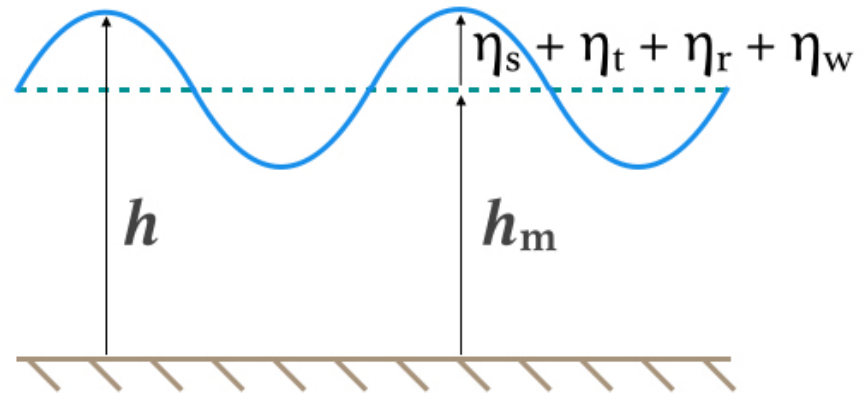

Figure 1.2: Sketch of total water elevation in equation (1.1), with the positive vertical axis pointing up- wards.

Intergovernamental Panel on Climate Change (IPCC) Fifth Assessment Report (Church et al., 2013) estimated that it has increased from $1.5 \mathrm{~mm} /$ year in 1901-1990 to $3.2 \mathrm{~mm} /$ year during 1993-2010. Over the last century, sea level rose by $0.19 \mathrm{~m}$. IPCC projections for the $21 \mathrm{st}$-century global sea level rise range from $0.28 \mathrm{~m}$ to $0.98 \mathrm{~m}$ by 2100 , compared with $1986-2005$. Nicholls et al. (2011) computed mean sea level rises between $0.5 \mathrm{~m}$ and $2 \mathrm{~m}$ until the end of the 21 st century, using predicted IPCC emission scenarios. About $45 \%$ to $90 \%$ of this rise would be caused by ice melting in high latitudes and by thermosteric effects which would induce ocean volume expansion due to the global warming (Church et al., 2013). They estimated that the sea level will rise in more than $95 \%$ of the global ocean.

\subsection{Thesis hypotheses and objectives}

The hypothesis tested in Chapter 2 is that storm tides in the SSVBES can be simulated and predicted by numerical modeling. To test this assumption, our goal is to describe the design of a forecasting system built for the SSVBES and to validate the results using observed data during storm tide events. In Chapter 3 , a physical description of the estuary based on both observed and modeled data focused in the Porto Channel is given. In Chapter 4, the forecasting system framework of Chapter 2 is used to test if climate changes can increase the number and the intensity of storm tide events. 


\section{Chapter 2}

\section{An operational forecasting system for physical processes in the Santos-São Vicente-Bertioga Estuarine System, Southeast Brazil}

\subsection{Introduction}

Among the physical processes happening in estuarine systems, storm tides cause some of the biggest impacts on economics and society of coastal cities worldwide since they can cause flooding that threatens infrastructure and human life. A storm tide is the anomalous high water induced in coastal zones by the combination of the astronomical tide and a meteorologically induced storm surge. The meteorological component has frequencies lower than the semidiurnal and diurnal tides. In the South Brazil Bight (SBB), storm surges are forced during cold front passages that reach the region every 6-10 days throughout the year (Castro and Lee, 1995). In this situation, both the southwesterly winds promoting Ekman transport convergence on the coast and the low atmospheric pressure causing an inverted barometer effect contribute to the storm surge. When strong storm surges coincide with high astronomical tides during the spring tide cycle, coastal flooding is most likely to occur.

Several initiatives have been established worldwide to predict storm surge occurrence. For instance, the New York Harbor Observing and Prediction System (NYHOPS) (Georgas et al., 2009; Georgas and Blumberg, 2010) integrates observing sensors and forecast models to provide environmental awareness for the New York City and coastal New Jersey area of the United States. In Europe, the pan-European Storm Surge Forecasting System (EU-SSF) has been established by Fernández-Montblanc et al. (2019). In Brazil, a storm surge warning system based on a 2D numerical model has recently been developed in Santos region by Ribeiro et al. (2019).

The SBB (Figure 2.1) is a wide shelf located on the southeast coast of Brazil that spans $1100 \mathrm{~km}$

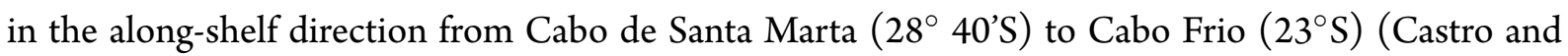
Miranda, 1998). The Santos-São Vicente-Bertioga Estuarine System (SSVBES) is located at the central 
and widest part of the SBB, near latitude $24^{\circ} \mathrm{S}$ and longitude $46.3^{\circ} \mathrm{W}$ (Figure 2.2). The SSVBES spans $30 \mathrm{~km}$ in the east-west direction and $19 \mathrm{~km}$ in the north-south direction forming a complex of estuarine channels, rivers, mangrove areas, islands and the Santos Bay. The Porto Channel, the region of focus of this study, harbors the Santos Port, the largest sea port in Latin America.

Previous works have studied the tidal circulation in the SSVBES using numerical models (Harari and Camargo, 1998; Harari et al., 2000; Harari and Camargo, 2003). Alfredini et al. (2014) investigated a possible increase in significant wave height, and Marengo et al. (2017) estimated possible structural damages and economic impacts caused by flooding as consequences of global changes. Estuary classification has been addressed in Bertioga Channel by Miranda and Castro (1998) and in Piaçaguera Channel by Miranda et al. (2012). The authors found that both channels behave as partially mixed estuaries. However, a forecasting system that takes into account the three most important forcings for estuarine circulation (Miranda et al., 2017), tides, river discharges and longitudinal salinity gradients, is still nonexistent in the SSVBES region.

The goals of this study are (i) to describe the initial design of the Santos Operational Forecasting System (SOFS), built using a 3D model to predict 3D currents, sea surface elevations, temperatures and salinities in the SSVBES, and (ii) to evaluate the model performance in simulating observed surface currents and sea surface elevations.

\subsection{Materials and Methods}

To build the SOFS, we used the version of the Princeton Ocean Model (POM) (Blumberg and Mellor, 1987) named POM-rain, available at $h t t p: / / w w w . c c p o . o d u . e d u / P O M W E B /$ serinfo.htm. Comparisons of numerical results with in situ measurements were carried out using observed currents and sea level in the SSVBES collected by the Santos Pilots.

\subsubsection{SBB and SSVBES model grids}

The SOFS works with two numerical grids. A high-resolution SSVBES grid is one-way nested into a coarse-resolution grid for the SBB. The orthogonal curvilinear SBB grid (Pereira et al., 2007), shown in Figure 2.1, extends from Cabo de Santa Marta ( $\left.28^{\circ} 40^{\prime} \mathrm{S}\right)$ to Cabo de São Tome ( $\left.22^{\circ} \mathrm{S}\right)$ for approximately $1100 \mathrm{~km}$ in the along-shelf $(y)$ direction and a few hundred kilometers in the cross-shelf $(x)$ direction. Cross-shelf resolution varies from $200 \mathrm{~m}$ over the continental shelf to $35 \mathrm{~km}$ in the deep ocean. On the continental shelf, grid cells are elongated in the alongshore direction with a highest resolution of $500 \mathrm{~m}$. The grid depths range from $5 \mathrm{~m}$ to $2000 \mathrm{~m}$.

The curvilinear grid for the SSVBES, comprising the four main estuarine channels, the Santos Bay and the adjacent inner shelf region has 322 by 132 cells in the directions parallel and perpendicular to the coastline at the Santos Bay, respectively. The curvilinear grid lines are designed to create orthogonal grid 


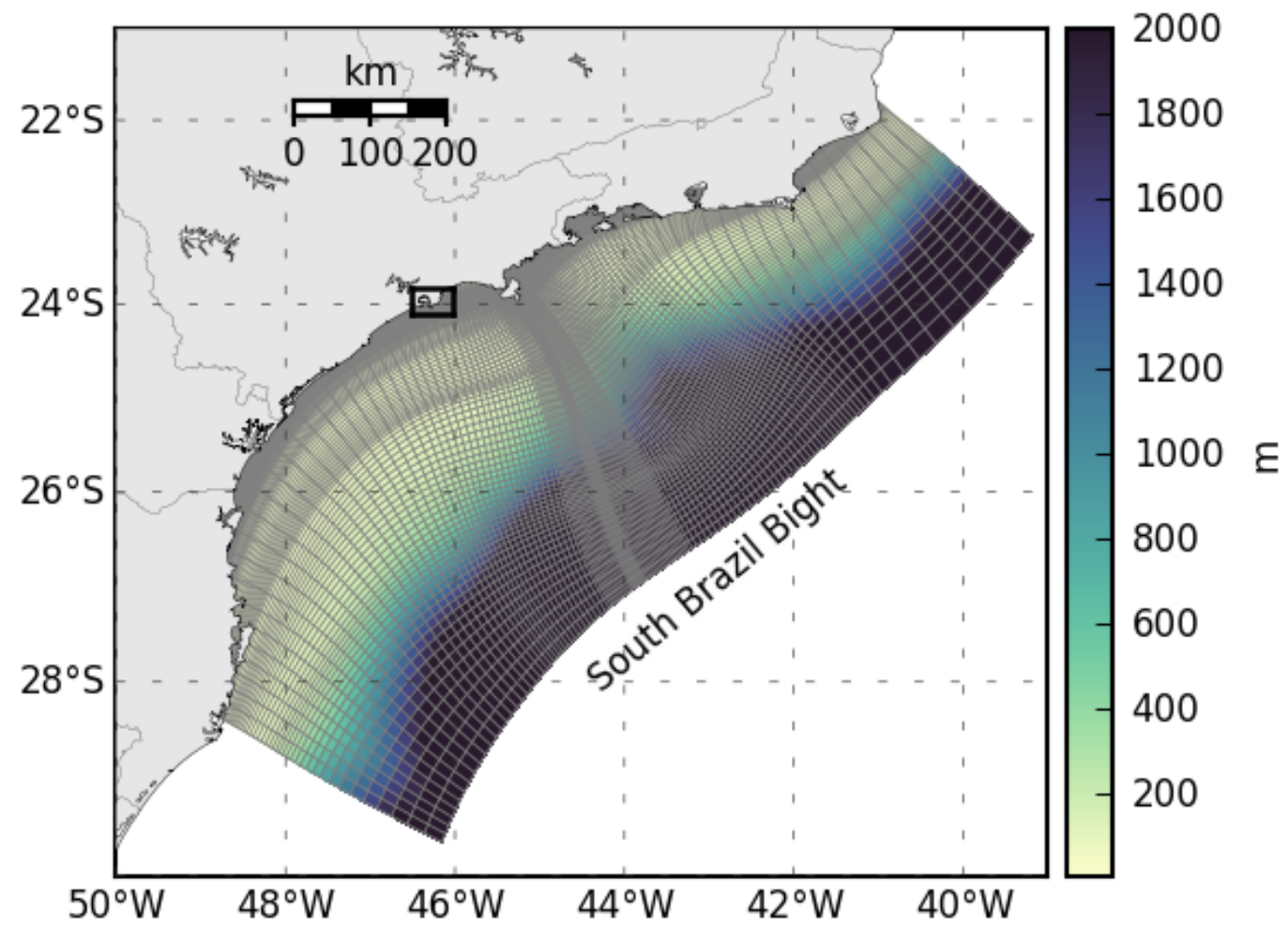

Figure 2.1: SBB model grid with bathymetry $(\mathrm{m})$ shown in colors. The black rectangle encloses the SSVBES region shown in Figure 2.2

cells with low aspect ratio and relatively high horizontal resolution inside the estuarine channels. The average values of orthogonality and aspect ratio are 0.009 and 1.9, respectively. The average resolution of the 19,165 wet cells is $144.5 \mathrm{~m}$ and varies from $26.7 \mathrm{~m}$ in São Vicente and Bertioga channels to 444.5 $\mathrm{m}$ in the southwestern part of the domain. In Porto Channel (shown in Figure 2.3), the horizontal resolution is approximately $100 \mathrm{~m}$. Inside the estuarine channels, the grid cells are aligned to the channel orientation whenever orthogonality does not exceed 0.04. For the open boundaries placed along the inner shelf, the grid cells are arranged according to the SBB grid orientation.

The SSVBES grid cells at the ocean open boundaries (and each respective adjacent cell) have the same depth as the closest SBB grid point in order to guarantee mass conservation. Depths range from $2.0 \mathrm{~m}$ to $26.9 \mathrm{~m}$ relative to the local nautical chart datum (Mean Lower Low Water, MLLW). The deepest cells are found in the Porto Channel entrance (Figure 2.3).

\subsubsection{Numerical model}

POM-rain is a three-dimensional estuarine and coastal model discretized on an orthogonal, curvilinear Arakawa C-grid with sigma vertical coordinates, similar to other versions of POM. In our study, we use the hydrodynamic module from POM-rain, which is based on the primitive equations and provides prognostics of sea surface elevation and 3D fields of currents, temperature and salinity. Vertical and horizontal mixing processes are parameterized using the Mellor and Yamada (1982) turbulence 


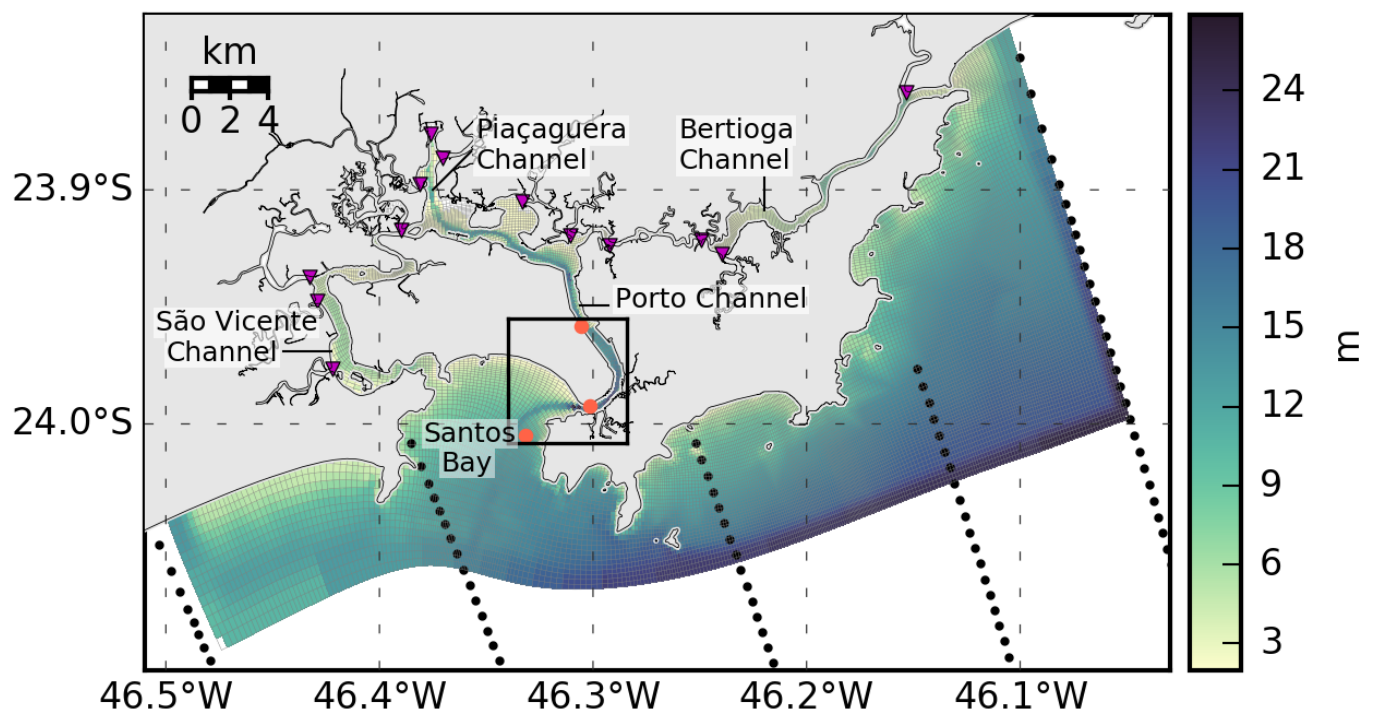

Figure 2.2: SSVBES model grid with bathymetry $(\mathrm{m})$ shown in colors. SBB grid cell centers are shown by black points. Magenta triangles symbolize positions where rivers are imposed. Orange circles mark sea level observation stations. The box encloses the area shown in Figure 2.3

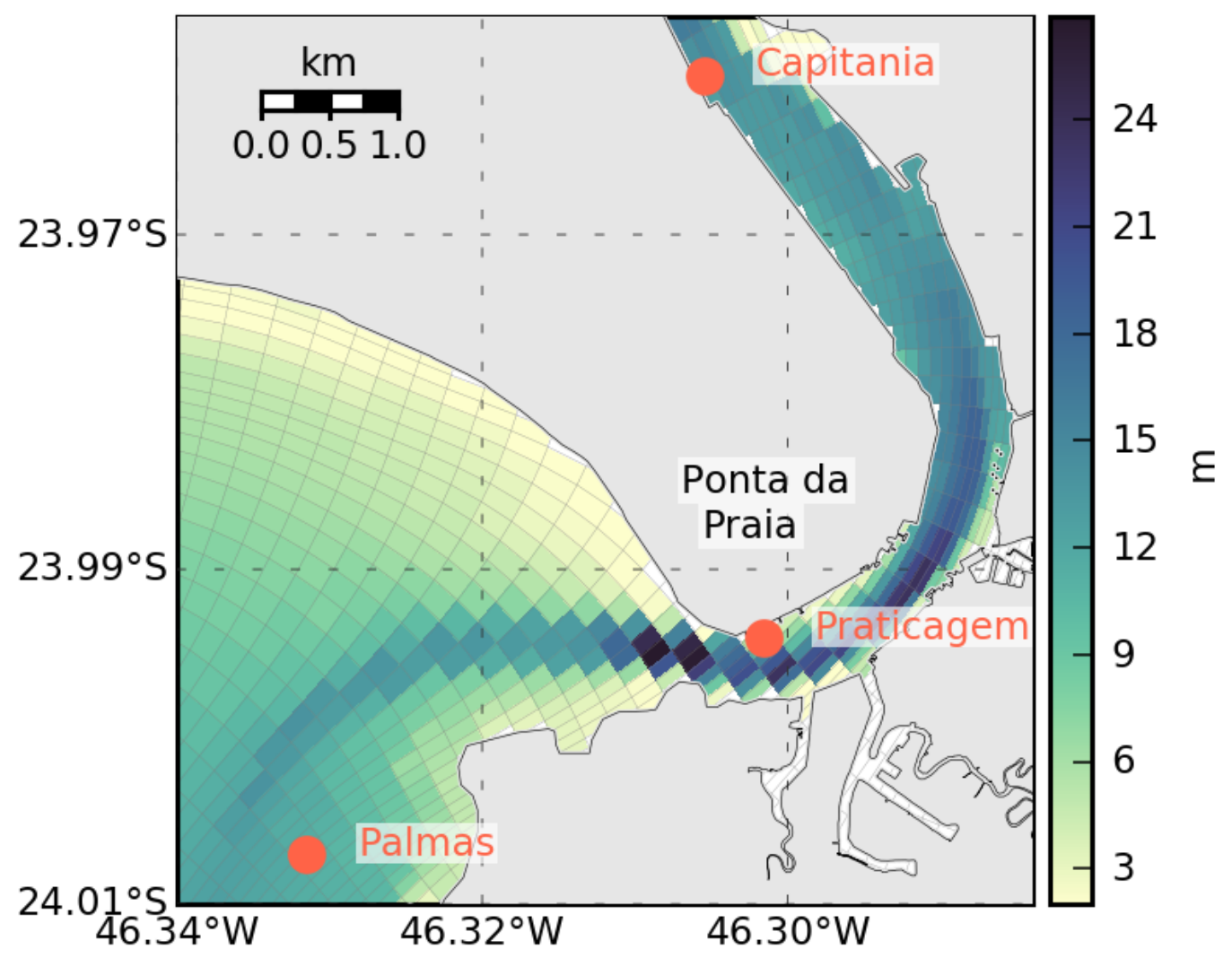

Figure 2.3: Zoom of the SSVBES grid in the Porto Channel entrance, indicated in Figure 2.2 by the black rectangle. The observation stations are labeled in orange. Bathymetry $(\mathrm{m})$ is shown in colors 
closure model and a Smagorinsky (1963) formulation, respectively. The model also includes a mode splitting technique where vertically integrated equations (external mode) and 3D equations (internal mode) are solved with different time steps.

Model parameters for both grids are set to avoid numerical instability and to adjust numerical results to observations. The Mellor and Yamada (1982) turbulence closure model calculates vertical mixing coefficients for momentum equations and temperature and salinity conservation equations taking into account a user-defined background value. Here, we assume background mixing values of $10^{-4}$ $\mathrm{m}^{2} / \mathrm{s}$ for SBB and $10^{-6} \mathrm{~m}^{2} / \mathrm{s}$ for SSVBES. The Smagorinsky diffusivity coefficient is set to 0.2 in the SBB model and to 0.1 in the SSVBES model.

Both grids run with equally spaced vertical sigma levels, 21 for the SBB and 11 for the SSVBES. The hydrodynamic equations in the SBB are solved with temporal resolutions of $0.5 \mathrm{~s}$ for the external mode and $5 \mathrm{~s}$ for the internal mode. In the SSVBES, the governing equations are calculated with temporal resolutions of $0.8 \mathrm{~s}$ and $4 \mathrm{~s}$ for the external and internal modes, respectively. These time steps respect the Courant-Friedrichs-Levy (CFL) computational stability condition. The Asselin parameter is set to 0.25 in both grids.

Both the SBB and SSVBES models use clamped boundary conditions for elevation, temperature and salinity by imposing the values assigned at the boundary cells. Such information comes from global models in the case of the SBB, which in turn provides boundary conditions to the SSVBES as detailed below. For $2 \mathrm{D}$ and $3 \mathrm{D}$ velocities, different boundary conditions for the along- and across-boundary components are set in each grid. In the SBB model, the along-boundary $2 \mathrm{D}$ velocity is set to zero at all boundary grid cells. This ensures that the vertically integrated flux occurs exclusively across the border. For the SBB along-boundary 3D velocities and for the SSVBES 2D and 3D along-boundary currents, no-gradient boundary conditions are applied. Energy radiation through the boundary is allowed by the across-boundary velocity boundary conditions in both models. For the SBB 2D normal velocity, a gravity wave adjustment based on the difference between the internal water elevation solution and the imposed boundary elevation is applied. For instance, the offshore external velocity boundary condition is:

$$
U_{b}=U i m p_{b} \cdot r a m p+\sqrt{\frac{g}{H_{b-1}}} \cdot\left(\eta_{b-1}-\eta i m p_{b} \cdot r a m p\right),
$$

where $U$ is the across-boundary vertically integrated current, $U$ imp is the imposed $2 \mathrm{D}$ across-boundary velocity, $g$ is the acceleration due to gravity, $H$ is the local depth, $\eta$ is the water elevation solution and ramp is a time step factor over which forcings vary linearly from zero to their full specified value (equivalent to 3 days in both models). The subscript $b$ denotes the boundary cell, and $b-1$ represents the adjacent wet point, in this case west of the boundary grid. For 3D velocities, the across-boundary horizontal component also allows energy radiation through the boundary based on the same long wave adjustment calculated at each level. As 3D velocities are specified at standard levels, a linear interpolation on sigma levels is first executed before equation 2.1 is applied at each sigma. 
The SSVBES model uses Reid and Bodine (1968) radiative boundary conditions for the depthaveraged component, similar to equation 2.1 except that no value is imposed $\left(U i m p_{b}=0\right)$. For instance, the $2 \mathrm{D}$ across-boundary velocity is:

$$
U_{b}=\sqrt{\frac{g}{H_{m}}} \cdot\left(\eta_{b-1}-\eta i m p_{b}\right),
$$

where $H_{m}$ is the average depth between cells $b$ and $b-1$. In this case, $\eta i m p_{b}$ is the SBB elevation added to the predicted tidal elevation at the boundary. No boundary condition is specified for the SSVBES 3D normal velocity, which is allowed to assume the model computed values.

Within the SOFS, the SBB model is initialized from stable 3D currents and water mass fields derived from a 110-day spin-up run, detailed in subsection 2.2.3. The SSVBES model is initialized from the rest with homogeneous $3 \mathrm{D}$ fields of temperature and salinity set to $22.3^{\circ} \mathrm{C}$ and 30.4 , respectively. These are the surface values measured in the Porto Channel during the ECOSAN project in October and November 2005. The adjustment between mass and velocity fields is allowed to occur naturally in the operational runs. The first 10 days of spin-up period are rejected.

\subsubsection{SBB spin-up run}

Four seasonal 110-day spin-up runs forced exclusively using 3D climatological fields of temperature and salinity (subsequently referred to as TS) are used to initialize the SBB model runs. At the beginning of every season, the operational model is initialized from the respective seasonal spin-up run. The climatology is constructed using two data sets, a seasonal field of temperature and salinity for the SBB continental shelf waters generated by Gabriel Paschoal, a graduate student at LHiCo, and a summer climatology produced by Rezende (2003) for the SBB region. The latter extends from the coast to the $2000 \mathrm{~m}$ isobath. Both datasets are bilinearly interpolated to the SBB grid, resulting in four seasonal fields of TS with 23 standard levels in the vertical direction. For levels deeper than $150 \mathrm{~m}$, the summer climatology data is used for every season, once continental shelf information is no longer available. Figure 2.4 illustrates the resulting TS fields for two cross-shelf sections close to the northern and southern limits of the SBB grid for the spring season.

The spin-up runs were forced at the open boundaries with clamped sea surface elevation, TS, and radiative $2 \mathrm{D}$ and $3 \mathrm{D}$ across-boundary currents. Neither atmospheric forcing nor tidal variations were added to the simulation. TS came from the seasonal climatology, and elevation and currents were taken from the Copernicus Marine Environment Monitoring Service (CMEMS) operated by Mercator Ocean. The Global Sea Physical Analysis and Forecasting product delivered by CMEMS was chosen to provide the boundary information. This product had a spatial resolution of $1 / 12^{\circ}$ and vertical coverage on 50 levels from the surface to $5000 \mathrm{~m}$. In the spring season, for example, the mean values of sea surface elevation and currents during the 2016 austral spring period were used to force the spin-up run. Elevation from the CMEMS product was linearly horizontally interpolated on the SBB grid. The 

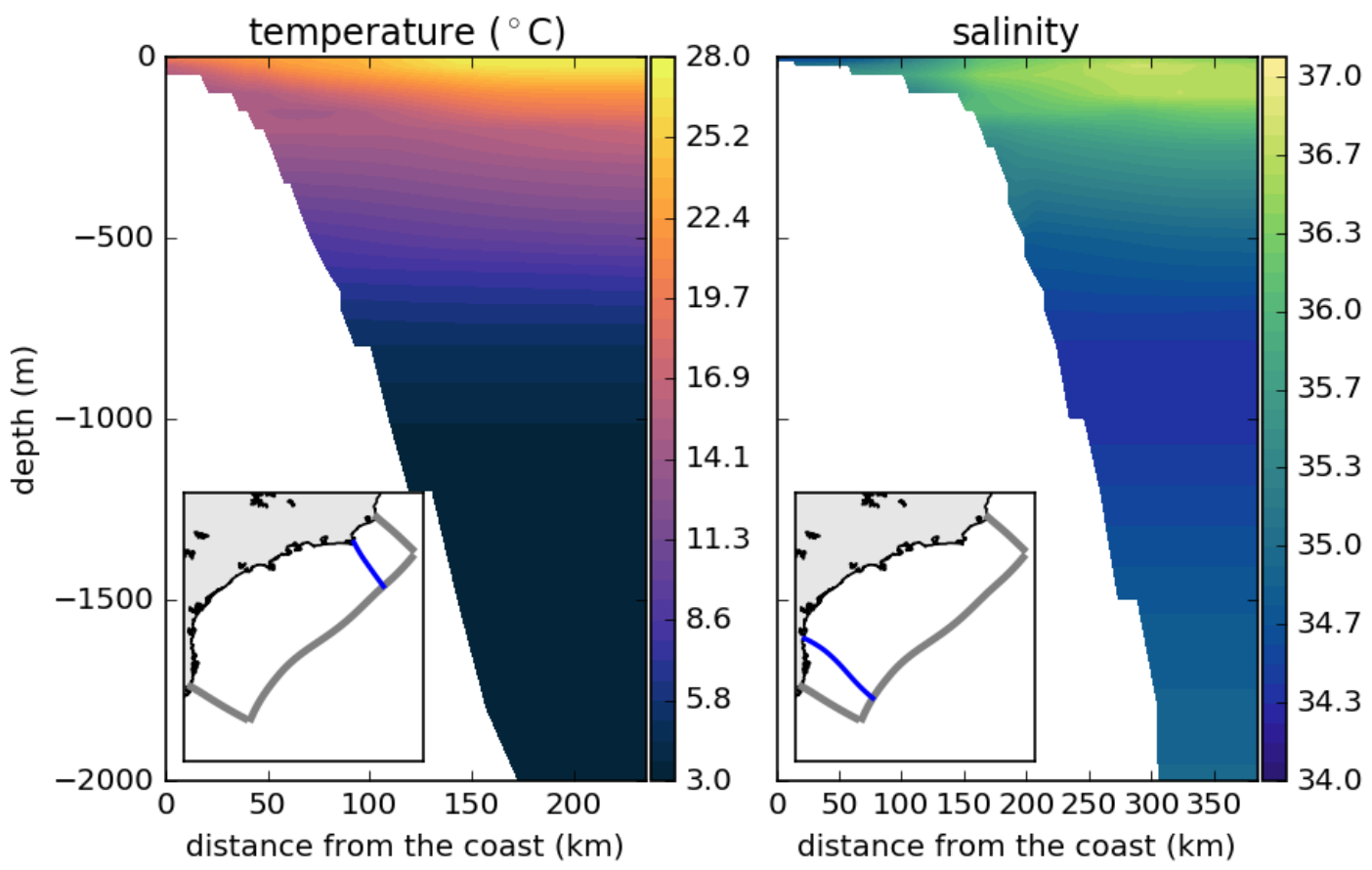

Figure 2.4: Examples of temperature (left) and salinity (right) sections at $26.5^{\circ}$ and $22.9^{\circ} \mathrm{S}$ from the spring climatology used as initial conditions for the SBB spin-up run. The location of the sections are indicated in the bottom left corner of each panel by the blue line. The gray lines show the limit of the model grid domain

same interpolation was performed for the CMEMS zonal and meridional currents at each level. Next, a vertical linear interpolation from the original 50 levels to the SBB 23 standard levels was performed for the velocity components of every boundary cell. Finally, 3D currents were vertically integrated and the resultant $2 \mathrm{D}$ as well as $3 \mathrm{D}$ velocity components were rotated to each boundary cell angle. Only the across-boundary component was imposed at the open boundaries, as in the case of the $2 \mathrm{D}$ velocities, the $U i m p_{b}$ in equation 2.1. All open boundary conditions were held constant over time.

Each SBB spin-up run was carried out for 110 days, consisting of 10 days in prognostic mode followed by 100 days of diagnostic integration. In the prognostic case, the equations of motion, continuity and conservation of temperature and salinity evolve over time, whereas in the diagnostic mode, the solution fields for temperature and salinity are held constant. The prognostic period allowed adjustments between the velocity and mass fields through geostrophic balance. The following 100 days of simulation allowed further velocity adjustments and were enough for a particle with the mean surface velocity $(0.14 \mathrm{~m} / \mathrm{s})$ to cross the entire modeled region. The results of the spin-up run and comparisons with previous studies are discussed in subsection 2.3.1.

\subsubsection{Tidal forcing specification}

In the operational model for the SSVBES, the tidal elevation at every boundary cell is predicted using predefined amplitudes and phases of 7 major tidal constituents: M2, S2, O1, K2, K1, N2 and Q1. These constituents are found by performing a harmonic analysis in a 1-year time series of observed sea 
level at Praticagem station and represent $93.5 \%$ of the total tidal energy. For every boundary grid cell, the phases of all constituents are delayed in time to account for the interval a gravity wave traveling at shallow water speed takes to propagate from the grid boundaries to the observation station. No corrections are applied to the tidal constituent amplitudes, which are held constant through the boundary cells.

The procedure to correct the tidal phases was done in 2 steps. First, the time lag between one point at the boundary and the observation point was calculated. Second, this time lag was projected to every boundary grid cell using a spatial distribution of phases derived from the barotropic ocean tides model TPXO8-atlas version 1(Egbert and Erofeeva, 2002). For the first step, a time lag between the observation point $\left(p_{o}\right)$ and the boundary grid point closest to $p_{o}\left(p_{b}\right)$ of 16 minutes was obtained as $d / c$. In this ratio, $d$ is the distance, in meters, between $p_{o}$ and $p_{b}$ calculated as the cumulative sum of consecutive grid cell sizes. $c$ is the shallow water gravity wave speed, defined as $c=\sqrt{g H}$, where $H$ is the mean depth among the same grid cells. For instance, the phase of the M2 component obtained with the harmonic analysis at $p_{o}$ as $182.5^{\circ}$ was assumed to be equal to $174.3^{\circ}$ at $p_{b}$. For the second step of the procedure, the along-boundary phase was obtained by bilinearly interpolating the phases of each tidal component from the TPXO 1/30-degree resolution model to the grid boundary. Next, the difference between the TPXO-derived phase at $p_{b}$ and the phase previously calculated by the first step was subtracted from every boundary grid cell. The value subtracted was a constant for each tidal constituent and acted as an offset to correct the TPXO-derived phase at all boundary grids based on observed data. This procedure therefore worked to project the tidal phase derived from a single observation point to a $2 \mathrm{D}$ distribution.

The prediction of tidal elevations based on observed data were more accurate compared to imposing the TPXO amplitudes and phases directly at the SSVBES grid. The errors of model results in relation to the observations were approximately 8 times larger using the TPXO compared to the observations. Given this, imposing the TPXO tides at the SBB and then nesting the results into the SSVBES grid should produce less accurate tidal elevations within the estuary.

\subsubsection{Design of the SOFS}

The SOFS is designed to provide up to 72 -h forecasts of daily updated sea surface elevations and surface currents in the SSVBES forced by winds, tides and river runoff. The system is hosted on a 24processor Dell server running in a Linux environment with $10 \mathrm{~TB}$ of available storage. The architecture of the operational system, shown schematically in Figure 2.5, consists of five main fully automated modules built in different programming languages including Unix shell, Python, MATLAB, Fortran and Javascript. Essentially, the system collects results from global and regional models to build the boundary conditions and model forcings. After running the SBB model and using its results as boundary conditions for the SSVBES grid, the SSVBES results are posted on $h t t p: / / p r e a m a r . i o . u s p . b r / e n$ (example in Figure 2.6). The complete framework takes approximately 6 hours to issue a new forecast. Running the SSVBES grid is the most time-consuming stage in the system. 


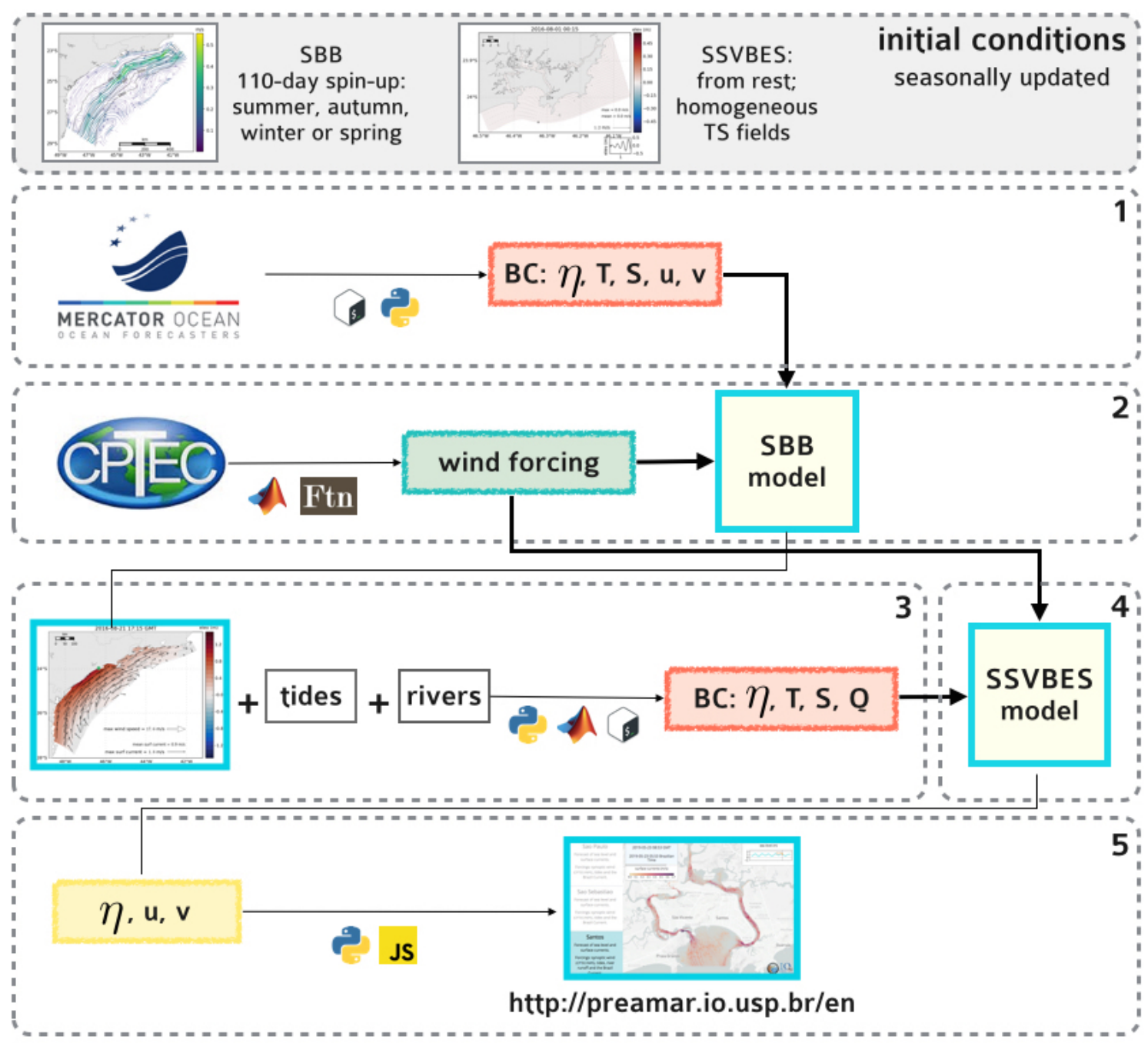

Figure 2.5: Flowchart of the SOFS framework. The number of each module is indicated. "BC" means boundary conditions. Programming languages used in each step are symbolically represented

The first operational module prepares boundary information to enter in the SBB model. The initial conditions for the SBB come from one of the four 110-day spin-up runs (subsection 2.2.3) at the first day of each season. The next daily updates restart from the previous forecast. The boundary conditions are similar to those for the SBB spin-up run, except that elevations and currents are updated every 24 $\mathrm{h}$ with the CMEMS daily product. In every operational run, the SOFS uses forecasts for the actual day and the next 2 days, interpolated to the SBB boundaries following the procedure explained in subsection 2.2.3. This process is similar to Georgas et al. (2016a) H3E forecasts.

The second module sets atmospheric forcing for both the SBB and SSVBES grids. Atmospheric forecasts come from regional climate models operated by the Center for Weather Forecasts and Climate Studies (Portuguese acronym CPTEC). The SOFS was first implemented using operational results from the Brazilian developments on the Regional Atmospheric Modeling System (BRAMS) which has 72$\mathrm{h}$ forecasts of atmospheric fields with spatial and temporal resolutions of $5 \mathrm{~km}$ and $6 \mathrm{~h}$, respectively. More recently, we have updated the system to use the Weather Research and Forecasting (WRF) Model 


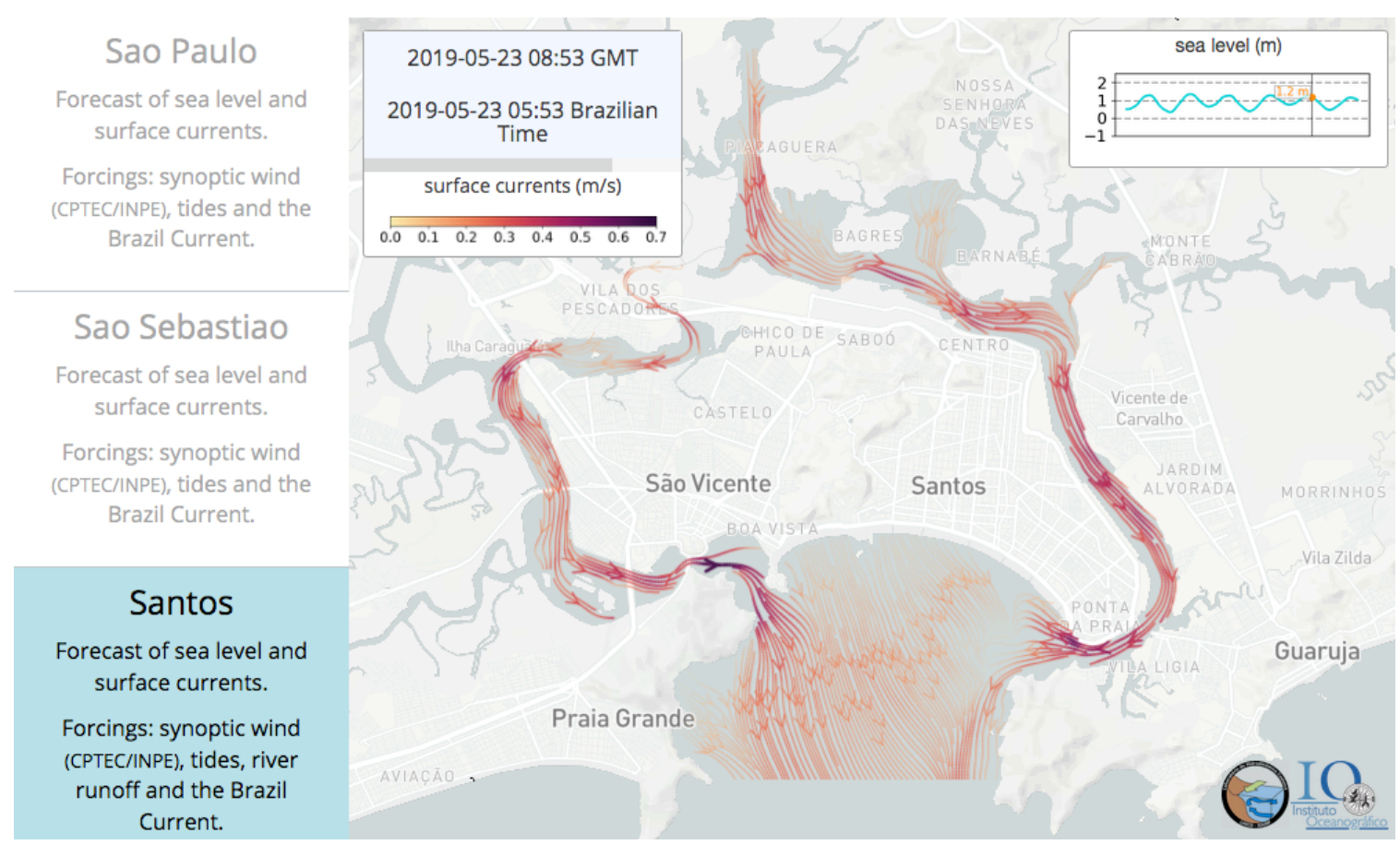

Figure 2.6: Online results of the SSVBES forecasts released at http://preamar.io.usp.br/en. Example of sea surface elevation and surface currents forecasts for May 23, 2019

results released by CPTEC (available at http://ftp.cptec.inpe.br/modelos/tempo/), with the same $5 \mathrm{~km}$ resolution and $72 \mathrm{~h}$ of forecast lead time and an improved temporal resolution of $1 \mathrm{~h}$. Forecasts of $10-\mathrm{m}$ wind components and sea level pressure are bilinearly interpolated on both the SBB and SSVBES grids.

After the SBB run is finished, the third module sets river runoff information into the SSVBES grid and implements the nesting scripts. Thirteen fresh water discharge points (Figure 2.2) are included with constant discharge values varying from $0.5 \mathrm{~m}^{3} / \mathrm{s}$ to $30 \mathrm{~m}^{3} / \mathrm{s}$, which represent the outflow contributions of the main rivers in the SSVBES obtained during the ECOSAN project. Next, the SBB results for sea level and TS are nested into the SSVBES boundary cells. The results are taken from the SBB grid point closest to each SSVBES boundary cell. Tidal amplitudes from 7 major constituents are added to SBB elevations and imposed at the SSVBES open boundary grids with temporal resolution of 6 minutes. Tidal elevation is operationally predicted using the MATLAB toolbox " $t$ _tide" (Pawlowicz et al., 2002). Amplitudes and phases for each boundary cell are calculated according to the procedure detailed in subsection 2.2.4.

The fourth module starts the SSVBES model run. The SSVBES is started from rest and with homogeneous thermohaline fields every beginning of season. The daily runs restart from the previous forecast until the end of the actual season. Subsequently and to the end of each run, the fifth module produces stream lines of surface currents and sea surface elevation time series that are released online at the mentioned website (Figure 2.6). 


\subsubsection{SOFS skill assessment}

Before putting the modules into operational form, two simulations were run in retrospective forecast mode for numerical calibration purposes. The simulations were integrated for 91 days, corresponding to the 2016 spring season. First, a homogeneous run (C1) forced exclusively by tides in the form described in subsection 2.2.4 was executed. Different values for horizontal diffusivity, vertical viscosity and bottom friction coefficients and for the bottom roughness height were extensively tested. For example, bottom friction coefficient was set to $2.5 \times 10^{-3}$ in the SBB model and to $2.5 \times 10^{-5}$ in the SSVBES. The bottom roughness height were fixed at $10^{-3} \mathrm{~m}$ and $10^{-1} \mathrm{~m}$ in the SBB and in the SSVBES models, respectively. The current velocities in the SSVBES revealed to be very sensitive to these two parameters, increasing substantially (more than $30 \%$ ) when the bottom friction was reduced by two orders.

Next, the calibration run (C2) was conducted including all the estuarine circulation forcings: tides, river runoff, wind and atmospheric pressure and the offshore marine effect, through nesting temperature, salinity and low-frequency sea level variation from the SBB model. Additionally, another seven short-term simulations were conducted to validate the operational system in reproducing recent storm tides in Baixada Santista: ST1, ST2, ST3, ST4, ST5, ST6 and ST7. Both 2D and 3D simulations were performed for each storm tide. Table 2.1 details the characteristics of all simulations.

The numerical simulations C2, ST1, ST2 and ST3 were forced with BRAMS; ST4-ST7 with WRF meteorological products. The two products contain both analysis and forecast atmospheric data. CPTEC combines the two kinds of products in the same output providing analysis at the first time step of each release and forecasts in the following time steps. As SOFS updates everyday, atmospheric analysis are used to force the model every $24 \mathrm{~h}$ (at time 00 GMT) and forecasts are used in the consecutive time steps, i.e. every $6 \mathrm{~h}$ for BRAMS and every $1 \mathrm{~h}$ for WRF. The analysis is the GFS analysis interpolated to the Brazilian regional grid.

The results from all simulations ( $1, \mathrm{C} 2, \mathrm{ST} 1-\mathrm{ST} 7)$ were compared to observations in terms of Willmott (1981) skill score (skill) and root mean square error (RMSE) using the following equations:

$$
\begin{gathered}
\text { skill }=1-\frac{\left\langle(m-o)^{2}\right\rangle}{\left\langle(|m-\langle o\rangle|+|o-\langle o\rangle|)^{2}\right\rangle}, \\
\text { RMSE }=\sqrt{\left\langle(m-o)^{2}\right\rangle},
\end{gathered}
$$

where $m$ is the modeled variable time series, $O$ is the observed time series and \langle\rangle denotes the average over the time series. Equations 2.3 and 2.4 were calculated for elevations and currents between modeled and observed data at the three stations shown in Figure 2.3. For the storm tide ST1, the water level peak reached during the storm and the arrival time were also compared to the observations. The results for sea surface elevations and surface currents are discussed in subsections 2.3.2 and 2.3.3 after presenting the results of the SBB spin-up run. 


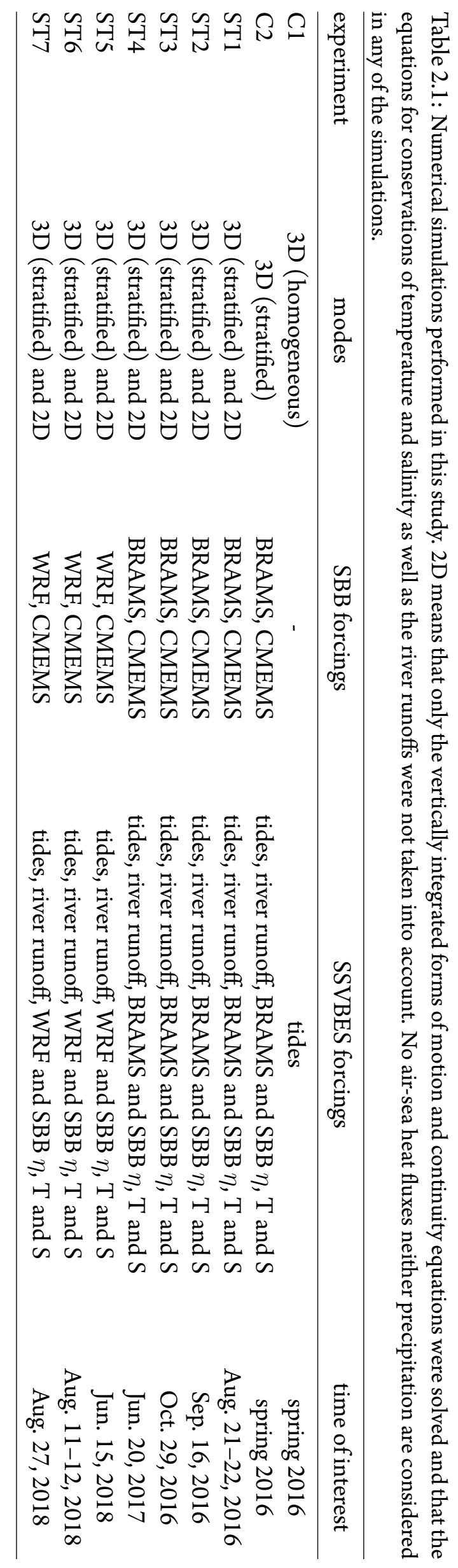




\subsection{Results}

\subsubsection{SBB spin-up run results}

The SBB spin-up runs provided the best-guess velocity fields for each season of the year, from which the SOFS is initialized. Figure 2.7 shows the best-guess velocity field for the spring season. Over the continental shelf at depths shallower than $100 \mathrm{~m}$, Figure 2.7 shows a relatively weak northeastward flux, with a mean speed of $0.1 \mathrm{~m} / \mathrm{s}$. In the inner shelf, the presence of a low-salinity plume from river inputs produces geostrophic currents that flow with the coast to the left in the Southern Hemisphere. The resulting northeastward currents corroborate the buoyancy mechanism proposed by Castro (2014) to explain inner shelf stratification offshore Ubatuba.

Over the shelf break and continental slope regions, the initial field of Figure 2.7 was assumed to represent the features of the Brazil Current (BC) flowing offshore, a southwestward current with speeds greater than $0.4 \mathrm{~m} / \mathrm{s}$ between the $100-\mathrm{m}$ and $1800-\mathrm{m}$ isobaths. Current speeds agree with observed velocities in the SBB summarized by Silveira et al. (2000). In the northern part of the domain, offshore Cabo Frio, the current flows over the continental shelf region, where its signature is found at depths shallower than $200 \mathrm{~m}$. As it flows to the south, the current deviates offshore and flows mainly over the continental slope. These characteristics are typical of the BC as described by Silveira et al. (2000) and are attributed to high meander activity offshore Cabo Frio (Signorini, 1978) due to changes in coastline orientation and continental shelf width (Campos et al., 1995) and to baroclinic instability (Silveira et al., 2008).

A cross-shore section of the alongshore velocity component near Cabo Frio is shown in Figure 2.8. The vertical structure features the Brazil Current-Intermediate Western Boundary Current (BC-IWBC) structure obtained from both velocity and CTD data by Silveira et al. (2004) and Silveira et al. (2008), respectively. A southwestward current jet $\sim 120 \mathrm{~km}$ wide is found spanning from the surface to $300-\mathrm{m}$ depth in the region between $50 \mathrm{~km}$ and $170 \mathrm{~km}$ from the $100-\mathrm{m}$ isobath. The nucleus has a maximum speed of $0.3 \mathrm{~m} / \mathrm{s}$ and is found in the first $100 \mathrm{~m}$ of the water column. This result is in good agreement with information found in the literature for the Brazil Current jet features offshore Cabo Frio (Silveira et al., 2004,2008 ). Southwestward velocities limited to the first $100 \mathrm{~m}$ depths are found near the continental shelf with speeds up to $0.1 \mathrm{~m} / \mathrm{s}$. Underneath the southwestward current, a northeastward jet over the continental slope reaches speeds up to $0.15 \mathrm{~m} / \mathrm{s}$ and is similar to the IWBC structure observed by Evans and Signorini (1985) and Silveira et al. (2004). Although the core velocity is weaker than the $0.3 \mathrm{~m} / \mathrm{s}$ reported in the literature, its position close to $800 \mathrm{~m}$ and the thickness of thousands of meters of the northeastward flow are similar to those of the IWBC.

Although numerical results for the SBB show good agreement with the BC characteristics, no comparison to observed data was performed to quantify the ability of the model to reproduce the western boundary current. The SBB grid is part of the SOFS to provide low-frequency sea level oscillations and TS information for the SSVBES grid, which is not influenced by the BC. Our interest is restricted to 


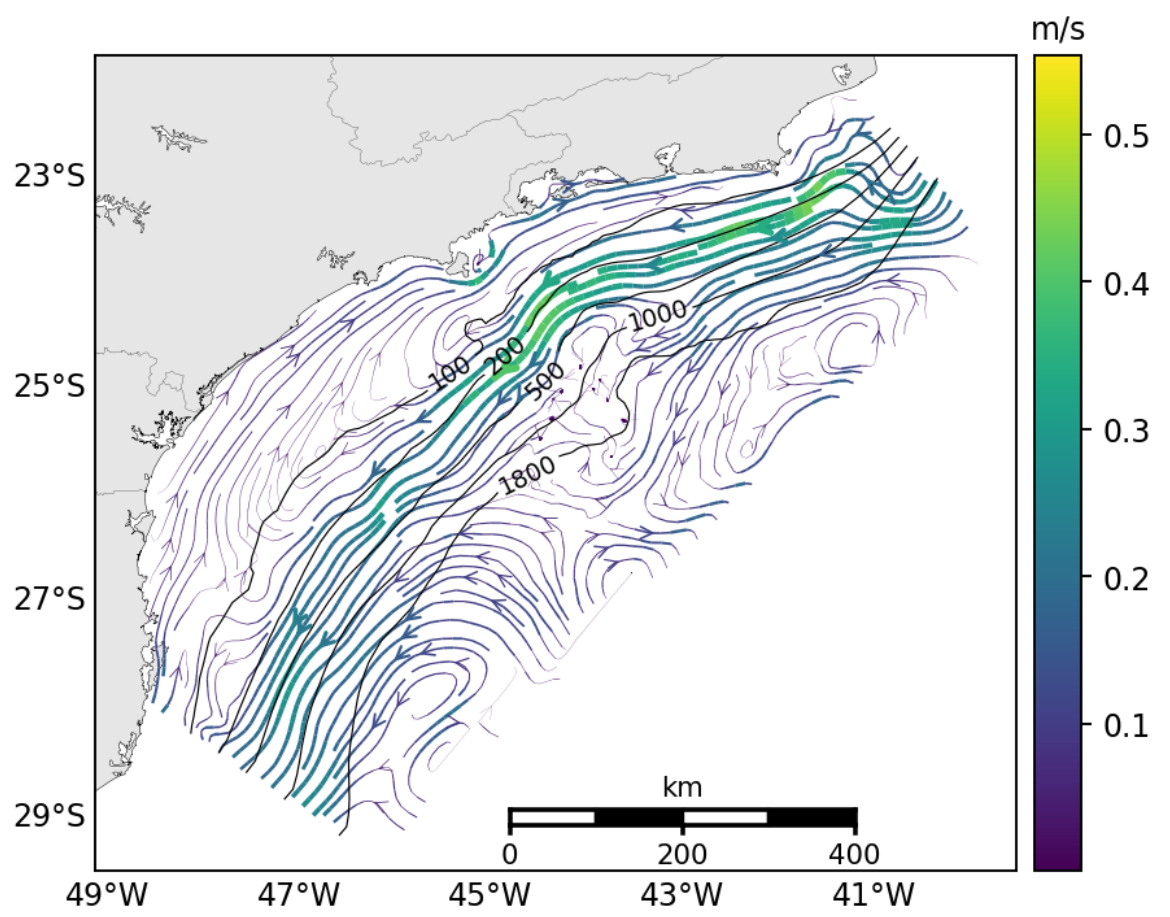

Figure 2.7: Stream plot of the SBB best-guess surface currents resulting from the 110-day spin-up run. Color and thickness of stream lines change according to current speed. The $100-\mathrm{m}, 200-\mathrm{m}, 500-\mathrm{m}, 1000-\mathrm{m}$ and $1800-$ $m$ isobaths are shown by black contours

the inner shelf, although a realistic representation of this region would not be achieved without the entire SBB region, including the Brazil Current. This study focuses on the SSVBES, and calibration and validation of numerical results with in situ data are performed and discussed in subsections 2.3.2 and 2.3.3.

\subsubsection{SOFS calibration}

Comparisons between observed and modeled sea surface elevations and the along-estuary component $(u)$ of surface velocity at Capitania (station 1), Praticagem (station 2) and Palmas (station 3) are shown in Figures 2.9 and 2.10 for the tidal and total variabilities, respectively. Model time series at the grid point nearest to each observation station are plotted. The metrics used to quantify the model performance, skill and RMSE, are found in Tables 2.2 and 2.3. These values were calculated at Capitania and Praticagem during 86 days of the C1 and C2 simulations, from September 27 to December 21, 2016. At Palmas station, performance parameters were computed for 68 days, from September 27 to December 4.

The simulation forced uniquely by tides (C1) shows sea level skills of 0.97 at Capitania and 0.96 at Praticagem and Palmas and RMSE values of $13.0 \mathrm{~cm}, 13.5 \mathrm{~cm}$ and $14.6 \mathrm{~cm}$, respectively (Table 2.2). These RMSE values represent 15.9\% (Capitania), 17.8\% (Praticagem) and 18.9\% (Palmas) of the mean tidal range at each station. For $u$ velocity, skill progressively decreases from north to south, with values 


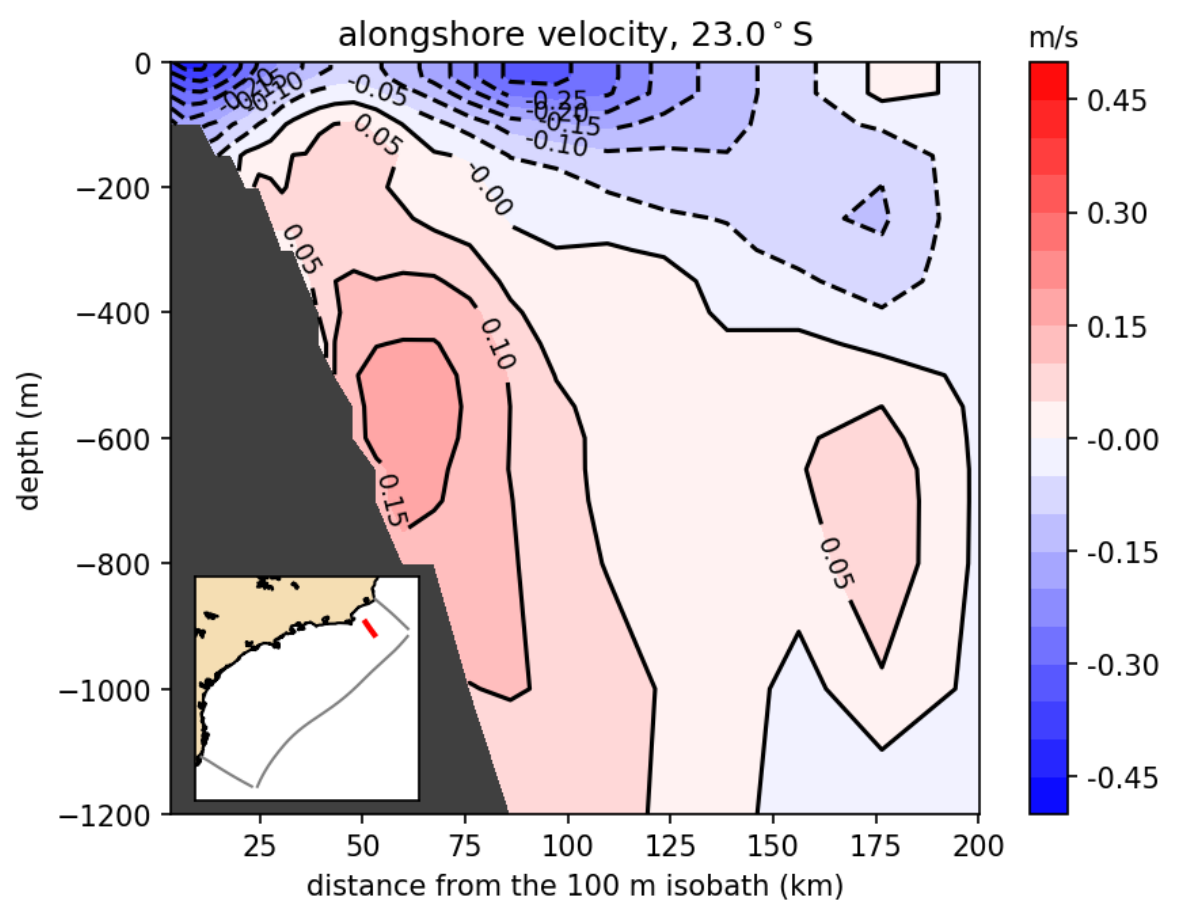

Figure 2.8: Cross-shore section of alongshore velocity near Cabo Frio. Contours are plotted every $0.05 \mathrm{~m} / \mathrm{s}$. Northward (southward) currents are shown in red (blue) colors. The location of the section is indicated in the bottom left corner

above 0.99 (Capitania), 0.98 (Praticagem) and 0.89 (Palmas). The corresponding RMSEs are $3.8 \mathrm{~cm} / \mathrm{s}$, $16.6 \mathrm{~cm} / \mathrm{s}$ and $8.9 \mathrm{~cm} / \mathrm{s}$ (Table 2.3), which represent 4.3\% (Capitania), 10.8\% (Praticagem) and 19.4\% (Palmas) of the mean tidal current range. The model performance is relatively worse in terms of the RMSE for C2, when winds, river runoff and SBB sea level oscillations are taken into account. The water level RMSE for C2 is 1.8 times greater than for $\mathrm{C} 1$ at the three stations. For the $u$ velocity, the RMSE increases 2.3 times at Praticagem and by 1 order of magnitude at Capitania and Palmas. Nevertheless, the loss of performance from $\mathrm{C} 1$ to $\mathrm{C} 2$ measured by the skill score is not as severe as that by the RMSE. As the skill equation considers both the correlation and the standard deviation between compared series, the benefit to the skill score acquired through the corrected phase of the modeled signal dominates in relation to the error in the signal amplitude. The largest decrease in water level occurs at Palmas, with a reduction of 0.06 in the skill score relative to the tidal variability. For the $u$ velocity, the skill decreases by 0.15 at both Capitania and Palmas.

$\mathrm{C} 2$ is less accurate than $\mathrm{C} 1$ due to the nature of the forcings used in each simulation. Tidal oscillation is relatively easy to predict given the deterministic behavior of the astronomic tides. On the other hand, lower-frequency signals such as wind velocity and atmospheric pressure variations are stochastic and therefore more challenging to predict. Further, accuracy is impacted by the limited forcing variability. River flow is approximated, since the runoff rates that depend highly on precipitation rates are held constant through the $\mathrm{C} 2$ simulation. In addition, the boundary TS information (that come from the SBB diagnostic model) is held constant over time.

In the estuary environment, where the circulation is largely influenced by river inputs and the lon- 

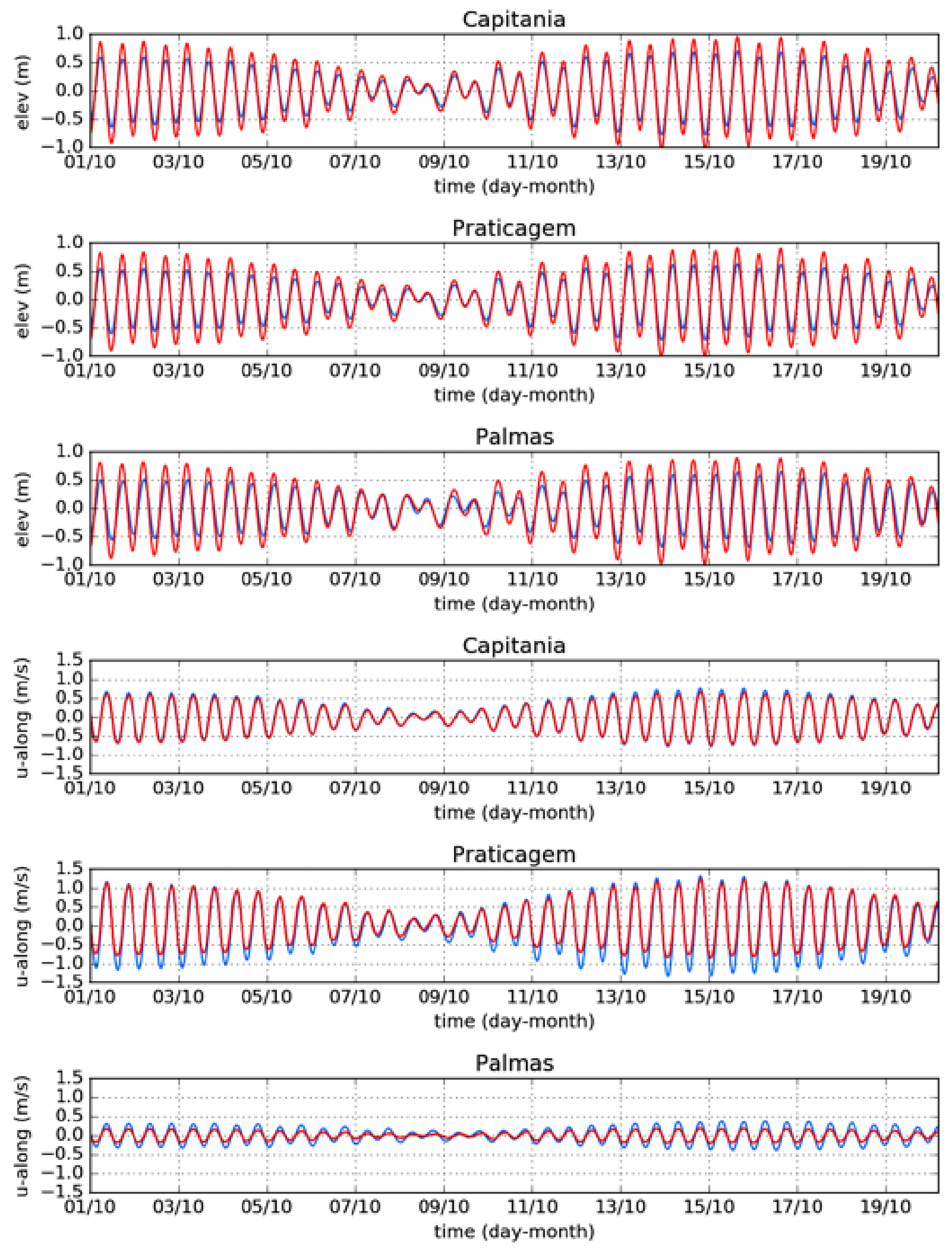

Figure 2.9: Comparisons of observed (blue) and modeled (red) tide (top panels) and along-estuary component of surface tidal currents (bottom panels) at Capitania, Praticagem and Palmas (simulation C1) 

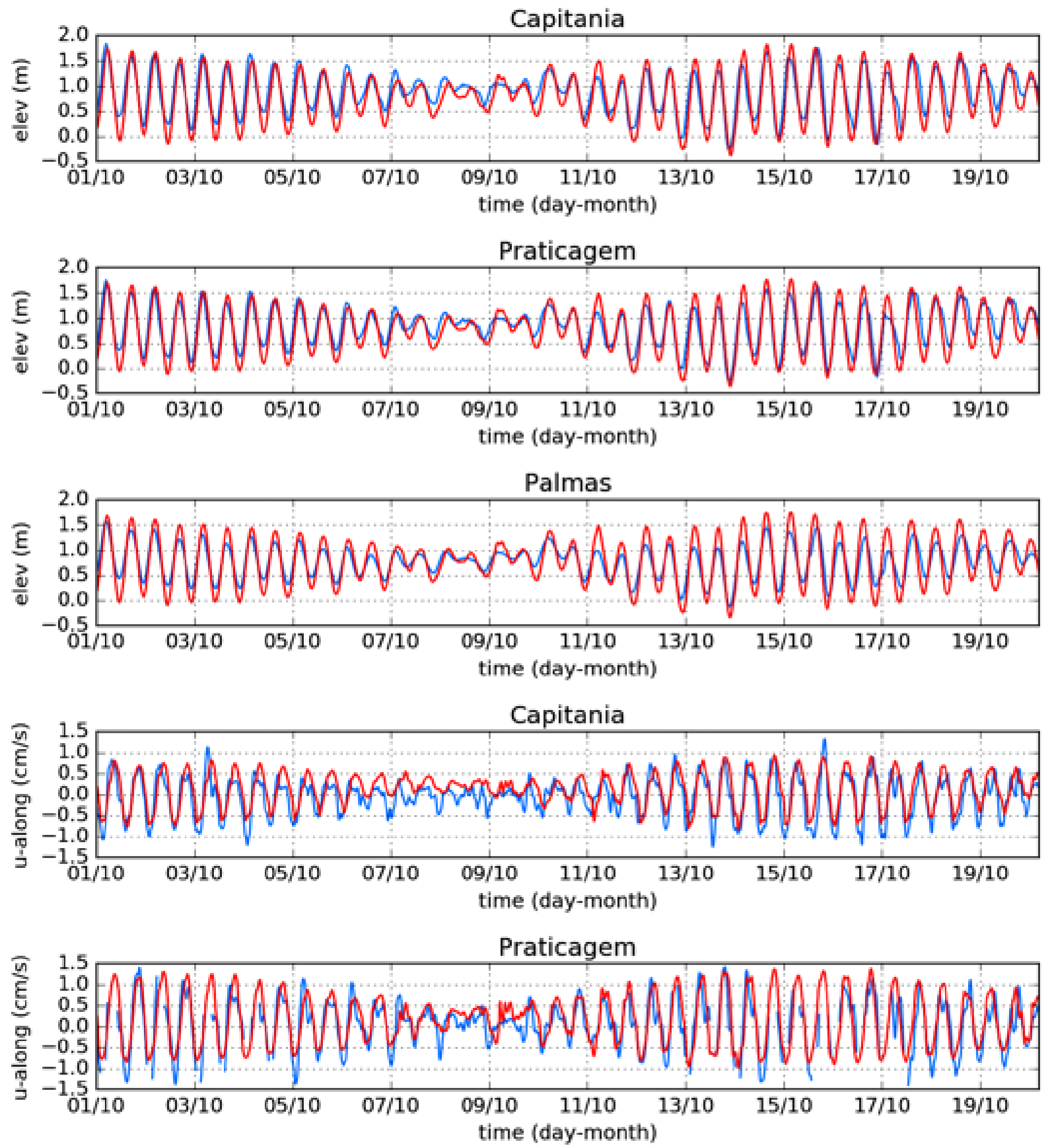

Palmas

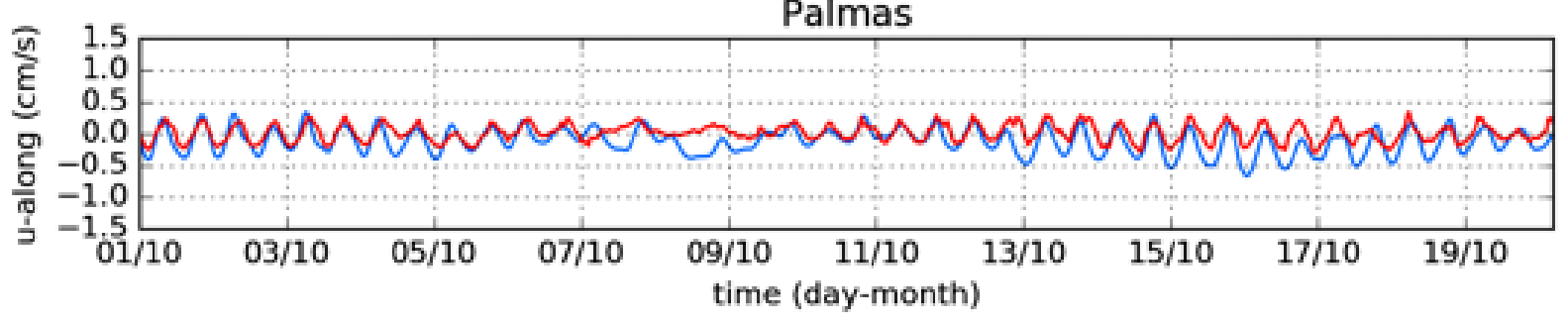

Figure 2.10: Comparisons of observed (blue) and modeled (red) sea surface elevations (top panels) and alongestuary component of surface currents (bottom panels) at Capitania, Praticagem and Palmas (simulation C2) 
Table 2.2: Skill assessment statistics for simulations C1 (tides only) and C2 for sea surface elevations at Capitania (1), Praticagem (2) and Palmas (3)

\begin{tabular}{cccccc}
\hline & & Skill & & \multicolumn{2}{c}{ RMSE $(\mathrm{cm})$} \\
& C1 & & C2 & C1 & C2 \\
\hline 1 & 0.97 & 0.93 & 13.0 & 23.3 \\
2 & 0.96 & 0.92 & 13.5 & 23.7 \\
3 & 0.96 & 0.90 & 14.6 & 26.6 \\
\hline
\end{tabular}

Table 2.3: Skill assessment statistics for simulations $\mathrm{C} 1$ (tides only) and $\mathrm{C} 2$ for the along-estuary surface current component at Capitania (1), Praticagem (2) and Palmas (3)

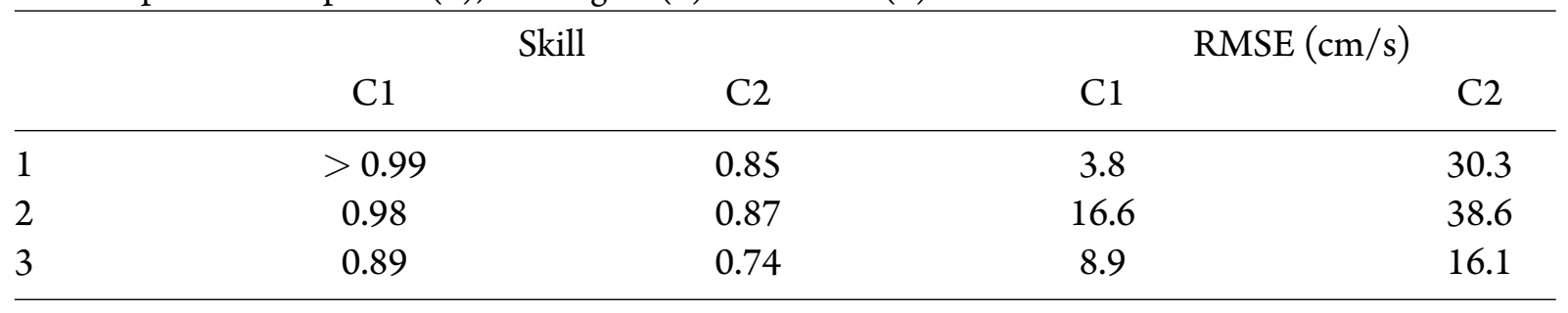

gitudinal salinity gradient (Miranda et al., 2017), the restricted contributions of these forcings greatly impact the velocity simulation. For instance, the relatively large error in the $u$ velocity prediction during the neap tide period of October 9 (Figure 2.10, bottom panels) is probably due to an overestimation of river discharge, which acts as an offset of the $u$ velocity towards positive values (down-estuary).

Tidal ellipses of the four major constituents are shown in Figure 2.11 for the observations and simulation C1. Ellipse semimajor axis intensities and inclination are summarized in Table 2.4. Figure 2.11 shows that tidal ellipses are highly polarized along the navigation channel. The minor axes are significantly smaller than the major axes, revealing that the across-channel velocity is negligible. Tidal currents are dominated by the $\mathrm{M} 2$ component, followed by the $\mathrm{S} 2$, at the three stations. Observed velocities for the $\mathrm{M} 2$ component range from $20.2 \mathrm{~cm} / \mathrm{s}$ at Palmas to $67.8 \mathrm{~cm} / \mathrm{s}$ at Praticagem.

The tidal circulation in the SSVBES was previously modeled by Harari and Camargo (2003). Modeled M2, S2 and $\mathrm{O} 1$ tidal velocities at Capitania are in agreement with the values found by the authors. Our results from observed (modeled) currents show that tidal velocities are 1.7 (1.5) times stronger at Praticagem than at Capitania.

In general, modeled semidiurnal major axes are approximately equal to the observed values at Capitania and slightly underestimated at Praticagem. At Capitania, errors of $0.1 \mathrm{~cm} / \mathrm{s}$ and $1.1 \mathrm{~cm} / \mathrm{s}$ are found for the M2 and S2 constituents, respectively. Modeled semidiurnal currents are underestimated at Praticagem by $13.5 \%$ (M2) and $20.7 \%$ (S2), with differences of no more than $10 \mathrm{~cm} / \mathrm{s}$. In contrast, the phase of tidal propagation is better reproduced at Praticagem than at Capitania, although errors smaller than $4.8^{\circ}$ are found at this station. The inclination of the modeled semidiurnal ellipses agrees with the observations by less than $0.8^{\circ}$ at Praticagem. The same pattern occurs in the diurnal components, with intensity better modeled at Capitania and inclination at Praticagem.

The greatest errors in major axis intensity are found outside of the estuary, with semidiurnal and 

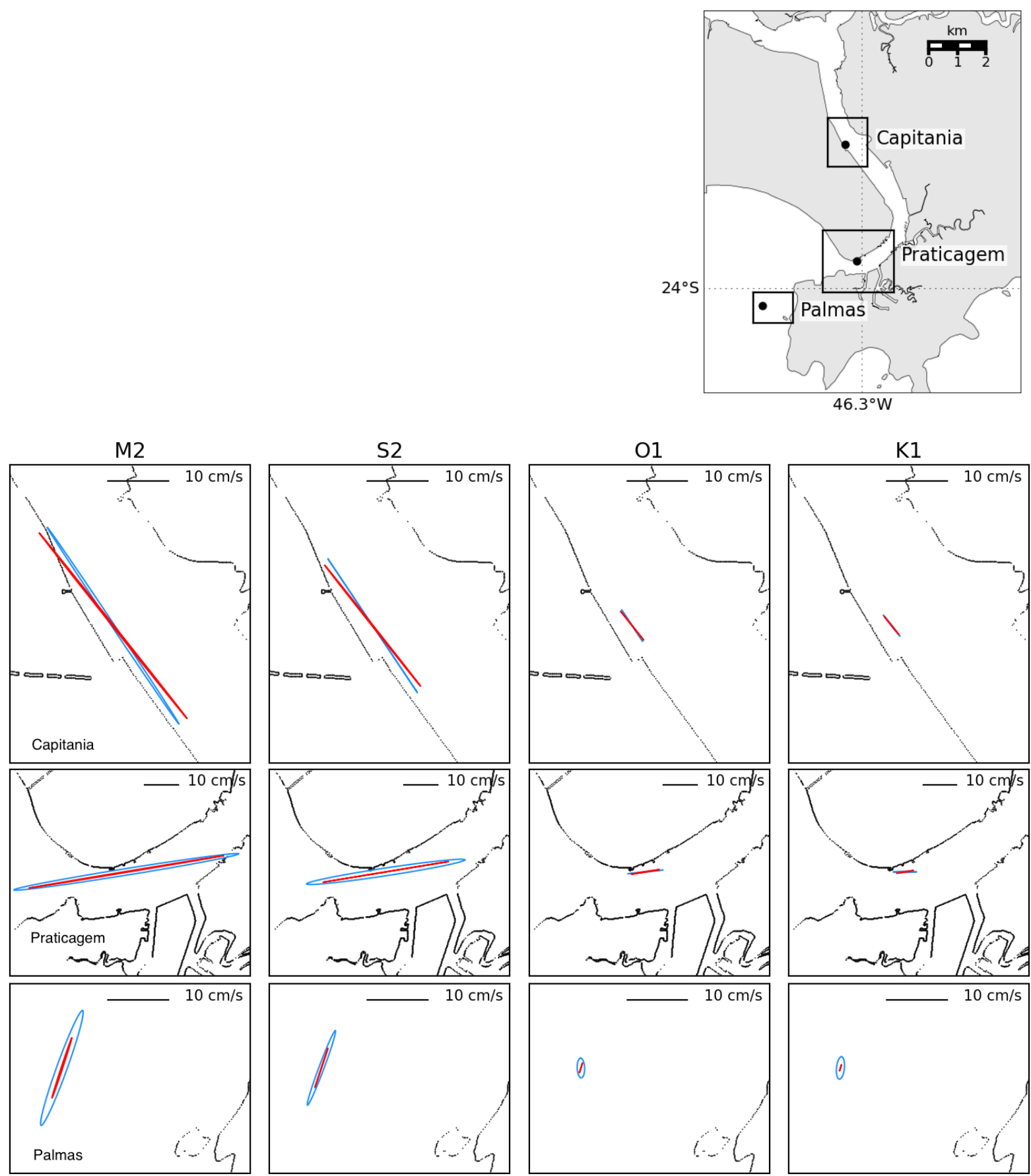

Figure 2.11: Tidal ellipses of the four major tidal components (M2, S2, O1 and K1) for the observed (blue) and modeled (red) surface currents at Capitania (top), Praticagem (middle) and Palmas (bottom). Note that velocity scales are different at each station. The location of each region is indicated in the map at the top right corner. 
Table 2.4: Observed and modeled semimajor axis $(A, \mathrm{~cm} / \mathrm{s})$ and inclination $(\theta$, degrees $)$ of tidal ellipse components shown in Figure 2.11. Stations are numbered from north to south: Capitania (1), Praticagem (2) and Palmas (3)

\begin{tabular}{ccccc|cccc}
\hline & \multicolumn{3}{c}{ Observed } & \multicolumn{2}{c}{ Modeled } & \multicolumn{2}{c}{ Observed } & \multicolumn{2}{c}{ Modeled } \\
& $A$ & $\theta$ & $A$ & $\theta$ & $A$ & $\theta$ & $A$ & $\theta$ \\
\hline 1 & 39.1 & 123.8 & 39.2 & 128.5 & 26.6 & 123.8 & 25.5 & 128.4 \\
2 & 67.8 & 9.1 & 58.6 & 9.5 & 47.7 & 8.6 & 37.8 & 9.3 \\
3 & 20.2 & 70.1 & 10.4 & 71.7 & 13.2 & 69.4 & 6.8 & 71.6 \\
\hline
\end{tabular}

\begin{tabular}{ccccc|cccc}
\hline & \multicolumn{2}{c}{ O1 } & \multicolumn{2}{c}{ Modeled } & \multicolumn{2}{c}{ Observed } & \multicolumn{2}{c}{ Modeled } \\
& $A$ & $\theta$ & $A$ & $\theta$ & $A$ & $\theta$ & $A$ & $\theta$ \\
\hline 1 & 6.2 & 123.7 & 6.0 & 128.6 & 4.4 & 128.4 & 3.7 & 128.7 \\
2 & 10.4 & 6.1 & 8.4 & 9.5 & 6.9 & 0.2 & 4.9 & 9.5 \\
3 & 3.4 & 92.1 & 1.6 & 72.5 & 3.7 & 84.3 & 1.0 & 73.1 \\
\hline
\end{tabular}

diurnal velocities approximately $49 \%$ less intense than the observations at Palmas. However, the major axis inclinations of the semidiurnal constituents coincide with the observations within $2.2^{\circ}$.

Similar comparisons between observations and numerical model results in estuaries have been published in the literature. For instance, Zheng et al. (2003) and Liu et al. (2009) found similar differences between observed and modeled tidal ellipses in the Satilla River and Columbia River estuaries, respectively. Also, the skills obtained by Liu et al. (2009) for tidal sea surface oscillation and $u$ velocity are highly comparable to those in our study.

The model performance obtained in the Porto Channel for tidal currents shows an average skill of 0.99 and an RMSE of $10.2 \mathrm{~cm} / \mathrm{s}$ (between stations 1 and 2). These results are comparable to those for the NYHOPS (Georgas and Blumberg, 2010).

\subsubsection{SOFS validation}

SOFS storm tide prediction was tested in both 2D and 3D modes for all the recent (since 2016) storm tides in Baixada Santista: August 21-22, 2016 (ST1), September 16, 2016 (ST2), October 29, 2016 (ST3), June 20, 2017 (ST4), June 15, 2018 (ST5), August 11-12, 2018 (ST6) and August 27, 2018 (ST7) (Table 2.1). The 3D model performed better than the 2D for three of the seven tested events (ST1, ST2 and ST3) and these results are discussed in subsection 3.3.2. For ST4, ST5, ST6 and ST7, the 3D simulations did not represent significant gains or losses in relation to the $2 \mathrm{D}$ results, as will be shown in this subsection. The greatest differences between $2 \mathrm{D}$ and $3 \mathrm{D}$ results occurred at ST 1 , which is described in more details below. 


\section{The August 21-22, 2016 storm tide}

On August 21-22, 2016, Baixada Santista was exposed to a storm tide that caused serious damage to Santos infrastructure due to coastal flooding. The storm tide signal was captured by the SSVBES observing stations indicated in Figure 2.3. Observed sea levels at Palmas, Praticagem and Capitania are shown by the orange lines in Figure 2.12. An abnormal rise of approximately $1 \mathrm{~m}$ in relation to tidal heights (black lines) occurs on records from August 21 to August 22.

The sea level increase above the astronomic tide was caused by the passage of a cold front bringing strong alongshore winds from the southern quadrant. The extreme event took place during spring tides, and the combined effects promoting sea level rise resulted in the uncommon total water elevation of more than $2 \mathrm{~m}$ relative to MLLW. Observed elevations (orange lines) were filtered with a $40 \mathrm{~h}$ lowpass Lanczos square filter (Walters and Heston, 1982) to remove tidal variability. ${ }^{1}$ The resulting lowfrequency signal is an approximation of the storm surge, shown by the turquoise lines in Figure 2.12. The maximum surge elevation reaching more than $1 \mathrm{~m}$ occurs at approximately $0300 \mathrm{~h}$ on August 22, during the low astronomic tide. This effect is a typical non-linear surge and tide interaction as suggested by Prandle and Wolf (1978) for the Thames estuary. If the storm surge had peaked 6 hours earlier or later (during high tide), the total water level would not necessarily have been as high as a linear superposition of tide and surge heights, as noticed for hurricane Sandy in the New York Harbor region by Georgas et al. (2014).

The SSVBES 3D modeling results for sea surface elevations during the storm tide of August 2016 (ST1) are shown in Figure 2.13 as well as the observed time series at Capitania, Praticagem and Palmas. The solid lines show the storm tide (or total water level) and the dashed lines represent the storm surge component. Statistics assessment between the modeled and observed sea surface elevations for the storm tide period are summarized in Table 2.5. Skill scores, RMSEs and water peak errors were calculated for the 3D and 2D simulations.

The best model performance was achieved with the 3D simulation at the three stations, with skills of $0.96-0.98$ for the storm tide and skills of $0.91-0.96$ for the storm surge components. The RMSEs of both components range from $9.4 \mathrm{~cm}$ to $17.5 \mathrm{~cm}$. Both skill and RMSE show that model performance increase in the up-estuary direction. For the first water level peak, the modeled results (red solid lines in Figure 2.13) were $3.7-8.0 \mathrm{~cm}$ above (peak error column in Table 2.5) the observations (blue solid lines). For the second storm tide peak, the modeled water levels were lower than the observations by 2.6-6.2 cm. For the storm surge component in Figure 2.13 (dashed lines), the model underestimated the surge peak by only $1.7-3.7 \mathrm{~cm}$. The arrival times of the total water level peaks were well captured, with no temporal lag in relation to the observations at Praticagem, $0-1 \mathrm{~h}$ later at Capitania and $3 \mathrm{~h}$ in advance at Palmas (solid lines in Figure 2.13). The bigger errors in the arrival times of the storm surge peaks are due to the lower predictability condition of the wind-induced sea level component in relation

\footnotetext{
${ }^{1}$ Another way to obtain the storm surge signal is to subtract the predicted tide. However, the obtained time series would still be contaminated by the tidal signal, partially due to the remaining tidal components not considered in the tidal prediction performed with the 7 major constituents in the SSVBES (subsection 2.2.4).
} 


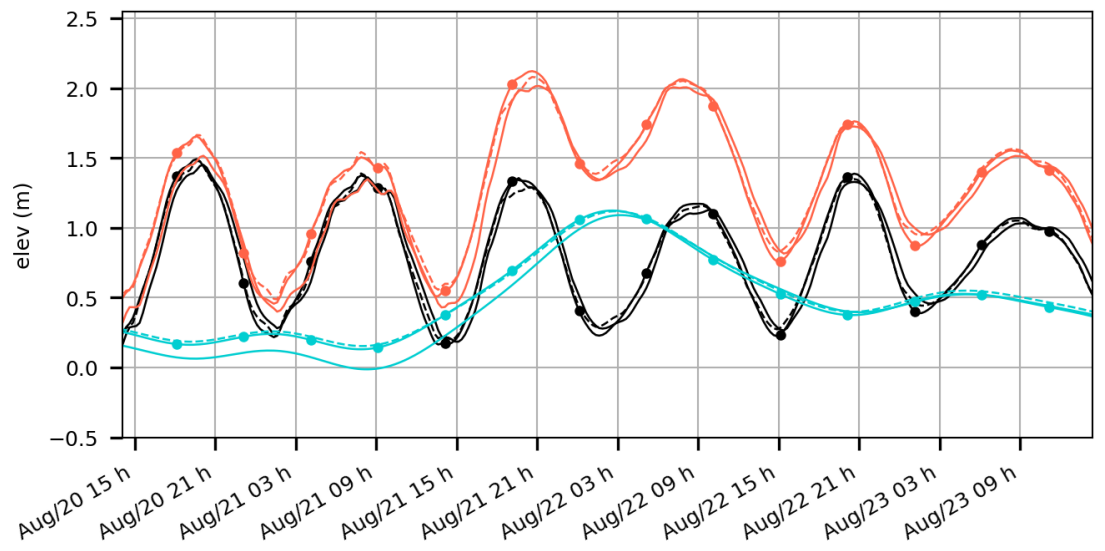

Figure 2.12: Observed storm tide (orange) at Capitania (dotted), Praticagem (dashed) and Palmas (solid). Black and turquoise lines show the tidal and storm surge signals, respectively, with the same line pattern for each station
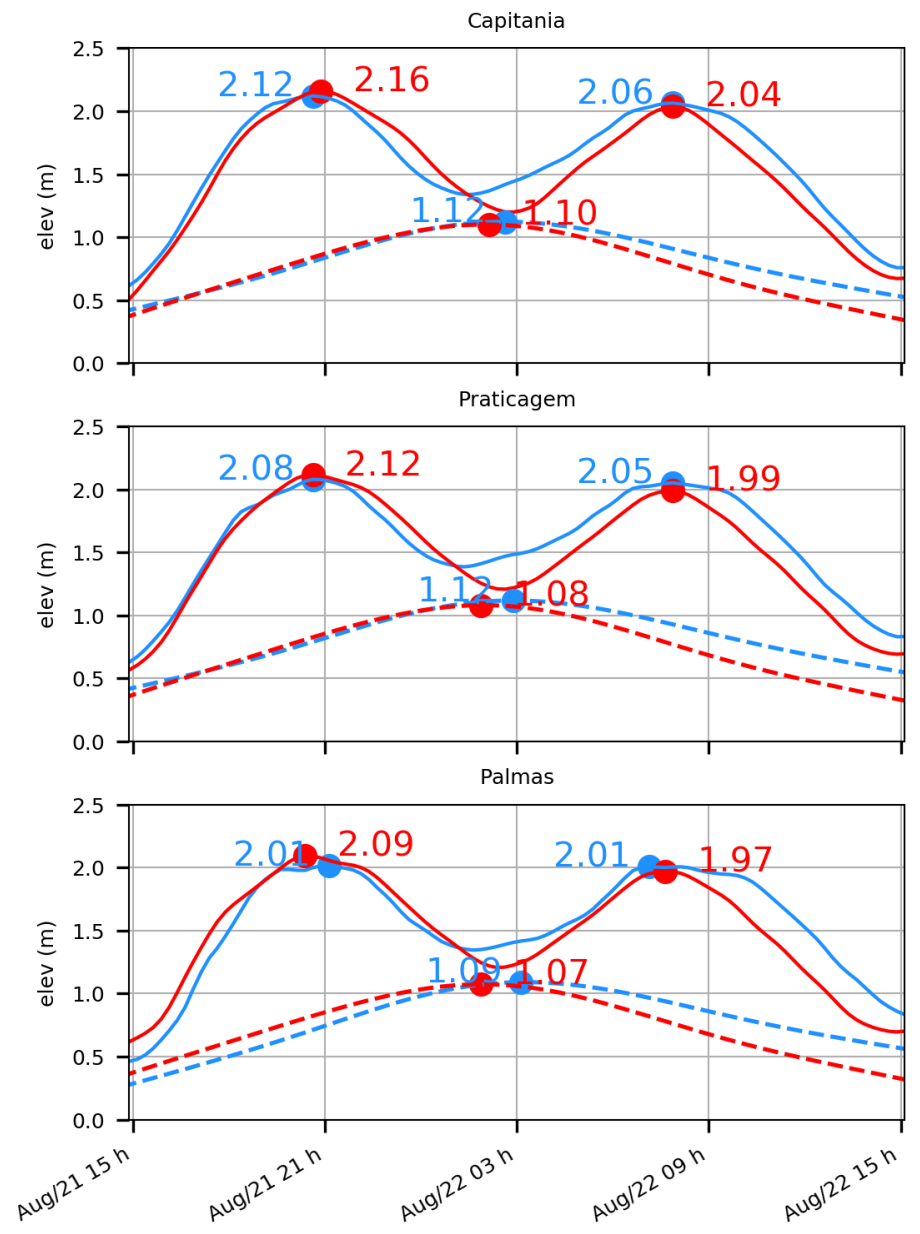

Figure 2.13: Storm tide event on August 21-22, 2016. Solid lines show the total water elevation time series of observed data (blue) and the modeled results (red) at the three stations. Dashed lines show the storm surge component. The peaks of water level heights are indicated in each graphic 


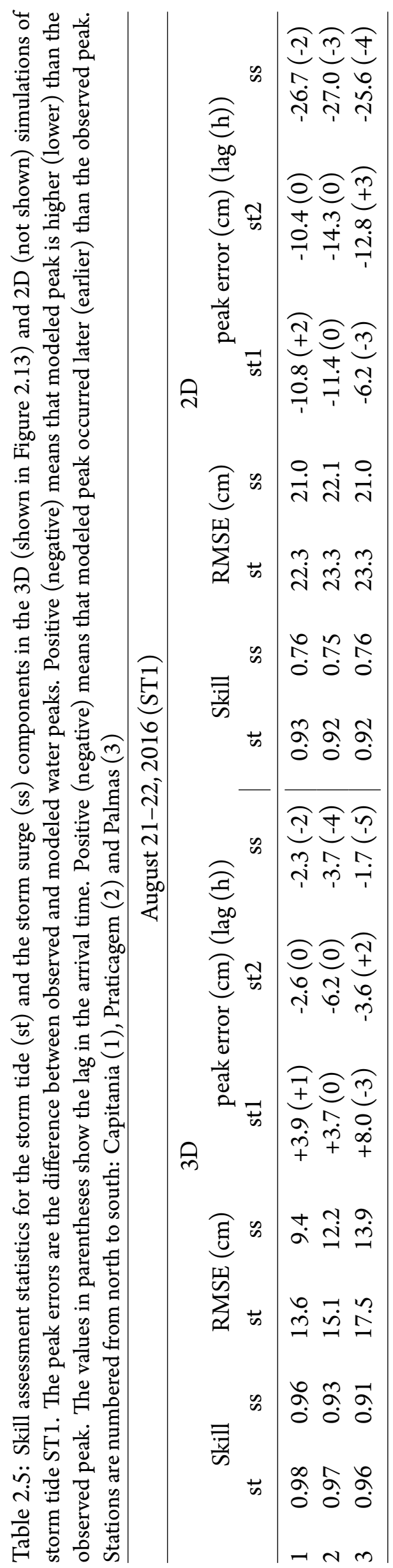


to the astronomic tides, present in the storm tide signal (as shown in subsection 2.3.2).

The greatest differences between $3 \mathrm{D}$ and $2 \mathrm{D}$ results are seen in the storm surge peaks (Table 2.5). The $2 \mathrm{D}$ storm surge peak error (column ss) is 7.3-15.1 times bigger than the $3 \mathrm{D}$ among the three stations. The skill parameter shows that the $3 \mathrm{D}$ mode exceeds the $2 \mathrm{D}$ by $0.04-0.05$ (storm tide) and $0.15-$ 0.20 (storm surge) skill scores. The RMSEs of storm tide and storm surge components are 1.3-2.2 times bigger at the $2 \mathrm{D}$ in relation to the $3 \mathrm{D}$ results. Also, the errors in the storm tide peaks are 2.3-4.0 times bigger at the $2 \mathrm{D}$ simulation, except for the first water level peak at Palmas, that was 1.3 times smaller than the 3D. The arrival time of the peaks are usually the same or 1-2 $\mathrm{h}$ later at the $2 \mathrm{D}$ simulation. Reasons for differences between the barotropic and baroclinic modes will be discussed in subsection 2.3.3.

Our model is presently limited in representing river runoff and TS variability. These forcings are certainly variable during storm tide events, due to the increase in precipitation with cold front passage and the increase in the vertical mixing of SBB waters by strong winds. These effects are not incorporated in the model currently. Nevertheless, the storm surge RMSEs obtained in the SSVBES, especially at Capitania and Praticagem, are within the range found by Georgas et al. (2016b) $(10.8-17.3 \mathrm{~cm})$ and by Orton et al. (2012) $(20 \mathrm{~cm}$ ) for simulated storm surges in the New York Harbor region. Also, the skills found at these stations are highly comparable to what was found by the same authors.

\section{Recent storm tides simulations}

SOFS performance in predicting the seven storm tides using both $3 \mathrm{D}$ and $2 \mathrm{D}$ modes is summarized in Figure 2.14. For the storm tide performances ( $\times$ markers), the greatest differences between $3 \mathrm{D}$ and 2D models were found for ST1, ST2 and ST3. In these events, the 3D model outperformed the 2D by 0.01-0.04 average skill scores and $2.5-7.5 \mathrm{~cm}$ average RMSEs. For the other storms (ST4-ST7), there is no significant difference between $3 \mathrm{D}$ and $2 \mathrm{D}$ results as seen by the similar values of skills and RMSEs. Average skills and RMSEs differ by 0.007 and $1.4 \mathrm{~cm}$ at maximum (ST7), respectively. For the storm surge performance, however, the 3D formulation produced higher skills and lower RMSEs than the $2 \mathrm{D}$ mode for the five most intense events (ST1, ST2, ST3, ST6 and ST7). Differences ranged from 0.03 (ST3) to 0.17 (ST1) skill scores and from $1.8 \mathrm{~cm}$ (ST6) to $9.5 \mathrm{~cm}$ (ST1) RMSEs.

For the two weakest events, the 3D model performance for storm surge was worse than the $2 \mathrm{D}$ (for ST4) or comparable to the 2D (for ST5). The strength of these storms was identified in the observed storm surge peaks, that were lower than $0.67 \mathrm{~m}$ for ST 4 and ST5 and between $0.74 \mathrm{~m}$ and $1.12 \mathrm{~m}$ for the other storms. For this reason, the tidal component, which is the barotropic part equal in the two modes, was responsible for making the total water elevation response (the storm tide) comparable between the $3 \mathrm{D}$ and $2 \mathrm{D}$ formulations as seen by the similar skills and RMSEs of the storm tide signals in Figure 2.14.

Although Kodaira et al. (2016) verified the importance of density stratification through the propagation of coastal trapped waves to produce more accurate results than 2D models, Dottori and Castro (2009) showed that the response of the SBB to the frontal winds is essentially barotropic. No difference between 2D and 3D models would be expected. Within the estuary, however, freshwater inputs 
and density stratification play a crucial role in the storm levels, as demonstrated by Orton et al. (2012).

Figure 2.15 shows the time series of each analyzed event in the observed data and modeled results (3D and 2D) for the storm tide and the storm surge components. The storm surge heights were consistently under predicted, specially during the five most intense events, causing the bigger RMSEs (36.2\%, in average) in Figure 2.14. The 2D model underestimation of storm surge peaks were, in average, 3.7 times larger than the 3D. The better 3D model skill on the prediction of storm surges are due to the inclusion of density stratification and river runoff. This is consistent with the results found by Orton et al. (2012).

The importance of stratification in the estuary is demonstrated in Figure 2.16. The top panels illustrate the modeled vertical profiles of TS and along-channel velocity during the storm tide ST 1 at Capitania (a) and Praticagem (b). The bottom panels show the sea surface elevations (black thick lines), the storm surges (dashed lines) and the temporal variations of density difference between bottom and surface waters (black thin lines). The stratification (thin) varies with the tidal oscillation (thick), increasing during ebb and peaking at low water. Even though this modulation was slightly less pronounced during the storm (colored background period in bottom panels) relative to normal conditions (gray background) due to increased mixing by the storm surge, the absolute differences between surface and bottom salinities (temperatures) were greater than $4\left(1^{\circ} \mathrm{C}\right)$ at Capitania. At Praticagem, the same conclusions can be drawn although the profiles are less stratified because of the more intense mixing at the estuary mouth. At the beginning of the storm, during flood (negative along-channel velocities), waters are less stratified (blue profiles of TS in (a) and (b)) than at the end of the storm (red profiles). The contribution of river inputs is seen in the surface salinities (lower than 29) during the ebb cycle.

The 3D model underestimated the storm surge peaks in ST1 by O $(1-10) \mathrm{cm}$, as seen in Figure 2.15 and in the negative peak errors of Table 2.5 (column ss). One possible reason is the accuracy of the atmospheric forecasts. Another reason is the climatological condition of the 3D TS field used in the SBB grid within SOFS. Although 3D peak errors are smaller than the 2D, the 3D TS field is not an instantaneous representation of the water mass field at the exact moment of the storm tide. However, the differences between observed and modeled water level peaks found here are similar to what was found by Kodaira et al. (2016).

The storm tide ST3 had the worst performance among the seven simulated events, as seen by the lower skills and higher RMSEs in Figure 2.14. Further simulations forced with meteorological fields from the ERA5 reanalysis, the fifth generation of reanalyses from the European Centre for MediumRange Weather Forecasts (not shown) provided improved results, with average skill of 0.88 and average RMSE of $28.3 \mathrm{~cm}$ for the storm tide component. Although better than what produced by BRAMS forecasts, the performance was still lower than the other events, revealing that the atmospheric accuracy alone does not explain the worse performance of the ST3 simulation. Other reasons would be errors in the river discharge during the event and also a not well resolved TS climatology. The ST3 was the only analyzed storm in spring season. It could be that the climatological water mass field did not represent the actual conditions of this particular event properly. 

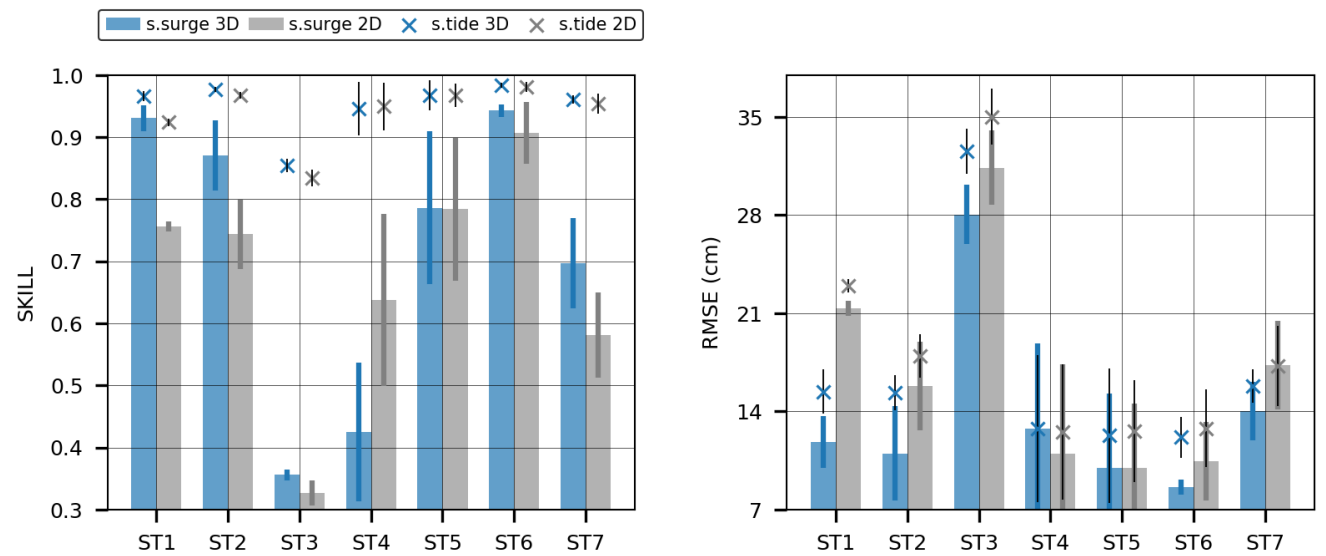

Figure 2.14: Skills and RMSEs of 3D (blue) and 2D (gray) models in simulating the storm tides ST1-ST7 (Table 2.1). The values represent the average between the three observed stations (Capitania, Praticagem and Palmas). The standard deviations are shown by the error bars.
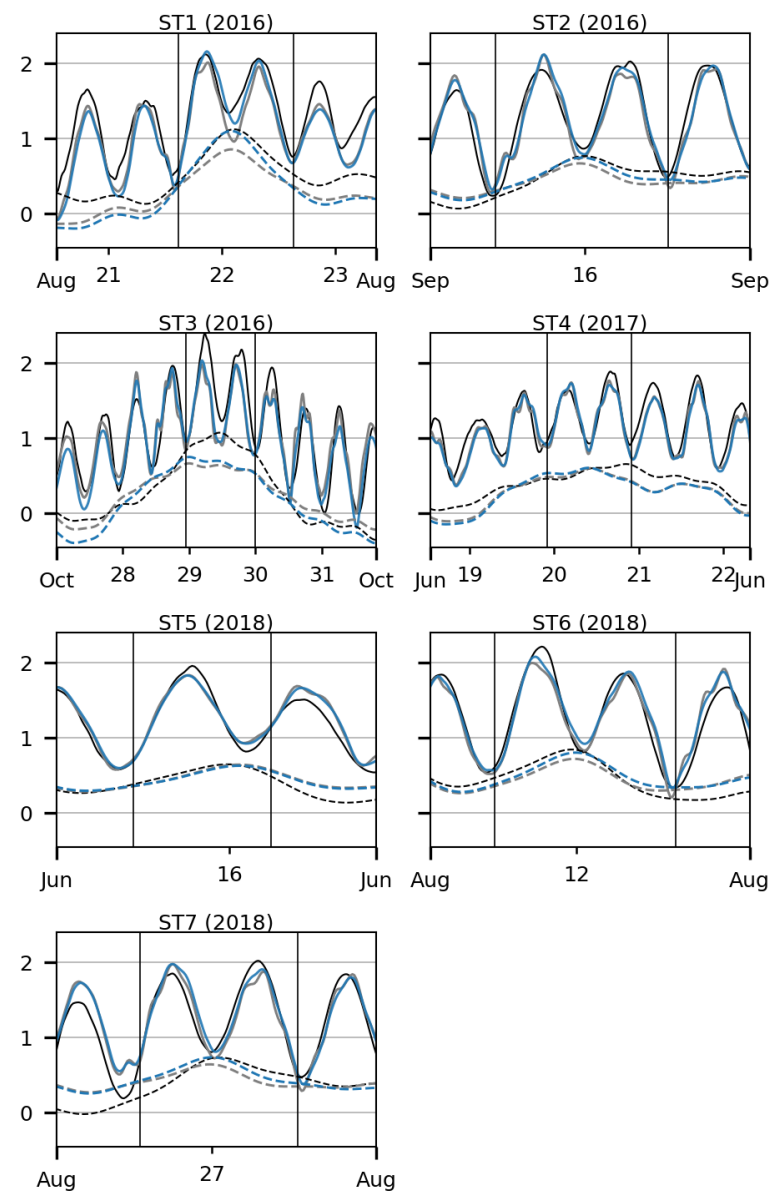

Figure 2.15: Storm tides (solid lines) and storm surges (dashed lines) at Capitania station for the seven analyzed events. The observed data is plotted in black and the 3D (2D) model is plotted in blue (gray). The vertical black lines limit the time period for which the statistics in Figure 2.14 were calculated. 


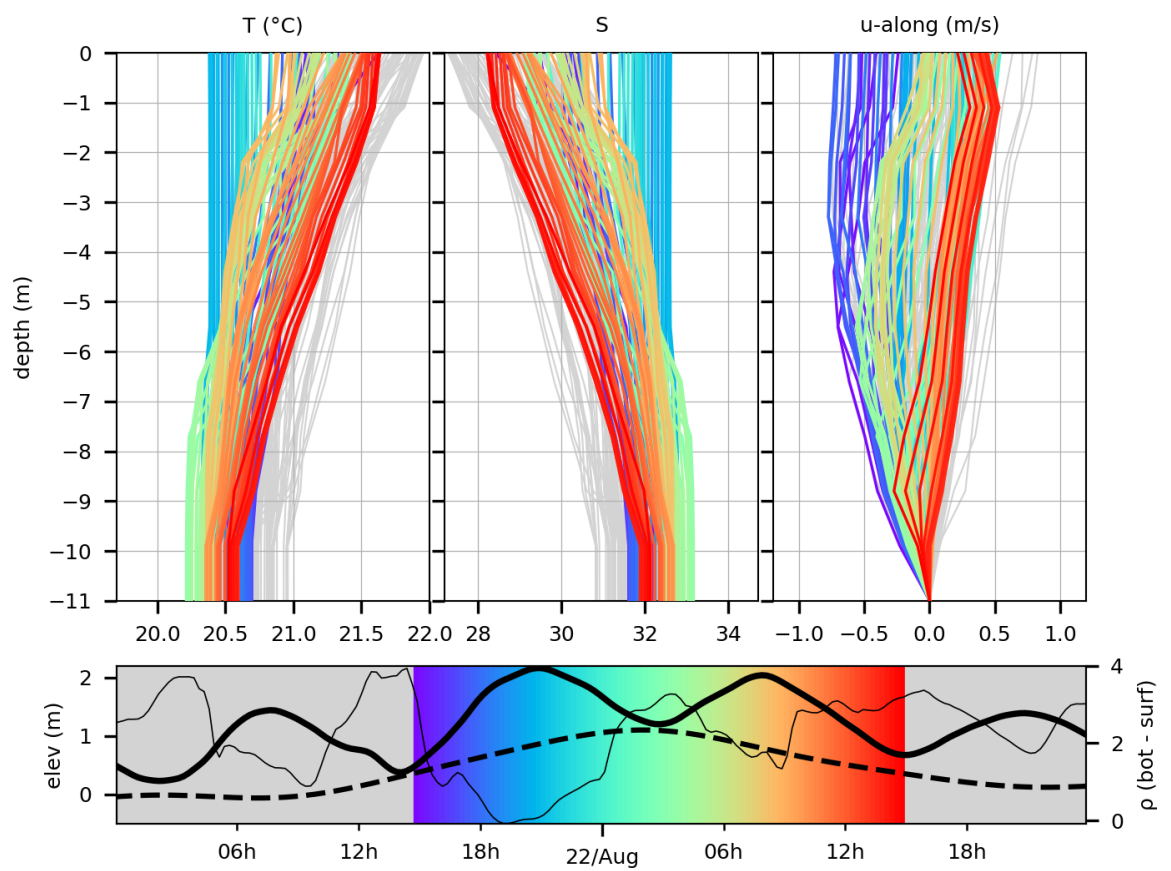

(a) Capitania

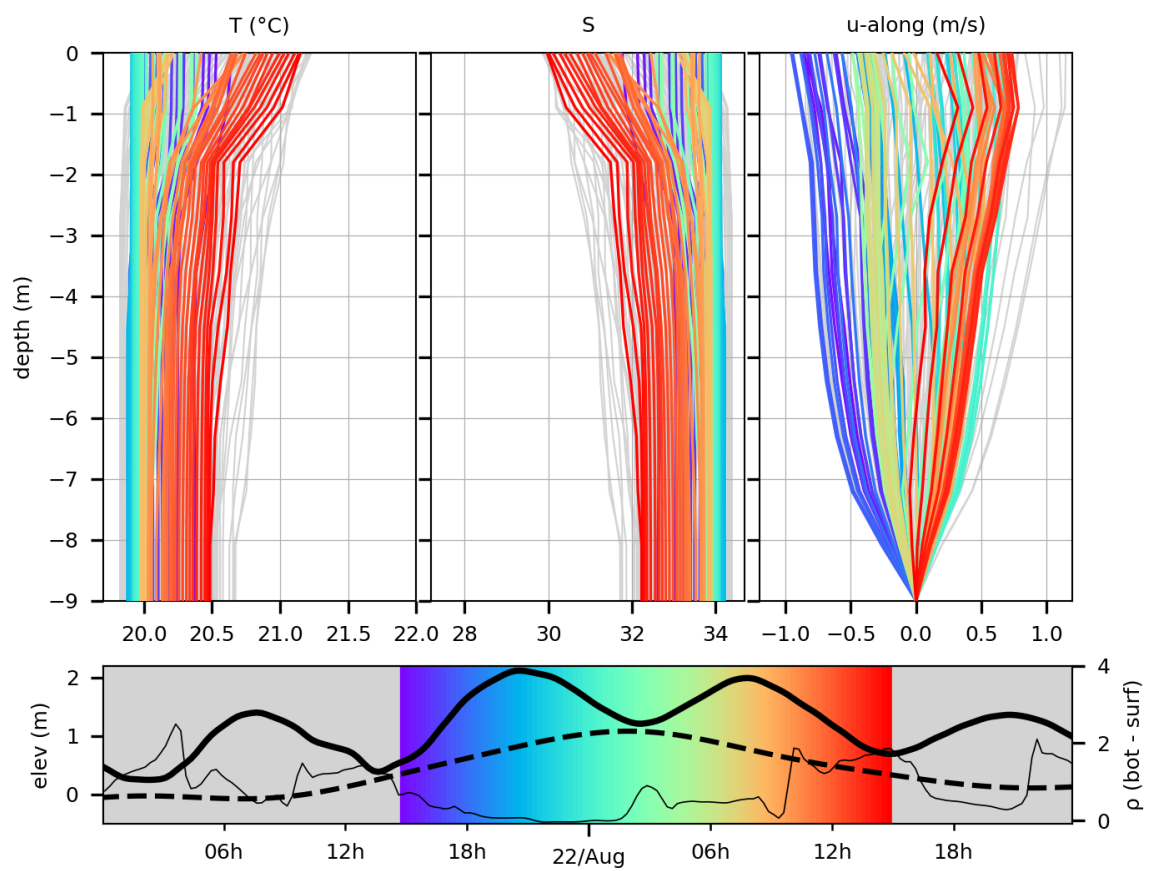

(b) Praticagem

Figure 2.16: Modeled vertical profiles of temperature $(\mathrm{T})$, salinity $(\mathrm{S})$ and along-channel velocity (u-along) at Capitania (a) and Praticagem (b) stations during the storm tide ST1 (top panels). The bottom panels in (a) and (b) show the total water elevations (black thick lines), the storm surges (black dashed lines) and the difference between bottom and surface water density $(\rho)$ (black thin line). The background color in the bottom panels marks the time of each correspondent profile in the top panels. Positive (negative) values of $u$-along indicate waters flowing down-estuary (up-estuary). 


\subsection{Conclusions}

This work describes the initial design and present state of the SOFS (coupled SBB-SSVBES system). The SOFS has an overall objective to fulfill the needs of the local navigation and emergency management communities by providing forecasts of sea surface elevations, 3D currents, water temperatures and salinity in the Santos-São Vicente-Bertioga Estuarine System. To date, the system is capable of providing up to 72 -h forecasts of sea surface elevations and 3D currents forced by tides, winds, 3D water mass fields and river runoff. The main advantage of this system is the predictability of both barotropic and baroclinic currents, crucial for safe navigation.

The simulations for the 2016 spring season showed that tidal variability can be reproduced in the nearshore SSVBES model with skill scores as high as 0.97 for sea surface elevation and above 0.99 for the along-estuary component of surface currents. For the total variability, skill scores at the observation stations were lower ( 0.93 and 0.87 , respectively), reflecting the need for improvement in the river runoff and in the longitudinal salinity gradient forcing. The next step in the development of the SOFS should be to improve the hydrologic information to provide better forcing and forecasts of temperature and salinity in the SSVBES. Further progress in the model performance would include the use of an ensemble of weather forecasting models. This change would theoretically converge to a more realistic prediction and decrease the error in the subtidal hydrodynamic simulations (Georgas et al., 2016a).

The ability of the SOFS 3D model in predicting storm tides outperformed the 2D simulations in three of the seven tested events. The improvement in performance with the 3D model were quantified by: (i) average increases in the skill scores of 0.02 (2.7\%) for storm tides and (ii) average decreases in the RMSEs of $4.2 \mathrm{~cm}$ (18.1\%) for storm tides. For the storm surge component, the 3D model yielded improved performance during the five most intense storms, with average gains of 0.10 skill scores $(14.6 \%)$ and of $4.6 \mathrm{~cm}$ in RMSEs (24.5\%). The 3D model produced water level peaks closer to the observations by $\mathrm{O}(10) \mathrm{cm}$, revealing the importance of the freshwater inputs and the density stratification to storm level forecasts.

The 3D SOFS modeling system was able to capture the signal of seven recent storm tides in Baixada Santista. The strong agreement with observed data, with skills of $0.95 \pm 0.05$ and RMSEs $17.0 \pm 6.8 \mathrm{~cm}$, shows the potential of the designed system to predict storm tides and to support emergency services. As quantified here, based on comparisons of the SOFS predictions to observations, the system has a predictive skill that is comparable to that provided by NYHOPS in New York Harbor and is thus able to support marine navigation through the Santos Port approaches. 


\section{Chapter 3}

\section{Estuarine Physics of the Santos-São Vicente-Bertioga Estuarine System}

\subsection{Introduction}

Estuaries are transitional environments formed where the river encounters the sea. They are influenced by continental and marine physical process, which coexistence in place and time generates singular water circulation patterns and mixing of water properties within the estuary. Several definitions with different perspectives have been proposed in the literature. The classical definitions describe an estuary as a semi-enclosed coastal body of water where the ocean salinity is measurably diluted by river runoff (e.g. Cameron and Pritchard (1963), Dyer (1997)). In this study, we consider the definition from Perillo (1995) as the one that best characterize the Santos-São Vicente Bertioga Estuarine System (SSVBES):

"An estuary is a semi-enclosed coastal body of water that extends to the effective limit of tidal influence, within which sea water entering from one or more free connections with the open sea, or any other saline coastal body of water, is significantly diluted with fresh water derived from land drainage, and can sustain euryhaline biological species from either part or the whole of their life cycle."

This definition is suitable for the SSVBES because it admits that the estuary does not necessarily connect with the open sea. Both Port Channel and São Vicente Channel connect to the Santos Bay, which in turns communicate with the inner shelf.

The definitions of estuaries comprises a large variety of environments. From the geomorphological perspective, the SSVBES is a coastal plain estuary. From the dynamic aspect, estuaries are classified according to the water circulation pattern and the vertical salinity structures.

The advective physical processes that dominate in coastal plain estuaries can be organized as in the diagram of Figure 3.1. This diagram illustrates which dominant process in the sea (blue) and in the river (green) environments act to promote the water dynamics within the estuary (pink). According to 


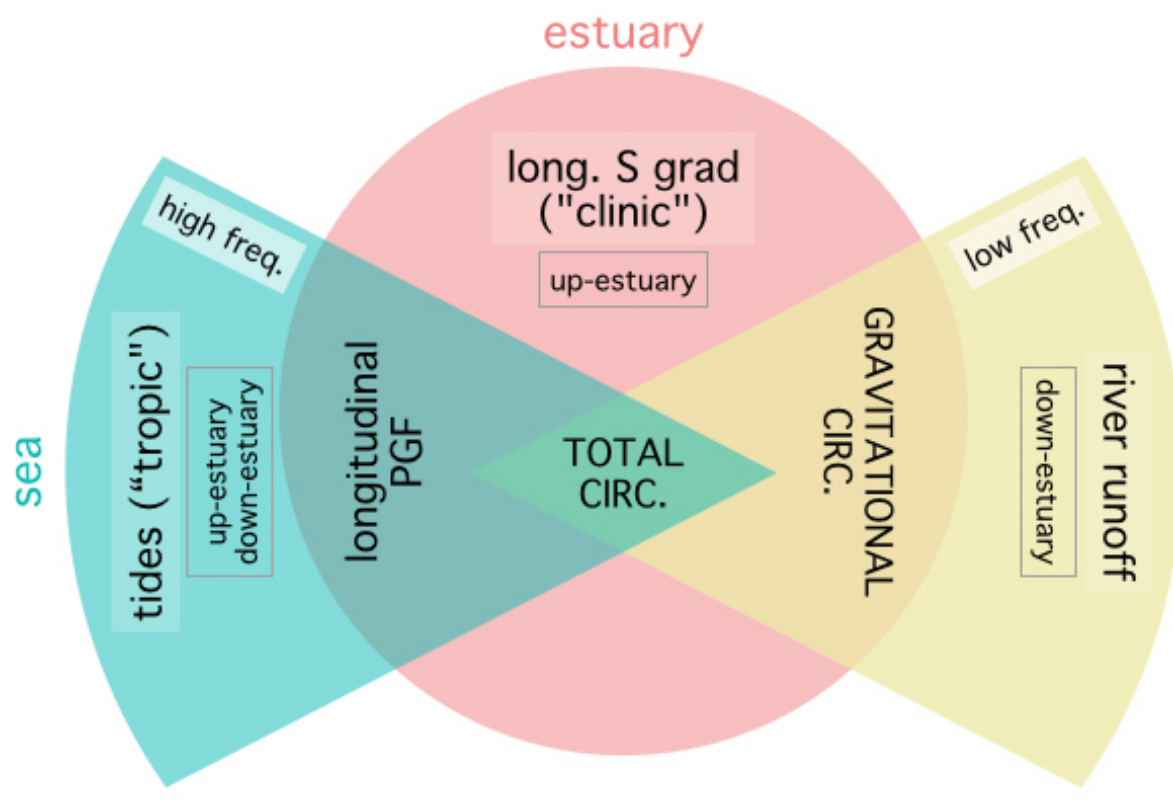

Figure 3.1: Diagram of the physical processes controling the circulation within coastal plain estuaries. "Tropic" is barotropic component, "clinic" is baroclinic component, "circ" is circulation, "long" is longitudinal, "grad" is gradient, "S" is salinity, "PGF" is pressure gradient force and "freq" is frequency.

Miranda et al. (2017), the estuarine circulation depends on water level variations, river discharges, baroclinic pressure gradients related to freshwater inputs, offshore marine circulation and wind. Although the diagram ignores the atmospheric forcings as winds and atmospheric pressure and the continental shelf influence (wind dominated), it takes into account the most important and dominant forcings to the estuarine circulation according to Miranda et al. (2017): tidal oscillations, river discharges and longitudinal salinity gradients. All these mechanisms together force the total circulation observed within the estuary.

The longitudinal (along the estuarine channel) salinity gradient (S gradient) generates the upestuay circulation, while river discharge causes down-estuarine fluxes, that are usually low-frequency movements. Tidal oscillations are essentially barotropic and cause high-frequency bidireccional fluxes deterministically. If the river runoff flow (green) is neglected, but the related $S$ gradient is considered, the resulting forcing is the longitudinal pressure gradient force (PGF) composed by the barotropic (tide, blue) and baroclinic (S gradient, pink) components. If the barotropic tidal movement is filtered, i.e. during complete tidal cycles, the resultant flow is the classical estuarine circulation, which is bidimensional, divided in two layers, with salt water flowing up-estuary in the lower layer and fresh water flowing downestuary in the upper layer. This circulation creates the salt wedges, which are observed in salinity vertical profiles with lower salinity near the surface and higher salinity waters near the bottom.

Previous works in the SSVBES studied the tidal dynamics using numerical models and showed the importance of semidiurnal and diurnal components to the estuary circulation (Harari and Camargo, 1998; Harari et al., 2000; Harari and Camargo, 2003). Salt intrusion was estimated by Alfredini et al. (2008) for present and future conditions through experiments carried out in a realistic physical model 
of the estuarine system. Roversi et al. (2016) calculated water renewal time scales in different regions of the SSVBES and found that after 30 days the system is completely renewed.

Miranda and Castro (1998) and Miranda et al. (2012) classified the estuarine channels according to Hansen and Rattray (1966) stratification-circulation diagram using observed salinity and velocity profiles at fixed stations. Miranda and Castro (1998) found that Bertioga Channel is a partially mixed estuary being highly stratified (type $2 \mathrm{~b}$ ) during neap tides and moderately stratified (type $2 \mathrm{a}$ ) under spring tide conditions. Changes in estuary classification are closely followed by changes in the up-estuary advective salt transport, which is reduced by $40 \%$ from neap to spring tides. Miranda et al. (2012) found that the estuary is a type $2 \mathrm{a}$ (partially mixed and weakly stratified) during both neap and spring tide cycles.

Classification can differ at distinct regions in the same estuarine system once forcing factors that dominate coastal plain estuaries dynamics and which directly impact both stratification and circulation classification parameters, river runoff and tidal influence, may be unequal at particular locations. Indeed, Bertioga station is 1-2 km distant from the estuary mouth while Piaçaguera is located further north, dozens kilometers far from the closest estuarine mouth. Nevertheless, Porto Channel, the deepest estuary entrance where ships pass through and reach sea port terminals, has not been classified yet.

The general goal of this chapter is to describe the dynamics of the SSVBES focused in the Porto Channel using observed and modeled data. More specifically, the objectives of this work are to:

1. characterize the estuarine physics of the Porto Channel through (i) the calculation of estuarine quantities, as the tidal regime, the form number, the tidal prism, the flux ratio, the tidal excursion and the estuarine Richardson number (Rie), and (ii) the tidal propagation along the Porto Channel;

2. classify Porto Channel according to Hansen and Rattray (1966) stratification-circulation diagram.

\subsection{Data and methods}

For this analysis, both observed and modeled data were used. Table 3.1 describes which data were used for the proposed calculations. The modeled results came from the numerical experiment $\mathrm{C} 2$ for the 2016 spring season (Chapter 2). The observed data comprises two different datasets. The first comprehend the Santos Pilots data collected at 4 stations (marked in Figure 3.2). These measurements include sea surface elevation and surface currents, also used in the study of Chapter 2 . The second observed dataset comprises vertical profiles of velocity, temperature and salinity collected by the ECOSAN project and will be detailed in section 3.2.2. In section 3.2.1, the definitions of the estuarine quantities in Table 3.1 are presented. 


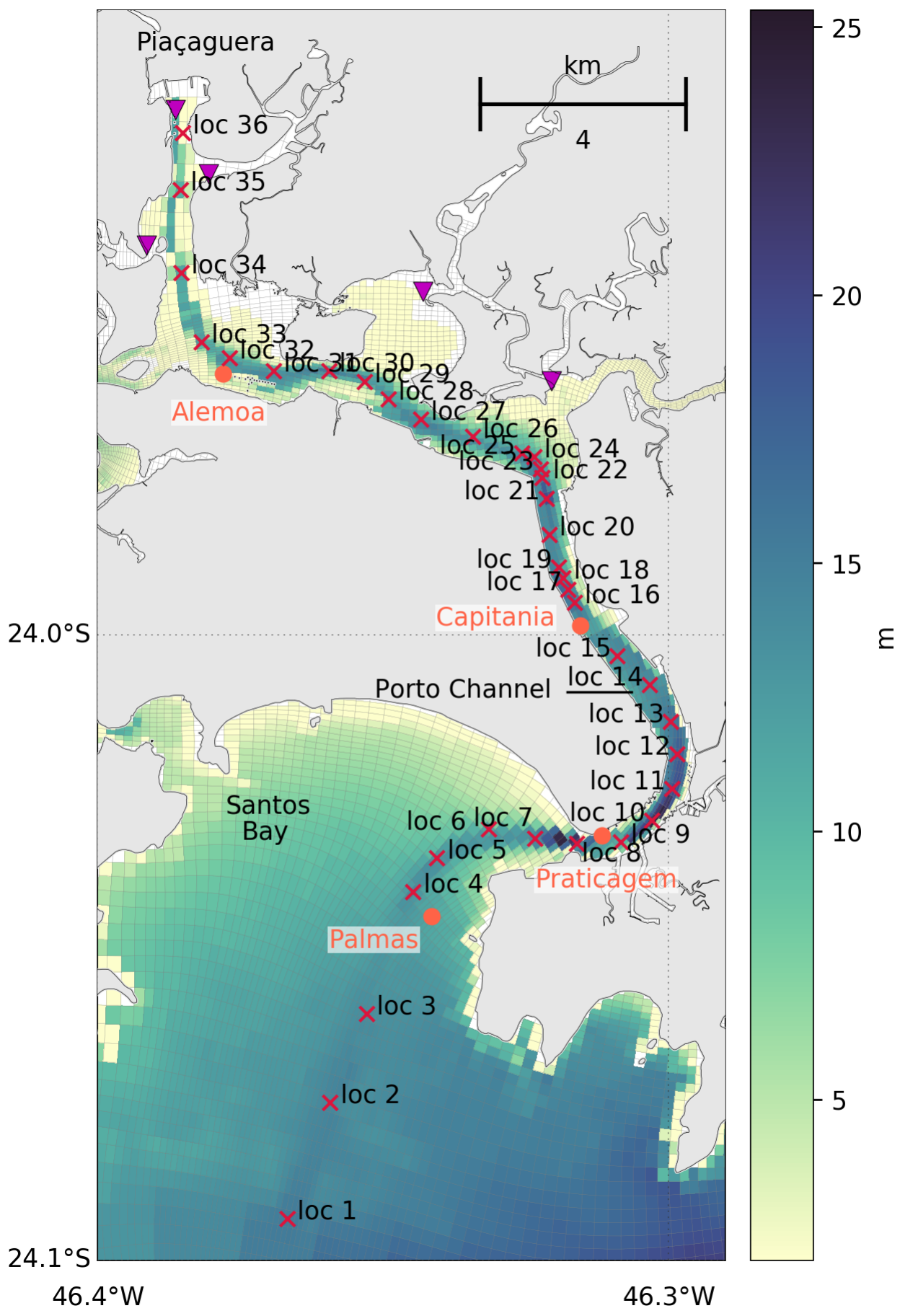

Figure 3.2: Locations of the 36 points analyzed along the navigation channel, numbered from south to north. The colors represent the SSVBES grid bathymetry. The positions of observation stations are shown in orange circles. The river discharge points are marked by the magenta triangles. 
Table 3.1: Estuarine quantities addressed in the study and the type of data used in each calculation. $R i_{e}$ is the estuarine Richardson number.

\begin{tabular}{llccc}
\hline & & observed (Santos Pilots) & observed (ECOSAN) & modeled (C2) \\
\hline 1 & tidal regime & $\times$ & & \\
2 & form number & $\times$ & & \\
3 & tidal prism & $\times$ & \\
4 & flux ratio & $\times$ & \\
5 & tidal excursion & $\times$ & \\
6 & $R i_{e}$ & $\times$ & \\
7 & tidal propagation & & $\times$ & \\
8 & estuary classification & & $\times$ \\
\hline
\end{tabular}

\subsubsection{Estuarine physics definitions}

For the first five quantities listed in Table 3.1, the Santos Pilots observed data at Praticagem were used (Figure 3.2). This station was chosen due to the proximity to the ECOSAN measurements. The period considered for the calculations ranged from July 2016 to February 2017, a 7-month term where gaps in both elevation and current data were minimal and that encompasses the 2016 spring season as well.

To address the tidal regime, the form number and the tidal prism, a harmonic analysis was performed over the 7-month sea surface elevation data using the MATLAB toolbox "t_tide" (Pawlowicz et al., 2002). The maximum tidal height, that describes the local tidal regime, was estimated through the reconstruction of the tidal signal for the same 7-month period using the obtained amplitude and phase of the first 7 most significant constituents (M2, S2, O1, K2, K1, N2 and Q1). The form number $(F)$ was defined as in Defant (1960):

$$
F=\frac{K 1+O 1}{M 2+S 2}
$$

The tidal prism $(P)$ was calculate according to the following equation (Miranda et al., 2017):

$$
P=H_{0} \cdot A_{s}
$$

where $H_{0}$ is the tidal height and $A_{s}$ is the estuary surface area. $H_{0}$ was estimated from the same 7month harmonic analysis for both spring $\left(H_{0}=1.15 \mathrm{~m}\right)$ and neap $\left(H_{0}=0.30 \mathrm{~m}\right)$ tide cycles. $A_{s}$ was calculated as the surface area of the navigation channel from Porto Channel entrance (Praticagem) to the upper reaches at Piaçaguera, equal to $164.16 \times 10^{5} \mathrm{~m}^{2}$. For the $A_{s}$ calculation, the numerical grid cell sizes from the SSVBES grid, at the interest area were used to obtain the channel dimensions.

The flux ratio was determined through the comparison of the river discharge volume per unit of time $(R)$ with the tidal prism $(P)$ as $R / P$ (Miranda et al., 2017). $P$ came from equation (3.2). A total of 5 river discharge points (shown in Figure 3.2) were considered in the calculation of $R$, which total discharge contribution $\left(Q_{f}\right)$ was assumed to be equal to $11.2 \mathrm{~m}^{3} / \mathrm{s}$. Defining $R=Q_{f} \cdot T$, resulted in 
$R=5.0 \times 10^{5} \mathrm{~m}^{3}$, where $T$ is the period of the most energetic tidal constituent (M2, equal to $12.4 \mathrm{~h}$ ).

The tidal excursion $\left(E_{M}\right)$ was calculated with the following equation (Miranda et al., 2017):

$$
E_{M}=\frac{U_{0} \cdot T}{\pi}
$$

where $U_{0}$ is the tidal current amplitude, estimated from the 7-month period harmonic analysis of surface currents collected at Praticagem. For spring and neap tides, $U_{0}=1.25 \mathrm{~m} / \mathrm{s}$ and $U_{0}=0.35 \mathrm{~m} / \mathrm{s}$, respectively. $T$ is the $\mathrm{M} 2$ tidal period, equal to $12.4 \mathrm{~h}$.

The estuarine Richardson number $\left(R i_{e}\right)$ (Fischer, 1972) is defined as:

$$
R i_{e}=\frac{g \frac{\Delta \rho_{H}}{\bar{\rho}} Q_{f}}{B u_{r m q}^{3}},
$$

where $g$ is the gravitational acceleration, $\Delta \rho_{H}$ is the horizontal gradient of density along the estuary, $\bar{\rho}$ is the average density of the estuarine water, $Q_{f}$ is the river discharge $\left(Q_{f}=11.2 \mathrm{~m}^{3} / \mathrm{s}\right), B$ is the channel width and $u_{r m q}$ is the root mean square velocity. $\Delta \rho_{H}$ was estimated as $\rho_{\text {sea }}-\rho_{\text {river }}$ using the imposed temperature and salinity at the river outflow positions in the numerical simulation (C2) for the $\rho_{\text {river }}$ calculation and the temperature and salinity imposed at the SSVBES boundaries offshore Santos Bay for the $\rho_{\text {sea }}$. In this way, $\Delta \rho_{H}=1024.84-996.23=28.61 \mathrm{~kg} / \mathrm{m}^{3}$. The average density $(\bar{\rho}=1023.47$ $\mathrm{kg} / \mathrm{m}^{3}$ ) was calculated in the $\mathrm{C} 2$ simulation as the depth-mean density at Praticagem. The width $B=$ $485.1 \mathrm{~m}$ was calculated with the numerical grid size from the SSVBES grid in a section perpendicular to the channel direction at Praticagem. For the root mean square velocity, the expression for standing waves was considered (Miranda et al., 2017):

$$
u_{r m q}^{3}=1.4 U_{0} \sin k x
$$

and the maximum possible value was assumed:

$$
u_{r m q}^{3}=1.4 U_{0}
$$

The tidal current amplitude $U_{0}$ was defined as the depth-mean velocity at Praticagem. In the $R i_{e}$ equation (3.4), the variables $\rho$ and $U_{0}$ were obtained as a function of time. Therefore, the $R i_{e}$ results will be shown in the form of a time series.

The tidal propagation through the estuary was evaluated along the entire navigation channel, that extends from Santos Bay to Piaçaguera Channel passing through Porto Channel (Figure 3.2). A total of 36 points along the navigation channel was chosen. For this investigation, both modeled ( 22 simulation) and observed data were used. Harmonic analysis was performed over all datasets, for elevation and surface currents. The observations comprise the 4 stations distributed along the navigation channel shown in Figure 3.2. The period of study of each station varied with the availability of regular elevation and current information. For Palmas, a 4-month time series from December 2016 to March 2017 was 
used. At Praticagem, the same 7-month time series used in the previous calculations was selected. At Capitania a 6-month time series from October 2016 to April 2017 was used. Finally, at Alemoa, a 5month term from February 2015 to July 2015 was chosen.

The stratification-circulation diagram of Hansen and Rattray (1966) was computed using the approximated equation of Miranda et al. (2017) that admits only real solutions:

$$
\begin{gathered}
\left(\frac{\delta S}{\bar{S}}\right)^{-1}\left[210+252\left(\frac{u_{s}}{u_{f}}-\frac{3}{2}\right)\right] \nu^{2}+ \\
{\left[-\left(\frac{\delta S}{\bar{S}}\right)^{-1}\left(210+252\left(\frac{u_{s}}{u_{f}}-\frac{3}{2}\right)\right)+76\left(\frac{u_{s}}{u_{f}}-\frac{3}{2}\right)+\frac{152}{3}\left(\frac{u_{s}}{u_{f}}-\frac{3}{2}\right)^{2}\right] \nu=0}
\end{gathered}
$$

where $\delta S$ is the top-to-bottom salinity difference, $\bar{S}$ is the stationary depth mean salinity, $u_{s}$ is the net surface current, $u_{f}$ is the mean freshwater velocity and $\nu$ is the diffusive fraction of the total upstream salt flux. The dimensionless ratios $\delta S / \bar{S}$ and $u_{s} / u_{f}$ are the stratification and circulation parameters, respectively. Equation (3.7) admits only $u_{s} / u_{f}>1.5$ and for a fixed value of the circulation parameter, each value of $\nu$ (for $0<\nu<1$ ) gives a different solution for the stratification parameter. For $\nu=$ 1 , equation (3.7) becomes independent of the stratification parameter and the solution is $u_{s} / u_{f}=$ 1.5. Computed solutions of equation (3.7) for different values of $\nu$ gives the stratification-circulation diagram, which has the stratification parameter in the $\mathrm{y}$-axis and the circulation parameter in the $\mathrm{x}$-axis.

The stratification and circulation parameters were computed using the salinity profiles of Figures 3.4 to 3.8 and the longitudinal velocity profiles closest to the primes (shown in Figures 3.11 to 3.15). As suggested by Miranda et al. (2017), we used $u_{f}$ as the stationary depth mean longitudinal velocity, once river discharge data were not available.

Classification was also addressed for the numerical model results in experiment C2. The SSVBES grid point closest to Praticagem station was selected. The vertical profiles of along-channel velocity and salinity were used to compute the stratification and circulation parameters. Although the salinity field in the numerical experiment is representative of climatological conditions, Figure 3.3 shows that the differences between surface and bottom salinities over time agree with the measured differences in the ECOSAN spring months.

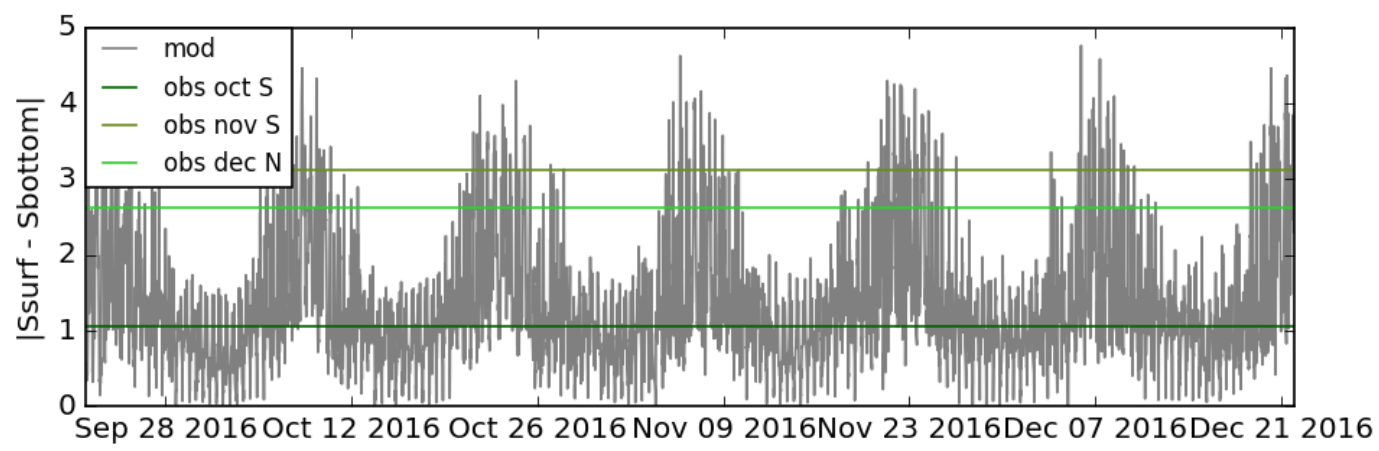

Figure 3.3: Absolute differences between surface (Ssurf) and bottom (Sbottom) salinities along the modeled 
C2 simulation (gray line). The 12-h average surface to bottom differences of observed salinity in 3 different months during the ECOSAN project (2005) are shown in green lines.

\subsubsection{The ECOSAN observed data}

The hydrographic and current dataset used for this analysis were collected in 2005 in the course of the ECOSAN project. For July, August, October, November and December, a fixed hydrographic station in Porto Channel was repeated every $\sim 1$ h during 1 tidal cycle every month. Velocity data were measured in the end of each hydrographic profile with a vessel-mounted ADCP (Acoustic Doppler Current Profiler) in a trajectory perpendicular to the direction of the channel, close to Santos Pilots Praticagem station (Figure 3.2). All expeditions were conducted in the spring tidal cycle.

For each month, all temperature $(\mathrm{T})$ and salinity $(\mathrm{S})$ profiles were vertically interpolated by cubic spline method to the non-dimensional depth from surface $(Z=0)$ to bottom $(Z=-1)$ at every -0.1 interval, following the method proposed by Miranda et al. (2017). Maximum depth of each profile $(h(t))$ was used to convert every level of measurement $(z)$ in terms of $Z$ by $Z=z / h(t)$. Figures 3.4 to 3.8 show the obtained $\mathrm{T}$ and $\mathrm{S}$ profiles in the upper panels. Bottom panels show the tidal elevation and colored lines mark the time of each correspondent profile. Figure 3.9 shows surface and bottom currents for each transect of the July cruise as an example. Figure 3.9 shows that as a result of the ebb cycle, a down-estuary flux is observed at the first panel, followed by weak velocities characteristic of the slack water condition in the second panel. As the flood cycle starts, currents turn to up-estuary direction, as in the following panels, until the low tide when the flux reverses again.

For each transect, all profiles deeper than $2 \mathrm{~m}$ were used in the subsequent calculations. Selected profiles were rotated according to the geographic alignment at the fixed station with the longitudinal velocity $u$ poiting positively to the down-estuary direction. An angle of $130^{\circ}$ was used. For each profile, the value of the first vertical bin measured by the ADCP was extrapolated to the surface and no slip condition was assumed at the bottom. Velocity profiles were then linearly interpolated to the nondimensional depth $Z$ at -0.1 intervals. The obtained velocity component profiles for panel 8 of Figure 3.9 is shown in Figure 3.10. The channel averaged along-channel and across-channel components are shown by black solid and dashed lines, respectively. The profile transect closest to the fixed station are also indicated for the along-channel component as well as the deepest velocity profile. In the case of Figure 3.10 they coincide. The longitudinal velocity profiles that were closest to the hydrographic station at each transect are show in Figure 3.11 to Figure 3.15 for each month. 

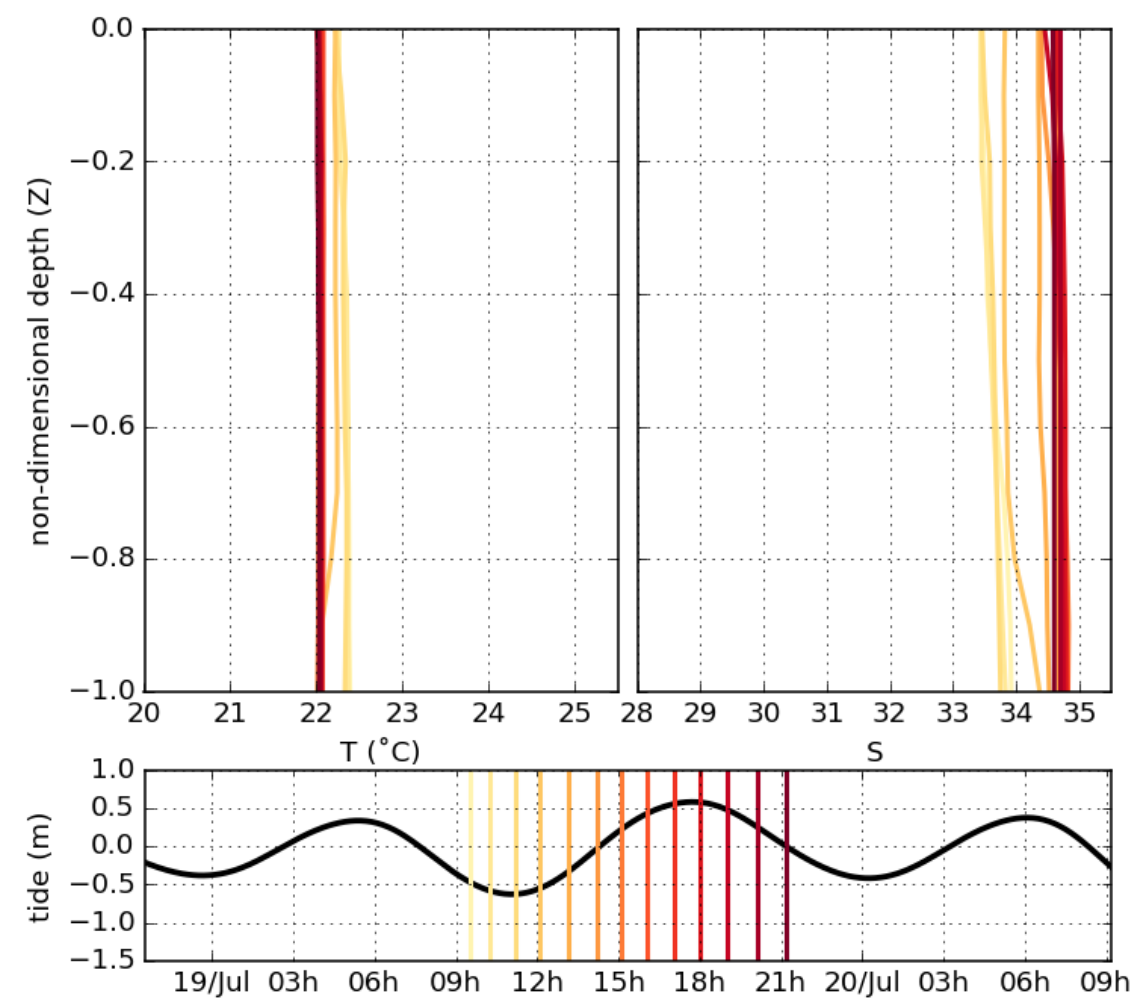

Figure 3.4: Vertical profiles of temperature (top left) and salinity (top right) observed at the fixed station in Porto Channel in July. The $y$-axes is the non-dimensional depth $(Z)$. Tidal elevation is shown at the bottom panel in black. Colored lines mark the time of each correspondent profile.

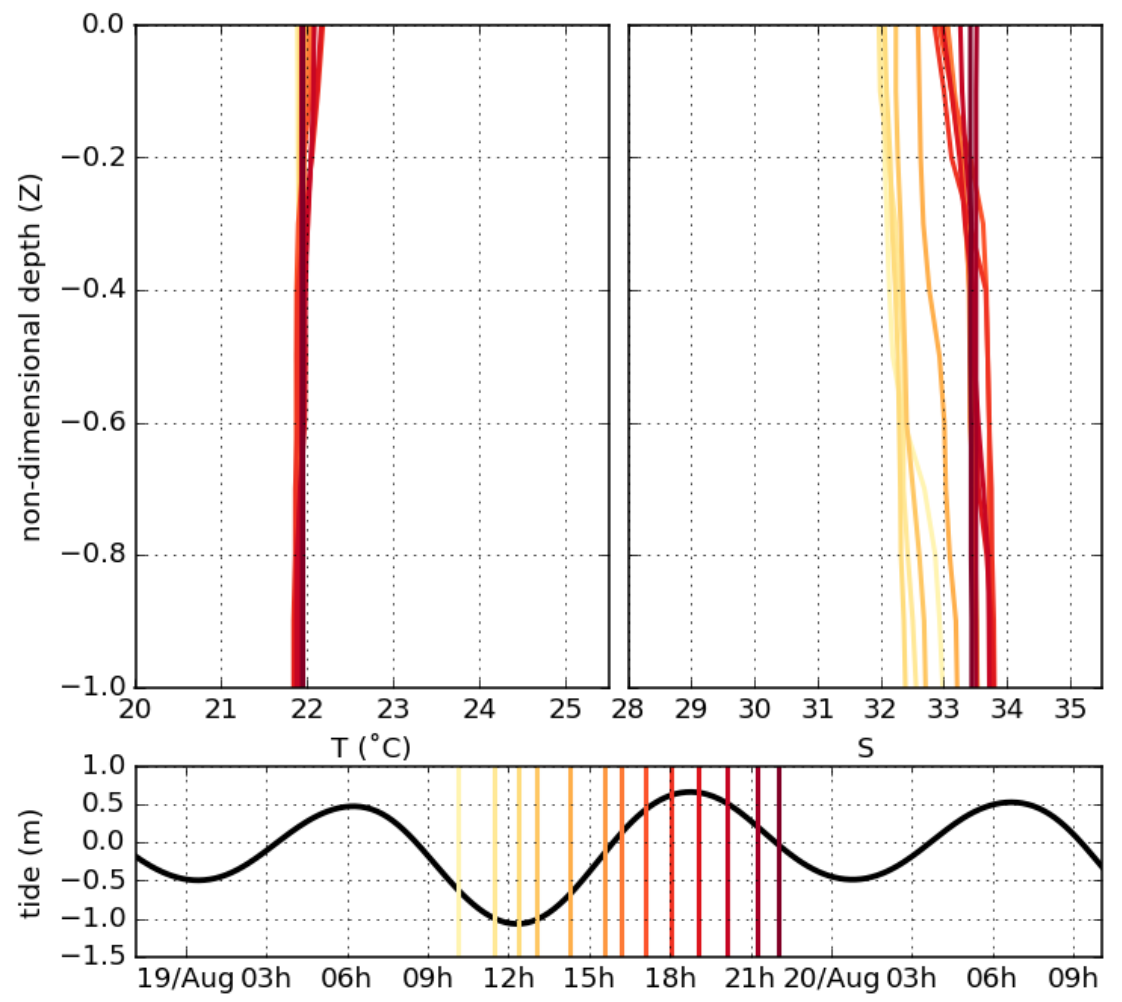

Figure 3.5: Similar to Figure 3.4 for August, 2005. 

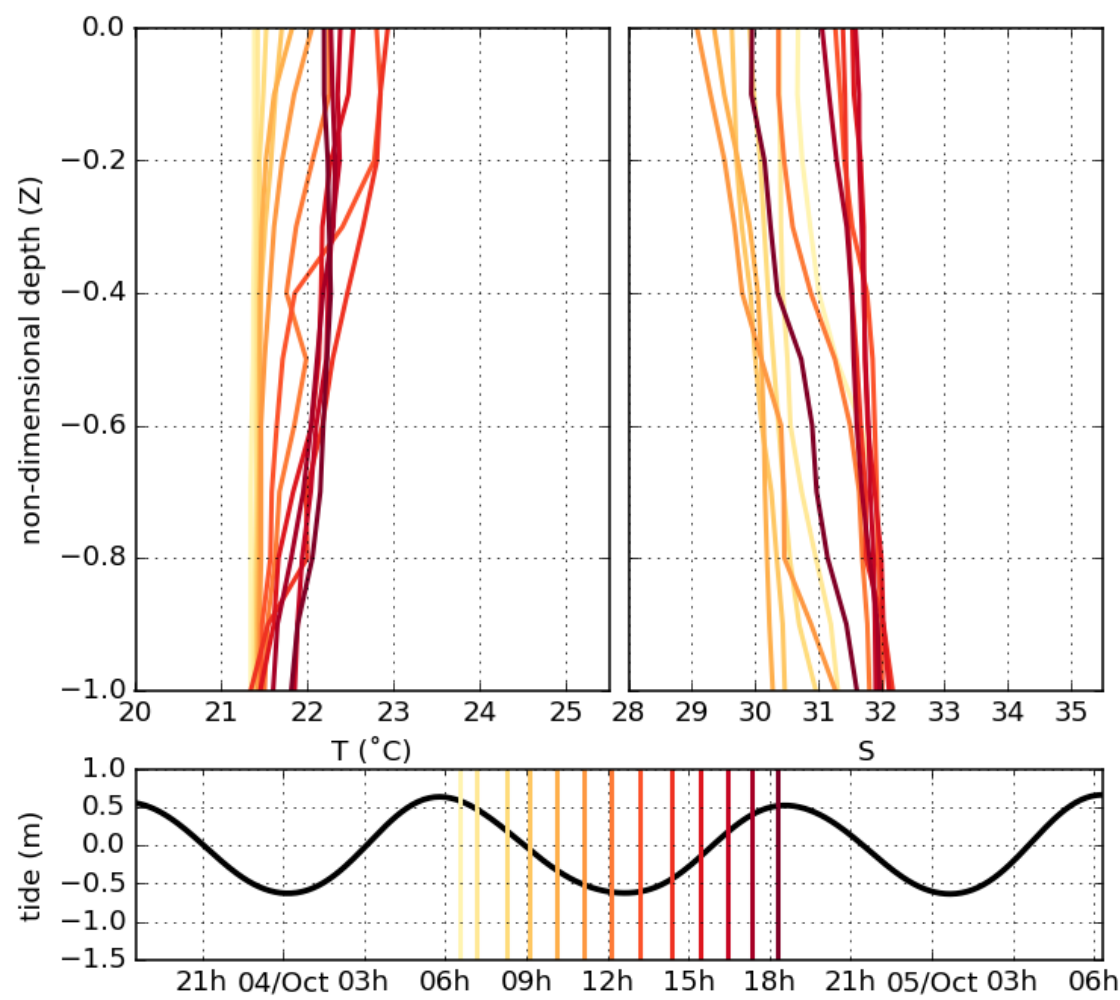

Figure 3.6: Similar to Figure 3.4 for October, 2005.
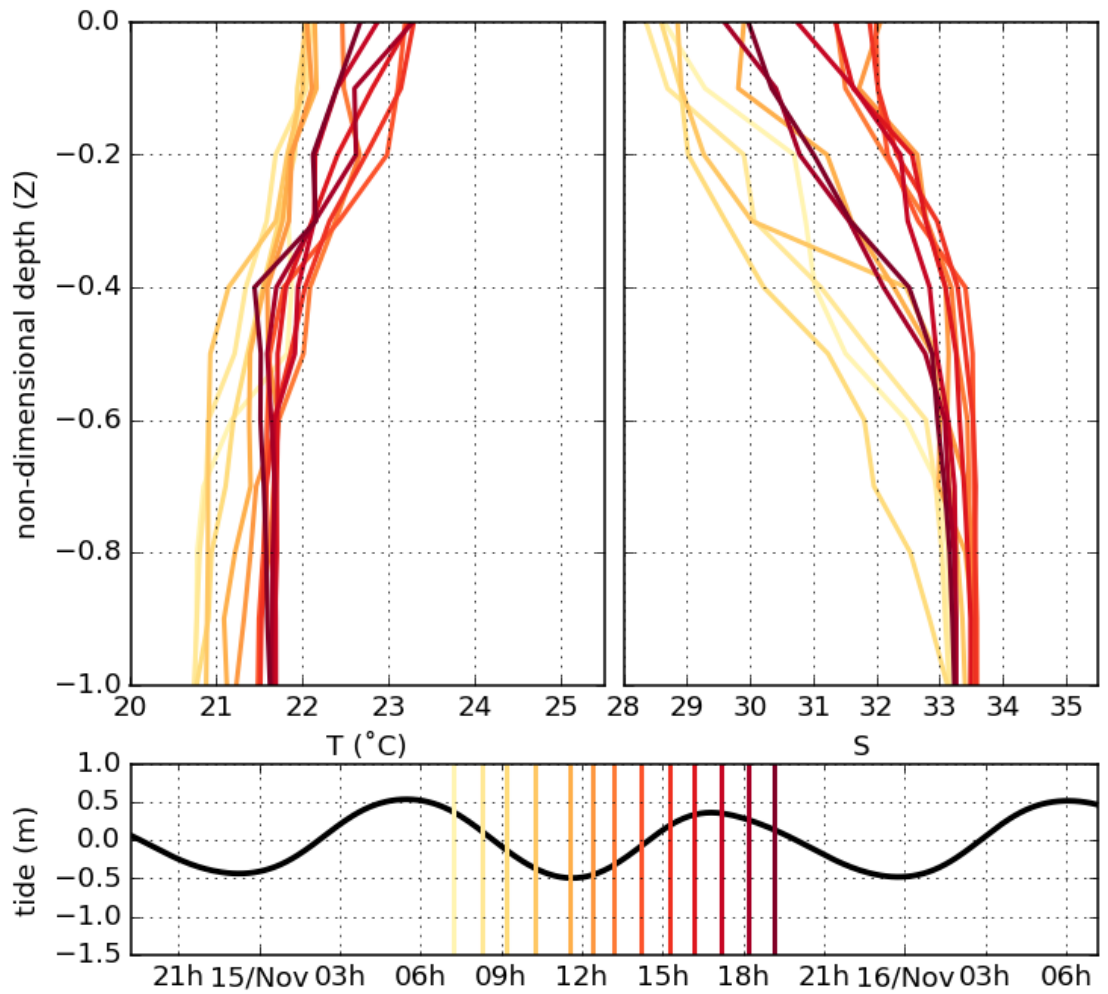

Figure 3.7: Similar to Figure 3.4 for November, 2005. 


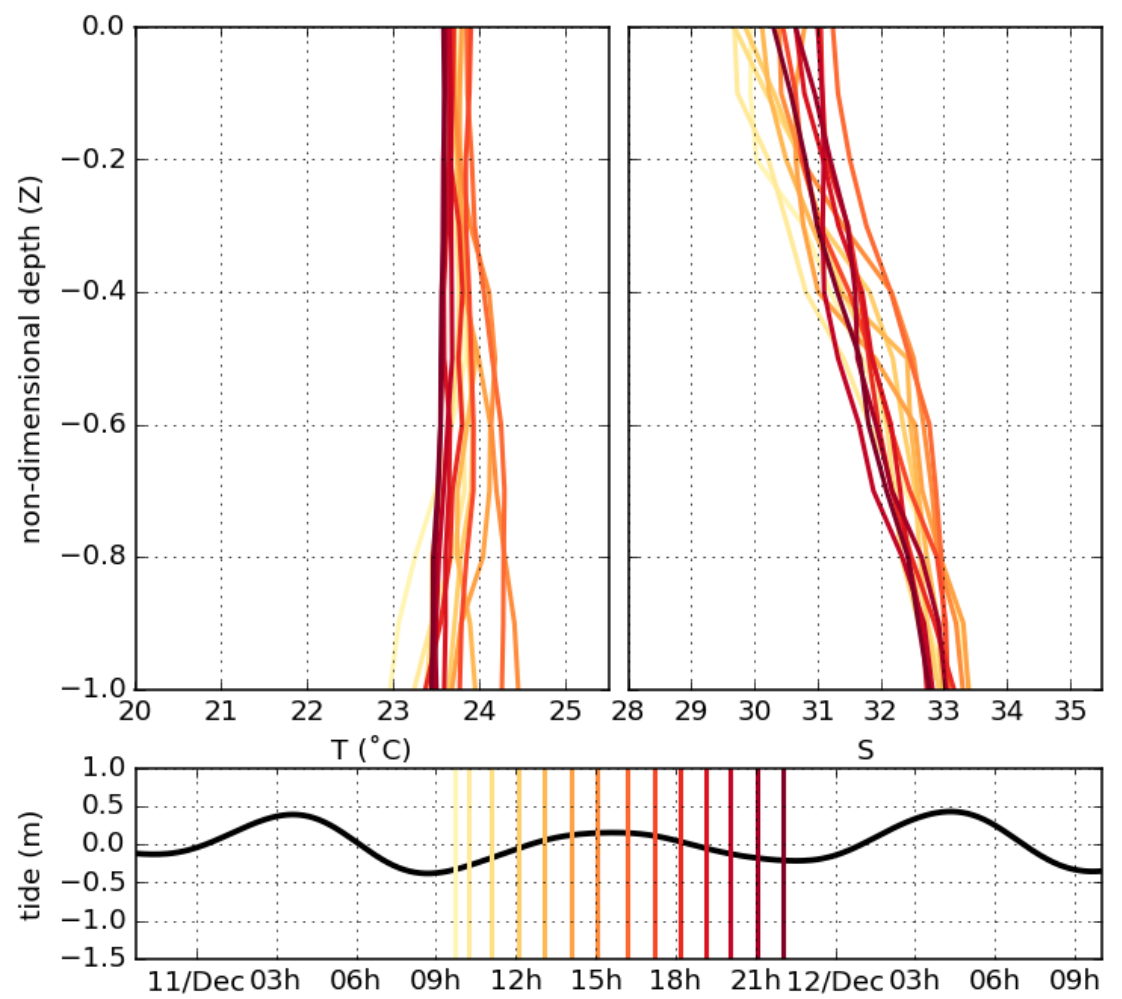

Figure 3.8: Similar to Figure 3.4 for December, 2005. 


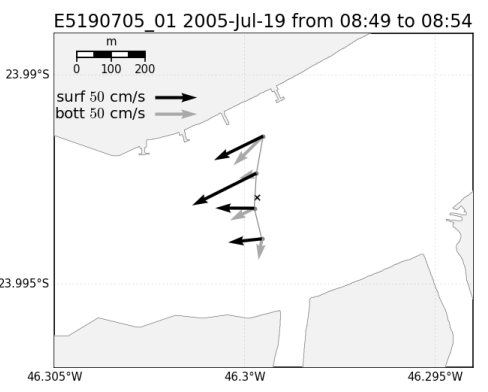

E5190705 04 2005-Jul-19 from 11:57 to $12: 00$ $\frac{\mathrm{m}}{\mathrm{D}}$

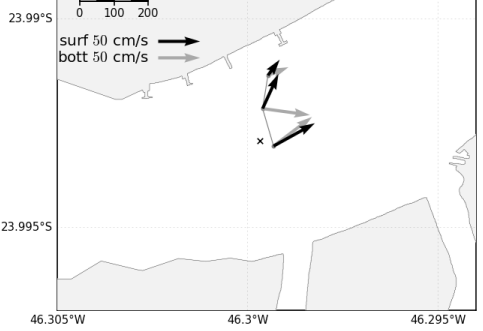

E5190705_07 2005-Jul-19 from 14:59 to 15:02 달

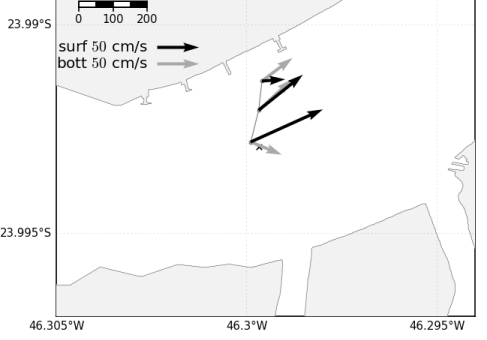

E5190705 10 2005-Jul-19 from 17:56 to $17: 59$
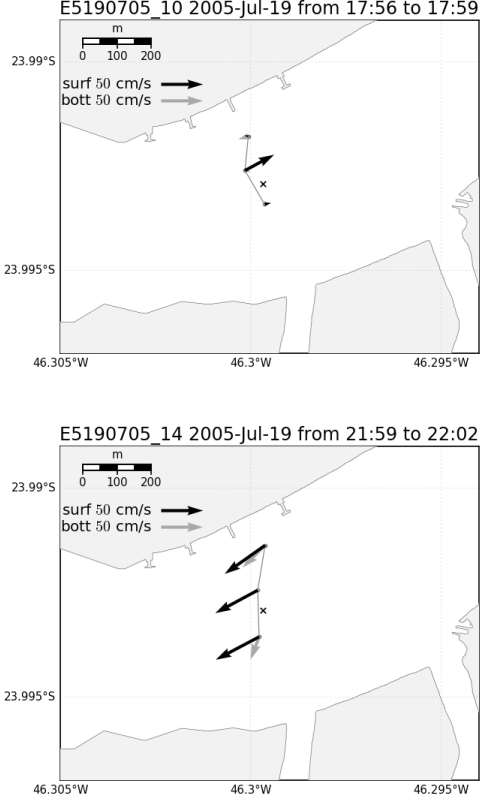

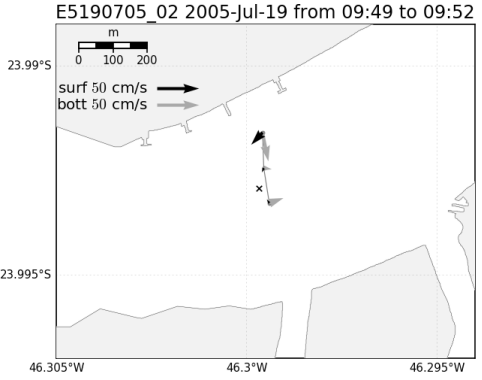

E5190705 05 2005-Jul-19 from 13:03 to 13:06 $\frac{\mathrm{m}}{\mathrm{P}}$

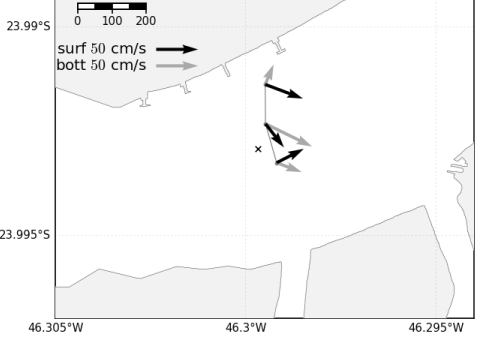

E5190705 08 2005-Jul-19 from 15:56 to $15: 59$ $\frac{\mathrm{m}}{100200}$

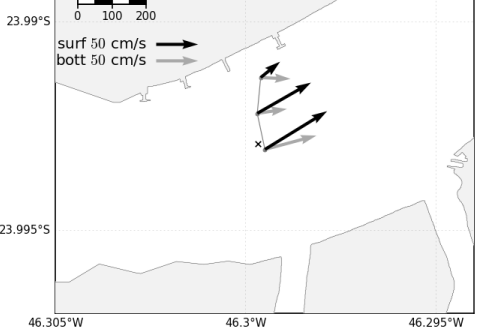

E5190705 11 2005-Jul-19 from 18:56 to 19:00
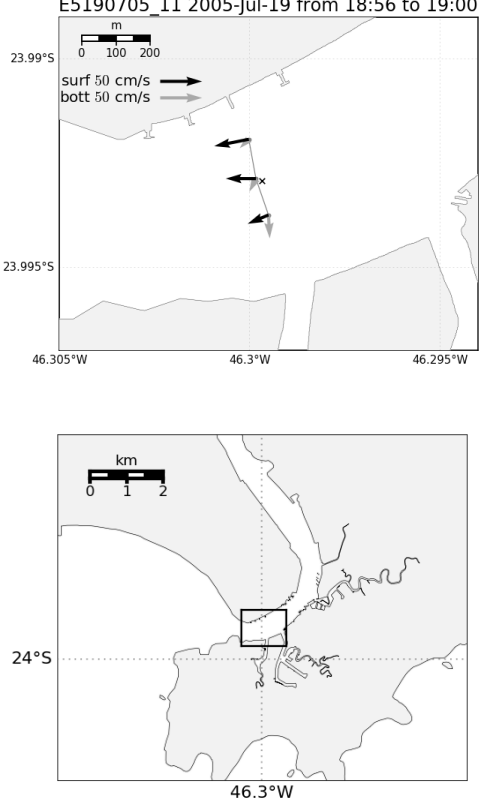

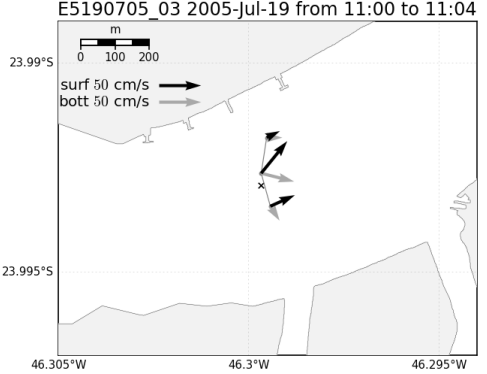

E5190705 06 2005-Jul-19 from 13:57 to $14: 01$ $\frac{\mathrm{m}}{\mathrm{P}}$

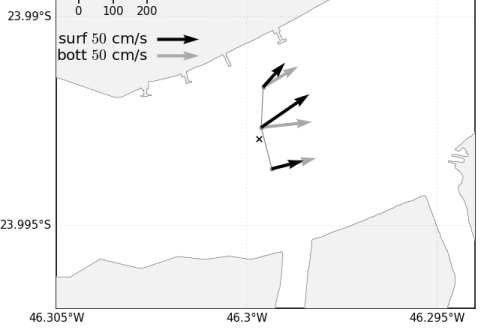

E5190705 09 2005-Jul-19 from 16:55 to $16: 58$ $\frac{\mathrm{m}}{\mathrm{P}}$

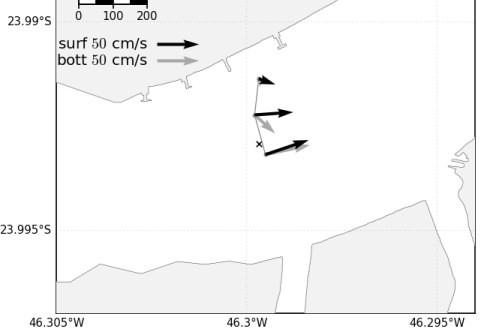

E5190705 12 2005-Jul-19 from 19:54 to 19:57

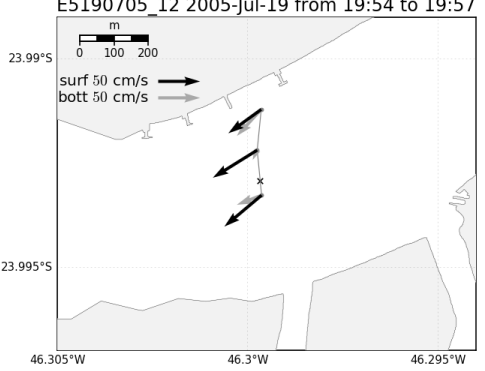

Figure 3.9: Observed currents at surface (black arrows) and bottom layers (gray arrows) measured with a vessel-mounted $\mathrm{ADCP}$ over the trajectory sketched by the gray line. Position of the fixed CTD station is marked with a "x". The last panel illustrates the location where the measurements were conducted. 

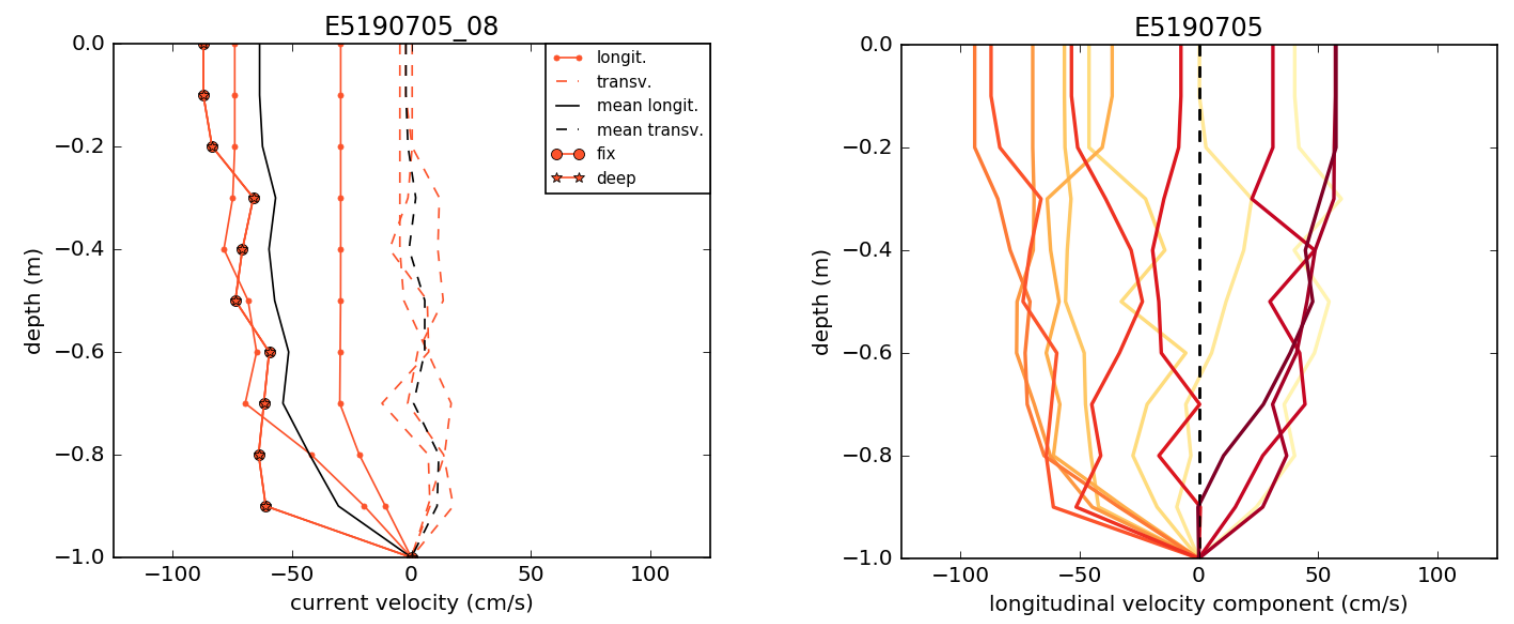

Figure 3.10: Velocity components measured by eachFigure 3.11: Lateral mean longitudinal velocity proADCP profile in transect 8 of Figure 3.9. Black solidfiles for the July Cruise. Each transect in Figure 3.9 is (dashed) lines represent the lateral mean of longitudi-represented by a different line. Same color code of Fignal (transversal) component. ure 3.4 applies.

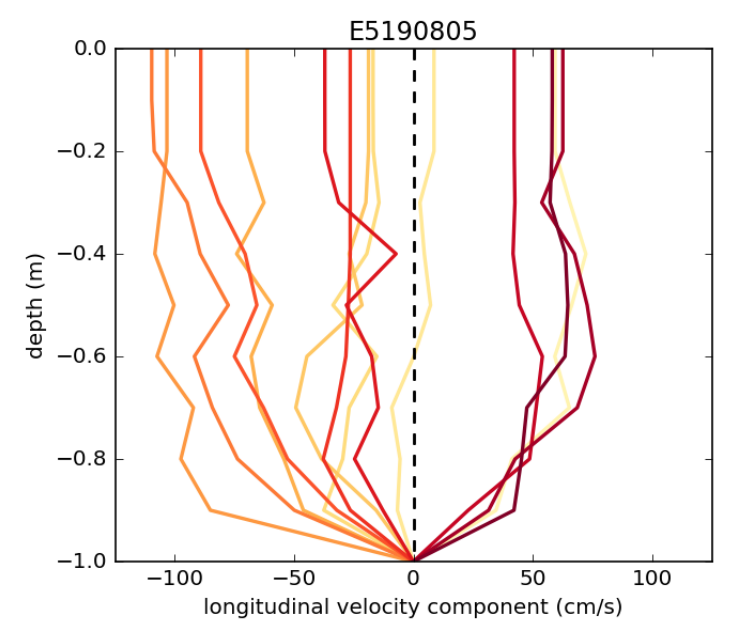

Figure 3.12: Similar to Figure 3.11 for August.

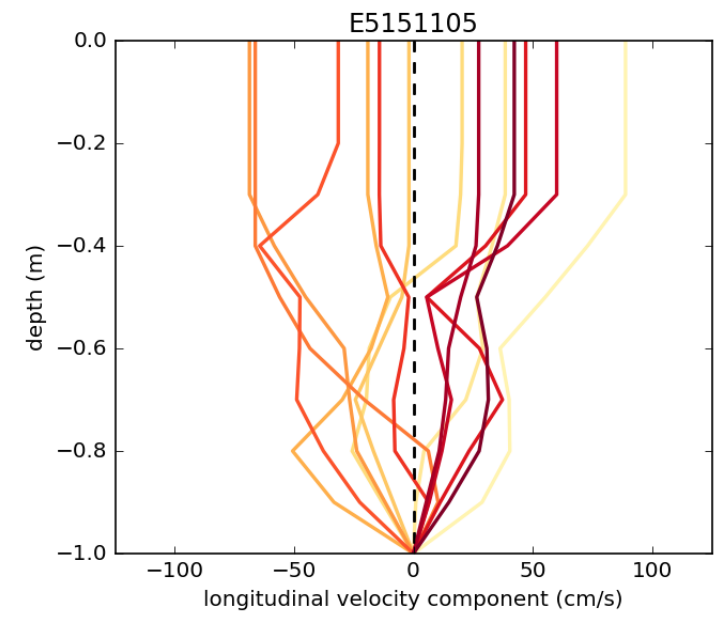

Figure 3.14: Similar to Figure 3.11 for November.

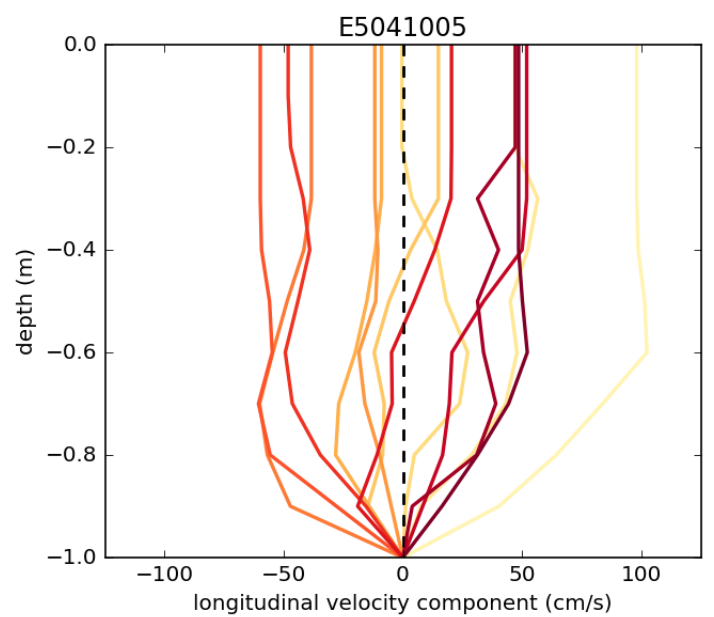

Figure 3.13: Similar to Figure 3.11 for October.

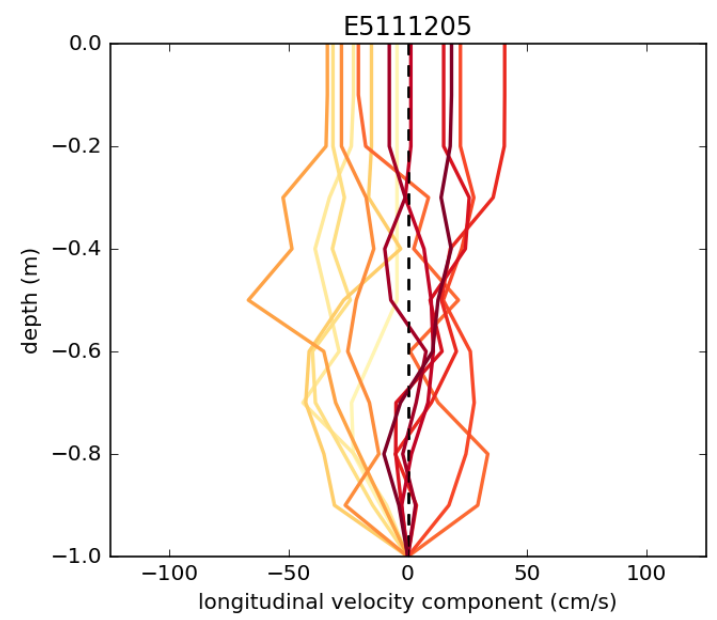

Figure 3.15: Similar to Figure 3.11 for December. 


\subsection{Results}

First, the observed $\mathrm{T}$ and $\mathrm{S}$ profiles measured in Porto Channel during the ECOSAN project in 2005 is discussed. Next, the estuarine quantities calculated according to Table 3.1 are presented. Finally, the estuary classification is addressed through the stratification-circulation diagram.

\subsubsection{Observed temperature and salinity profiles}

The winter hydrographic data of Figures 3.4 and 3.5 show homogeneous vertical profiles with (vertical and temporal) mean $\mathrm{T}$ and $\mathrm{S}$ pairs of $22.1^{\circ} \mathrm{C}$ and 34.3 in July and $21.9^{\circ} \mathrm{C}$ and 33.1 in August. Figure 3.4 reveals that the water temperature gradually decreases from $09 \mathrm{~h}$ to $21 \mathrm{~h}$ (from low to high tide), suggesting that the advection of relatively cold waters from Santos Bay entering the estuary overcomes the diurnal heating cycle. An increase in both temperature and salinity stratification occurs in spring time (October and November), with bottom temperatures varying from $21^{\circ} \mathrm{C}$ to $22{ }^{\circ} \mathrm{C}$ and surface values reaching $23^{\circ} \mathrm{C}$ (Figures 3.6 and 3.7). Surface salinity during these months and also in December (Figure 3.8) decreases down to 28.3 probably due to a seasonal increase in precipitation and river runoff. In the summer cruise (December) waters are warmer and vertically homogeneous with mean temperature equal to $23.7^{\circ} \mathrm{C}$. Monthly variations suggest that $\mathrm{T}$ and $\mathrm{S}$ vertical profiles are in accordance with the seasonal stratification variability observed in the inner shelf of the SBB by Castro (2014).

In July and August, the water column is more vertically homogenous and the salinity values increase from low to high tide as shown in Figures 3.4 and 3.5. Temporal variations of the depth-mean salinity are bigger than 1, reflecting the up-estuary movement of higher salinity waters from Santos Bay during high tide. Indeed, linear correlations between the depth mean $S$ and the tidal elevation are equal to 0.90 and 0.93 in July and August, respectively. Figure 3.16 shows good agreement between the depth mean $S$ and the tidal oscillation over time. Depth mean salinity seems to lead tidal elevation over time by a few hours, as found by Miranda and Castro (1998) in Bertioga Channel. Insignificant correlations (less than $10^{-2}$ ) were found for October and November and a weaker correlation of 0.81 (not shown) was found in December.
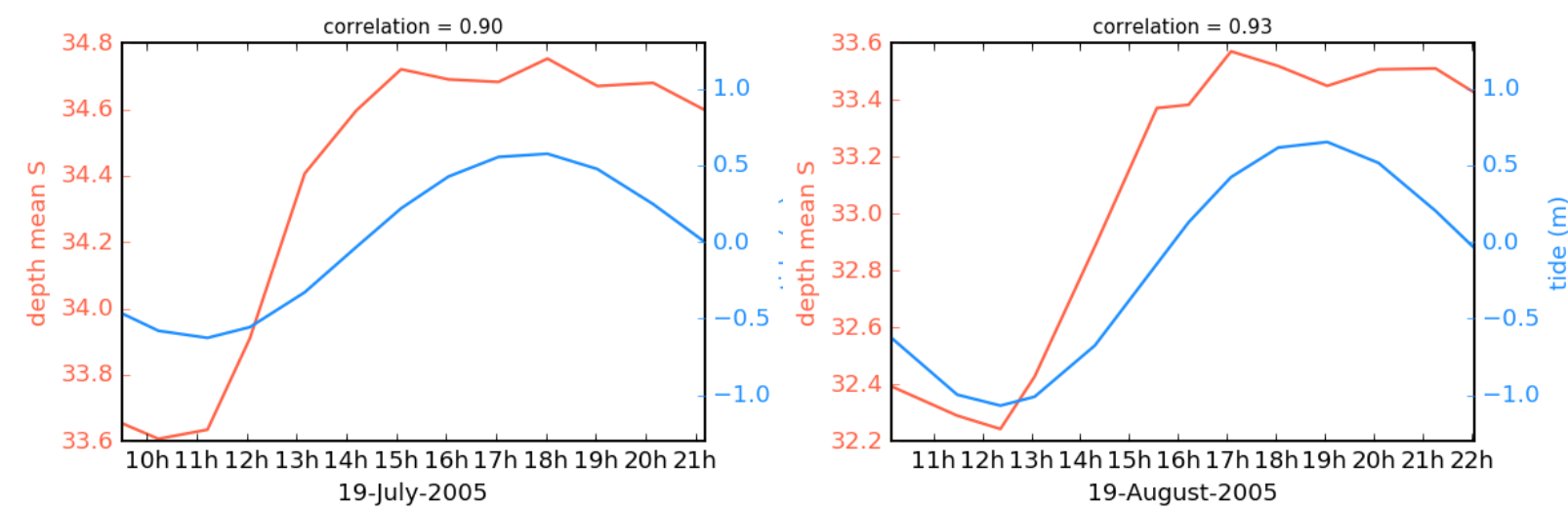

Figure 3.16: Temporal variations of the depth-mean salinity (orange line) and the tidal elevation (blue line) observed in July (left) and August (right). Linear correlation between time series is show in titles. 


\subsubsection{Estuarine quantities}

The results of the estuarine quantities 1-6, detailed in Table 3.1, are now presented. The first 5 calculations were based on the 7-month period sea surface elevation data collected at Praticagem station. The tidal prediction derived from the harmonic analysis of this time series revealed a maximum tidal height of $1.33 \mathrm{~m}$, characteristic of a microtidal regime (Davies, 1964). The same harmonic analysis provided the amplitudes for the form number calculation through equation (3.1). A value of $F=0.32$ was found, revealing that tides in the Porto Channel are mixed, mainly semidiurnal. Same results were obtained by Miranda et al. (2012) and Harari and Camargo (2003) at stations further North in the same channel and by Miranda and Castro (1998) in Bertioga Channel.

The tidal prism $P$, calculated through equation (3.2), was equal to $1.9 \times 10^{7} \mathrm{~m}^{3}$ and $4.9 \times 10^{6} \mathrm{~m}^{3}$ for spring and neap tide cycles, respectively. Comparing to the volume of the estuarine channel through the same area $A s$ used in the $P$ calculation, the tidal prism during the spring cycle represents approximately $1 / 6$ of the channel volume. For semidiurnal spring tides, this means that the water system is completely renewed after approximately 3 days. This is the time a pollutant thrown in the navigation channel would persist in the system during spring tides. The flux ratio $R / P$ was equal to 0.02 (spring tides) and to 0.08 (neap tides). The small flux ratio values reveal that Porto Channel is a tide-dominated estuary.

The tidal excursion estimation through equation (3.3) resulted in values of $17.8 \mathrm{~km}$ during spring and $5.0 \mathrm{~km}$ during neap tides. This is a rough approximation of the length of the mixing zone (Miranda et al., 2017). The distance from Praticagem station to the upper reaches of the navigation channel at Piaçaguera are approximately $20 \mathrm{~km}$. Therefore, the tidal current amplitudes during spring cycles are able to produce a salt intrusion that reaches the estuary head. Indeed, Miranda et al. (2012) found bottom salinities at Piaçaguera exceeding 30 during both spring and neap cycles.

Finally, the values of the non-dimensional estuarine Richardson number $R i_{e}$ calculated through equation (3.4) are shown in Figure 3.17. The $R i_{e}$ is a measurement of the water column stratification comparing the contribution of river discharge that increases stratification with the tidal mixing power that lowers stratification. The larger the $R i_{e}$, the more stratified (more stable) the water column. When $R i_{e}$ is big (small), the estuary is forced mainly by the river discharge (tide). The criteria to define which process dominate range from $0.08<R i_{e}<0.8$ (Fischer et al., 1979; Miranda et al., 2017). The $R i_{e}$ in Figure 3.17 varied from $5.2 \times 10^{-3}$ to 179.3 , with average value of 0.1 . The peak values occured during both spring and neap cycles, but are isolated events that do not persist for more than $1 \mathrm{~h}$. Table 3.2 shows the maximum, minimum and average values during spring and neap tides. The highest average values during neap tides are due to the decrease in the tidal mixing power. The average $R i_{e}$ is one order of magnitude smaller during spring cycle. The average $R i_{e}$ reaches the range of dominant process transition only during neap cycle. Along the entire time series, the $R i_{e}$ were $89 \%$ of the time smaller than 0.08 (the lower limit) and $99 \%$ of the time smaller than the upper limit of 0.8 . Therefore, the stratification in the Porto Channel can be considered as weak. The $R i_{e}$ showed that the estuary is mainly forced by the tides, corroborating the conclusions obtained with the flux ratio analysis. 


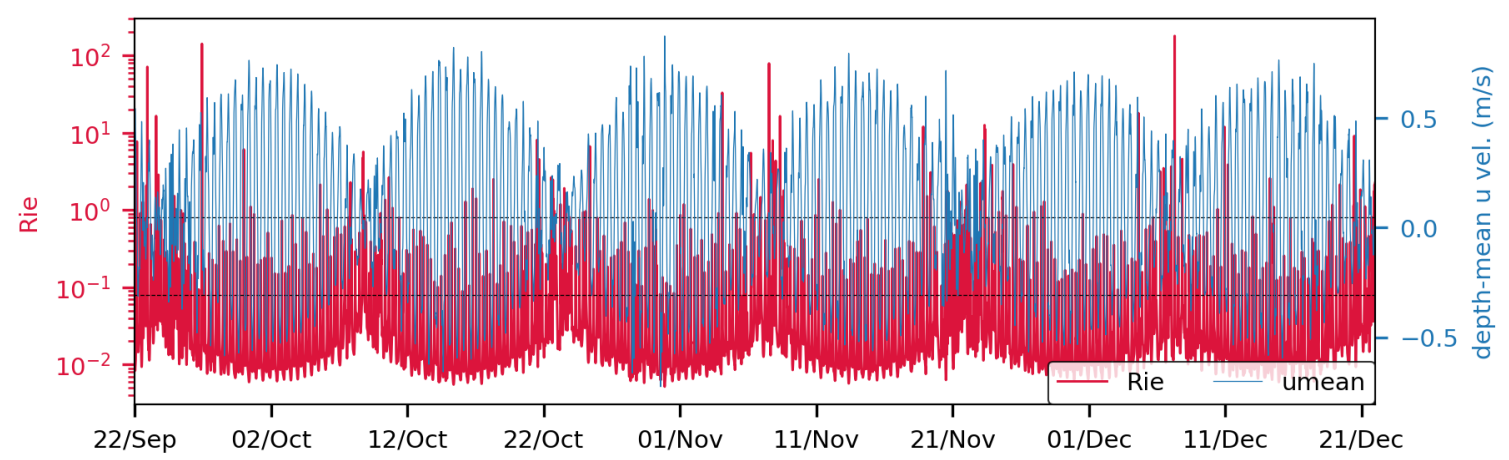

Figure 3.17: Time series of the estuarine Richardson number $\left(R i_{e}\right)$ (red line) calculated from the modeled C2 simulation at Praticagem. The tidal signal in the depth-mean velocity is shown in blue and features the spring and neap tidal periods.

Table 3.2: Maximum, minimum and average values of the estuarine Richardson number $\left(R i_{e}\right)$ for spring and neap tidal cycles.

\begin{tabular}{cccc}
\hline & \multicolumn{3}{c}{$R i_{e}$} \\
& minimum & maximum & average \\
\hline spring & $5.2 \times 10^{-3}$ & 141.9 & $5.9 \times 10^{-2}$ \\
neap & $6.3 \times 10^{-3}$ & 179.3 & $1.8 \times 10^{-1}$ \\
\hline
\end{tabular}

\subsubsection{Tidal propagation}

The tidal propagation in the SSVBES was studied at 36 locations along the navigation channel marked in Figure 3.2. Figure 3.18 shows the tidal elevations and surface tidal currents (solid lines) for the four most energetic constituents (M2, S2, O1 and K1), obtained through harmonic analysis of the C2 simulation (Chapter 2). The observed amplitudes are shown by the dashed lines for the 4 stations in Figure 3.2. The $\mathrm{M} 2$ and $\mathrm{K} 1$ amplitudes along the estuary are in accordance to what was found by Harari and Camargo (2003).

For both modeled and observed data, the tidal elevation amplitudes increase from the estuary mouth (Praticagem) towards the estuary head (Alemoa) for M2, S2 and O1. The K1 constituent shows opposite behavior between modeled and observed results with the modeled (observed) amplitudes increasing (decreasing) in the up-estuary direction. Increases of $2.7 \mathrm{~cm}(5.1 \mathrm{~cm})$ and $1.8 \mathrm{~cm}(3.5 \mathrm{~cm})$ are seen in the modeled (observed) results from Praticagem to Alemoa for M2 and S2, respectively. The increases of semidiurnal components represent approximately $7.5 \%$ (13.5\%) of the modeled (observed) tidal amplitude at Praticagem. For $\mathrm{O} 1$ and $\mathrm{K} 1$, the changes of amplitude along the estuary are smaller than the two strongest components, $0.2 \mathrm{~cm}$ for modeled and $0.5-0.8 \mathrm{~cm}$ for observed, and are less important for the total tidal elevation. Contrary to the elevation, in general, the tidal currents decrease in the up-estuary direction. The modeled tidal current amplitudes decrease by $79 \%$ in M2 and S2 and by $83 \%$ in $\mathrm{O} 1$ and $\mathrm{K} 1$ at Alemoa in relation to Praticagem. The observed tidal current amplitude decreases range from $91 \%(\mathrm{~K} 1)$ to $94 \%(\mathrm{~S} 2)$. 
Although the tidal elevation amplitude rise in the up-estuary direction, the increase was not big enough to consider the navigation channel as a hyper-synchronous estuary. For instance, in the hypersynchronous estuary of Bahia Blanca (Argentina) (Perillo and Piccolo, 1991), the increment of tidal amplitude with the distance from the estuary mouth reaches almost $60 \%$. In the Gironde estuary (France), the increase is about 33\% during spring tides (Allen et al., 1980). Both examples are for mesotidal or macrotidal and funnel shaped estuaries, features that do not necessarily characterize the SSVBES. The navigation channel suffers regular dredgings that alters the geometry of the estuary constantly. Furthermore, in hyper-synchronous conditions, the maximum current velocity occurs in the upper reaches of the estuary (Allen et al., 1980), differently from what is found in the SSVBES (Figure 3.18). Therefore, the navigation channel of the SSVBES can be considered a synchronous estuary.

In a synchronous estuary, friction and convergence are balanced and the tidal amplitude is held approximately constant along the estuary (Miranda et al., 2017). Because the elevation does not increase significantly in the up-estuary direction, one should expect that energy is being dissipated through friction when the sectional area act to constraint the flux. The combined effect of both factors can be seen in Figure 3.19. The modeled depth-mean currents are plotted against the channel width in 16 points along Porto Channel, from loc 8 to loc 23. From loc 10 to loc 23, the wider the channel, the weaker the currents. Geometry effect is also observed in Figure 3.18 (right panels) with the tidal velocities increasing sharply from loc 1 to loc 9 (Praticagem), the entrance of Porto Channel, due to geographic constraints and conservation of volume. However, velocity drastically decrease from loc 9 to the subsequent ones with similar channel width (loc 10 to loc 12) (Figures 3.18 and 3.19), what can be attributed to frictional dissipation. The intense velocity at the entrance of the channel increases the energy dissipation through friction that decreases velocities and prevents higher elevation increases. The overall damping of tidal velocities along the navigation channel is the result of a complex combined effect between geometry constraints and friction.

The relation between tidal elevation and currents provides information about the tidal propagation along the estuary. In the simplified solution for the tidal propagation problem in which friction is omitted, the elevations and currents are in phase and the estuary is progressive. When a reflected wave is taken into account, the two quantities are $90^{\circ}$ out of phase, characterizing the tidal wave along the estuary as a standing wave (Miranda et al., 2017). For standing wave systems in short estuaries, the tidal amplitude increases towards the estuary head and the tidal currents are maximum at the estuary mouth (Dyer, 1997), as observed in Figure 3.18.

Figure 3.20 shows the lag correlation between modeled sea surface elevation and depth-mean velocities at the 36 locations analyzed along the navigation channel. The velocity time series (orange lines) peak approximately during slack water (solid blue lines). The decrease in tidal velocities with the distance from the estuary mouth is also evident from loc 8 to loc 36 . The greatest linear correlation coefficient were obtained when the elevation time series (solid blue lines) were advanced $3.4 \mathrm{~h}$ (on average) (dashed blue lines) in relation to the depth-mean velocities (orange lines).

In the observed data at Capitania and Praticagem (not shown), the maximum correlation was ob- 
tained with tidal elevation delays of $3.5 \mathrm{~h}$ and $3.75 \mathrm{~h}$, respectively, corroborating the modeled results. Within the estuarine channels (loc 8 to loc 36 ), correlations varied from 0.81 to 0.91 and the temporal lags range from $2.8 \mathrm{~h}$ to $3.8 \mathrm{~h}$. For the two most energetic tidal constituents, $\mathrm{M} 2$ and S2, a $90^{\circ}$ phase difference is equivalent to a temporal lag of $3.0 \mathrm{~h}$ and $3.1 \mathrm{~h}$, respectively. For $\mathrm{O} 1$ and $\mathrm{K} 1$, the lag is equal to $6.4 \mathrm{~h}$ and $6.0 \mathrm{~h}$, respectively. A lag of $3.4 \mathrm{~h}$ is obtained through averaging these lags with weighting factors of 7 for the semidiurnal and 1 for the diurnal components. The applied semidiurnal weight, 7 , is roughly the difference in the velocity amplitudes between semidiurnal and diurnal constituents at Praticagem in Figure 3.18 (see also Table 2.4 in Chapter 2). Therefore, the tidal propagation through the navigation channel in the SSVBES is consistent with a standing wave pattern. Figure 3.21 shows the diagrams of elevation against velocity (top panels) for four 24-h tidal cycles indicated in the lower panels. The colored curves were plotted using the elevations (blue solid lines) and the depth-mean along-channel velocities (orange lines) in Figure 3.20. The modeled results (colored lines) deviate from the approximate progressive wave solution (gray lines) indicating that, although there may have some progressive wave contribution, the standing wave pattern dominates.

The tidal standing wave aspect can be attributed to the reflection of the incident wave at the estuary head, as formulated in Miranda et al. (2017), or to the influence of tidal waves coming from the different channels that composes the SSVBES. Harari and Camargo (2003) found progressive characteristics along Porto Channel and standing patterns along São Vicente and Bertioga channels. Nevertheless, the authors assessed the progressive/standing aspects through the co-tidal phase maps. The approach adopted in the present study, comparing the elevation and velocity time series delays, may be responsible for the different conclusions, once modeled results are validated against the observations in both studies. 

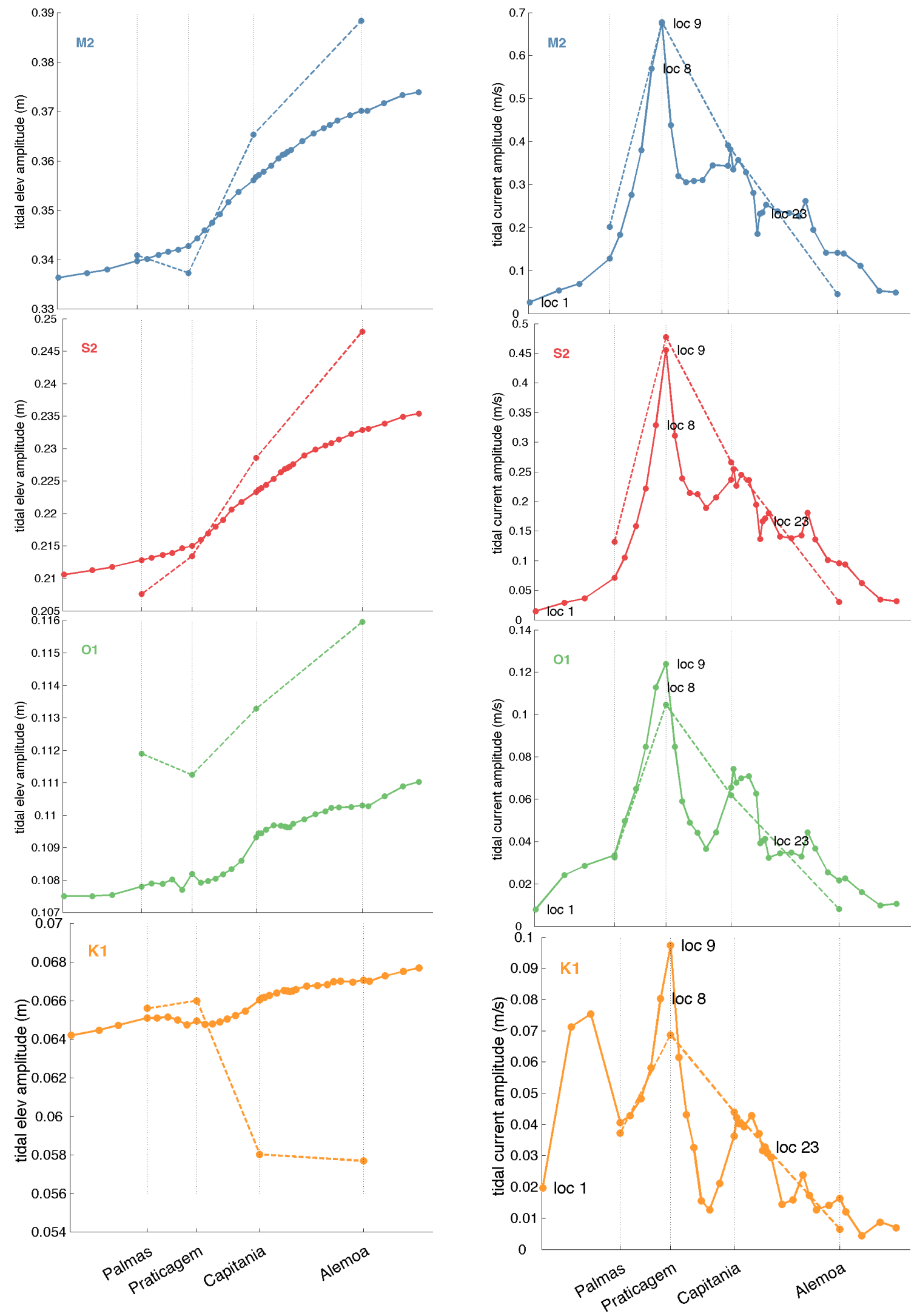

Figure 3.18: Amplitudes of tidal elevations (left) and surface tidal currents (right) for M2, S2, O1 and K1 constituents (from top to bottom) along the navigation channel. The solid lines show the modeled results for the 36 locations marked in Figure 3.2. Some locations are labeled for reference. The dashed lines are the observed results at the 4 stations shown in Figure 3.2. 


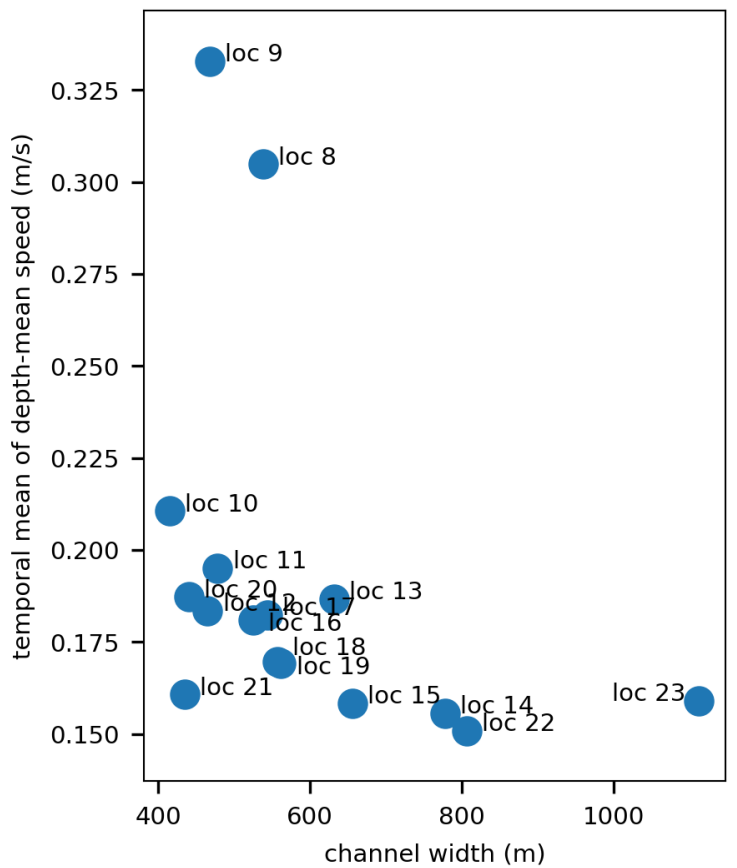

Figure 3.19: Depth-mean velocity $(\mathrm{m} / \mathrm{s})$ as a function of channel width $(\mathrm{m})$ for 16 points along the navigation channel (loc 8 to loc 23 in Figure 3.2). 


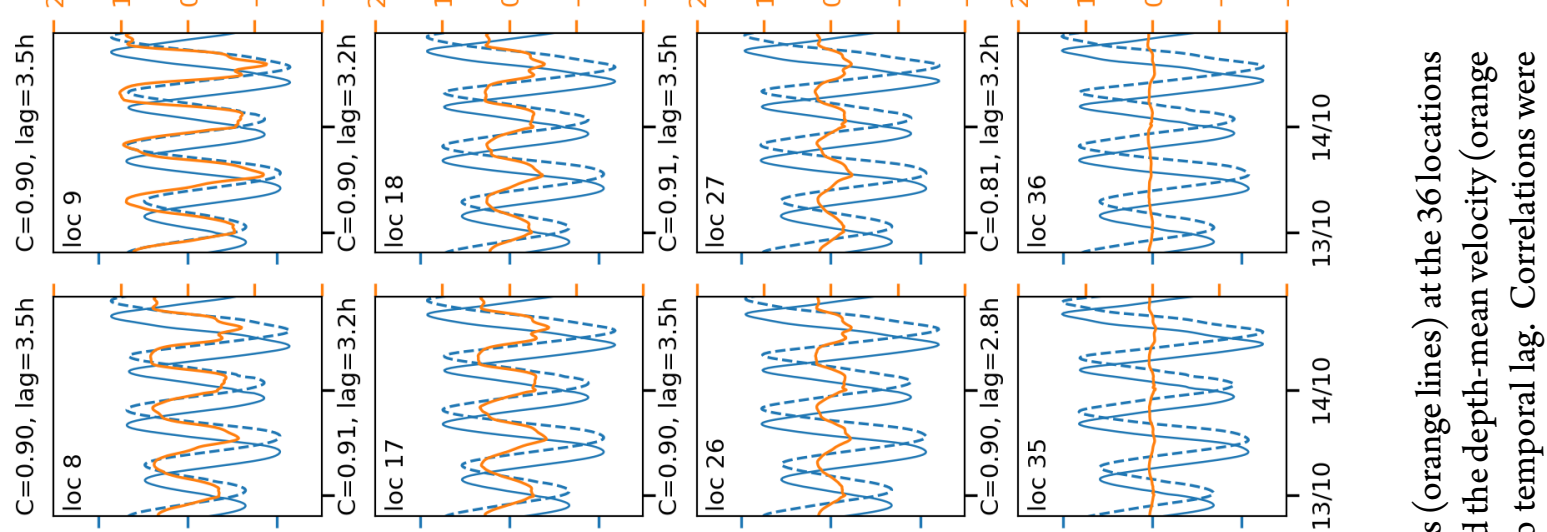

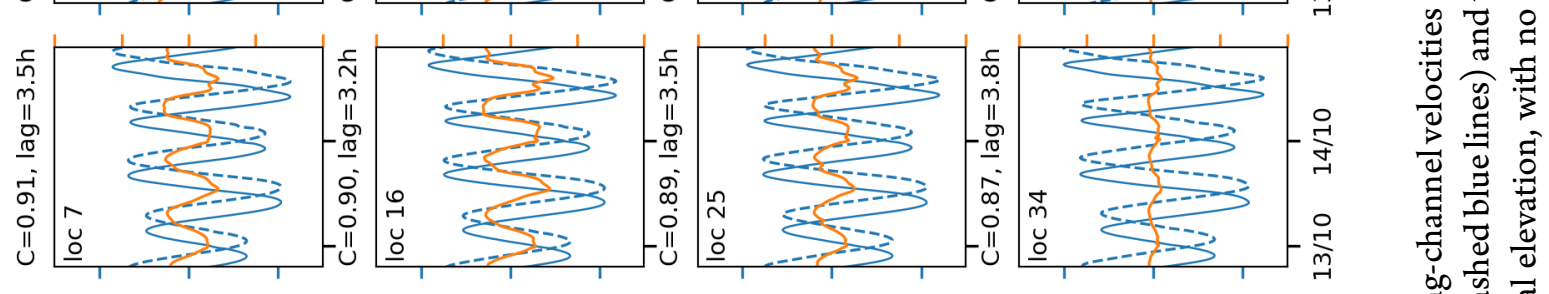

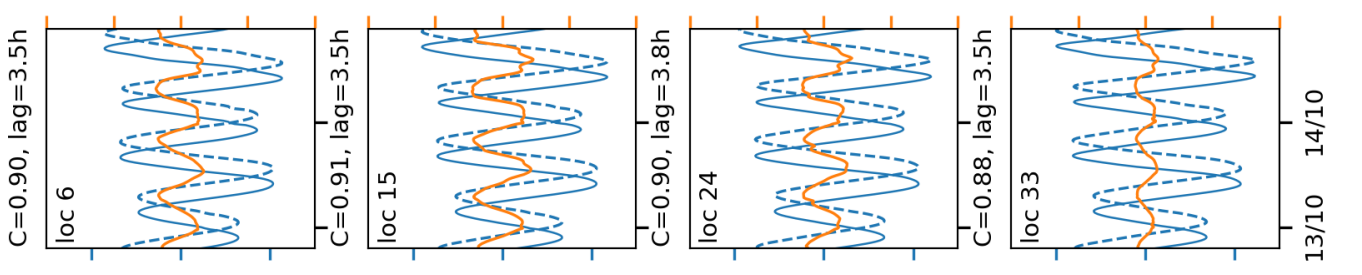

0ี

으 홀

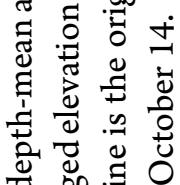

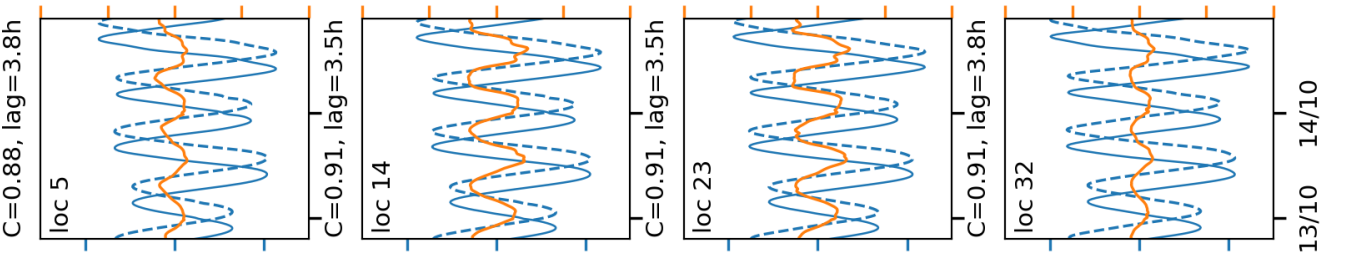

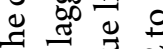

$\exists \stackrel{0}{\Xi}$

击

ఖे

$\exists$ 寻 0

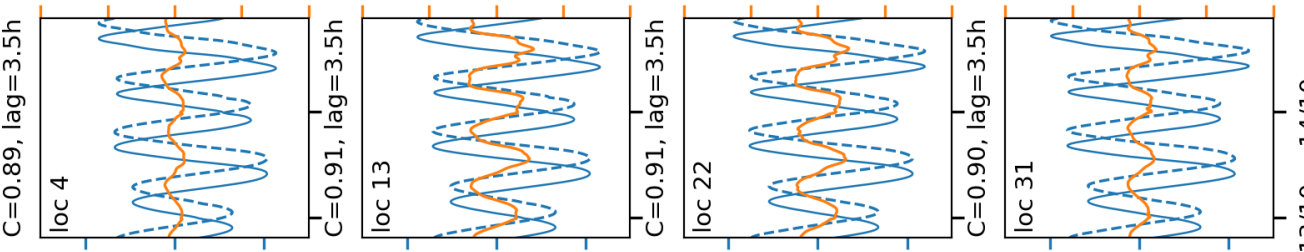

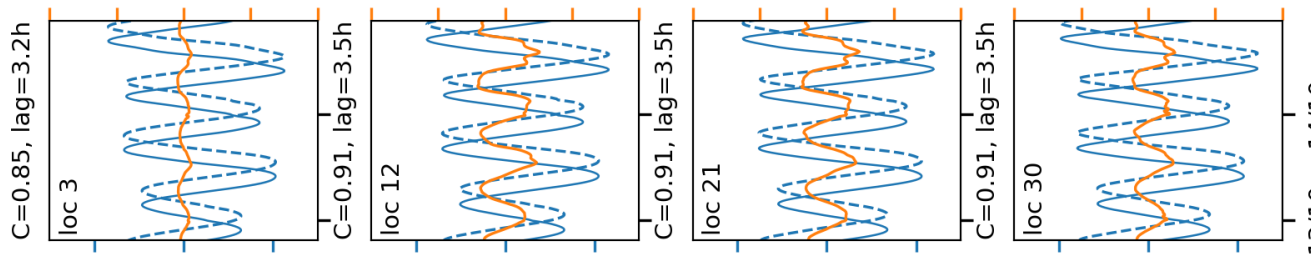

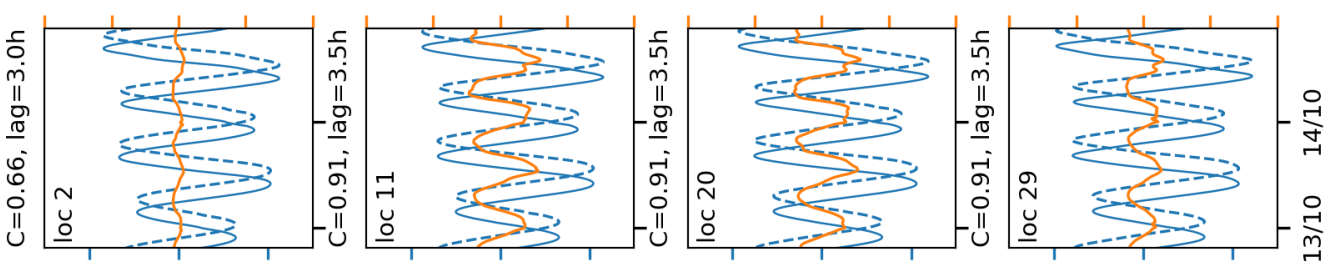

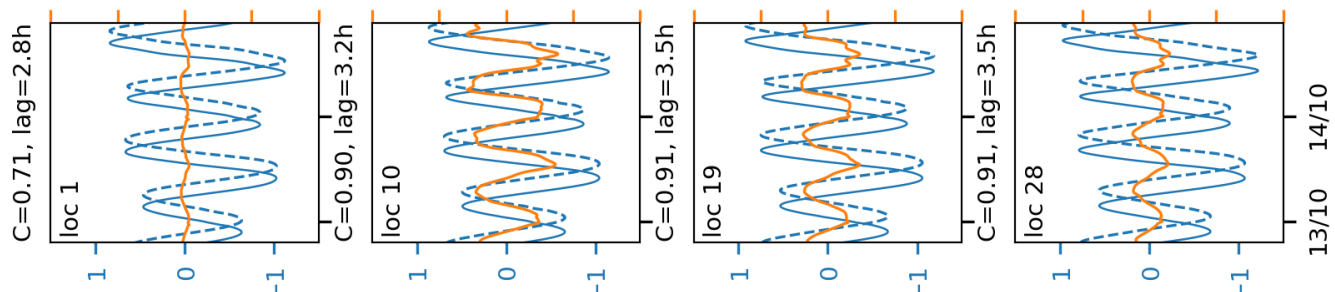

(w) ^әәә

(u) ^әәә

(w) ^әәә

(u) ^әəә

苛泀递

矛过

粷

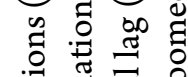

总造造

ष च च्च

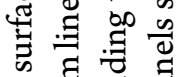

ฐ

它

ष्ठ है च

ㅌ. ‥

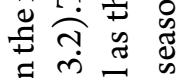

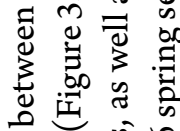

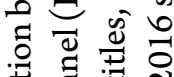

औ

矛苛

赵

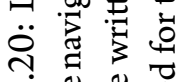

ते छ

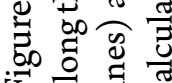



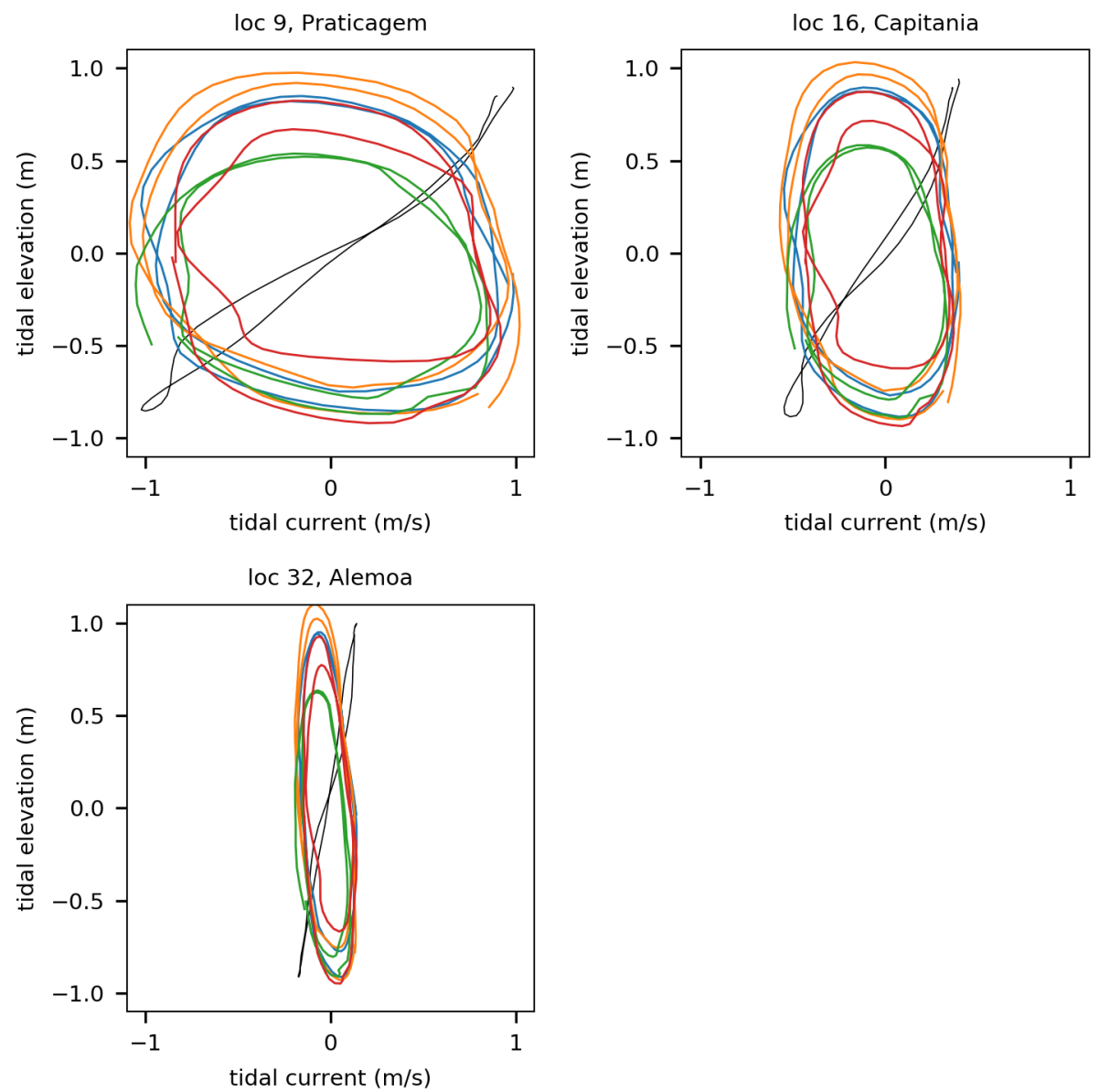

(a)

loc 9, Praticagem

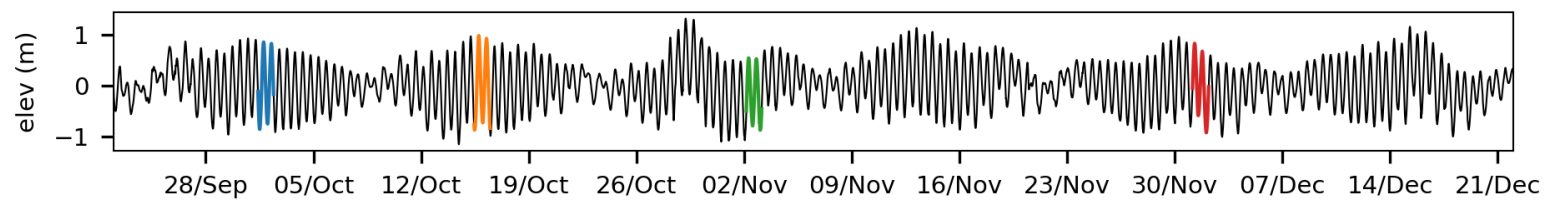

loc 16, Capitania

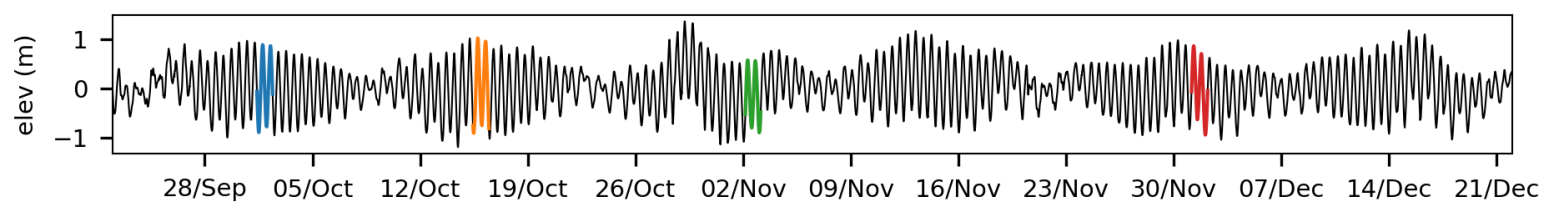

Ioc 32, Alemoa

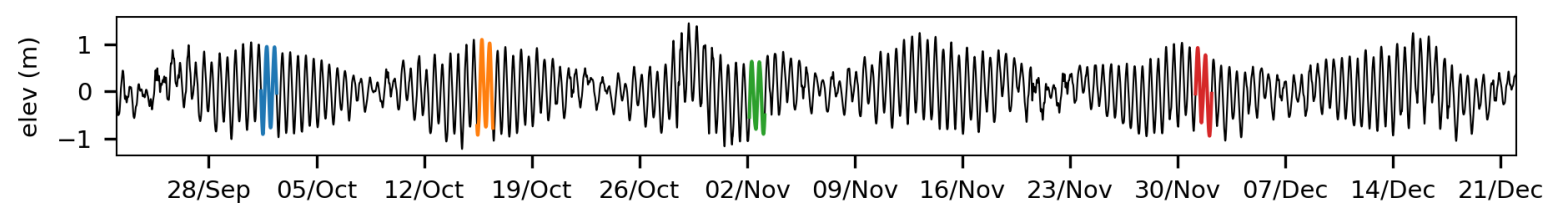

(b)

Figure 3.21: (a) Diagram of tidal elevation against tidal velocity for the modeled results at Praticagem, Capitania and Alemoa. The colors represent four different 25 -h tidal cycles indicated in (b). The black thin lines are for the shifted tidal elevations (dashed lines in Figure 3.20), representing the progressive wave solution. (b) Sea surface elevation time series. The periods plotted in (a) are indicated in colors. 


\subsubsection{Estuary classification}

Results of monthly hydrographic and current data from the ECOSAN used in the estuary classification diagram of Hansen and Rattray (1966) are shown in Figure 3.22 (colored circles). All months fall at type $a$ classification $\left(\delta S / \bar{S}<10^{-1}\right)$ showing that Porto Channel is a weakly stratified estuary. July and August results reveal that the estuary is a type 1 (well-mixed) in winter while October and November fall into type 2 (partially mixed).

Curiously, the circulation parameter for December falls out of the limit of Hansen and Rattray (1966) diagram, with $u_{s} / u_{f}=0.79$. Earlier attempts to calculate $u_{s} / u_{f}$ using the lateral mean longitudinal velocity (average along vessel transect) resulted in 3 of the 5 monthly samples (July, August and December) with $u_{s} / u_{f}<1$. Using the velocity profile closest to the fixed station on the calculations of the circulation parameter brought December value close to 1 and July and August inside the limits of Hansen and Rattray (1966) classification.

A clear seasonality is observed in the diagram of Figure 3.22, with stratification gradually increasing from winter to summer. November and December stratification parameters approach the limit between type $a$ and type $b$ (highly stratified) estuaries. Migration to slightly more stratified values in spring and summer may due to seasonal variations of freshwater inputs, which are greater during the rainy season.

Modeled results from C2 simulation were also plotted in the stratification-circulation diagram with $\times$ colored markers. The simulation was performed for the 2016 spring season at prognostic mode forced by winds, tides, rivers, seasonal temperature and salinity fields and the wind-induced subtidal sea level oscillations. The results show a seasonal agreement with the observed data, with modeled results close to October (blue) and November (pink) positions. In the modeled parameters, a vertical and lateral migration in the diagram towards more stratified salinity profiles and larger circulation parameter values was observed from spring (green markers) to neap tides (light purple markers), following the weakening of the tidal mixing power. The increase in stratification and the decrease in mixing were approximately of $50 \%$. No monthly migration was observed in the modeled classification because the temperature and salinity profiles entering the SSVBES were held constant along the entire spring season. According to the modeled results, Porto Channel can be classified as type $2 a$, weakly stratified and partially mixed estuary, during the spring season.

As shown in Chapter 2, a strong storm tide occurred in the SSVBES in October 29, 2016. The C2 experiment was able to simulate the event and the values of the stratification and circulation parameters were calculated for the period of the storm, from October 28 to October 30. The results are shown in Figure 3.22 by the black $\times$ marker. A migration towards less stratified and more mixed conditions in relation to normal spring tide periods was observed during the event. Strong mixing was caused by the higher total water elevation amplitudes, increasing the mixing power and bringing larger volumes of higher salinity inner shelf waters. The strong winds that caused the storm surge also contributed to increase mixing through the stronger wind stress over the water surface. Nevertheless, the changes in the stratification and circulation parameters generated by the storm tide in relation to the spring cycle 


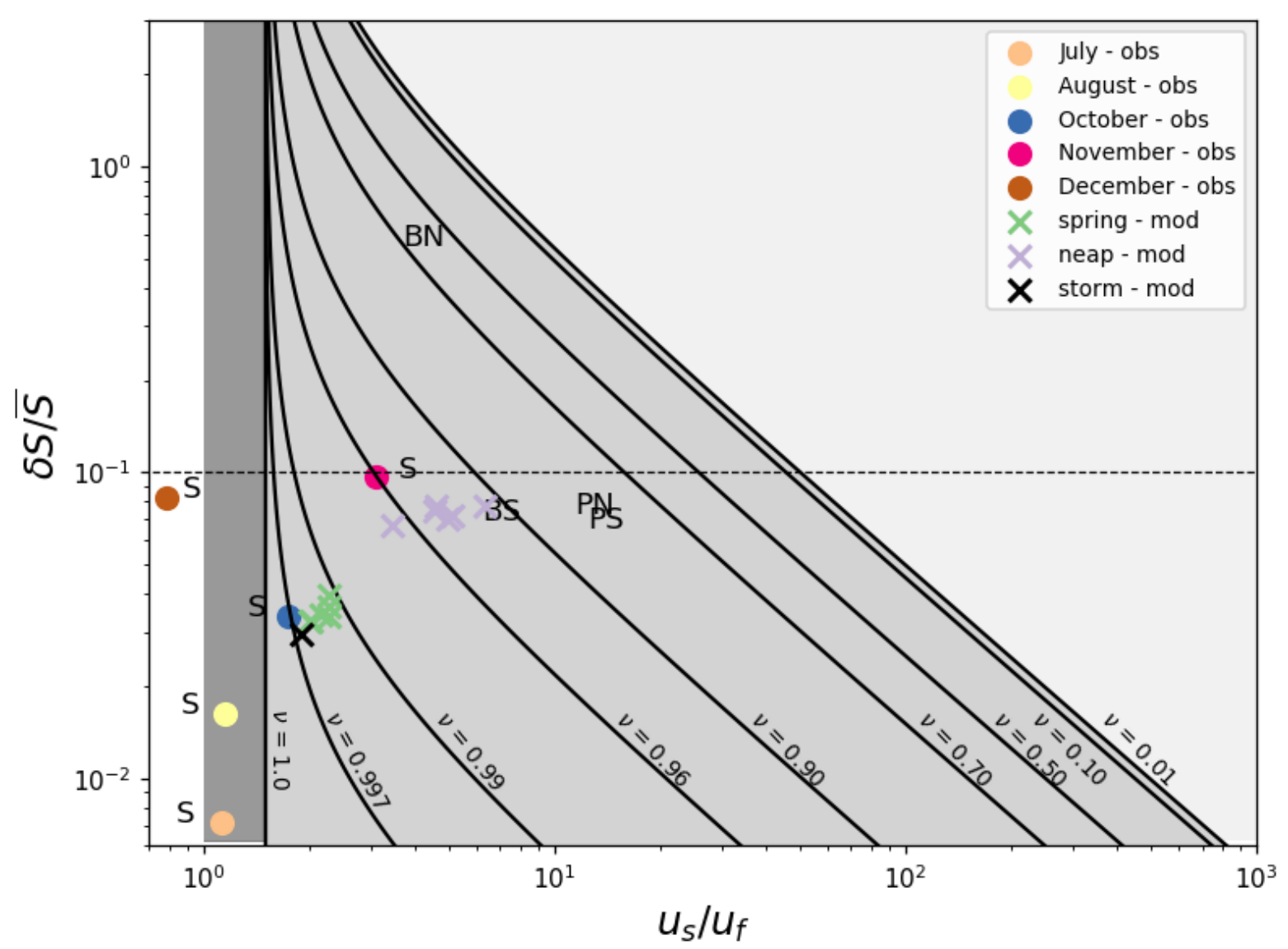

Figure 3.22: Stratification-circulation diagram of Hansen and Rattray (1966) showing solutions for different values of the diffusive fraction of the total upstream salt flux $(\nu)$. The dashed line divides type $a(\delta S / \bar{S}<$ $10^{-1}$ ) from type $b\left(\delta S / \bar{S}>10^{-1}\right)$ estuaries. Colored circles were calculated from $\sim 12 \mathrm{~h}$ measurements of salinity and velocity profiles in Porto Channel in 2005. Neap and spring tidal cycles of each observation are denoted by "N" and "S", respectively. Colored " $X$ " symbolizes modeled results for spring (green) and neap (light purple) tide cycles. The black " $X$ " represents the results during the storm tide of October 29, 2016. Symbols "BN" and "BS" are the values found by Miranda and Castro (1998) in Bertioga Channel and "PN" and "PS" are Miranda et al. (2012) results for Piaçaguera Channel.

were of about $12 \%$, much smaller than the fortnightly modulation induced changes.

For comparison reasons, Bertioga and Piaçaguera classification addressed by Miranda and Castro (1998) and Miranda et al. (2012), respectively, are also plotted in the diagram of Figure 3.22. The values of the stratification and circulation parameters are shown in Table 3.3 together with the observed and modeled values at Porto Channel. The previous works of Miranda et al. (2012) and Miranda and Castro (1998) found that Piaçaguera and Bertioga Channels are type 2 estuaries, with the former alternating between type $a$ and type $b$ from spring to neap tide, respectively. Piaçaguera Channel is type $a$ for both tidal cycles.

The values of the diffusive fraction in Porto Channel are quite close to $1(\nu \rightarrow 1)$ for both observed and modeled results. This shows that the total upstream salt flux is dominated by turbulent diffusion and that the gravitational circulation plays no important role. However, in the modeled results, a fortnightly modulation was observed with the spring $\nu$ values larger than the neap values by approximately 0.05 
units. Although small, this difference quantifies that the salt transport through the turbulent diffusion (advective process of the classical estuarine circulation) decreases (increases) 5\% from spring to neap tides. Bertioga Channel is also dominated by tidal diffusion during spring tides. During neap tides, diffusion and advection contribute with $70 \%$ and $30 \%$ to the salt transport, respectively (Miranda and Castro, 1998). In Piaçaguera Channel both process are important and no fortnightly modulation is observed (Miranda et al., 2012).

Stratification parameter values of Table 3.3 show that Bertioga is over 5 times more stratified during neap tides in relation to Piaçaguera and Porto (observed and modeled) probably because the fixed station was placed close to the Itapanhaú river discharge. Circulation parameters indicate that Piaçaguera is 2-10 (4-6) times less mixed than Porto and 3 (2) times less mixed than Bertioga during neap (spring) tides. Piaçaguera has relatively small mixing because the channel is located in the northern limit of the SSVBES, far from the estuary mouth where tides dominate. The smallest circulation parameters were found for the modeled results at Porto Channel, reflecting the powerful tidal mixing at the channel entrance.

Table 3.3: Values of the circulation and stratification parameters for Piaçaguera Channel(Miranda et al., 2012), Bertioga Channel(Miranda and Castro, 1998) and Porto Channel, for modeled (mod) and observed (obs). Spring and neap values are shown for Piaçaguera, Bertioga and Porto (mod). In Porto (obs), parameters are shown for July and November, when minimum and maximum values occur, respectively.

\begin{tabular}{lcccc}
\hline & \multicolumn{2}{c}{ stratification } & \multicolumn{2}{c}{ circulation } \\
\hline Piaçaguera & spring & neap & spring & neap \\
Bertioga & 0.066 & 0.073 & 12.49 & 11.42 \\
Porto (mod) & 0.07 & 0.55 & 6.2 & 3.7 \\
\hline & 0.034 & 0.073 & 2.14 & 4.83 \\
\hline Porto (obs) & $\min (\mathrm{Jul})$ & $\max (\mathrm{Nov})$ & $\min (\mathrm{Nov})$ & $\max (\mathrm{Jul})$ \\
\hline
\end{tabular}

\subsection{Conclusions}

In this study, the Porto Channel in the SSVBES is described as a microtidal, synchronous and tidedominated estuary with standing tidal wave characteristics. The tides are mixed, mainly semidiurnal. The tidal excursion varied from $5.0 \mathrm{~km}$ during neap tides to $17.8 \mathrm{~km}$ in spring cycles. The average values of the $R i_{e}$ during neap $\left(1.8 \times 10^{-1}\right)$ and spring $\left(5.9 \times 10^{-2}\right)$ cycles show that the Porto Channel is a weakly stratified estuary dominated by tides, corroborating the results of the flux ratio.

The tidal propagation along the navigation channel revealed that the tidal velocity amplitudes are strongly reduced in the up-estuary direction. The weakening of the currents was probably due to a complex combination of convergence and friction, preventing significant tidal elevation increases. The navigation channel was, therefore, classified as a synchronous estuary. The temporal lag between tidal eleva- 
tion and tidal current peaks was $3.4 \mathrm{~h}$, in accordance with a $90^{\circ}$ phase difference in a mainly semidiurnal estuary. The average phase difference between the variables is consistent with a dominant standing tidal wave. Both modeled and observed data corroborate these conclusions.

Results of monthly observations of salinity and velocity vertical profiles over 1 tidal cycle used in the Hansen and Rattray (1966) stratification-circulation diagram revealed that Porto Channel is a weakly stratified estuary (type $a$ ), being well-mixed (type 1) in winter and partially-mixed (type 2) in spring. The up-estuary salt flux is dominated by tidal induced turbulent diffusion, responsible for at least $96 \%$ of the salt transport. Seasonal variation of circulation parameter is consonant with an increase in the stratification parameter. This winter to summer vertical migration on Hansen and Rattray (1966) diagram appears to be a result of a seasonal change in the freshwater inputs. Nevertheless, final assumptions regarding seasonal influence on estuary classification can only be made with observations over several years.

The circulation parameter revealed to be very sensitive to the velocity data treatment. River discharge information would contribute to a more precise measurement of $u_{f}$ and, consequently, a better estimative of the circulation parameter. Furthermore, we assume that a fixed current station in place of vessel-mounted ADCP transects would produce more accurate results. Finally, longer observations of both salinity and velocity profiles over more than 1 tidal cycle would improve estuary classification.

The estuary classification addressed with the modeled C2 results for the 2016 spring season are in accordance with the observations collected in November and December, 2005. In the modeled results, a fortnightly modulation associated to the increase in the tidal mixing power from neap to spring tides was observed. The estuary was approximately 2 times more stratified and less mixed in neap than in spring periods. Despite this difference, Porto Channel was classified as type $2 a$ in both tide cycles. This result is in accordance with the vertical stratification quantified by the $R i_{e}$ that did not reveal differences between tide and river dominance between spring and neap tides. The tidal diffusion was responsible for $94 \%$ (neap) and 99\% (spring) of the salt transport in the up-estuary direction.

The present results complement Miranda and Castro (1998) and Miranda et al. (2012) studies once each work evaluated estuary classification in a different channel of the SSVBES. Tidal mixing influence increases in accordance with the proximity to the estuary mouth, being higher in Porto Channel and smaller in Piaçaguera Channel.

The estuary classification evaluated during the period of a storm tide, from October 28 to October 30, revealed a modest migration to slightly less stratified and more mixed conditions in relation to normal spring tides. The fortnightly tidal modulation was able to produce larger differences in the circulation and stratification parameters than the storm surge increased mixing effect. However, classification changes during storm tide conditions were not fully addressed in this study, once river discharges that should increase significantly during these events due to the increase in precipitation, was held constant throughout the simulation. Therefore, the full impact of storm tides on estuarine dynamics should be addressed by future works. 


\section{Chapter 4}

\section{Storm tides in the Santos-São Vicente-Bertioga Estuarine System for present conditions and climate change projections}

\subsection{Introduction}

Storm tides are responsible for some of the biggest impacts on coastal infrastructure and society due to coastal flooding. In Brazil, 12 million people (6.6\% of the population) lived in low-elevation coastal zones (LECZ) in 2000, ranking the country among the top 25 coastal countries (place 15) with highest population living in the LECZ (Neumann et al., 2015). Specifically, the Metropolitan Region of Baixada Santista, located at the central part of the São Paulo state coastal zone, has a population estimated for 2018 of almost 1.8 millions residents (Seade, 2018). Baixada Santista is ranked at place 89 among the 136 port cities (or agglomerations) in the world with populations exceeding 1 million that are exposed to 1 in 100 year flood event (Nicholls et al., 2008).

The Intergovernmental Panel on Climate Change (IPCC) in its Fifth Assessment Report (AR5) evaluated the possible future scenarios under four Representative Concentration Pathways (RCPs): RCP2.6, RCP4.5, RCP6.0 and RCP8.5 (IPCC, 2013). The different RCPs take into account gradually increasing radiative forcing derived from distinct greenhouse gases and aerosols concentrations in the atmosphere that result in warming. One relevant impact of global climate change on storm tides is related to changes in the atmosphere circulation patterns that affect the storm surge variability.

In the AR5, the IPCC Working Group I has projected a poleward shift of the annual mean midlatitude jet in the Southern Hemisphere by 2100 under both RCP4.5 and RCP8.5. (Collins et al., 2013). In agreement with this projection, a poleward migration of the winter extratropical storm tracks is also expected for both scenarios, reaching several degrees of latitude in RCP8.5. As a consequence, a decrease in the number of cyclones over the Southwest Atlantic is expected (Reboita et al., 2018b). Using both global and regional circulation models for RCP8.5, Reboita et al. (2018b) computed future de- 
creases in the cyclone annual frequencies of $10.4 \%$ and $11.4 \%$, respectively, for the $2070-2098$ term in relation to present conditions (1979-2005). In this situation, a negative influence on storm tide frequencies in São Paulo coastal zone is presumed.

Another important consequence of climate change to storm tides is the sea level rise (SLR), which can increase the vulnerability of LECZ to relatively weak storms. The IPCC projects increases in the global mean sea level from $0.44 \mathrm{~m}$ (RCP2.6) to $0.74 \mathrm{~m}$ (RCP8.5) at 2100 relative to the 1986-2005 period. The largest contribution for the expected SLR is the thermal expansion (30-55\%) followed by ice melt (15-35\%) (Church et al., 2013). In Brazil, Toste et al. (2018) used one of the global circulation models that comprises the multi-model IPCC projections to produce a downscaling experiment for the Brazilian coast under the RCP4.5 scenario. The authors found that the average coastal sea level may increase by $78 \mathrm{~cm}$ in relation to 1995. The maximum values (larger than $80 \mathrm{~cm}$ ) were found in São Paulo state coast.

The region of focus of this study is the Porto Channel, situated within the Santos-São VicenteBertioga Estuarine System (SSVBES) (Figure 4.1), located on the central part of the South Brazil Bight (SBB) (Castro and Miranda, 1998). Tidal characteristics and mean sea level variabilities related to cold front passages were studied by Harari and Camargo (1995) during 46 years of observed data at Porto Channel. Other researches based on historical records in the SSVBES evaluated future conditions of wetland flooding and waves. Using 30 years of tidal gauge measurements in Porto Channel, Alfredini et al. (2008) estimated a total sea level rise of $1.5 \mathrm{~m}$ by 2100 , what may flood $50 \%$ of the mangroves areas and most of the beaches and dry areas. Pezzoli et al. (2013) studied changes in the wave climate and the impacts on maritime navigation. Alfredini et al. (2014) found that significant wave height and wave period has increased in Santos from 1957 to 2002. Assuming a linear increase, the significant wave height may increase by $0.45 \mathrm{~m}$ untill 2100. A more interdisciplinary work of Marengo et al. (2017) proposed adaptation strategies to minimize the structural damage and economical losses from future sea level rise and severe storm projections. Other works in the region described the recent characteristics of storm surges. Campos et al. (2010) analyzed the seasonal variabilities of positive and negative storm surges using 40 years of observed sea surface elevation data. According to the authors, the SSVBES is subjected to 12 positive storm surges per year with greatest frequency in autumn and winter.

In this study, the total water elevation in relation to the sea floor $(h)$ is defined as:

$$
h=h_{m}+\eta_{s}+\eta_{t}+\eta_{r}+\eta_{w}
$$

where $h_{m}$ is the mean sea level and $\eta_{s}, \eta_{t}, \eta_{r}$ and $\eta_{w}$ are the anomaly components caused, respectively, by storm surges, tides, rivers and the waves with different frequencies and wavelengths as the surface gravity waves. Previous works have studied the impacts of climate change over $h_{m}$ and $\eta_{w}$. Nevertheless, potential changes in storm tide occurrence, specifically over $h_{m}$ (SLR) and $\eta_{s}$ (related to changes in the atmospheric circulation), under future IPCC climate projections have not been investigated yet. 
The goal of this chapter is to quantify possible changes in the number and the intensity of storm tides under IPCC projections of sea level rise (SLR), and of modified atmospheric circulation. To address these questions, the winter season of 2016 is used as the control against which the comparisons are made. The specific goals are to:

1. Calculate the number and the maximum elevations of the storm tides that occurred in recent years using observed data in Porto Channel;

2. Determine a threshold over which a sea level rise event is classified as a storm tide using observed data in Porto Channel;

3. Evaluate model sensitivity to capture the same observed storm tides (in number of events and maximum elevations) in the winter of 2016;

4. Quantify possible changes in either the number or the intensity of storm tides under projected SLR and atmospheric circulation scenarios for 2100 in relation to 2015-2018 winter conditions;

\subsection{Data and methods}

\subsubsection{Observed sea level}

The observed sea surface elevation data used for this analysis was collected at Capitania station located in the Porto Channel (Figure 4.1). This data belongs to a net of real time observation stations at the SSVBES maintained by the Santos Pilots (orange points in Figure 4.1). Such data set is remotely collected at the Coastal Hydrodynamics Laboratory (LHiCo) through a memorandum of understanding established between LHiCo and Santos Pilots. For this study, a time series of 4 years, from December 22,2014 to December 22, 2018 was used to analyze the storm tide occurrence in the estuarine region.

\subsubsection{Long-term simulations}

The numerical simulations were performed using the POM-rain based SOFS framework described in Chapter 2. The experiments conducted to evaluate possible climate change impacts over storm tides in the SSVBES were split into four groups: control (E1), sea level rise (E2) and atmospheric changes with and without SLR under RCP8.5 (E3) and RCP4.5 (E4) scenarios (Table 4.1). The inclusion of the non-SLR simulations in the E3 and E4 groups were conducted to compare the importance of the atmospheric changes and the SLR to future storm tides separately.

For the E1 experiment, a 94-day run comprehending the 2016 austral winter season was obtained from the operational products of SOFS. For E2, the same E1 experiment was performed over a SLR scenario of $0.6 \mathrm{~m}$, held constant through the duration of the run. In the E3 group, eight experiments were conducted, two for each winter season from 2096 to 2099: E3-96, E3-96-SLR, E3-97, E3-97SLR, E3-98, E3-98-SLR, E3-99 and E3-99-SLR. Similarly, the E4 group comprised eight simulations: 


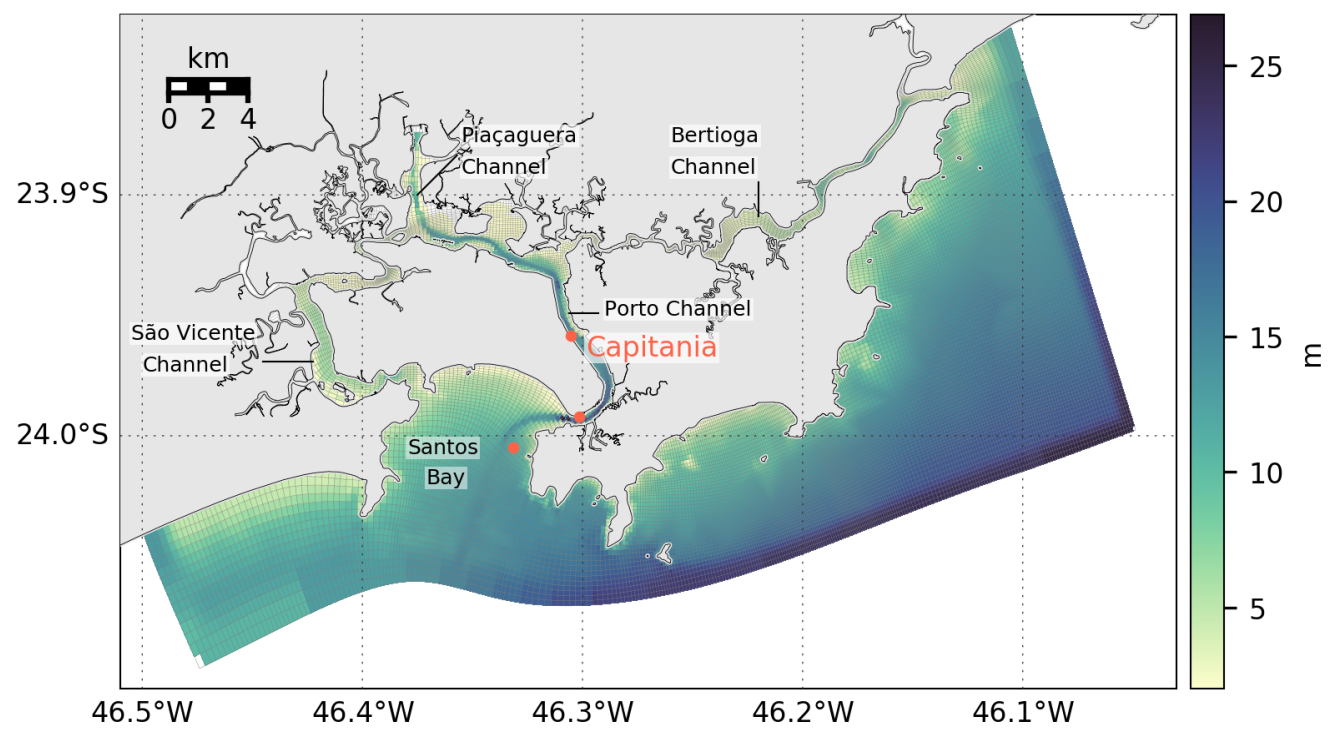

Figure 4.1: Map of the SSVBES region with the names of the main channel. The colors represent the bathymetry of the SSVBES model grid (m). The orange circles mark the positions of the sea level observation stations.

E4-96, E4-96-SLR, E4-97, E4-97-SLR, E4-98, E4-98-SLR, E4-99 and E4-99-SLR. The suffix “-SLR" means that a SLR value was also included in the simulation. The winter season was chosen for this investigation because of the stronger southwestern winds over the SBB in winter that causes the highest sea level anomalies in Santos (Campos et al., 2010). Also, the historical occurrence cyclogenesis activity is higher during the cold months (Gan and Rao, 1991) and the greatest number of cold fronts are found in both winter and spring (Foss et al., 2017).

As described in Chapter 2, the SOFS framework works with two one-way nested numerical grids, a coarse resolution grid for the SBB and a higher resolution grid for the SSVBES. The forcing fields used in each grid are detailed in Table 4.1 for the three groups of experiments. The meteorological information for E1 and E2 experiments came from the Brazilian developments on the Regional Atmospheric Modeling System (BRAMS), a 5-km and 6-h resolution wind and atmospheric pressure fields provided by the Center for Weather Forecasts and Climate Studies (Portuguese acronym CPTEC) ${ }^{1}$. SBB boundary information, sea surface elevation and 3D fields of currents, temperature and salinity (TS) came from the daily Global Sea Physical Analysis and Forecasting product released by the Copernicus Marine Environment Monitoring Service (CMEMS) ${ }^{2}$. For E1 and E2 experiments, the CMEMS boundary conditions were updated every $24 \mathrm{~h}$, as they derive from the operational SOFS runs. For E3 group, constant boundary conditions of elevation, currents and TS were assumed through the duration of each run. The constant boundary conditions were calculated from the same CMEMS product for elevation, currents and TS averaged over the 2016 austral winter period, also used in the spin-up runs for the SOFS as detailed in Chapter 2 (section 2.2.3). For E1, E2 and E3, a winter spin-up climatology (Chapter 2, section 2.2.3) was used as the SBB diagnostic TS fields, that is also imposed into the SSVBES grid through the

\footnotetext{
${ }^{1} \mathrm{http}: / /$ ftp.cptec.inpe.br/modelos/tempo/BRAMS/

${ }^{2}$ http://marine.copernicus.eu/services-portfolio/access-to-products/
} 
Table 4.1: Experiments conducted to evaluate possible climate change impacts over storm tides in the SSVBES. SLR means that a sea level rise constant value was added to the simulation. A check mark under RCP scenarios means that the experiments were forced with projected fields of atmospheric circulation changes. HadGEM2ES is the Hadley Centre Global Environment Model 2 of the UK Met Office Hadley Centre

\begin{tabular}{|c|c|c|c|c|c|c|}
\hline \multirow[b]{2}{*}{ experiment } & \multirow[b]{2}{*}{ time range } & \multicolumn{4}{|c|}{ HadGEM2-ES } & \multirow{2}{*}{$\begin{array}{c}\text { CMEMS, TS } \\
\text { tides, rivers }\end{array}$} \\
\hline & & BRAMS & RCP8.5 & $\mathrm{RCP} 4.5$ & $\operatorname{SLR}(\mathrm{m})$ & \\
\hline E1 (control) & Jun $20-$ Sep 22, 2016 & $\checkmark$ & & & & $\checkmark$ \\
\hline E2 (SLR) & Jun $20-\operatorname{Sep} 22,2016$ & $\checkmark$ & & & 0.60 & $\checkmark$ \\
\hline E3-96 & Jun $20-\operatorname{Sep} 22,2096$ & & $\checkmark$ & & & $\checkmark$ \\
\hline E3-97 & Jun $20-\operatorname{Sep} 22,2097$ & & $\checkmark$ & & & $\checkmark$ \\
\hline E3-98 & Jun $20-\operatorname{Sep} 22,2098$ & & $\checkmark$ & & & $\checkmark$ \\
\hline E3-99 & Jun 20 - Sep 22, 2099 & & $\checkmark$ & & & $\checkmark$ \\
\hline E3-96-SLR & Jun $20-$ Sep 22, 2096 & & $\checkmark$ & & 0.63 & $\checkmark$ \\
\hline E3-97-SLR & Jun $20-\operatorname{Sep} 22,2097$ & & $\checkmark$ & & 0.63 & $\checkmark$ \\
\hline E3-98-SLR & Jun $20-\operatorname{Sep} 22,2098$ & & $\checkmark$ & & 0.63 & $\checkmark$ \\
\hline E3-99-SLR & Jun 20 - Sep 22, 2099 & & $\checkmark$ & & 0.63 & $\checkmark$ \\
\hline E4-96 & Jun $20-\operatorname{Sep} 22,2096$ & & & $\checkmark$ & & $\checkmark$ \\
\hline E4-97 & Jun 20 - Sep 22, 2097 & & & $\checkmark$ & & $\checkmark$ \\
\hline E4-98 & Jun $20-$ Sep 22, 2098 & & & $\checkmark$ & & $\checkmark$ \\
\hline E4-99 & Jun 20 - Sep 22, 2099 & & & $\checkmark$ & & $\checkmark$ \\
\hline$\overline{\text { E4-96-SLR }}$ & Jun $20-$ Sep 22, 2096 & & & $\checkmark$ & 0.59 & $\checkmark$ \\
\hline E4-97-SLR & Jun 20 - Sep 22, 2097 & & & $\checkmark$ & 0.59 & $\checkmark$ \\
\hline$\overline{\text { E4-98-SLR }}$ & Jun $20-$ Sep 22, 2098 & & & $\checkmark$ & 0.59 & $\checkmark$ \\
\hline E4-99-SLR & Jun 20 - Sep 22, 2099 & & & $\checkmark$ & 0.59 & $\checkmark$ \\
\hline
\end{tabular}

nesting procedure. In the SSVBES experiments in E1, E2 and E3, the tidal forcing and the thirteen river runoff outflows were equal to the ones established for the SOFS (described in Chapter 2, sections 2.2.4 and 2.2.5).

The climate change projections of SLR and atmospheric circulation fields used in the E2, E3 and E4 groups of experiments, came from the Coupled Model Intercomparison Project Phase 5 (CMIP5) (Taylor et al., 2012) coordinated by the World Climate Research Program (WCRP). This a multi-model dataset with results analyzed by the IPCC to produce the AR5 report (IPCC, 2013). Within the CMIP5 dataset, the present study used one Earth System (ES) model, the Hadley Centre Global Environment Model 2 (HadGEM2-ES) of the UK Met Office Hadley Centre. The ES configuration within the HadGEM2 family of models includes coupled atmosphere, ocean and sea ice components and the earth-system feedbacks (carbon cycle processes, tropospheric chemistry, aerosols, dynamic vegetation and ocean biogeochemistry) (Martin et al., 2011). The HadGEM2-ES was chosen due to the reasonable representation of the present meteorological features over the South Atlantic Ocean, compared to regional modeling (Reboita et al., 2018b). This model was also used by Toste et al. (2018) to force an oceanic model for the Brazilian coastal and oceanic regions. The authors found a good representation of the sea surface temperature, the sea surface height and the Brazil Current features for the present condition simulations. 
The HadGEM2-ES products were downloaded from the Earth System Grid Federation (ESGF) database. Two RCP scenarios were used, the RCP4.5 and the RCP8.5, with one ensemble member each (rlilp1). The different RCPs take into account distinct contributions of future greenhouse gas, aerosol and land use scenarios for global warming. Such scenarios result in global radiative forcing in 2100 relative to pre-industrial conditions of 2.6 (RCP2.6), 4.5 (RCP4.5), 6.0 (RCP6.0) and 8.5 (RCP8.5) $\mathrm{W} / \mathrm{m}^{2}$, with CO2 equivalent greenhouse gas emissions of $\sim 490 \mathrm{ppm}, \sim 650 \mathrm{ppm}, \sim 850 \mathrm{ppm}$ and $\sim 1370$ ppm, respectively (van Vuuren et al., 2011). The HadGEM2-ES variables used as the meteorological forcings in the E3 and E4 experiments were the 6-h sea level pressure and eastward and northward wind components with spatial resolutions of $1.875^{\circ} \times 1.25^{\circ}$ (longitude $\times$ latitude). HadGEM2ES products containing both the sea level pressure and the $10-\mathrm{m}$ winds were not available at the ESGF database with temporal resolutions lower than daily, insufficient for the study of storm surges. Following the procedure adopted by Reboita et al. (2018a), the wind field at $850 \mathrm{hPa}$ was extrapolated to the 10-m wind velocities with the following logarithmic method (Manwell et al., 2010):

$$
U(Z)=U\left(Z_{r}\right) \frac{\ln \left(\frac{Z}{Z_{r}}\right)}{\ln \left(\frac{Z_{r}}{Z_{0}}\right)},
$$

where $U(Z)$ is the wind velocity at the desired level $Z(10 \mathrm{~m}), U\left(Z_{r}\right)$ is the wind velocity at the original level $Z_{r}(\sim 1500 \mathrm{~m})$ and $Z_{0}$ is the ocean surface roughness length, assumed to be equal to $4 \times 10^{-4}$ (Elguindi et al., 2014). Finally, the horizontal fields of sea level pressure and 10-m wind were bilinearly interpolated from the global regular grid to the SBB and SSVBES grids.

For the E2, E3 and E4 simulations, the SLR value was estimated using the HadGEM2-ES monthly sea surface height projected from 2005 to 2100 under RCP8.5 and RCP4.5 scenarios. Figure 4.2 shows the sea level time series and the sea level rise trends for a grid point located at the SBB in front of Santos region $\left(24.1^{\circ} \mathrm{S} 46^{\circ} \mathrm{W}\right)$. According to RCP8.5 scenario, a linear sea level rise trend of $7.6 \mathrm{~mm} / \mathrm{yr}$ is expected. The difference between the sea surface height above the geoid from August 2016 to December 2099 was equal to $0.63 \mathrm{~m}$. For RCP4.5, the difference between 2099 and 2016 sea level was of $0.59 \mathrm{~m}$, with a sea level rise trend of $7.1 \mathrm{~mm} / \mathrm{yr}$. From this analysis, a SLR value of $0.6 \mathrm{~m}$ was imposed in the E2 experiment at the SBB model, considered to represent the approximated sea level height in the winter of 2099 relative the 2016 condition. Differently from the E2, where the SLR was added as a forcing to the hydrodynamic simulation, the four experiments with SLR in the E3 group (E3-96-SLR, E3-97-SLR, E3-98-SLR and E3-99-SLR) were accomplished by adding the RCP8.5 SLR of $0.63 \mathrm{~m}$ to the results of each respective run (E3-96, E3-97, E3-98 and E3-99). The same was done in the E4 group, but with the RCP4.5 SLR of $0.59 \mathrm{~m}$. The reason for this different approach will be discussed in section 4.3.2.

Although the SLR in Santos shown in Figure 4.2 reveals a linear trend, the global mean SLR under RCP8.5 in Figure 4.3 is exponential. As mentioned by Church et al. (2013), the regional response of the sea level changes can differ from the global average due to regional ocean dynamics, the shape of the ocean floor and water mass inputs. Furthermore, the range of sea level changes differs because Figure 


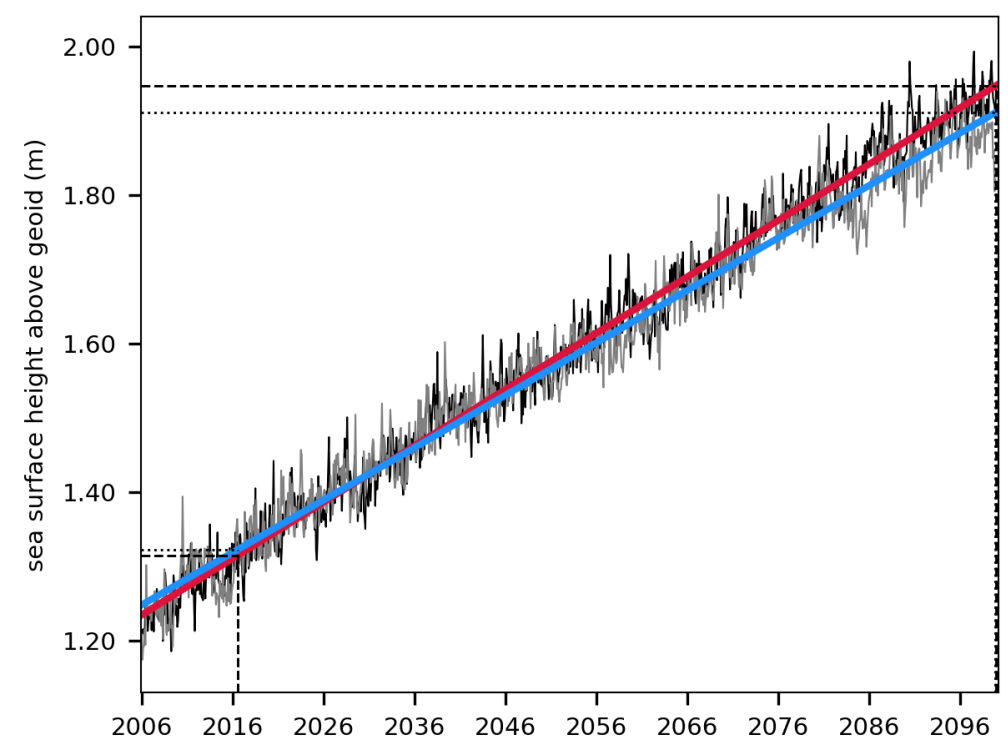

Figure 4.2: Sea level rise projections under RCP8.5 (black line) and RCP4.5 (gray line) scenarios derived from the HadGEM2-ES output for rlilp1 in a coastal point in front of Santos - SP - Brazil $\left(24.1^{\circ} \mathrm{S} 46^{\circ} \mathrm{W}\right)$. The angular coefficient of the linear trends are equal to $7.6 \mathrm{~mm} / \mathrm{yr}$ for RCP8.5 (red line) and $7.1 \mathrm{~mm} /$ year for RCP4.5 (blue line). The upper (lower) dashed line depicts the December 2099 (August 2016) sea level height above the geoid from RCP8.5, equal to $1.95 \mathrm{~m}$ (1.31 m), relative to 1860-2005. Similarly, the upper and lower dotted lines delineate the future $(1.91 \mathrm{~m})$ and actual $(1.32 \mathrm{~m})$ sea levels from RCP4.5, respectively.

4.2 accounts for all the ES model constituents, while Figure 4.3 is the steric SLR component only (dominated by the thermosteric contribution). The curves for both scenarios in Figure 4.3 are very similar to the global mean SLR resulting from thermal expansion reported by Church et al. (2013).

According to the IPCC AR5, chapter 13 (Church et al., 2013), the median and the likely ranges of the global mean sea level (GMSL) expected for 2100 relative to 1986-2005 under RCP8.5 is 0.74 [0.52-0.98] m. To insert the approximated SLR of 0.6 relative to 2016 in the São Paulo State coastal region in a global perspective, one should first reference the IPCC GMSL to the year 2016. Considering the rate of rise of $3.7 \mathrm{~mm} / \mathrm{yr}$ (Church et al., 2013) from 2005 to 2016, the mean sea level would be equal to $0.04 \mathrm{~m}$ in 2016 relative to $1986-2005$. Then, the IPCC inferred GMSL in 2100 relative to 2016 for the RCP 8.5 would be approximately equal to 0.70 [0.48-0.94] m. Similarly for the RCP6.0 scenario, the relative increase of the GMSL would be $0.51[0.34-0.69] \mathrm{m}$. Therefore, the estimated $0.6 \mathrm{~m}$ of SLR in São Paulo State continental shelf falls in both RCP6.0 and RCP8.5 expected GMSL, considering the likely ranges. Also, the sea level rise trend of $7.6 \mathrm{~mm} / \mathrm{yr}$ calculated in Figure 4.2 is in accordance with the projected rate of rise in 2081-2100 of both RCP6.0 and RCP8.5 (Church et al., 2013). The rates of rise of $7.1 \mathrm{~mm} / \mathrm{yr}(\mathrm{RCP} 4.5)$ and $7.6 \mathrm{~mm} / \mathrm{yr}$ (RCP8.5) obtained directly from the HadGEM2-ES results is comparable to the rate of $7.3 \mathrm{~mm} / \mathrm{yr}$ found by Toste et al. (2018) through the downscaling of the same model in the Brazilian coast. 


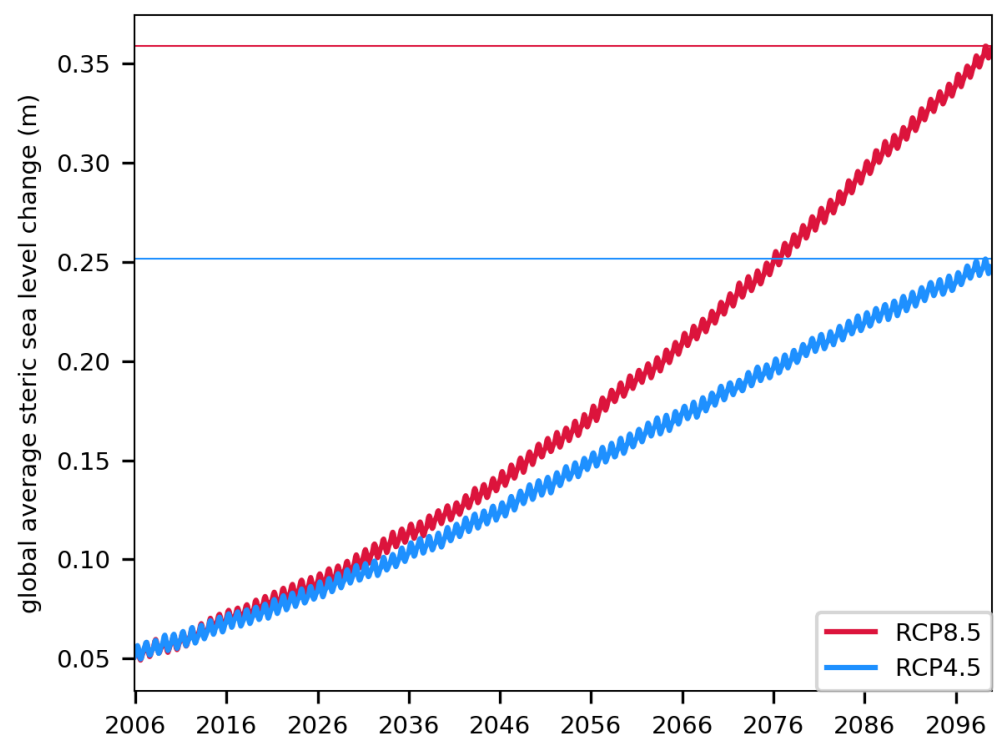

Figure 4.3: Global average steric sea level change under RCP8.5 (thick red line) and RCP4.5 (thick blue line) scenarios derived from the HadGEM2-ES output for rlilp1. The thin red (blue) line depicts the December 2099 global average steric sea level for RCP8.5 (RCP4.5), equal to $0.36 \mathrm{~m}(0.25 \mathrm{~m})$.

\subsubsection{Detection of storm tide events}

Storm tides were defined as the constructive combination between a storm surge and the tidal oscillation, in accordance with the terminology adopted by NOAA (National Oceanic and Atmospheric Administration, USA). The detection of these events followed the methodology detailed in Aguiar (2018), that briefly consists of: (i) defining a threshold above which storm surges are possibly to occur, (ii) detecting the significant surges as the subtidal sea level rise events that exceeded the threshold, and (iii) identifying the storm tides as the total water elevation events whose associated storm surges coincided with a high spring tide. In this study, a surge (or subtidal elevation) is referred to as storm surge only when a storm tide is detected. Also, the term total water elevation is also used in reference to a storm tide level.

To perform the detection method, missing data in the time series were filled with linear interpolation whenever the missing period was smaller to or equal to $6 \mathrm{~h}$. The duration of the gaps in the elevation data varied from 15 minutes to 8.8 days. Gaps longer than 6 h, that represented only $1.6 \%$ of the total time series, remained empty. Next, the obtained 4-year time series was filtered with a $40 \mathrm{~h}$ low-pass second order Lanczos filter (Walters and Heston, 1982) to remove the tidal signal and to isolate the subtidal component (or surge) that was used in steps (i) and (ii) to find the significant surges.

In step (i), the threshold was defined using the observed subtidal elevation time series. For instance, a threshold of two standard deviations was used by Zhang et al. (2014) to detect extreme sea level events in the Great Lakes operational products of the NOAA National Ocean Service. Campos et al. (2010) also used the two standard deviations limit to identify storm surges in Santos. However, such threshold should successfully detect the same storm tides in the E1 control experiment. In the present study, a 
value equal to 1.9 standard deviations of the observed subtidal time series was defined as the threshold. A value of 1.9 standard deviations had to be chosen for the success of the storm tide detection method on both observed and E1 modeled elevation time series. This same threshold was used to evaluate the number and the intensity of the storm tides in the long-term sea level projections of E3 and E4 groups of experiments.

In step (iii), each spring-neap cycle was delimitated in the time series according the tidal amplitude. A fortnightly modulation was built based on the tidal heights, as shown in Figure 4.4 (black line). The crests (troughs) in the fortnightly oscillations were assumed to be the peaks of the spring (neap) tides. An average period of $14.8 \pm 1.1$ days between consecutive spring peaks (black markers) was found for a 4-year time series. Then, the duration of each spring period (red lines) was determined as half of the cycle duration, centered on each spring peak.

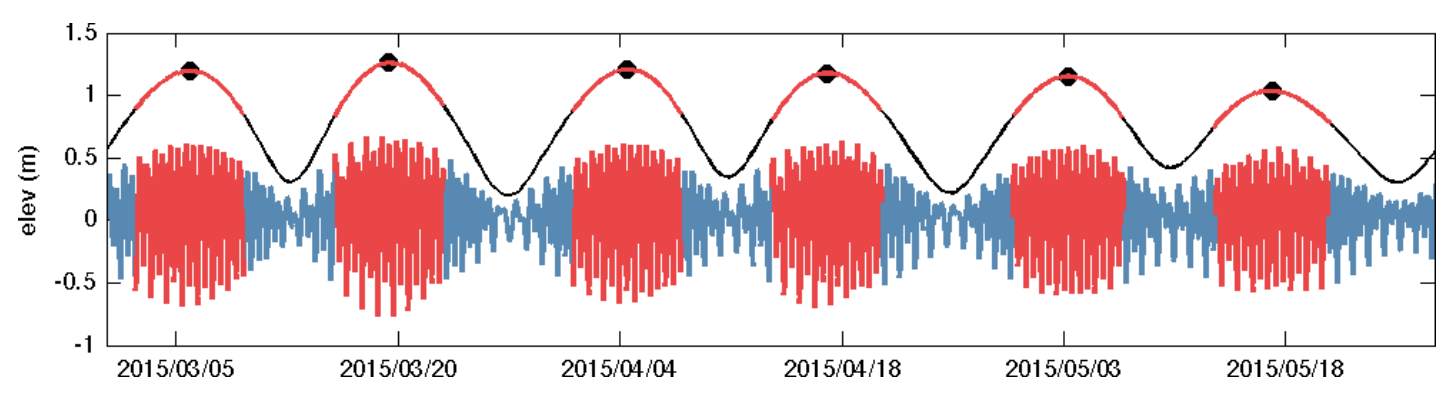

Figure 4.4: Determination of spring-neap cycles. The black line shows the fortnightly oscillation and the black circles mark the peak of each spring tide. The red line highlights the duration of each spring period. The blue and red lines depict the neap and spring terms, respectively, for the tidal elevation time series observed at Capitania.

\subsection{Results}

\subsubsection{Observed storm tides}

Figures 4.5 and 4.6 show the subtidal component and the total water elevation time series, respectively, observed at Capitania (black lines). The subtidal component (or surge) is the signal obtained by Lanczos filtering of the total elevation to remove the tides. The significant surges are seen as positive peaks in the black line exceeding the threshold (blue line), equal to $1.34 \mathrm{~m}$. When a significant surge coincided with a high spring tide (marked by the red dots in Figure 4.5) the event was identified as a storm tide (red dots in Figure 4.6).

From December 22, 2014 to December 22, 2018, there were 107 significant surges in the elevation data collected at Capitania station. The most intense events, measured by the maximum peak surge height, occured in the winter season, reaching $1.92 \mathrm{~m}$, as seen in the left panel of Figure 4.7 (dark gray bars). However, the average of the maximum peaks among the events in each individual season (light gray bars) are roughly the same in all seasons and approximately equal to $1.45 \mathrm{~m}$. The right panel of Figure 4.7 shows that the significant surges are more frequent in autumn (43 events), followed by winter 


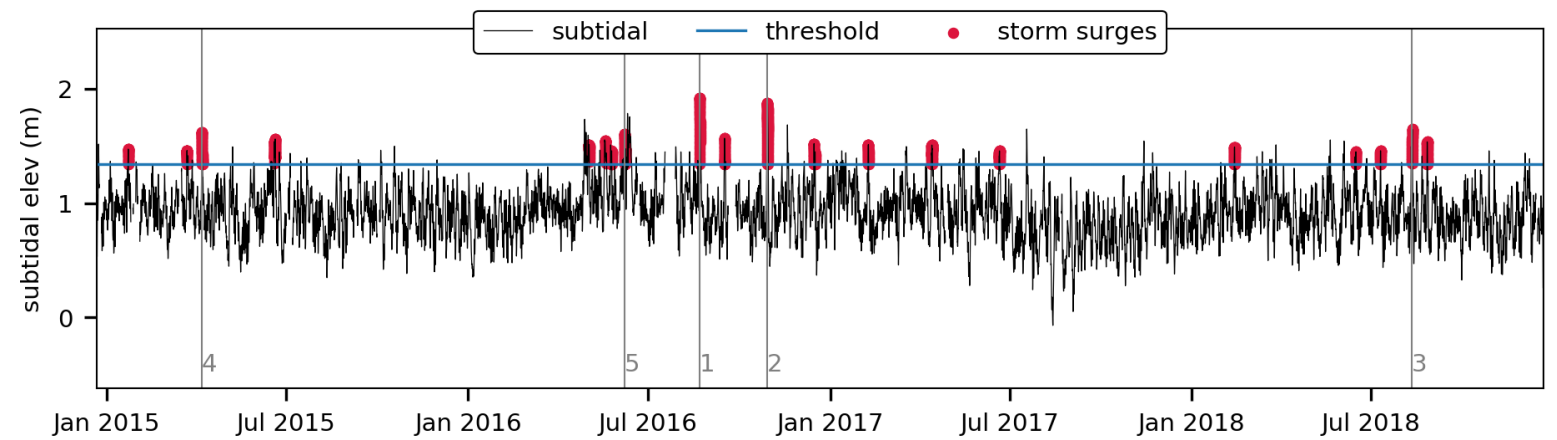

Figure 4.5: Storm surges (blue dots) detected in the observed data at Capitania. The black line shows the subtidal (or storm surge) component of the elevation time series. The threshold over which a subtidal sea level increase is identified as a significant surge is shown by the red line $(1.34 \mathrm{~m})$. The magenta vertical lines numbered from 1 to 5 mark the strongest storm surges, from higher to lower intensity.

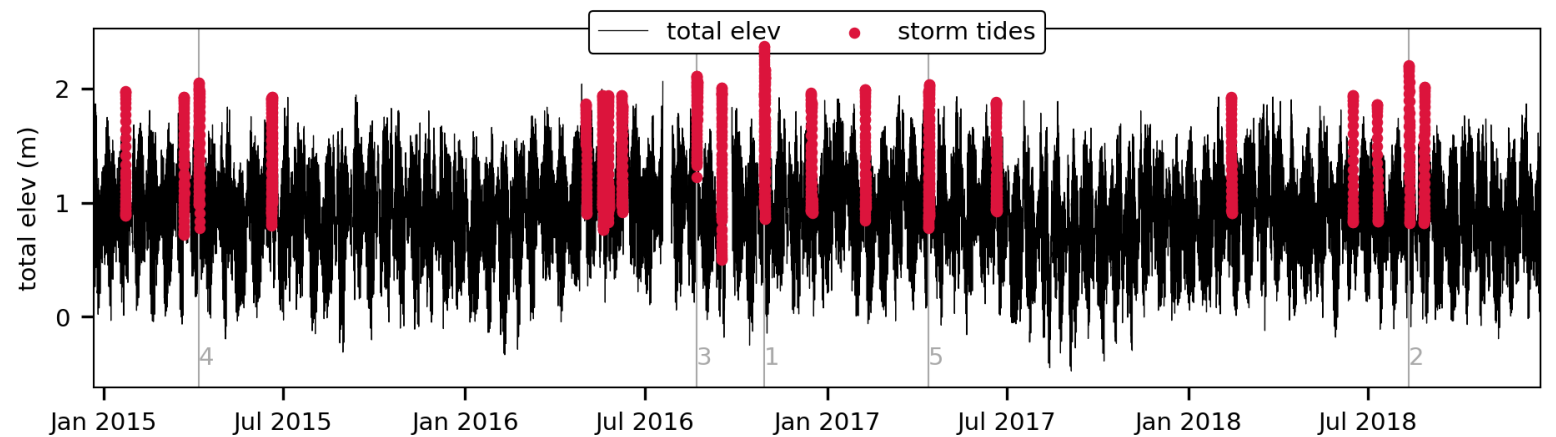

Figure 4.6: Storm tides (blue dots) detected in the observed data at Capitania. The black line shows the total water elevation time series. The magenta vertical lines numbered from 1 to 5 mark the strongest storm tides, from higher to lower intensity. 
(26), summer (22) and spring (16). This is similar to what was found by Campos et al. (2010), with autumn and winter being the months with more significant surges in Santos.

Among the 107 significant surges, 22 were identified as storm tides, yielding an average of $5.5 \pm$ 3.1 storm tides per year in the SSVBES. Figure 4.8 shows the number of storm tides in each year divided in the four seasons. The year of 2016 had the biggest number of events, 10 in total, followed by 2018 (5 events), 2015 (4 events) and 2017 (3 events). The number of events by seasons, shown in the left panel of Figure 4.9, reveals the same seasonal pattern of the significant surges. The storm tides occurred preferably during autumn ( 11 events in total), with a frequency of 2.75 events per autumn (right pannel). Winter is the second season with more storm tides (5), followed by spring and summer ( 3 events in each). The frequencies of storm tides per season were equal to 1.25 (winter) and 0.75 (spring and summer).

The strongest storm surges do not necessarily correspond to the strongest storm tides as seen by the highest events ordered in Figures 4.5 and 4.6. Three of the five most intense storm surge appear as the three most intense storm tides, but not in the same order. For instance, the strongest storm surge occurred in August 21, 2016 (winter) whereas the strongest storm tide was in October 28, 2016 (spring). Differences are due to the tidal amplitude, that was approximately $0.15 \mathrm{~m}$ lower in August 21 relative to October 28.

Figure 4.10 summarizes the total water level peaks of the 22 storm tides (upper panel) and the correspondent storm tide durations (lower panel). The duration was defined as the total time the correspondent storm surge signal exceeded the threshold. The maximum and minimum storm tide peaks were $2.37 \mathrm{~m}$ (October 28, 2016) and $1.85 \mathrm{~m}$ (June 7, 2016), respectively. The average storm tide peaks was $1.98 \pm 0.12 \mathrm{~m}$. The average duration of the storm tides was $16.8 \pm 9.1 \mathrm{~h}$ with the maximum duration (40.5 h) occurring on May 18, 2016 and the minimum ( $7.7 \mathrm{~h}$ ) on June 15, 2018. No strong relation between duration and maximum total water level was observed. 

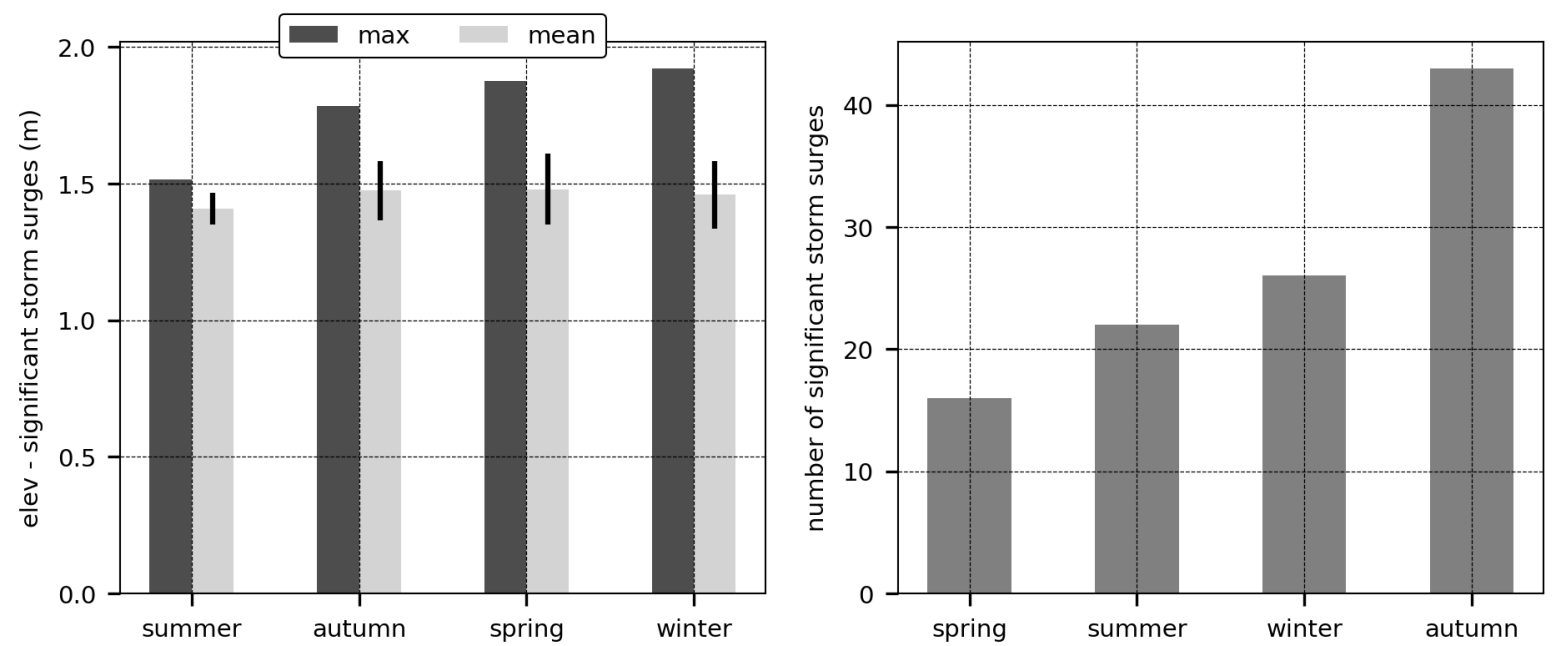

Figure 4.7: Maximum and mean significant surge water levels per season (left panel) and number of significant surge per season (right panel) for the 91 events identified in the 4-year time series at Capitania. The vertical lines in the left panel show the standard deviations of the maximum surge levels for each season.

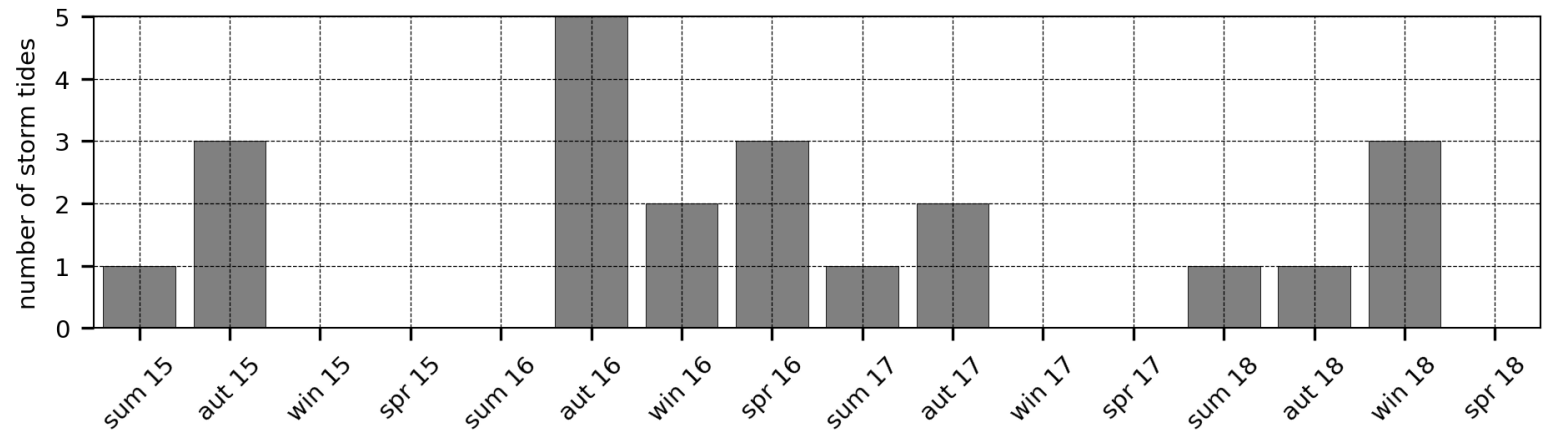

Figure 4.8: Number of observed storm tide events from summer 2015 to spring 2018 at Capitania. 

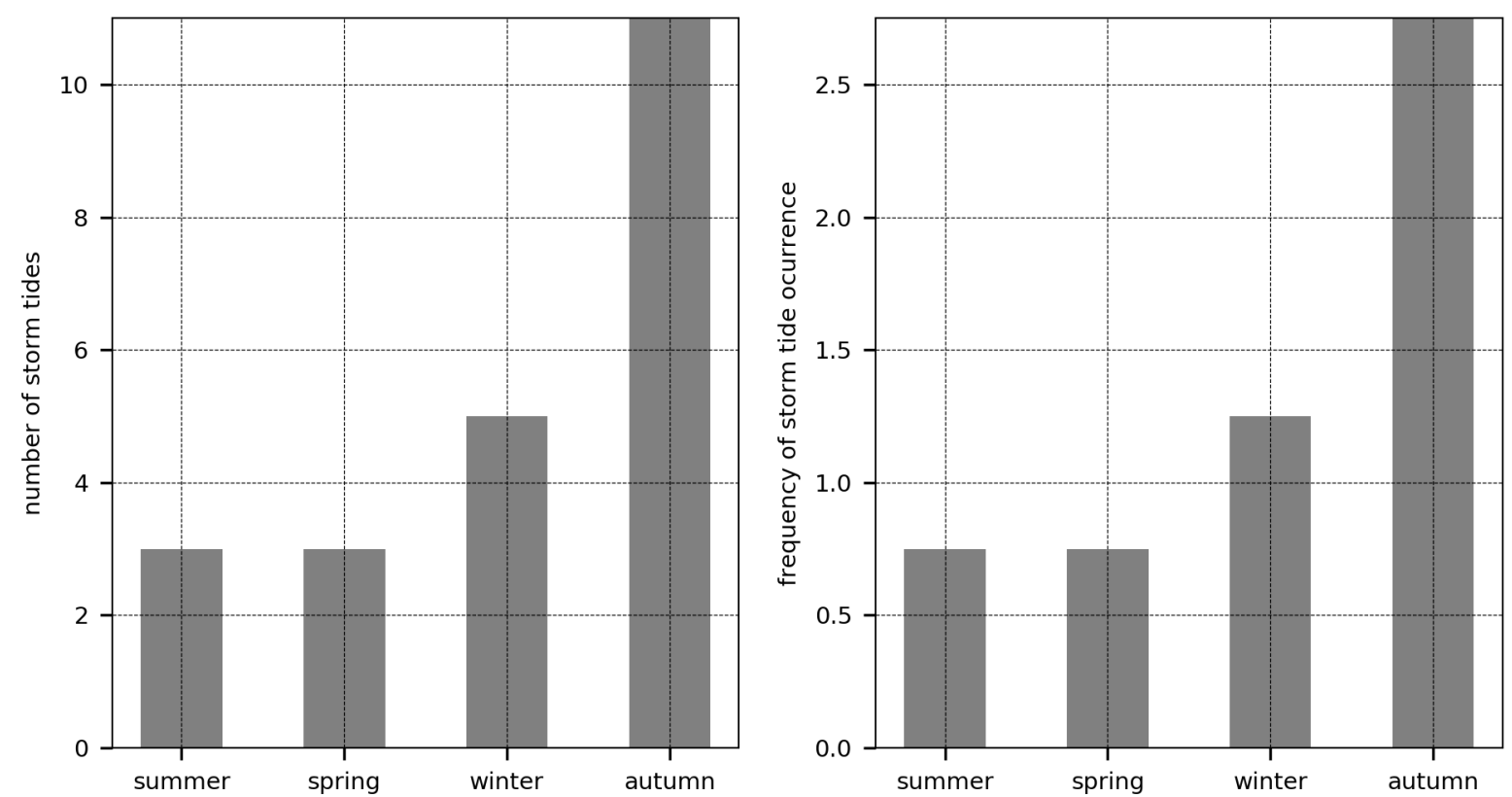

Figure 4.9: Number of storm tides (left panel) and frequency of storm tide ocurrence (right panel) for the 35 storm tides observed in the 4-year time series at Capitania.
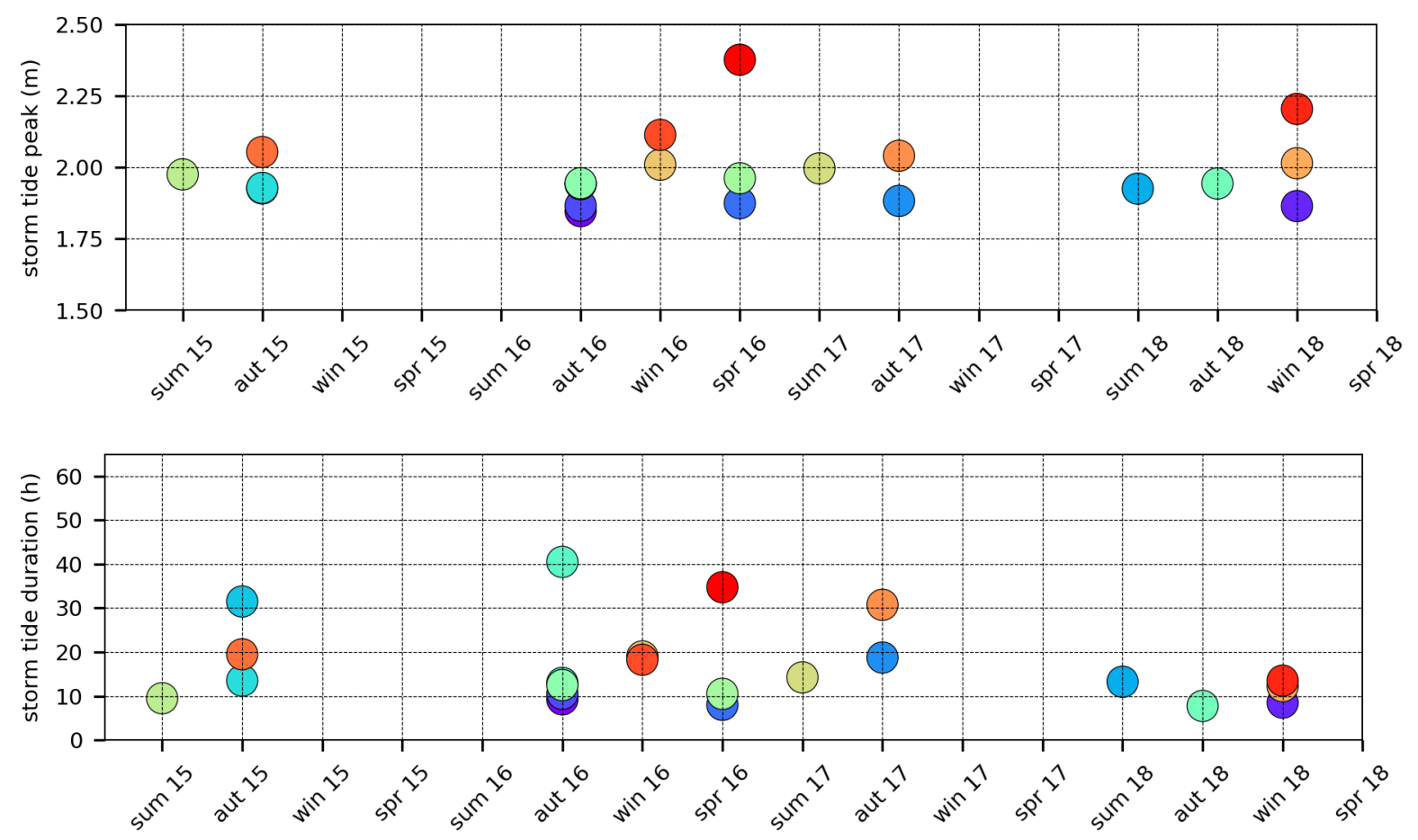

Figure 4.10: Storm tide water level peaks (top) and duration (bottom) of the 26 events identified from summer 2015 to spring 2018 at Capitania. Each colored symbol represents a different storm tide and panels have the same color correspondence. 


\subsubsection{The winter of $\mathbf{2 0 1 6}$}

The previous section showed that surges tend to be more intense during the winter season and that the year of 2016 had the strongest storm surges among the 4 analyzed years. The strongest storm surge component of the 22 storm tides was in August 21, 2016. For these reasons, the winter of 2016 was chosen as the reference for the long-term sea level rise simulations. How high would the storm tides be if the 2016 atmospheric field was forced over the 2100 projected sea level rise? To answer this question, first the model ability to capture the number and the water level peaks in winter of 2016 is analyzed (E1 experiment). Second, the changes in number and intensity of storm tides events are quantified in a sea level rise simulation (E2 experiment).

The observed data and the modeled results for experiments E1 (control) and E2 (SLR) are shown in Figures 4.11 and 4.12 for the storm surge components and the total water elevations, respectively. Two storm tides occurred during the winter of 2016 both in the data (top panels) and in the control experiment (middle panels), the first in August 21 (\#1) and the second in September 15 (\#2). Table 4.2 details the duration and the maximum water level peaks for the two events in the observed data and in the $\mathrm{E} 1$ experiment. The maximum total water elevation is captured within $0.05 \mathrm{~m}$ in \# 1 and within 0.11 $\mathrm{m}$ in $\# 2$ and the storm surge within $0.01 \mathrm{~m}(\# 1)$ and $0.02 \mathrm{~m}(\# 2)$. The simulated $\mathrm{E} 1$ duration was $6.7 \mathrm{~h}$ smaller in \#1 and $7.5 \mathrm{~h}$ in \#2. Such differences in the duration are due to differences in the shape of the subtidal curve. Nevertheless, the control simulation was able to capture the number and the intensity of the events. As also shown in Chapter 2, the built SOFS framework, used for the E1 experiment, is able to reproduce several storm tides with high accuracy.

In the E2 experiment, a SLR of $0.6 \mathrm{~m}$ was added in the simulation and the resulting storm surge component and the total water elevation time series are shown in the bottom panels of Figures 4.11 and 4.12. During the E2 experiment, there were 45 events of significant surges and 20 were identified as storm tides. From the 25 remaining events, 15 occurred during neap tides and 10 did not coincide with a high spring tide. Storm tide conditions would be present $32 \%$ of the time if the mean sea level was 0.6 $\mathrm{m}$ higher during the winter of 2016. As the actual reference for sea level $(0.8 \mathrm{~m})$ and the imposed SLR together account for a mean sea level of $1.4 \mathrm{~m}$ that exceeds the threshold, storm tides are not present

Table 4.2: Comparisons between observed (obs) and modeled E1 and E2 experiments for the two storm tides in the winter of 2016 in terms of duration of the event, maximum total water elevation (max elev) and maximum surge height (max surge).

\begin{tabular}{cccc|ccc}
\hline event & \multicolumn{3}{c}{$\# 1$} & \multicolumn{3}{c}{$\# 2$} \\
\hline & Obs & E1 & E2 & Obs & E1 & E2 \\
\hline start date & Aug-21 & Aug-21 & Aug-21 & Sep-15 & Sep-15 & Sep-14 \\
& $16: 45$ & $16: 55$ & $07: 45$ & $18: 30$ & $18: 05$ & $09: 05$ \\
duration (h) & 18.5 & 11.8 & 21.0 & 19.0 & 11.5 & 92.0 \\
max elev (m) & 2.11 & 2.16 & 2.75 & 2.01 & 2.12 & 2.72 \\
max surge (m) & 1.92 & 1.91 & 2.50 & 1.57 & 1.55 & 2.15 \\
\hline
\end{tabular}



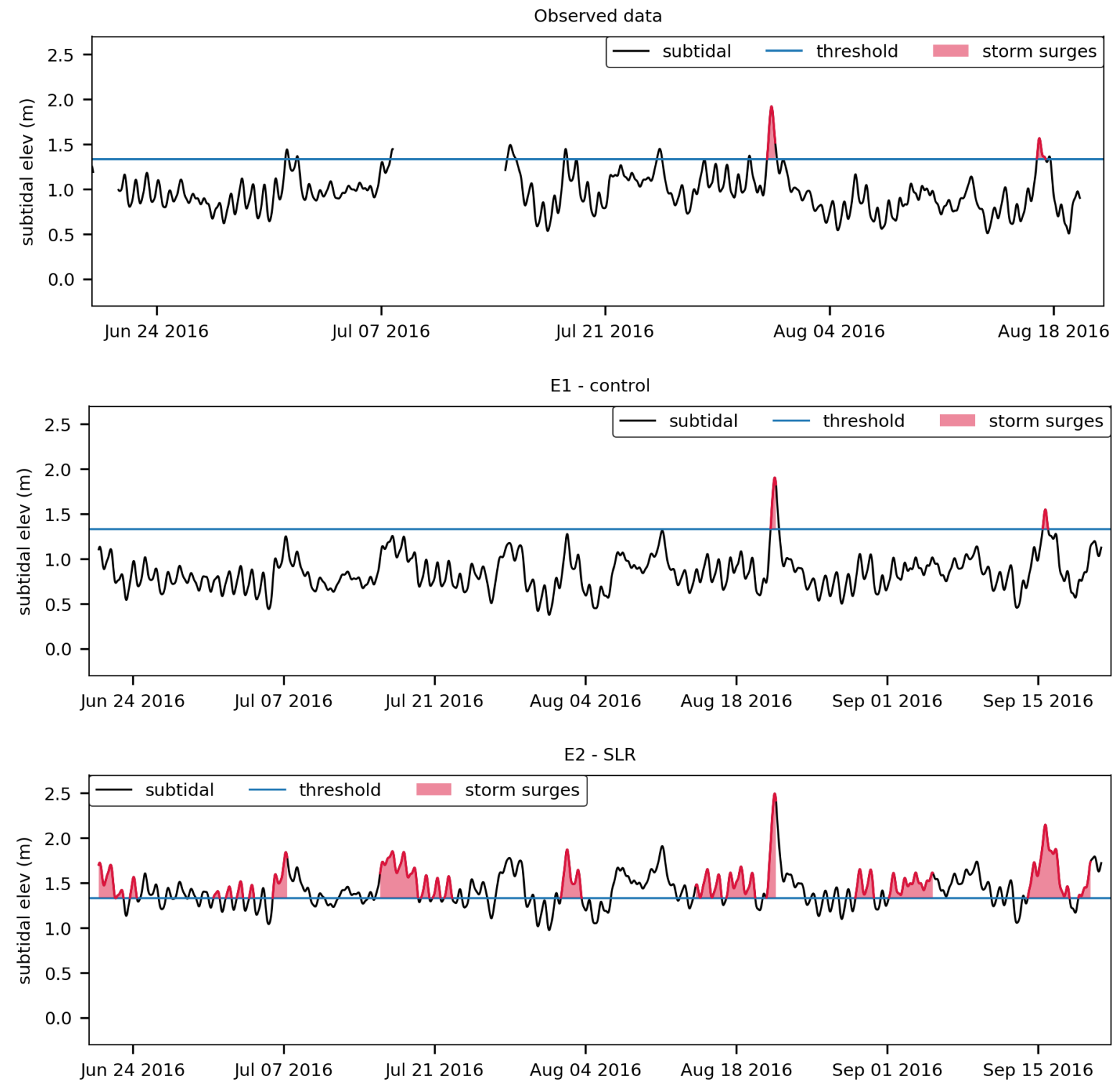

Figure 4.11: Subtidal component (black lines) of total water elevation at Capitania showing the detected storm surges (highlighted in red) during the winter of 2016. The top, middle and bottom panel show the observed data, the E1 control experiment and the E2 SLR experiment, respectively. The threshold over which a subtidal sea level increase is identified as a significant surge is shown by the blue line $(1.34 \mathrm{~m})$. 

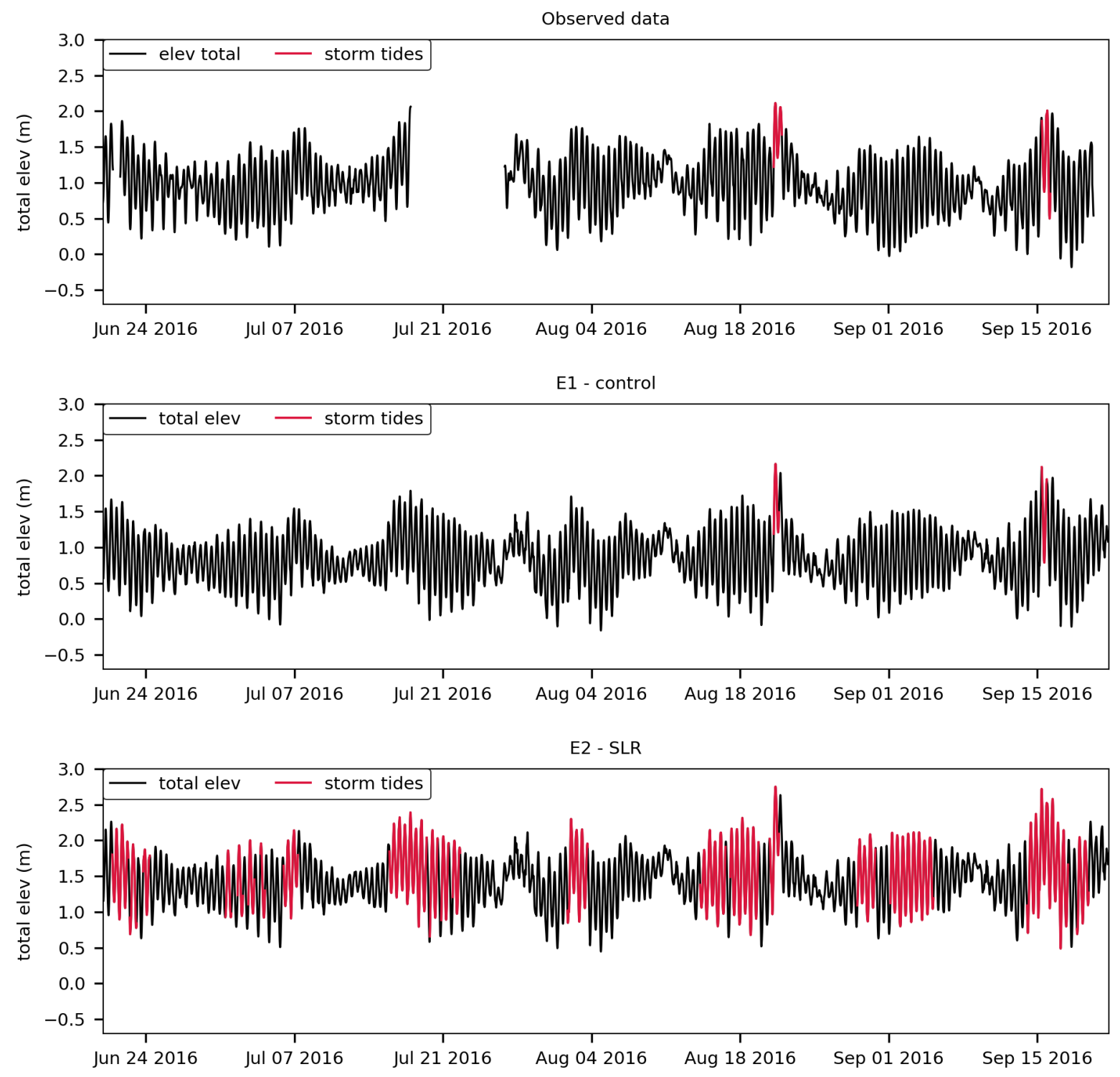

Figure 4.12: Total water elevation (black lines) at Capitania showing the detected storm tides (red dots) during the winter of 2016. The top, middle and bottom panels show the observed data, the E1 control experiment and the E2 SLR experiment, respectively. 
only over neap tides and/or if the atmospheric field acts to retreat water from the coast.

Table 4.3 shows the range of storm tide duration and water level peaks among the 20 events. The maximum water levels correspond to the storm tide of August 21. Table 4.2 shows that if the mean sea level was $0.6 \mathrm{~m}$ higher, the maximum water levels during the two storm tides identified in the actual conditions of simulation E1, would be approximately $0.6 \mathrm{~m}$ higher (for both total water elevation and storm surge component). The duration of the storm tides would be 1.8 times longer in $\mathrm{E} 2$ in relation to E1 for event \# 1 and 8 times longer for \#2. In summary, storm tides would increase from 2 to 20 and the increase in the maximum water levels during the storms would be the value of the SLR. This implication of the SLR trend used in this study is important to highlight. A higher or lower than $0.6 \mathrm{~m}$ SLR would directly impact the number and the intensity of the future storm tides.

Table 4.3: Summary of the 20 storm tides identified in the E2 experiment in terms of duration of the event, maximum total water elevation (max elev) and maximum surge elevation (max surge). For each parameter, the minimum, the maximum, the average and the standard deviation (std) values are shown.

\begin{tabular}{cccc}
\hline \# of events & \multicolumn{3}{c}{20} \\
\hline & minimum & maximum & average \pm std \\
\hline duration (h) & 10.3 & 96.7 & $36.3 \pm 28.0$ \\
max elev (m) & 1.86 & 2.75 & $2.15 \pm 0.25$ \\
max surge (m) & 1.41 & 2.50 & $1.69 \pm 0.26$ \\
\hline
\end{tabular}

Although the E2 experiment was originally performed to quantify the changes in number and intensity of storm tides, the results also helped to infer the differences between two methods of addressing the sea surface elevation changes due to SLR, the static and the dynamic methods. Both methods are useful on studies that aims to locate the future flooding areas due to SLR. In the static approach, a fixed SLR value is assumed in the entire domain and overland regions lower than the SLR value are expected to be flooded in the future. In the dynamic method, the future flooding zones are addressed through the use of a hydrodynamic model, as the E2 experiment performed in the present study. Orton et al. (2015) showed that both methods are able to map the possible future flooding zones in the New York City with differences of only $15 \mathrm{~cm}$. The benefit of the more complex dynamic method does not necessarily lie on the higher accuracy of mapping the flooding zones, but in the ability to simulate hypothetical scenarios as, for instance, with physical barriers to analyze how would the water elevation affect the overland areas (Orton et al., 2015).

Figure 4.13 shows the total sea surface elevation time series at Capitania from the E1 experiment added to the SLR (blue dotted line) and the E2 run (orange line). The two series are comparable, with mean differences (black lines) of $\mathrm{O}\left(10^{-2}\right) \mathrm{m}$ and maximum difference of $0.05 \mathrm{~m}$. The similarity between the results reveals that the static method can be used in place of the dynamic method to address sea surface elevation changes due to SLR in the SSVBES. The SLR experiments in the next section (E3 group) used the static approach to evaluate storm tide changes in the long-term simulations. 


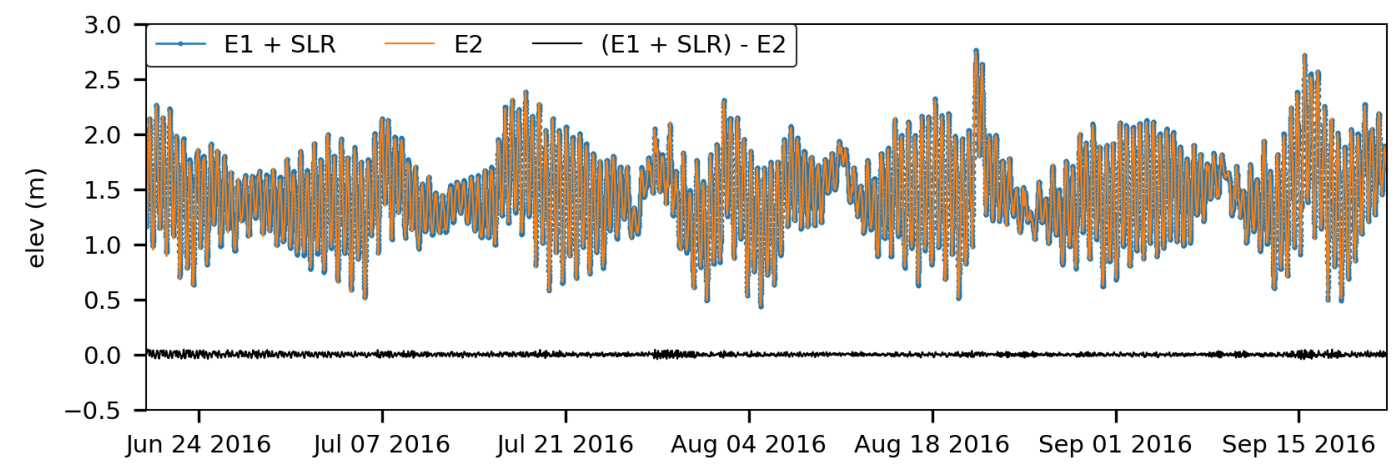

Figure 4.13: Sea surface elevation at Capitania from E1 experiment plus SLR of $0.6 \mathrm{~m}$ (blue dotted line) and from E2 experiment (orange line). The differences between the two series in shown in black.

\subsubsection{6-2099 winter projections}

In this section the results of the experiments performed with the Had-GEM2-ES atmospheric forcing fields projected to 2096-2099 (E3 and E4 groups, Table 4.1) are presented and discussed. Which mechanism should dominate the changes in the number and in the intensity of future storm tides, the changes in the atmospheric forcings or the SLR? This question is answered by comparing the results from the isolated atmospheric circulation experiments with the corresponding simulations with SLR.

Figures 4.14 and 4.15 show the subtidal and the total water elevation time series at Capitania, respectively, for simulations E3-96, E3-97, E3-98 and E3-99. Over the four winter simulated periods under RCP8.5, only one storm tide was detected, in June 2096 (top panels in Figures 4.14 and 4.15). The associated storm surge was the only one that exceeded the threshold of $1.34 \mathrm{~m}$ during a high spring tide. Another significant surge occurred in August 2097 (second panel in Figure 4.14) but during neap tides and, therefore, did not satisfied the criterion to derive a storm tide. There were no other significant surge during the four analyzed winter periods. For RCP4.5 (Figures 4.16 and 4.17), no storm tide was detected during the four analyzed winter seasons. There were more significant surges in E4 group relative to E3, despite none evolve to a storm tide. A total of six significant surge was observed in July, 2096 (E4-96), June (2 events) and July, 2097 (E4-97) and July and August, 2099 (E4-99). However, five of the six events did not coincide to a high spring tide and one event occurred during neap tides. The duration of the significant surges varied from $1.2 \mathrm{~h}$ to $5.8 \mathrm{~h}$.

Compared to the four winters of 2015-2018, the projected atmospheric circulation changes of 2096-2099 under both RCP8.5 and RCP4.5 may yield less storm tides than today. Whereas the observed data in Capitania revealed the occurrence of 5 storm tides in the winter season from 2015 to 2018 (Figure 4.9), the projected atmospheric circulation fields may reduce this number to 1 storm tide (RCP8.5) or 0 (RCP4.5) for the last four winters of the century.

Figures 4.18 and 4.19 shows the wind fields used in the simulations for groups E1 and E2 (winter 2016), E3 and E4 (winter periods of 2096, 2097, 2098 and 2099) in the form of wind roses. The wind roses were computed for a single SBB grid point in the 100-m isobath located in front of the SSVBES 
(marked in panels of Figures 4.20 and 4.21). The SW winds, responsible for storm surges evolution, were less frequent and less intense in the 2096-2099 period in relation to the actual conditions at both RCP8.5 (Figure 4.18) and RCP4.5 (Figure 4.19). Instead, winds from the NW and W directions might be more frequent and more intense. The general behavior does not change if points located in the inner shelf or further south were chosen for the comparisons. The SW winds occurred $8 \%$ of the time during the winter of 2016 and the frequency may decrease to $2 \%-6 \%$ in the 2096-2099 (RCP8.5). Also the SW wind speeds that today reach the $10-12 \mathrm{~m} / \mathrm{s}$ range may be reduced to the $4-6 \mathrm{~m} / \mathrm{s}$ range under RCP8.5. For RCP4.5, the frequency and the intensity of the SW winds may be reduced to $3-5 \%$ and to $2-6 \mathrm{~m} / \mathrm{s}$, respectively, except for E4-99, whose $\mathrm{SW}$ winds reach the 6-8 $\mathrm{m} / \mathrm{s}$ range.

Besides the wind field, the expected sea level atmospheric pressure distribution over the SBB for the end of the 21 st century also helped to decrease the storm tide occurrence. The maps in Figure 4.20 show that the atmospheric pressure over the SBB, and specially over depths shallower than $100 \mathrm{~m}$ in front of the SSVBES, may increase by 2-3 mbar in relation to the winter of 2016 in RCP8.5 experiments E3-97, E3-98 and E3-99. Similar increases were observed in the RCP4.5 experiments E4-96, E4-98 and E499. Differences between actual and future atmospheric pressure maps are smaller in E3-96 and E4-97 experiments, where the pressure fields were approximately 1 mbar greater than in the E1 experiment. These results show that the atmospheric pressure field is an important determinant for the occurrence of storm tides. The E4-97 was the experiment with the greatest number of significant surges, three in total, among the eight simulations in E3 and E4 groups. Also, The E3-96, even with the less frequent SW winds ( $2 \%$ of the time) among the four simulated long-term experiments in RCP8.5, the experiment was the only one with a storm tide. In the other three simulations of the same group, even with more frequent SW winds (3\%-6\% of the time), the storm tides were inhibited by the inverse barometer effect, that did not allow a higher increase in sea level.

A more complete understanding of climate change impacts on storm tides is obtained with the E3 and E4 experiments with SLR. As mentioned in the previous section, the SLRs of $0.63 \mathrm{~m}$ and $0.59 \mathrm{~m}$ were added to each E3 and E4 run, respectively. The resulting time series of subtidal and total water elevations are shown in Figures 4.22 and 4.23, respectively, for RCP8.5 (E3 group). Figures 4.24 and 4.25 show the analogous time series for RCP4.5 (E4 group). Storm tide conditions were found over $32.6 \%$ (E3-99-SLR) to 41.9\% (E3-96-SLR) of the time under RCP8.5. For RCP4.5, this percent varied from $32.0 \%$ (E4-99-SLR) to 34.9\% (E4-96-SLR). Similar to what was found for the E2 simulation, the SLR higher than the storm surge threshold preserve a high water level even during relatively weak surges.

A more detailed description of each winter period is given in Table 4.4. The increase of 1 order of magnitude in the number of events in relation to the actual conditions is seen in the E3 and E4 with SLR experiments. The increase in the maximum total water levels in relation to 2015-2018 range from $0.10 \mathrm{~m}$ to $0.32 \mathrm{~m}$ for RCP8.5 (E3 + SLR) and from $0.06 \mathrm{~m}$ to $0.39 \mathrm{~m}$ for RCP4.5 (E4 + SLR). For the storm surge component, the changes in the future surge peaks vary from $-0.11 \mathrm{~m}$ (decrease) to $0.50 \mathrm{~m}$ for RCP8.5 and from $0.11 \mathrm{~m}$ to $0.39 \mathrm{~m}$ for RCP4.5. The expected changes in the atmospheric circulation fields alone (column E3) is not responsible for this increase in storm tides. Storm surges will not nec- 

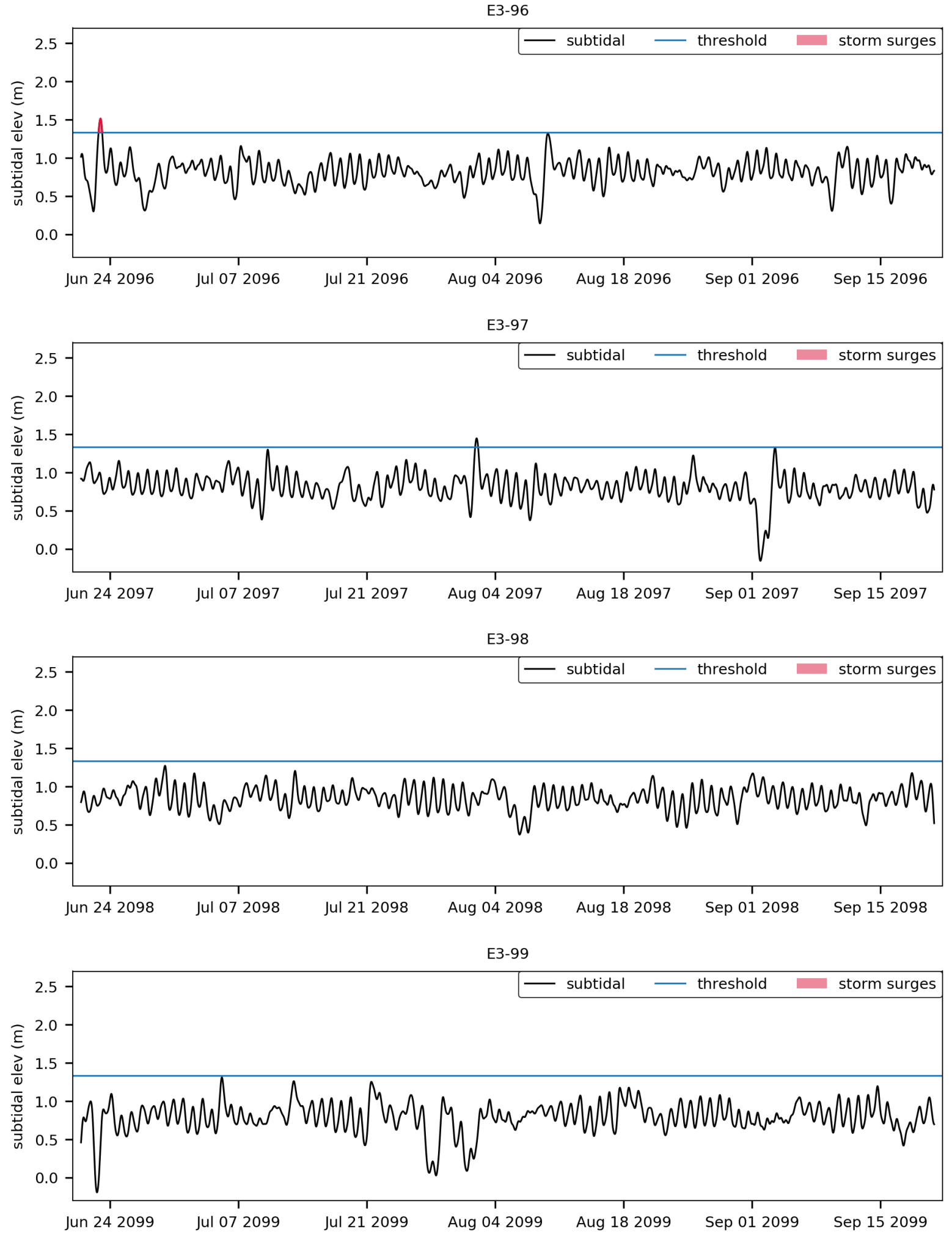

Figure 4.14: Subtidal component (black lines) of total water elevation at Capitania under RCP8.5 showing the detected storm surges (highlighted in red) during the winter of 2096, 2097, 2098 and 2099 (from top to bottom). The four time series are from the E3 experiments without SLR (E3-96, E3-97, E3-98 and E3-99). The threshold over which a subtidal sea level increase is identified as a significant surge is shown by the blue line $(1.34 \mathrm{~m})$. 

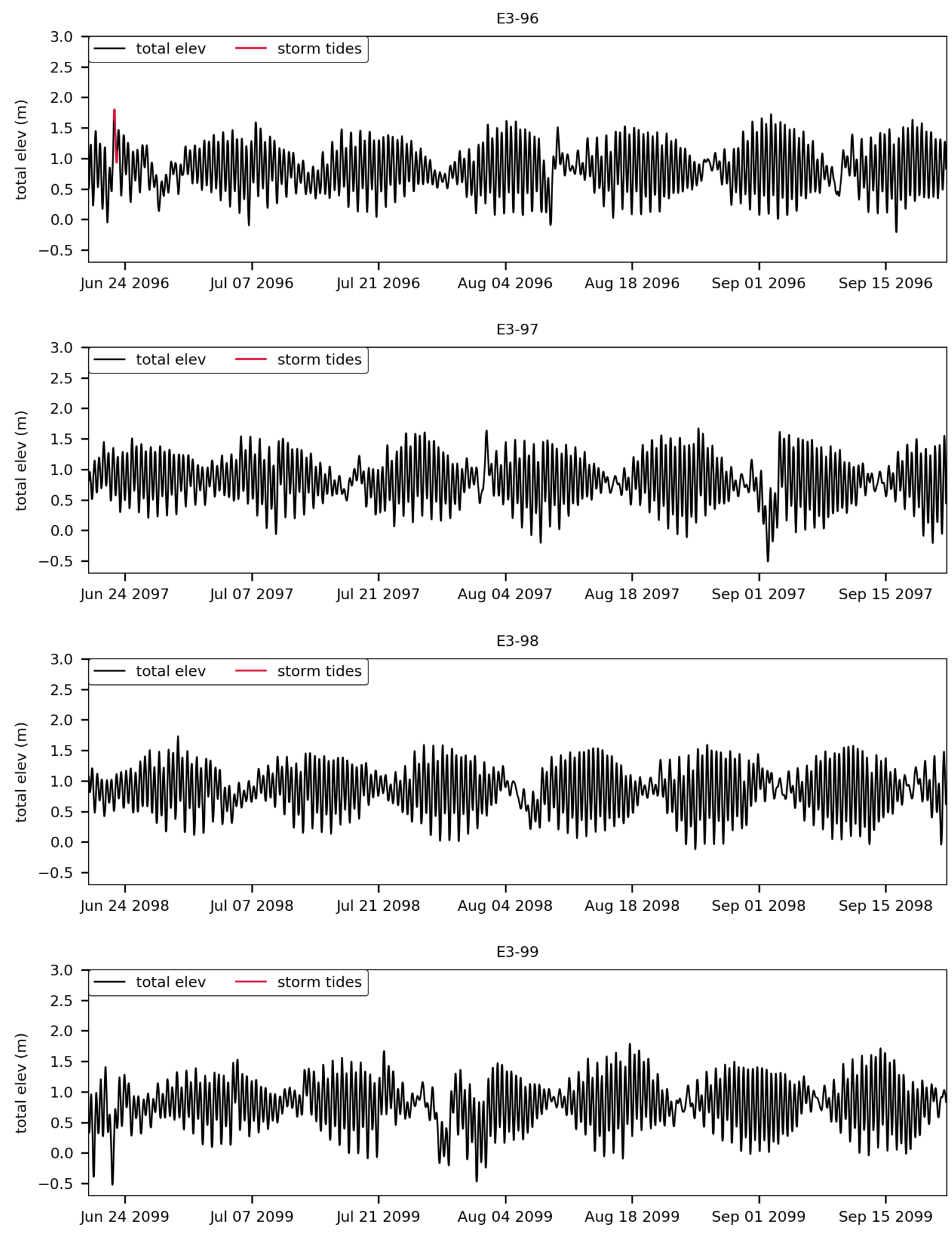

Figure 4.15: Total water elevation (black lines) at Capitania under RCP8.5 showing the detected storm tides (red dots) during the winter of 2096, 2097, 2098 and 2099 (from top to bottom). The four time series are from the E3 experiments without SLR (E3-96, E3-97, E3-98 and E3-99). 

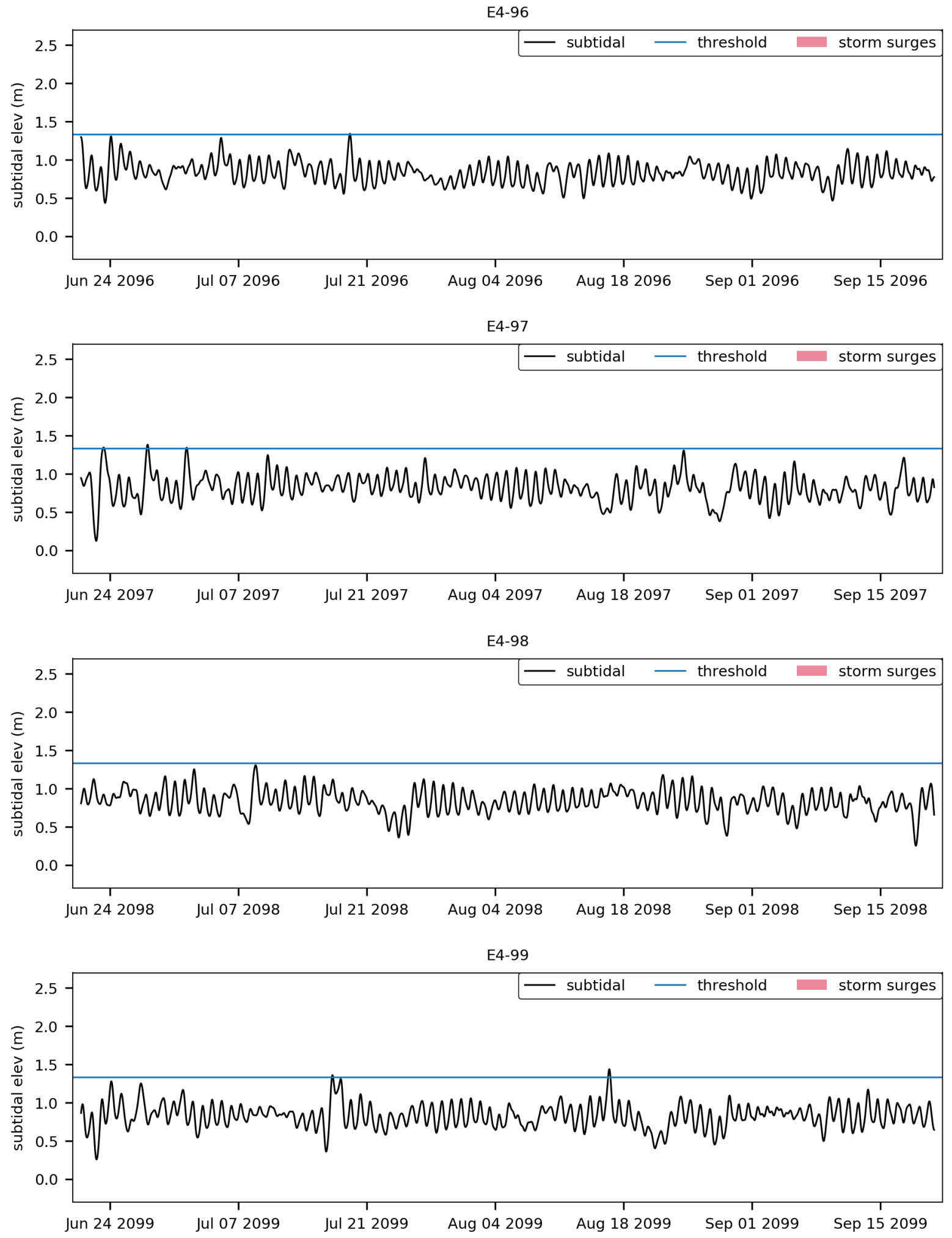

Figure 4.16: Subtidal component (black lines) of total water elevation at Capitania under RCP4.5 during the winter of 2096, 2097, 2098 and 2099 (from top to bottom). The four time series are from the E4 experiments without SLR (E4-96, E4-97, E4-98 and E4-99). The threshold over which a subtidal sea level increase is identified as a significant surge is shown by the blue line $(1.34 \mathrm{~m})$. 

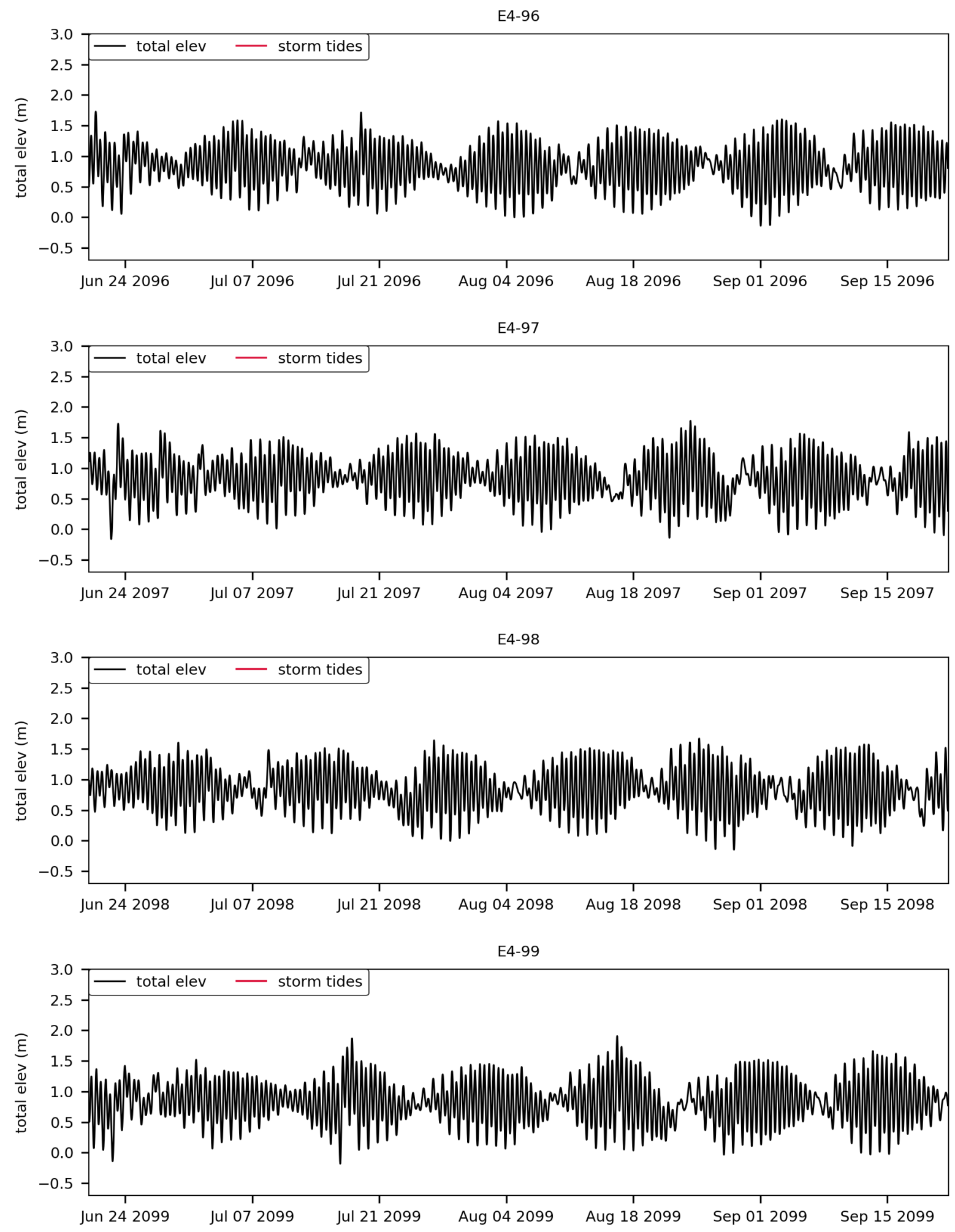

Figure 4.17: Total water elevation (black lines) at Capitania under RCP4.5 during the winter of 2096, 2097, 2098 and 2099 (from top to bottom). The four time series are from the E4 experiments without SLR (E4-96, E4-97, E4-98 and E4-99). 

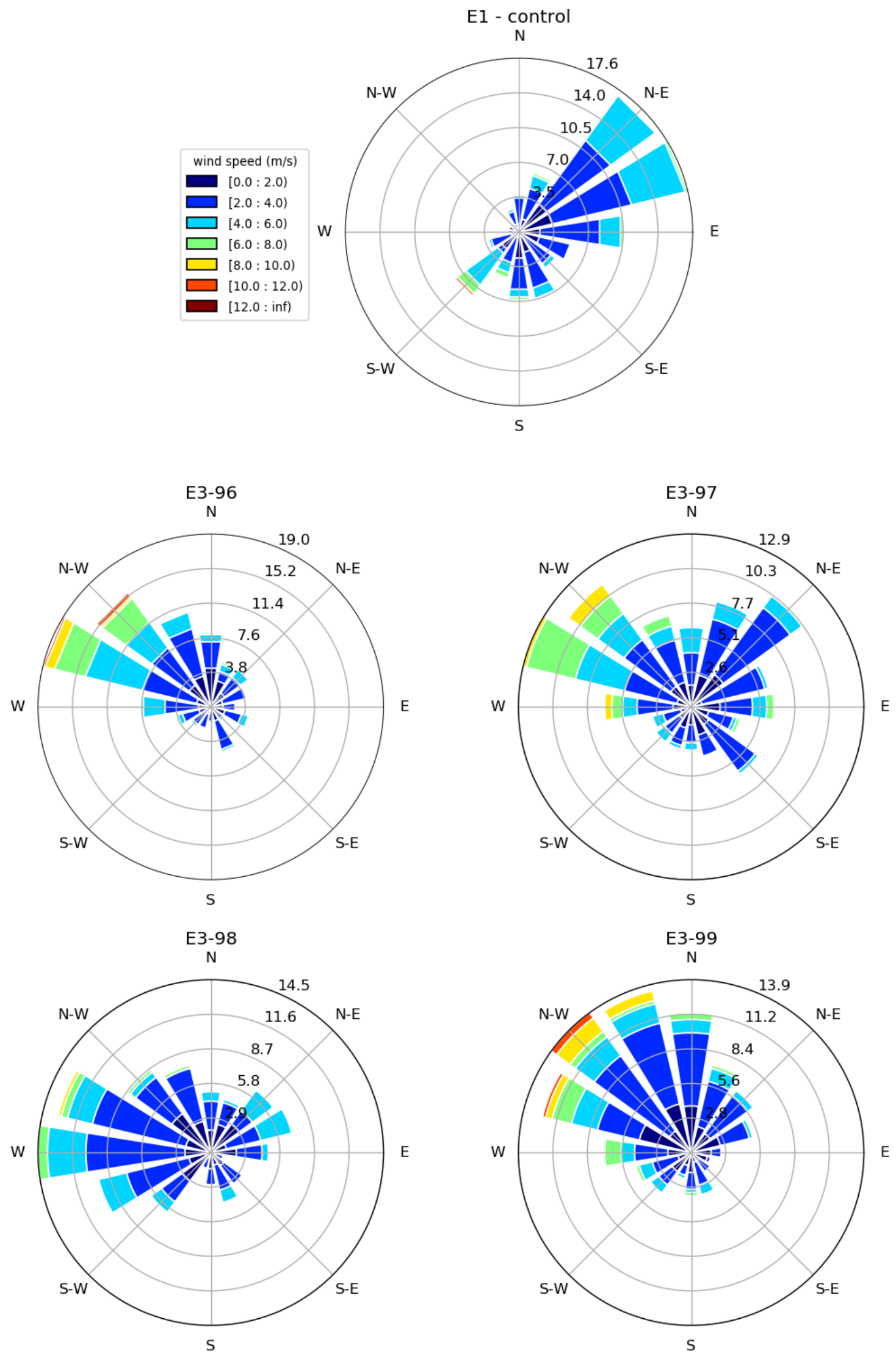

Figure 4.18: Wind rose for a SBB grid point in front of Santos city. Each graph represents the wind distribution for the entire winter period of experiments E1 (from CPTEC, BRAMS model), E3-96, E3-97, E3-98 and E3-99 (from HadGEM2-ES). 

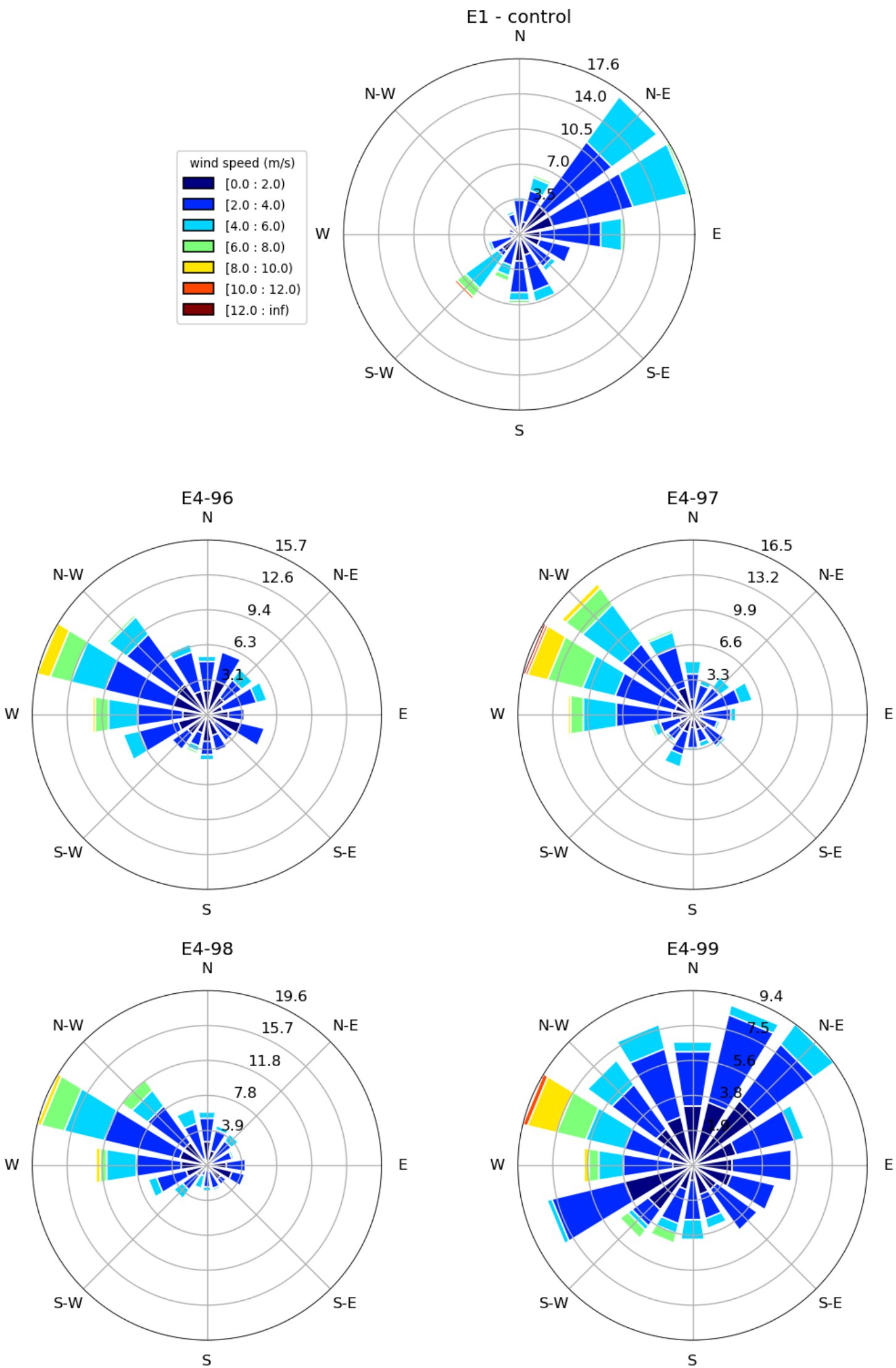

Figure 4.19: Wind rose for a SBB grid point in front of Santos city. Each graph represents the wind distribution for the entire winter period of experiments E1 (from CPTEC, BRAMS model), E4-96, E4-97, E4-98 and E4-99 (from HadGEM2-ES). 

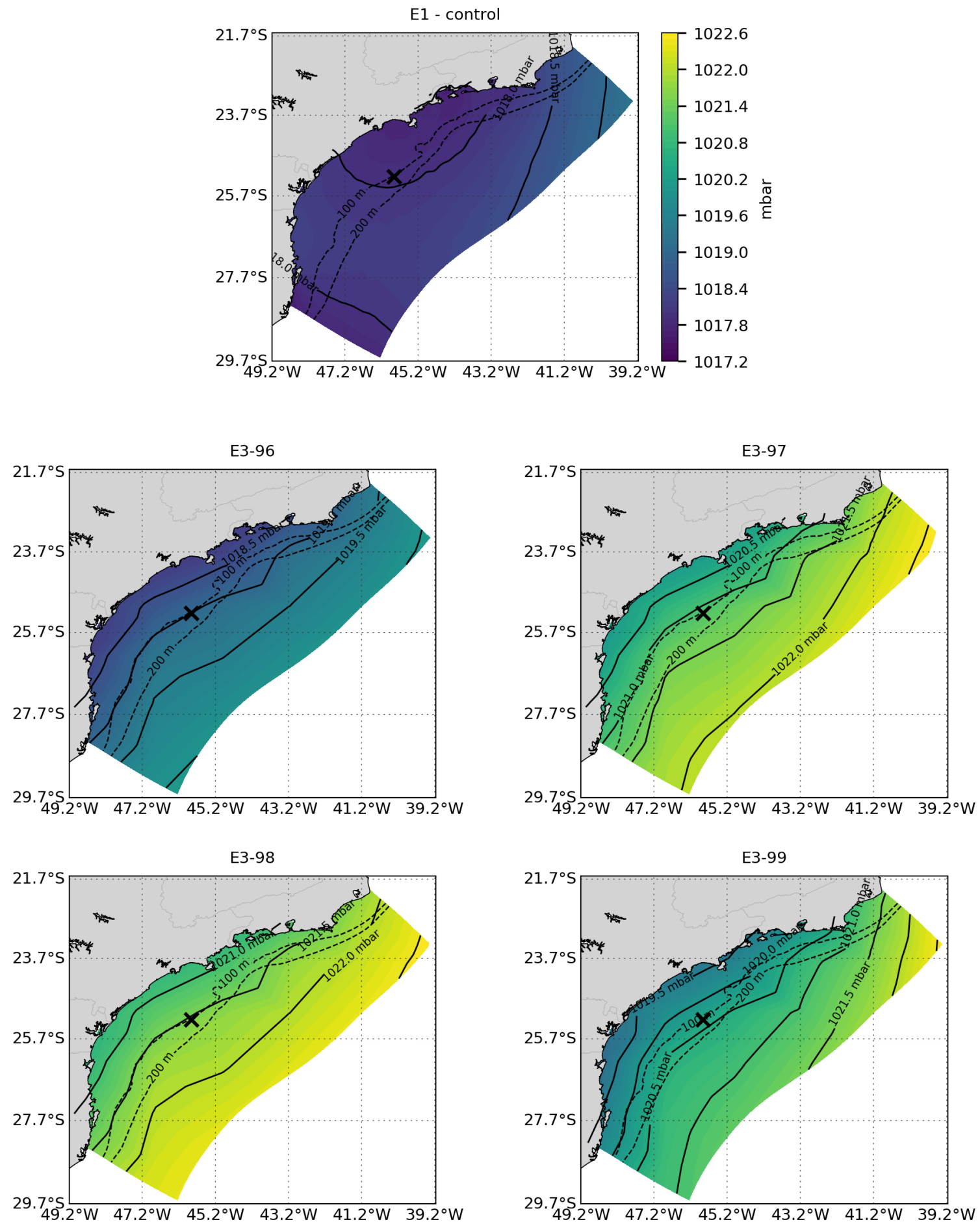

Figure 4.20: Maps of sea level atmospheric pressure (mbar) averaged over the duration of experiments E1 (from CPTEC, BRAMS model), E3-96, E3-97, E3-98 and E3-99 (from HadGEM2-ES). The solid contours show the atmospheric pressure isolines and the dashed contours represent the 100-m and 200-m isobaths. The black marker shows the position of the wind time series used to plot the wind roses in Figure 4.18. 

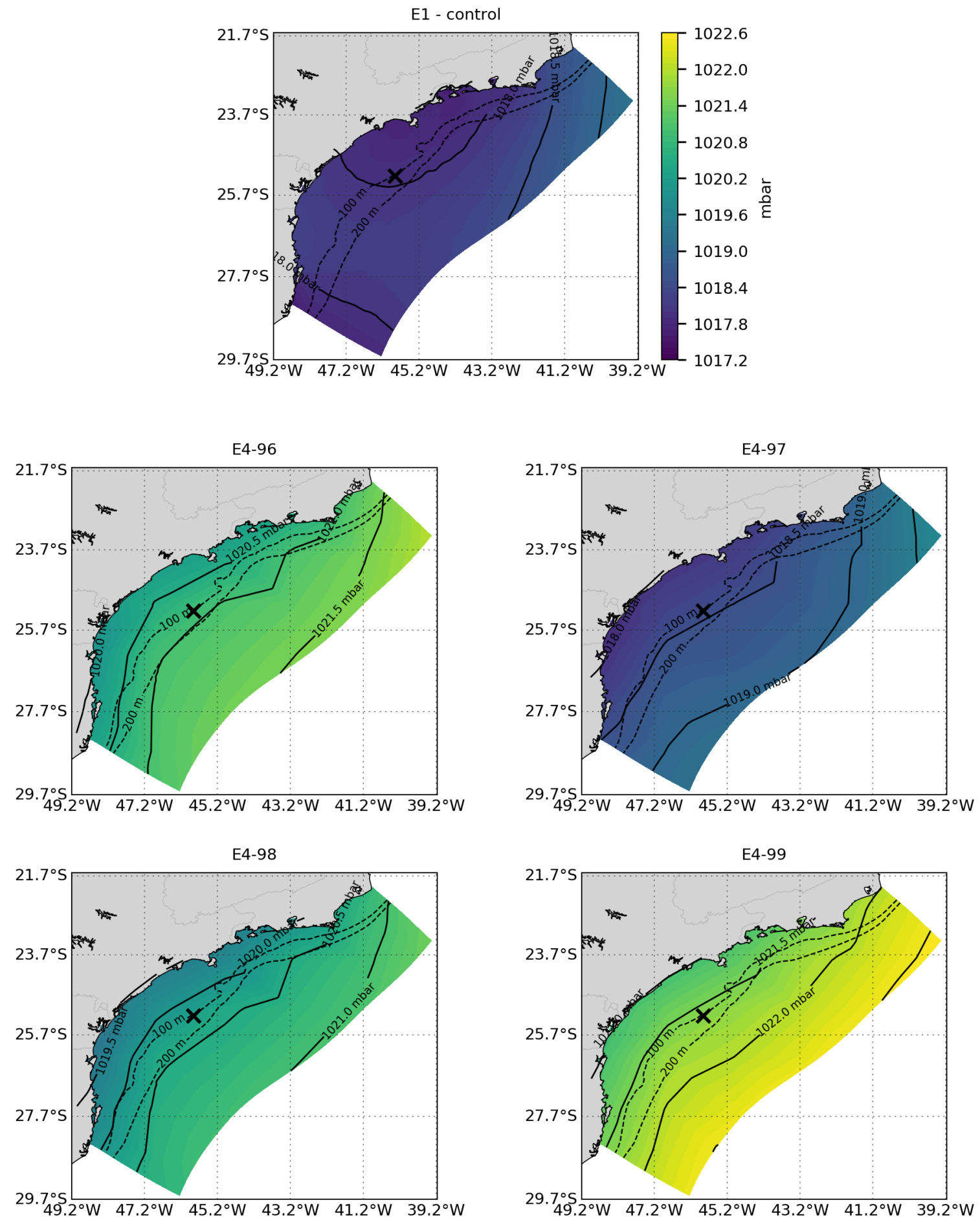

Figure 4.21: Maps of sea level atmospheric pressure (mbar) averaged over the duration of experiments E1 (from CPTEC, BRAMS model), E4-96, E4-97, E4-98 and E4-99 (from HadGEM2-ES). The solid contours show the atmospheric pressure isolines and the dashed contours represent the $100-\mathrm{m}$ and $200-\mathrm{m}$ isobaths. The black marker shows the position of the wind time series used to plot the wind roses in Figure 4.19. 
essarily become more intense. The intensity of the single storm tide in the E3 simulations without SLR (column E3, 2096) was similar to the present events. When SLR was added, the resulting storm tide of $2.43 \mathrm{~m}$ (column E3 + SLR, 2096) was higher than all the 2015-2018 winter events, although greatly comparable to the biggest storm tide registered in the entire 4-year record of $2.37 \mathrm{~m}$ in the spring of 2016 (Figure 4.10).

A summary of the changes in the number and the intensity of future storm tides relative to present conditions are present in Figure 4.26. In these panels, the four winter periods of 2015-2018 were averaged and compared to the averaged 2096-2099 winter seasons, separately for RCP8.5 and RCP4.5. The observed sea surface elevation data at Capitania was used for the actual period and the E3 + SLR and the E4 + SLR experiments were considered for the future terms. The top panels reveal that the total number of storm tides may increase from 5 to 112 (RCP8.5) or to 131 (RCP4.5). The average duration may rise from $14.3 \mathrm{~h}$ to $30.4 \mathrm{~h}$ (RCP8.5) or to $23.0 \mathrm{~h}$ (RCP4.5). The duration of each future event may vary from a few hours to more than six days. Such conclusions result from the oscillation of the subtidal sea level around the threshold line as seen in Figures 4.22 and 4.24. Every time a significantly high (red) subtidal elevation crosses the threshold and rise above back, another storm tide is computed. But, if the decreasing in the subtidal level does not reach the threshold, the duration of the storm tide gets longer. This explains the greater number but smaller durations of storms in RCP4.5 relative to RCP8.5. Also, the evident increase in number of events in future simulations relative to the actual time is not necessarily a consequence of favorable atmospheric conditions. This is directly because the SLR is high enough to consider a substantial part of the subtidal oscillation as significant surges, according to the threshold that defines a storm surge today. The wind field does not need to change to increase the number of storm surges (and consequently, storm tides), as seen in experiment E2.

The average water peaks (bottom panels in Figure 4.26) under RCP8.5 may lightly increase from $204.0 \mathrm{~m}$ to $209.6 \mathrm{~m}$ (storm tides) and from $162.6 \mathrm{~m}$ to $166.7 \mathrm{~m}$ (storm surges). The increases are quite small for RCP4.5, whose average storm tide and storm surge peaks may reach $205.0 \mathrm{~m}$ and $163.4 \mathrm{~m}$, similar to the present conditions. The smaller peaks of the RCP4.5 in relation to the RCP8.5 are due to the different expected SLR, $0.04 \mathrm{~m}$ lower in RCP4.5. Considering the standard deviations, both storm tide and storm surge future water level peaks under both scenarios may be similar to the actual estate. 

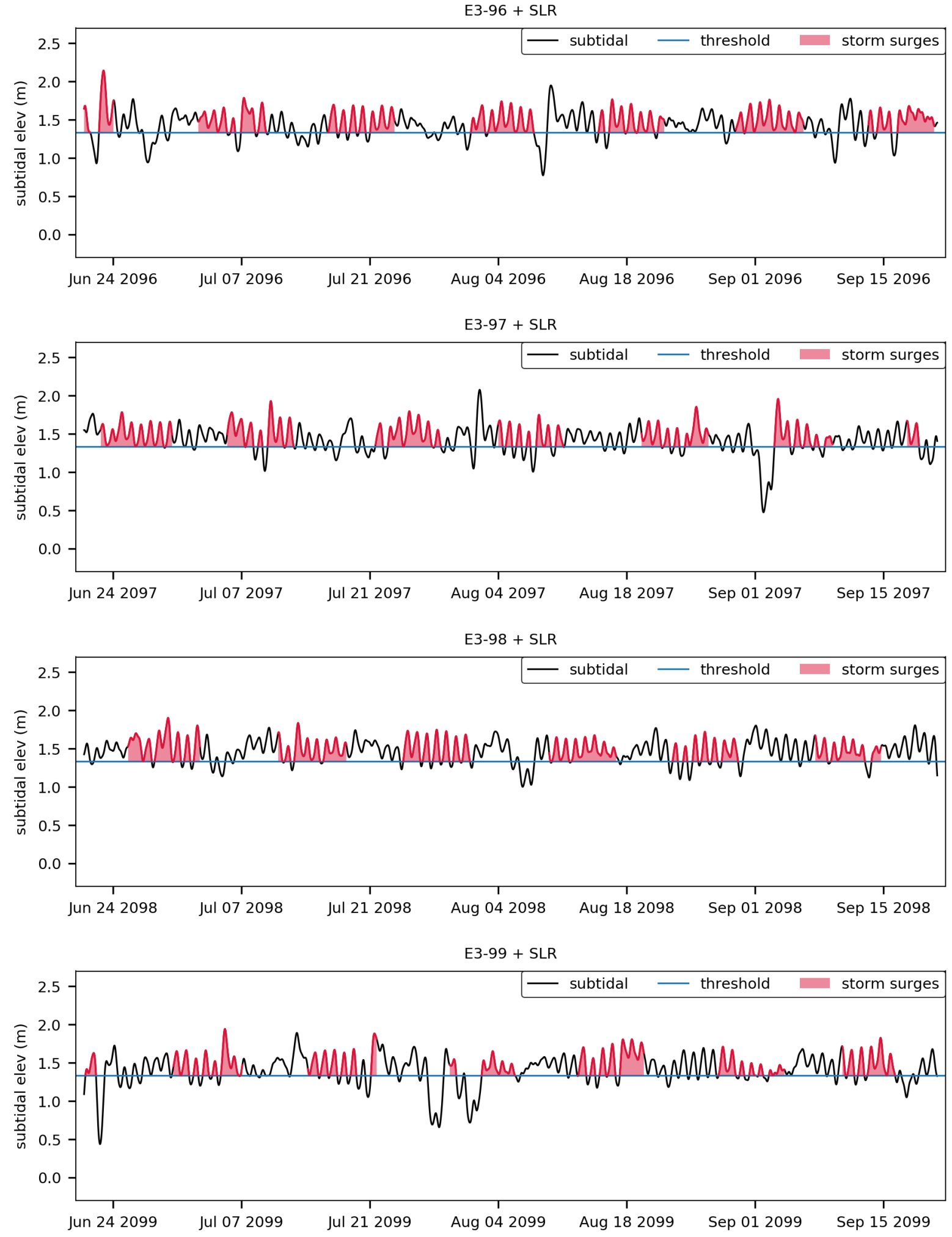

Figure 4.22: Subtidal component (black lines) of total water elevation at Capitania from the E3 experiments with SLR (E3-96-SLR, E3-97-SLR, E3-98-SLR and E3-99-SLR) during the winter of 2096, 2097, 2098 and 2099 (from top to bottom). The detected storm surges are highlighted in red. The threshold over which a subtidal sea level increase is identified as a significant surge is shown by the blue line $(1.34 \mathrm{~m})$. 

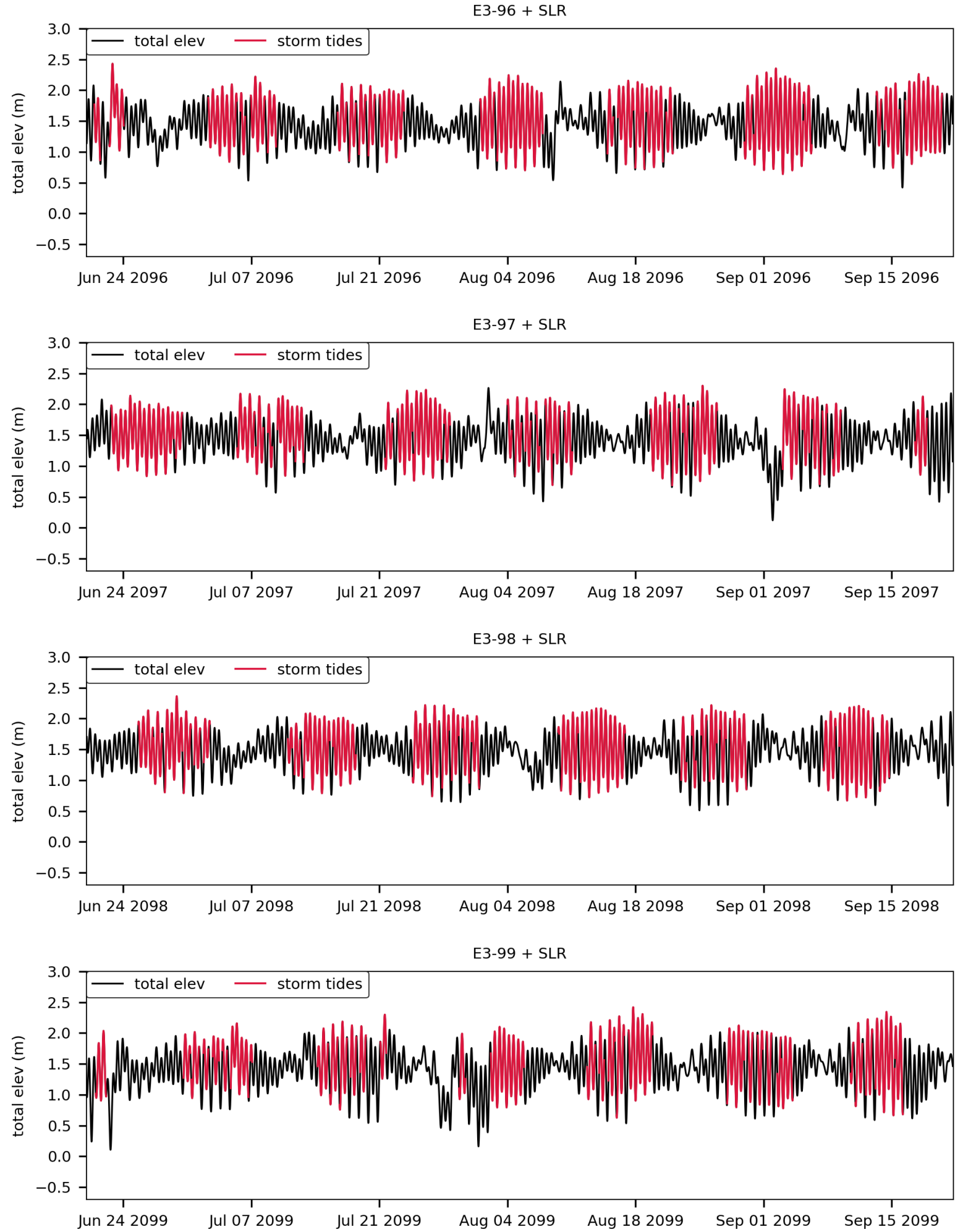

Figure 4.23: Total water elevation (black lines) at Capitania from the E3 experiments with SLR (E3-96-SLR, E3-97-SLR, E3-98-SLR and E3-99-SLR) during the winter of 2096, 2097, 2098 and 2099 (from top to bottom). The detected storm tides are marked in red dots. 

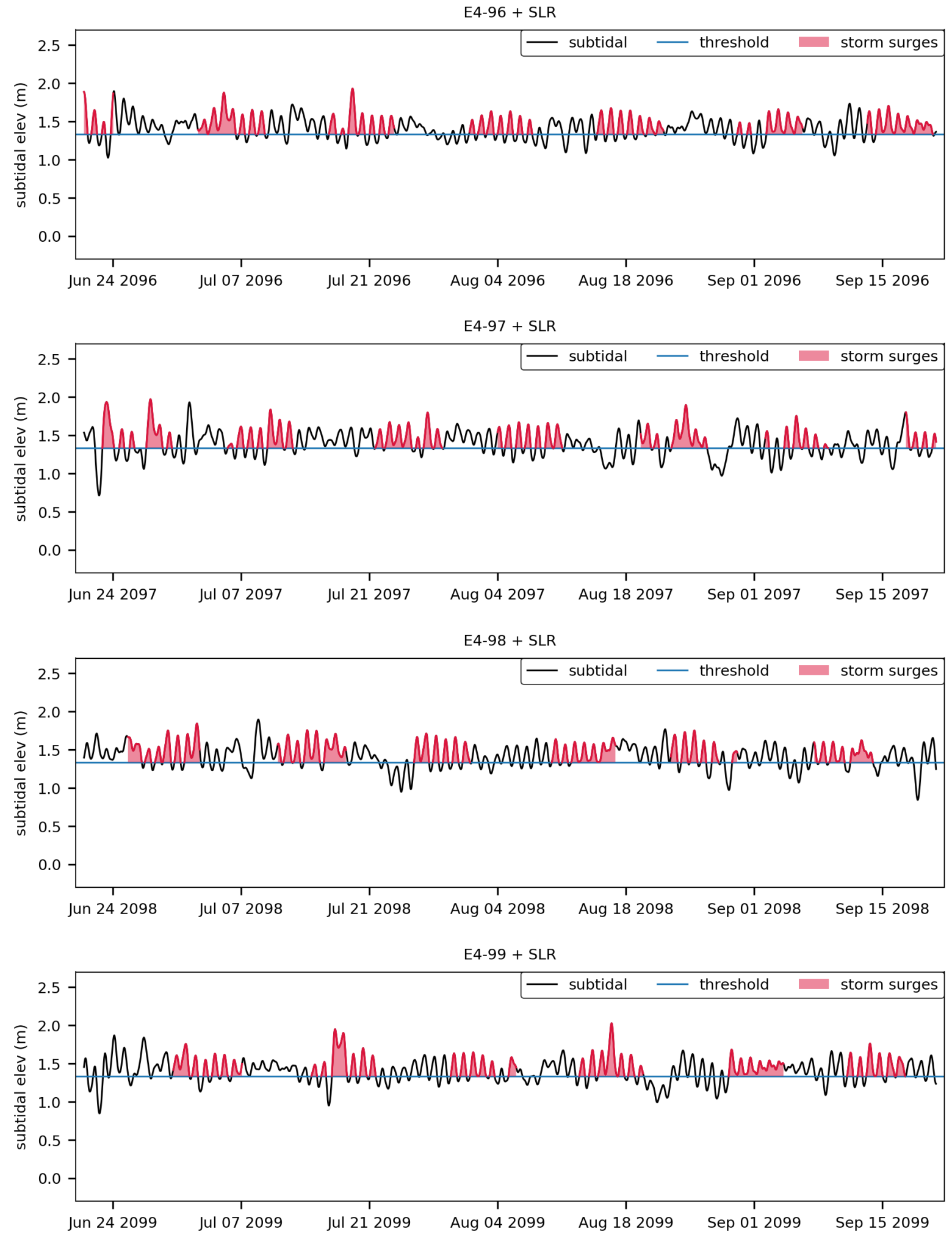

Figure 4.24: Subtidal component (black lines) of total water elevation at Capitania from the E4 experiments with SLR (E4-96-SLR, E4-97-SLR, E4-98-SLR and E4-99-SLR) during the winter of 2096, 2097, 2098 and 2099 (from top to bottom). The threshold over which a subtidal sea level increase is identified as a significant surge is shown by the blue line $(1.34 \mathrm{~m})$. 

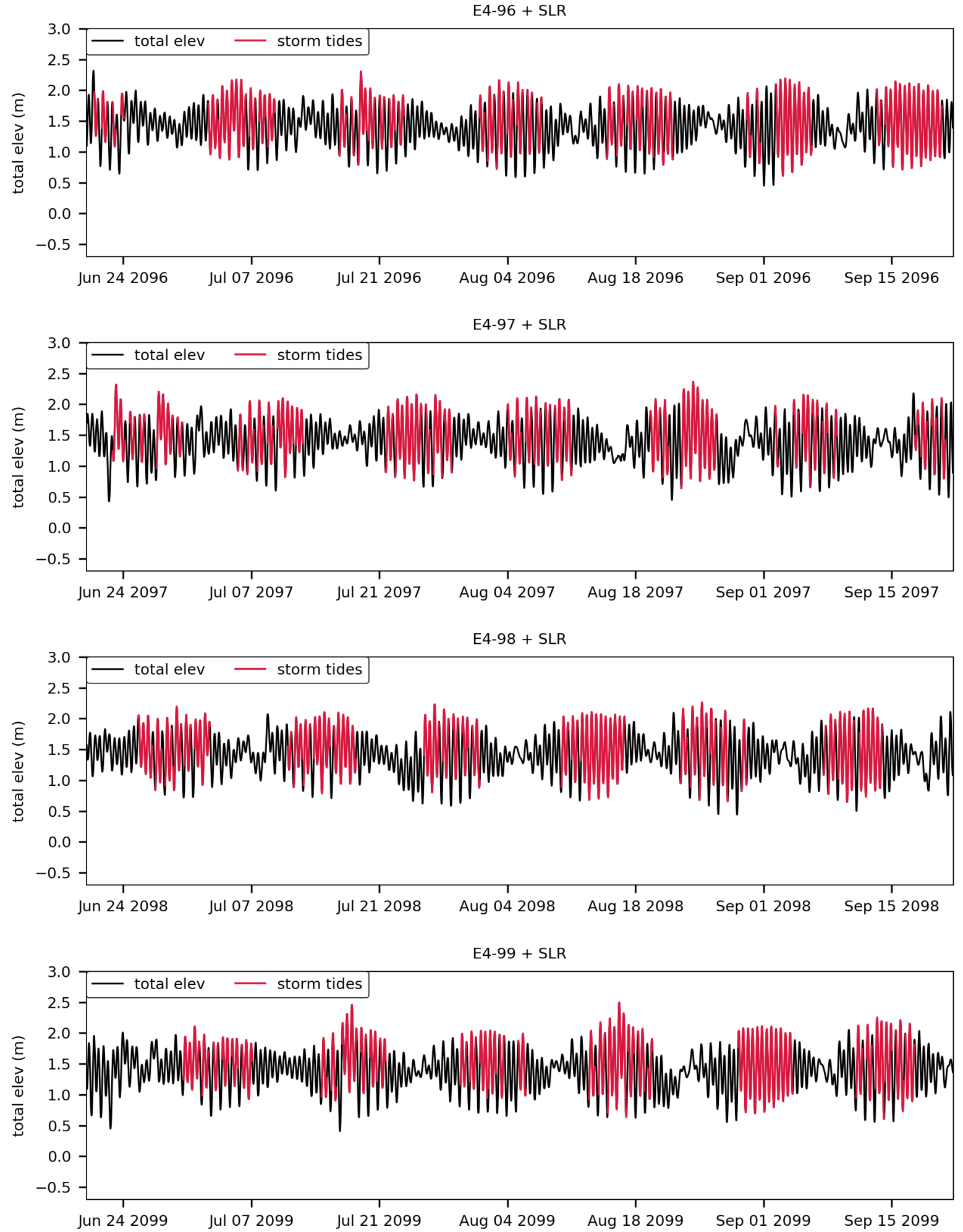

Figure 4.25: Total water elevation (black lines) at Capitania from the E4 experiments with SLR (E4-96-SLR, E4-97-SLR, E4-98-SLR and E4-99-SLR) during the winter of 2096, 2097, 2098 and 2099 (from top to bottom). The detected storm tides are marked in red dots. 


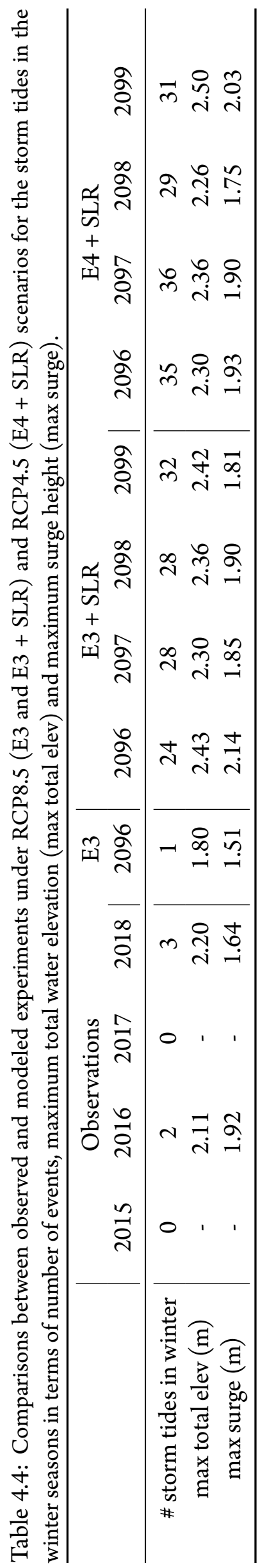



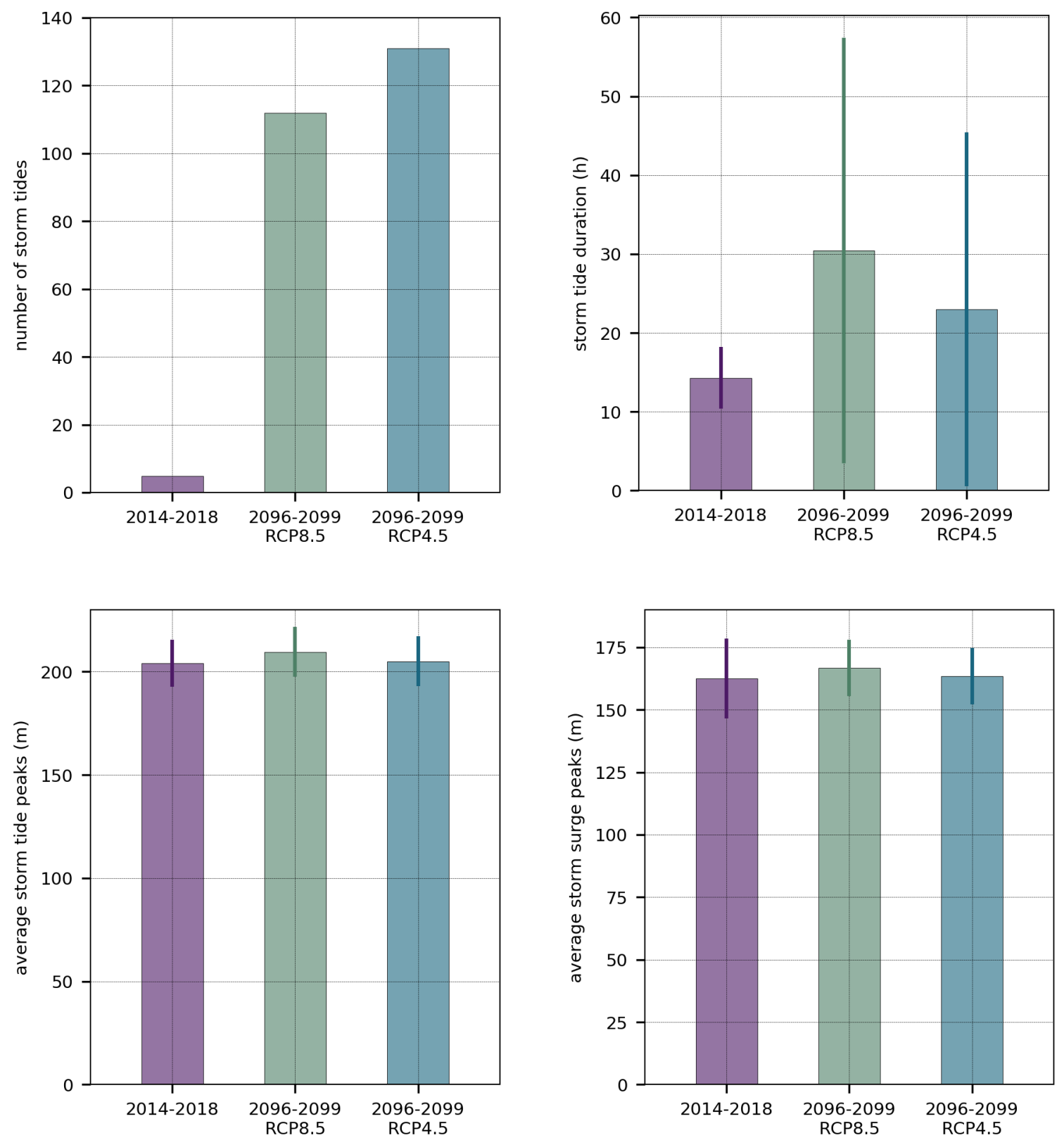

Figure 4.26: Comparisons between actual (purple) and future storm tides under RCP8.5 (green) and RCP4.5 (blue) in term of number of events, average duration and average peaks of storm surges and storm tides. The vertical bars represent the standard deviations. The statistics were computed during four winter periods of present (2014-2018) and future (2096-2099) conditions, from the observed data and the modeled E3 + SLR and E4 + SLR results. 


\subsection{Conclusions}

In this study, the number and intensity of storm tides in the SSVBES at the present time and under climate change projections were investigated. Four years from summer 2015 to spring 2018 of sea level data collected in Porto Channel, specifically at Capitania station, were used to describe the actual scenario of storm tide in terms of number of events and maximum water elevation (intensity). The future conditions were assessed using the HadGEM2-ES projections of SLR and atmospheric circulation fields under both RCP8.5 and RCP4.5 IPCC scenarios. The POM-rain based SOFS framework (Chapter 2) was used for the long-term simulations with the HadGEM2-ES projections focused on the winter season.

The observed data at Capitania revealed that the SSVBES was subjected to 22 storm tides during the 4-year record, yielding an average of $5.5 \pm 3.1$ storm tides per year (within one standard deviation). The maximum storm tide water level peaks varied from $1.85 \mathrm{~m}$ to $2.37 \mathrm{~m}$, with average equal to 1.98 $\mathrm{m}$. The strongest associated storm surges occurred at three seasons of year, except in summer, with the highest measured event in winter of 2016 (August 21). A total of 5 storm tides were observed during the winter seasons of the four analyzed years. The water level peaks in winter ranged from $1.86 \mathrm{~m}$ to $2.20 \mathrm{~m}$, with average of $2.04 \mathrm{~m}$.

The threshold that determines whether a storm surge can possibly generate a storm tide was equal to $1.34 \mathrm{~m}$. Such threshold was calculated with the 4-year observed elevation as the value of 1.9 standard deviations of the subtidal component. Using this threshold, the numerical simulation of the control experiment (E1) provided acceptable reproductions of the storm tides in winter 2016. The water levels of the two storm tides and the associated storm surges were captured with average error of $0.05 \mathrm{~m}$.

The long-term simulations were conducted to assess the contributions of the SLR and the atmospheric circulation changes separately. In the SLR alone experiment (E2), the same atmospheric winter fields of 2016 were forced with a $0.6 \mathrm{~m}$ sea level rise simulation. This scenario revealed that the number of storm tides increased from 2 to 20 . For the two events that occurred in the control run (E1), the storm tides and surge water level peaks rose by $0.6 \mathrm{~m}$. The maximum total water elevation among the 20 events were $2.15 \pm 0.25 \mathrm{~m}$.

The isolated atmospheric change experiments performed for the last four winter seasons of the 21 st century under RCP8.5 and RCP4.5 revealed that the number of storm tides may decrease. A single storm tide was identified, in June 2096, under RCP8.5. This was a consequence of the less frequent and less intense SW winds over the SBB and higher atmospheric pressure fields of 2-3 mbar at both RCP scenarios. SW winds may be 1.3-4.0 times less frequent and 1.7-5 times less intense in the 2096-2099 period in relation to the winter of 2016. Such conditions are in accordance with the expected poleward shift of the cyclogenesis region in the Southern Hemisphere projected by the IPCC (Collins et al., 2013) and the decrease in the frequency of cyclones in the Southwest Atlantic (Reboita et al., 2018b).

A more integrated climate change impacts on storm tides were assessed in the E3 and E4 experiments with SLR. The contribution of the SLR showed to be the only mechanism through which the 
number of storm tides may increase by the end of the 21 st century in relation to recent conditions. The number of expected events for the winter seasons in the 2096-2099 term was equal to 112 in RCP8.5 and to 131 in RCP4.5, approximately 22-26 times higher than the observed in the 2015-2018 period. If the projected HadGEM2-ES sea level rise occurs, the number of storm tides per winter will increase from 1.25 to 28 in RCP8.5 and to 32.75 in RCP4.5. This represents an increase in the frequency of storm tides in winter from 1 event every 75.2 days to 1 event every 2.9-3.4 days (RCP4.5-RCP8.5). However, the average intensity of the storm tide and storm surge peaks may not suffer significant changes in relation to what is observed in the present time. Storm tide peaks will reach $2.10 \mathrm{~m}(2.05 \mathrm{~m})$ in average for RCP8.5 (RCP4.5), within the range of actual observed storm tides. Similar conclusion is drawn for the storm surge component, which average peak may reach $1.67 \mathrm{~m}$ under RCP8.5 and $1.63 \mathrm{~m}$ for RCP4.5.

Future work could use other global circulation models from the CMIP5 multi-model data base and also from regional circulation models, if available, to increase the accuracy of the projected changes here estimated. Another interesting topic would be to estimate the flooding levels and flood pathways over the range of RCP scenarios and CMIP5 models to address what would be the most impacted inland areas due to climate change. Other changes in the forcing fields, as river outflows and precipitation could also be taken into account. 


\section{Chapter 5}

\section{Final remarks}

\subsection{Thesis summary}

This work investigated the hydrodynamics aspects of the SSVBES focused on storm tides by employing a numerical model combined with in situ observations and projected IPCC scenarios. In Chapter 2, the Santos Operational Forecasting System (SOFS) is established with the purpose of simulating and predicting physical processes within the estuarine system. Model efficiency was demonstrated through comparisons with observed sea surface elevations and surface currents along the navigation channel. The model performance measured by the Willmott skill were of 0.92 and 0.82 for sea level and surface along-channel currents, respectively. The RMSEs were of $24.5 \mathrm{~cm}$ (sea level) and $28.3 \mathrm{~cm} / \mathrm{s}$ (currents). The prediction of storm tide events were used to demonstrate the power of the designed system. The simulations of seven recent storm tides provided average sea level skills of 0.95 , average sea level RMSEs of $17.0 \mathrm{~cm}$ and average storm peak errors of $16.5 \mathrm{~cm}$. An operational system able to reproduce and forecast the estuarine circulation was still nonexistent in the SSVBES.

In Chapter 3, a more descriptive study of the estuarine physics in the SSVBES was given. A combination of in situ salinity and velocity profiles measured in Porto Channel during the ECOSAN project (2005) together with the recent, almost real-time, sea level and surface currents data from the Santos Pilots were used in conjunction with numerical simulations from Chapter 2 to understand the circulation patterns through the navigation channel. The estuarine quantities as the tidal regime, the form number, the tidal prism, the flux ratio, the tidal excursion and the estuarine Richardson number were calculated. The Porto Channel revealed to be a microtidal, tide-dominated, with mainly semidiurnal tidal regime and weakly stratified estuary. The amplitudes of both tidal elevations and tidal currents along the navigation channel suggested that Porto Channel behaves as a synchronous estuary. The phase differences between tidal elevations and currents showed the characteristics of a standing tidal wave. The Hansen and Rattray (1966) classification showed that Porto Channel is a partially mixed and weakly stratified, type $2 a$, estuary, during both spring and neap tides. This classification, although previously addressed in other estuarine channels of the SSVBES by Miranda and Castro (1998) and Miranda et al. (2012), 
had never been evaluated in the Porto Channel.

The built SOFS system framework was used in Chapter 4 to evaluate projected climate change impacts on storm tides in terms of frequency and intensity of events. Several experiments were conducted under two IPCC scenarios, the RCP8.5 and the RCP4.5, focused on the last four winter seasons of the 21st century. The impacts of the SLR and the changes in the atmospheric circulation patterns were addressed both together and independently. The SLR was responsible for an increase in the winter storm tide frequency from 1 event every 75.2 days to 1 event every 3.0 days, under both RCP scenarios. However, the average intensity of storm tides may not increase significantly, with average water level peaks of $2.10 \mathrm{~m}$ (RCP8.5) and $2.05 \mathrm{~m}$ (RCP4.5), comparable to actual conditions. The expected atmospheric circulation changes alone may yield less storm tides than today. Only one event was detected during the four winters of 2096-2099 under RCP8.5 and no event was identified in RCP4.5 simulations. This is accordance with the IPCC projected southward migration of the cyclogenesis region in the South Atlantic (Collins et al., 2013), resulting in decreases in the cyclone frequency over the Southwest Atlantic (Reboita et al., 2018b). The IPCC projected climate change impacts over storm tides had not been quantified by previous studies in the SSVBES .

The SOFS is an unprecedented operational system able to reproduce and forecast the estuarine circulation in the SSVBES. The results are being published online, freely available to everyone, as part of the first implemented observational and prediction system for the São Paulo State coast named PreAMar (Portuguese acronym for Forecast and Analysis of the Sea) (http://preamario.usp.br/en). Local fishing communities and tourism activities can benefit from these forecasts. Also, the knowledge of temporal and spatial variabilities of water levels and currents are important for safe navigation through the Santos Port. The use of operational models is able to extend the information initially restricted to the points of observation to the entire area of interest and also over time. SOFS provides both nowcasts and forecasts essential for navigation purposes with skills comparable to what is obtained with other operational systems around the world. Events that highly impact port logistics and economics such as storm tides can be predicted few days in advance and support both port operations and coastal communities.

\subsection{Future work}

This work established the SOFS in Chapter 2 and the built system was used to study estuarine physics in Chapter 3 and to evaluate climate change impacts on storm tides in Chapter 4. Nevertheless, several improvements can be made in the present operational system and other questions still do not have an answer. For example, river discharges are key informations to improve the modeled estuarine circulation. An estimative of river runoff can be made based on air temperature and precipitation as detailed in Miranda et al. (2017). Also, the inclusion of atmospheric forecasting ensembles would increase the accuracy of the hydrodynamics predictions. Other future goals for the operational system comprise the incorporation of temperature and salinity forecasts and other POM-rain capabilities, as the wind wave module and the wet and dry scheme. 
The subjects not explored in the present study that could be accomplished by future work include:

- expand the understanding of the hydrodynamics to the entire system, not only through the navigation channel (Porto Channel);

- address future changes in the estuarine dynamics and in the estuary classification;

- assess future impacts on storm tides including the IPCC hydrologic changes projections;

- map the actual and future flooding zones;

- calculate the estuary residence time and give support to studies that investigates the environmental impacts caused by the disposal of pollutants in the system. 



\section{References}

AGUIAR, V. C. M. Variabilidade Temporal de Ressacas na Plataforma Continental Sudeste. Thesis (B.S.) — University of São Paulo, 2018.

ALFREDINI, P.; ARASAKI, E.; AMARAL, R. F. do. Mean sea-level rise impacts on Santos Bay, Southeastern Brazil - physical modelling study. Environ. Monit. Assess., v. 144, p. 377-387, 2008.

ALFREDINI, P.; ARASAKI, E.; PEZZOLI, A.; ARCORACE, M.; CRISTOFORI, E.; SOUSA JR, W. C. de. Exposure of Santos Harbor Metropolitan Area (Brazil) to wave and storm surge climate changes. Water Qual. Expo. Health, v. 6, p. 73-88, 2014.

ALLEN, G. P.; SALOMON, J. C.; BASSOULLET, P.; PENHOAT, Y. D.; GRANDPRÉ, C. D. Effects of tides on mixing and suspended sediment transport in macrotidal estuaries. Sedim. Geology, v. 26, p. 69-90, 1980.

BLUMBERG, A. F.; MELLOR, G. L. A description of a three-dimensional coastal ocean circulation model. In: HEAPS, N. S. (Ed.). Three-dimensional coastal ocean models. Washington, D.C.: American Geophysical Union, 1987.p. 1-16.

CAMERON, W. M.; PRITCHARD, D. W. Estuaries. In: HILL, M. N. (Ed.). The Sea: Ideas and Observations on Progress in the Study of the Seas. [S.1.]: John Willey \& Sons, Inc, 1963. v. 2, p. 306-324.

CAMPOS, E. J. D.; GONÇALVES, J. E.; IKEDA, Y. Water mass characteristics and geostrophic circulation in the South Brazil Bight: Summer of 1991. J. Geophys. Res., v. 100, n. C9, p. 18537-18550, 1995.

CAMPOS, R. M.; CAMARGO, R. de; HARARI, J. Caracterização de eventos extremos do nível do mar em Santos e sua correspondência com as reanálises do modelo do NCEP no sudoeste do Atlântico Sul. Rev. Bras. Meteor., v. 25, n. 2, p. 175-184, 2010.

CASTRO, B. M. Summer/winter stratification variability in the central part of the South Brazil Bight. Cont. Shelf Res., v. 89, p. 15-23, 2014.

CASTRO, B. M.; LEE, T. N. Wind-forced sea level variability on the southeast Brazilian shelf. J. Geophys. Res., v. 100, n. C8, p. 16045-16056, 1995.

CASTRO, B. M.; MIRANDA, L. B. Physical oceanography of the Western Atlantic continental shelf located between $4^{\circ} \mathrm{N}$ and $34^{\circ} \mathrm{S}$ coastal segment. In: ROBINSON, A. R.; BRINK, K. H. (Ed.). The Sea. New York, NY: John Willey \& Sons, Inc, 1998. v. 11, p. 209-251.

CHURCH, J. A.; CLARK, P. U.; CAZENAVE, A.; GREGORY, J. M.; JEVREJEVA, S.; LEVERMANN, A.; MERRIFIELD, M. A.; MILNE, G. A.; NEREM, R. S.; NUNN, P. D.; PAYNE, A. J.; PFEFFER, W. T.; STAMMER, D.; UNNIKRISHNAN, A. S. Sea level change. In: STOCKER, T. F.; QIN, D.; PLATTNER, G.-K.; TIGNOR, M. M. B.; ALLEN, S. K.; BOSCHUNG, J.; NAUELS, A.; XIA, Y.; BEX, V.; MIDGLEY, P. M. (Ed.). Climate Change 2013: The Physical Science Basis. Contribution of Working Group I to the Fifth Assessment Report of the Intergovernmental Panel on Climate Change. Cambridge, United Kingdom and New York, NY, USA: Cambridge University Press, 2013. p. 1137-1216. 
COLLINS, M.; KNUTTI, R.; ARBLASTER, J.; DUFRESNE, J.-L.; FICHEFET, T.; FRIEDLINGSTEIN, P.; GAO, W. G. X.; JOHNS, T.; KRINNER, G.; SHONGWE, M.; TEBALDI, C.; WEAVER, A.; WEHNER, M. Long-term climate change: Projections, commitments and irreversibility. In: STOCKER, T.; QIN, D.; PLATTNER, G.-K.; TIGNOR, M.; ALLEN, S.; BOSCHUNG, J.; NAUELS, A.; XIA, Y.; BEX, V.; MIDGLEY, P. (Ed.). Climate Change 2013: The Physical Science Basis. Contribution of Working Group I to the Fifth Assessment Report of the Intergovernmental Panel on Climate Change. Cambridge, United Kingdom and New York, NY, USA: Cambridge University Press, 2013. p. 1029-1136.

DAVIES, J. H. A morphogenic approach of world shorelines. Z. Geomorphology, v. 8, n. 127-142, 1964. DEFANT, A. Physical Oceanography. Oxford, London, New York, Paris: Pergamon Press, 1960. 598 p. DOTTORI, M.; CASTRO, B. M. The response of the Sao Paulo Continental Shelf, Brazil, to synoptic winds. Ocean Dynamics, v. 59, p. 603-614, 2009.

DYER, K. R. Estuaries: A Physical Introduction. 2. ed. [S.1.]: John Willey \& Sons, Inc, 1997. 195 p.

EGBERT, G. D.; EROFEEVA, S. Y. Efficient inverse modeling of barotropic ocean tides. J. Atmos. Ocean. Tech., v. 19, p. 183-204, 2002.

ELGUINDI, N.; BI, X.; GIORGI, F.; NAGARAJAN, B.; PAL, J.; SOLMON, F.; RAUSCHER, S.; ZAKEY, A.; O’BRIEN, T.; NOGHEROTTO, R.; GIULIANI, G. Regional Climate Model RegCM User Manual Version 4.4. Triste, Italy, 2014.

FERNÁNDEZ-MONTBLANC, T.; VOUSDOUKAS, M. I.; CIAVOLA, P.; VOUKOUVALAS, E.; MENTASCHI, L.; BREYIANNIS, G.; FEYEN, L.; SALAMON, P. Towards robust pan-European storm surge forecasting. Ocean Modelling, v. 133, p. 129-144, 2019.

FISCHER, H. B. Mass transport mechanisms in partially stratified estuaries. J. Fluid Mech., v. 53, p. 672-687, 1972.

FISCHER, H. B.; LIST, E. J.; KOH, R. C. Y.; IMBERGER, J.; BROOKS, N. H. Mixing in inland and coastal waters. [S.l.]: Academic Press, 1979. 483 p.

FLATHER, R.; WILLIAMS, J. Climate change effects on storm surges: methodologies and results. In: Climate scenarios for water-related and coastal impacts. [S.l.]: Norwich: CRU, ECLAT-2 Workshop Report, 2000. p. 66-72.

FOSS, M.; CHOU, S. C.; SELUCHI, M. E. Interaction of cold fronts with the Brazilian Plateau: a climatological analysis. Int. J. Climatol., v. 37, p. 3644-3659, 2017.

GAN, M. A.; RAO, V. B. Surface cyclogenesis over South America. Mon. Wea. Rev., v. 119, p. 1293-1302, 1991.

GEORGAS, N.; BLUMBERG, A.; HERRINGTON, T.; WAKEMAN, T.; SALEH, F.; RUNNELS, D.; JORDI, A.; YING, K.; YIN, L.; RAMASWAMY, V.; YAKUBOVSKIY, A.; LOPEZ, O.; MCNALLY, J. The Stevens Flood Advisory System: Operational H3E flood forecasts for the greater New York / New Jersey Metropolitan Region. Int. J. of Safety and Security Eng., v. 6, p. 648-662, 2016 a.

GEORGAS, N.; BLUMBERG, A. F. Establishing confidence in marine forecast systems: The design and skill assessment of the New York Harbor Observation and Prediction System, version 3 (NYHOPS v3). In: ASCE. Eleventh International Conference in Estuarine and Coastal Modeling (ECM11). Seattle, WA, 2010. p. 660-685.

GEORGAS, N.; BLUMBERG, A. F.; BRUNO, M. S.; RUNNELS, D. S. Marine forecasting for the New York urban waters and harbor approaches: the design and automation of NYHOPS. In: $3 r d$ 
International Conference on Experiments/Process/System Modelling/Simulation \& Optimization. Athens, Greece: [s.n.], 2009. v. 1, p. 345-352.

GEORGAS, N.; ORTON, P.; BLUMBERG, A.; COHEN, L.; ZARRILLI, D.; YIN, L. The Impact of Tidal Phase on Hurricane Sandy's Flooding Around New York City and Long Island Sound. J. Extreme Events, v. 1, n. 1, p. 1450006, 2014.

GEORGAS, N.; YIN, L.; JIANG, Y.; WANG, Y.; HOWELL, P.; SABA, V.; SCHULTE, J.; ORTON, P.; BINWEN. An open-access, multi-decadal, three-dimensional, hydrodynamic hindcast dataset for the Long Island Sound and New York/New Jersey Harbor Estuaries. J. Mar. Sci. Eng., v. 4, n. 48, 2016 b.

HANSEN, D. V.; RATTRAY, M. New dimensions in estuary classification. Limnol. and Oceanog., XI, n. 3, p. 319-326, 1966.

HARARI, J.; CAMARGO, R. Tides and mean sea level variabilities in Santos (SP), 1944 to 1989. Relatório Interno do Instituto Oceanográfico da USP, v. 36, p. 1-15, 1995.

HARARI, J.; CAMARGO, R. Modelagem numérica da região costeira de Santos (SP): circulação de maré. Rev. Bras. Oceanogr., v. 46, n. 2, p. 135-156, 1998.

HARARI, J.; CAMARGO, R. Numerical simulation of the tidal propagation in the coastal region of Santos (Brazil, 24ㅇ 46ºW). Cont. Shelf Res., v. 23, p. 1597-1613, 2003.

HARARI, J.; CAMARGO, R.; CACCIARI, P. L. Resultados da modelagem numérica hidrodinâmica em simulações tridimensionais das correntes de maré na baixada santista resultados da modelagem numérica hidrodinâmica em simulações tridimensionais das correntes de maré na baixada santista. Rev. Bras. Rec. Hídric., v. 5, n. 2, p. 71-87, 2000.

IPCC. Climate Change 2013: The Physical Science Basis. Contribution of Working Group I to the Fifth Assessment Report of the Intergovernmental Panel on Climate Change. In: STOCKER, T. F.; QIN, D.; PLATTNER, G. K.; TIGNOR, M.; ALLEN, S. K.; BOSCHUNG, J.; NAUELS, A.; XIA, Y.; BEX, V.; MIDGLEY, P. M. (Ed.). Cambridge, United Kingdom and New York, NY, USA: Cambridge University Press, 2013. p. 1535.

KODAIRA, T.; THOMPSON, K. R.; BERNIER, N. B. The effect of density stratification on the prediction of global storm surges. Ocean Dynamics, v. 66, p. 1733-1743, 2016.

LIU, Y.; MACCREADY, P.; HICKEY, B. M.; DEVER, E. P.; KOSRO, P. M.; BANAS, N. S. Evaluation of a coastal ocean circulation model for the Columbia River plume in summer 2004. J. Geophys. Res., v. 114, p. 1-23, 2009.

MANWELL, J. F.; MCGOWAN, J. G.; ROGERS, A. L. Wind energy explained: theory, design and application. 2. ed. [S.1.]: Wiley, 2010.

MARENGO, J.; MULLER-KARGER, F.; PELLING, M.; REYNOLDS, C. J.; MERRILL, S. B.; NUNES, L. H.; PATERSON, S.; GRAY, A. J.; LOCKMAN, J. T.; KARTEZ, J.; MOREIRA, F. A.; GRECO, R.; HARARI, J.; SOUZA, C. R. G.; ALVES, L. M.; HOSOKAWA, E. K.; TABUCHI, E. K. An Integrated Framework to Analyze Local Decision Making and Adaptation to Sea Level Rise in Coastal Regions in Selsey (UK), Broward County (USA), and Santos (Brazil)). Am. J. Clim. Change, v. 6, p. 403-424, 2017.

MARTIN, G. M.; BELLOUIN, N.; COLLINS, W. J.; CULVERWELL, I. D.; HALLORAN, P. R.; HARDIMAN, S. C.; HINTON, T. J.; JONES, C. D.; MCDONALD, R. E.; MCLAREN, A. J.; O’CONNOR, F. M.; ROBERTS, M. J.; RODRIGUEZ, J. M.; WOODWARD, S.; BEST, M. J.; BROOKS, M. E.; BROWN, A. R.; BUTCHART, N.; DEARDEN, C.; DERBYSHIRE, S. H.; DHARSSI, I.; DOUTRIAUX-BOUCHER, M.; EDWARDS, J. M.; FALLOON, P. D.; GEDNEY, N.; GRAY, L. J.; HEWITT, H. T.; HOBSON, M.; HUDDLESTON, M. R.; HUGHES, J.; INESON, S.; 
INGRAM, W. J.; JAMES, P. M.; JOHNS, T. C.; JOHNSON, C. E.; JONES, A.; JONES, C. P.; JOSHI, M. M.; KEEN, A. B.; LIDDICOAT, S.; LOCK, A. P.; MAIDENS, A. V.; MANNERS, J. C.; MILTON, S. F.; RAE, J. G.; RIDLEY, J. K.; SELLAR, A.; SENIOR, C. A.; TOTTERDELL, I. J.; VERHOEF, A.; VIDALE, P. L.; WILTSHIRE, A. The HadGEM2 family of Met Office Unified Model climate configuration. Geosci. Model Dev., v. 4, p. 723-757, 2011.

MELLOR, G. L.; YAMADA, T. Development of a turbulence closure model for geophysical fluid problems. Rev. Geophys. Space Phys., v. 20, n. 4, p. 851-875, 1982.

MIRANDA, L. B.; ANDUTTA, F. P.; KJERFVE, B.; CASTRO, B. M. Fundamentals of Estuarine Physical Oceanography. Singapore: Springer Nature, 2017.

MIRANDA, L. B.; CASTRO, B. M. Circulation and mixing due to tidal forcing in the Bertioga Channel, São Paulo, Brazil. Estuaries, v. 21, n. 2, p. 204-214, 1998.

MIRANDA, L. B.; OLLE, E. D.; BÉRGAMO, A. L.; SILVA, L. S.; ANDUTTA, F. P. Circulation and salt intrusion in the Piaçaguera Channel, Santos (SP). Braz. J. Oceanog., v. 60, n. 1, p. 11-23, 2012.

NEUMANN, B.; VAFEIDIS, A. T.; ZIMMERMANN, J.; NICHOLLS, R. J. Future coastal population growth and exposure to sea-level rise and coastal flooding - A global assessment. PLoS ONE, v. 10, n. 6, p. e0118571, 2015.

NICHOLLS, R. J.; HANSON, S.; HERWEIJER, C.; PATMORE, N.; HALLEGATTE, S.; CORFEEMORLOT, J.; CHÂTEAU, J.; MUIR-WOOD, R. Ranking port cities with high exposure and vulnerability to climate extremes: exposure estimates. OECD Environment Working Papers, n. 1, 2008.

NICHOLLS, R. J.; MARINOVA, N.; LOEW, J. A.; BROWN, S.; VELLINGA, P.; GUSMÃO, D.; HINKEL, J.; TOL, R. S. J. Sea-level rise and its possible impacts given a 'beyond $4^{\circ} \mathrm{C}$ world' in the twenty-first century. Phil. Trans. R. Soc. A: Mathematical, Physical and Engineering Sciences, v. 369, n. 1934, p. 161-181, 2011.

ORTON, P.; GEORGAS, N.; BLUMBERG, A.; PULLEN, J. Detailed modeling of recent severe storm tides in estuaries of the New York City region. J. Geophys. Res., v. 117, n. C09030, 2012.

ORTON, P.; VINOGRADOV, S.; GEORGAS, N.; BLUMBERG, A.; LIN, N.; GORNITZ, V.; LITTLE, C.; JACOB, K.; HORTON, R. New York City panel on climate chande 2015 report chapter 4: Dynamics coastal flood modeling. Ann. N. Y. Acad. Sci., v. 1336, p. 56-66, 2015.

PAWLOWICZ, R.; BEARDSLEY, B.; LENTZ, S. Classical tidal harmonic analysis including error estimates in MATLAB using T_TIDE. Comput. Geosci., v. 28, p. 929-937, 2002.

PEREIRA, A. F.; CASTRO, B. M.; CALADO, L.; SILVEIRA, I. C. A. da. Numerical simulation of M2 internal tides in the South Brazil Bight and their interaction with the Brazil Current. J. Geophys. Res., v. 112, n. C04009, 2007.

PERILLO, G. M. E. Definitions and geomorphologic classifications of estuaries. In: PERILLO, G. M. E. (Ed.). Geomorphology and Sedimentology of Estuaries. [S.1.]: Elsevier, 1995, (Developments in Sedimentology, v. 53). chap. 2, p. $17-47$.

PERILLO, G. M. E.; PICCOLO, M. C. Tidal response in the Bahia Blanca Estuary, Argentina. J. Coastal Res., v. 7, n. 2, p. 437-449, 1991.

PEZZOLI, A.; ALFREDINI, P.; ARASAKI, E.; ROSSO, M.; SOUSA Jr., W. C. Impacts of climate changes on management policy of the harbors, land areas and wetlands in the São Paulo state coastline (Brazil). J. Climatol. Wea. Forecasting, v. 1, p. 1-7, 2013. 
PRANDLE, D.; WOLF, J. Surge-tide interaction in the southern North Sea. In: NIHOUL, J. C. J. (Ed.). Hydrodynamics of Estuaries and Fjords, Proceedings of the 9th Liege Colloquium on Ocean Hydrodynamics, Liege 1977. Amsterdam: Elsevier, 1978. p. 161-185.

REBOITA, M. S.; AMARO, T. R.; SOUZA, M. R. Winds: intensity and power density simulated by RegCM4 over South America in present and future climate. Clim. Dyn., v. 51, n. 187-205, 2018a.

REBOITA, M. S.; ROCHA, R. P.; SOUZA, M. R.; LLOPART, M. Extratropical cyclones over the southwestern South Atlantic Ocean: HadGEM2-ES and RegCM4 projections. Int. J. Climatol., v. 38, n. 2866-2879, 2018b.

REID, R. O.; BODINE, B. R. Numerical model for storm surges in Galveston Bay. J. Waterw. Harb. Div., v. 94, p. 33-58, 1968.

REZENDE, J. H. M. Intrusões da Água Central do Atlântico Sul na plataforma continental sudeste durante o verão. Thesis ( $\mathrm{PhD})$ - University of São Paulo, 2003.

RIBEIRO, R. B.; SAMPAIO, A. F. P.; RUIZ, M. S.; LEITÃO, J. C.; LEITÃO, P. C. First approach of a storm surge early warning system for Santos region. In: NUNES, L. H.; GRECO, R.; MARENGO, P. D. J. A. (Ed.). Climate Change in Santos Brazil: Projections, Impacts and Adaptation Options. [S.l.]: Springer, 2019. p. 135-157.

ROSSITER, J. R. Interaction between tide and surge in the Thames. Geophysical Journal of the Royal Astronomical Society, v. 6, n. 1, p. 29-53, 1961.

ROVERSI, F.; ROSMAN, P. C. C.; HARARI, J. Análise da renovação das águas do Sistema Estuarino de Santos usando modelagem computacional. Rev. Ambiente e Água, v. 11, n. 3, p. 566-585, 2016.

SEADE. Território e população. 2018. Available at: < http://www.perfil.seade.gov.br/>.

SIGNORINI, S. R. On the circulation and the volume transport of the Brazil Current between the Cape of São Tomé and Guanabara Bay. Deep-Sea Res., v. 25, p. 481-490, 1978.

SILVA, P. G.; DALINGHAUS, C.; GONZÁLEZ, M.; GUTIÉRREZ, O.; ESPEJO, A.; ABASCAL, A. J.; KLEIN, A. H. F. Estimating flooding level through the Brazilian coast using reanalysis data. J. Coastal Res., n. 75, p. 1092-1096, 2016.

SILVEIRA, I. C. A.; LIMA, J. A. M.; SCHMIDT, A. C. K.; CECCOPIERI, W.; SARTORI, A.; FRANCISCO, C. P. F.; FONTES, R. F. C. Is the meander growth in the Brazil Current system off Southeast Brazil due to baroclinic instability? Dyn. Atm. Oceans, v. 45, p. 187-207, 2008.

SILVEIRA, I. C. A.; SCHMIDT, A. C. K.; CAMPOS, E. J. D.; GODOI, S. S. de; IKEDA, Y. A Corrente do Brasil ao largo da costa leste brasileira. Rev. Bras. Oceanogr., v. 48, n. 2, p. 171-183, 2000.

SMAGORINSKY, J. General circulation experiments with the primitive equations. Mon. Weather Rev., v. 91, n. 3, p. 99-164, 1963.

TAYLOR, K. E.; STOUFFER, R. J.; MEEHL, G. A. An overview of CMIP5 and the experiment design. Bull. Am. Meteorol. Soc., v. 93, n. 4, p. 485-498, 2012.

TOSTE, R.; ASSAD, L. P. F.; LANDAU, L. Downscaling of the global HadGEM2-ES results to model the future and present-day ocean conditions of the southeastern Brazilian continental shelf. Clim. Dyn., v. 51, n. 143-159, 2018.

VAN VUUREN, D. P.; EDMONDS, J.; KAINUMA, M.; RIAHI, K.; THOMSON, A.; HIBBARD, K.; HURTT, G. C.; KRAM, T.; KREY, V.; LAMARQUE, J. F.; MASUI, T.; MEINSHAUSEN, M.; NAKICENOVIC, N.; SMITH, S. J.; ROSE, S. K. The representative concentration pathways: an overview. Climate Change, v. 109, p. 5-31, 2011. 
WALTERS, R. A.; HESTON, C. Removing tidal-period variations from time-series data using low-pass digital filters. J. Phys. Oceanogr., v. 12, n. 1, p. 112-115, 1982.

WILLMOT,, C. J. On the validation of models. Phys. Geogr., v. 2, n. 2, p. 184-194, 1981.

ZHANG, A.; HESS, K. W.; AIKMAN III, F. User-based skill assessment techniques for operational hydrodynamic forecast systems. J. Operat. Oceanography, v. 3, n. 2, p. 11-24, 2014.

ZHENG, L.; CHEN, C.; LIU, H. A modeling study of the Satilla River estuary, Georgia. I: floodingdrying process and water exchange over the saltmarsh-estuary-shelf complex. Estuaries, v. 26, n. 3, p. 651-669, 2003. 


\section{Links}

The presentation of this thesis is available with English subtitles at:

https://youtu.be/JqHH0Qh1tVI

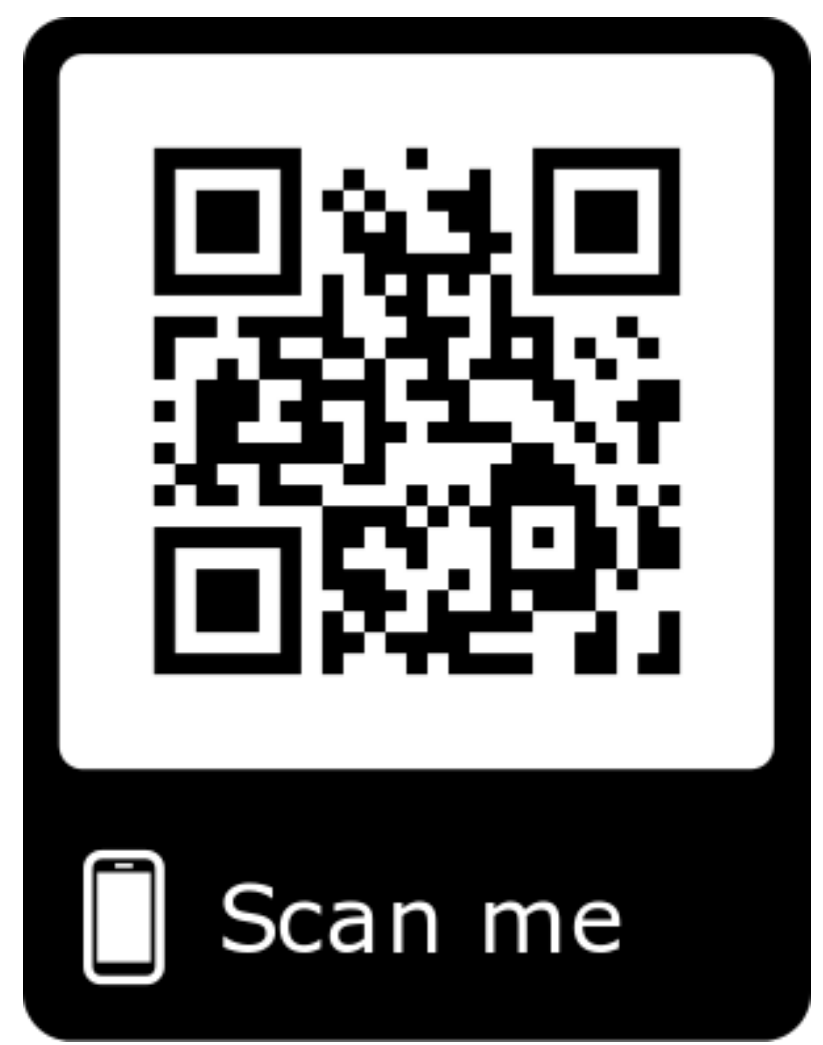

